\title{
VE-Cadherin Expression and Regulation of Sensitivity to Apoptosis in Philadelphia Chromosome Positive Acute Lymphoblastic Leukemia
}

\author{
Heather A. O'Leary \\ West Virginia University
}

Follow this and additional works at: https://researchrepository.wvu.edu/etd

\author{
Recommended Citation \\ O'Leary, Heather A., "VE-Cadherin Expression and Regulation of Sensitivity to Apoptosis in Philadelphia \\ Chromosome Positive Acute Lymphoblastic Leukemia" (2010). Graduate Theses, Dissertations, and \\ Problem Reports. 3207. \\ https://researchrepository.wvu.edu/etd/3207
}

This Dissertation is protected by copyright and/or related rights. It has been brought to you by the The Research Repository @ WVU with permission from the rights-holder(s). You are free to use this Dissertation in any way that is permitted by the copyright and related rights legislation that applies to your use. For other uses you must obtain permission from the rights-holder(s) directly, unless additional rights are indicated by a Creative Commons license in the record and/ or on the work itself. This Dissertation has been accepted for inclusion in WVU Graduate Theses, Dissertations, and Problem Reports collection by an authorized administrator of The Research Repository @ WVU. For more information, please contact researchrepository@mail.wvu.edu. 
VE-Cadherin Expression and Regulation of Sensitivity to Apoptosis in Philadelphia Chromosome Positive Acute Lymphoblastic Leukemia.

Heather A. O'Leary

Dissertation submitted to the School of Medicine at West Virginia University in partial fulfillment of the requirements for the degree of

\author{
Doctor of Philosophy \\ In \\ Cancer Cell Biology
}

\author{
Scott A. Weed, Ph.D., Chair \\ Solveig G. Ericson, M.D., Ph.D. \\ Daniel C. Flynn, Ph.D. \\ Karen H. Martin, Ph.D. \\ William Petros, Pharm.D. \\ Laura Gibson, Ph.D., Mentor
}
Cancer Cell Biology Program
Morgantown, West Virginia
2010

Key Words: microenvironment, bone marrow stromal cell, osteoblast, acute lymphoblastic leukemia, philadelphia chromosome, chemotherapy 


\section{Abstract \\ VE-Cadherin Expression and Regulation of Sensitivity to Apoptosis in Philadelphia Chromosome Positive Acute Lymphoblastic Leukemia}

\section{Heather A. O'Leary}

The bone marrow microenvironment serves as the primary site for post-natal hematopoiesis allowing for HSC development and maturation. More specifically, B lineage cells rely on key signals from both the physical and soluble components of the marrow for their survival and maturation. In addition to normal hematopoiesis the bone marrow has been shown to be a sanctuary for leukemic cells, as well as other tumors, that can interact with cues from the microenvironment allowing for their protection during chemotherapy. The studies described in this dissertation focus on two supportive components of the bone marrow microenvironment, osteoblasts and bone marrow stromal cells (BMSC), in the settings of post high dose chemotherapy and survival of leukemic cells during chemotherapy, respectively.

In the first study we investigated the effects of high dose chemotherapy on human osteoblasts (HOB). Previous studies from our laboratory have shown that high dose chemotherapy causes increases in the amount of active TGF- $\beta$ released from BMSC and subsequently leads to diminished ability to support pro-B cells. Here we describe the novel observation that HOB treated with chemotherapy have increased levels of active TGF- $\beta$ as well as a diminished capacity to interact with, and support, human embryonic stem cells and pro-B cells. Additionally, we determined that HOB treatment with chemotherapy or rTGF- $\beta$ led to increased levels of active TGF- $\beta$, as well as decreased CXCL12 mRNA and protein leading to a decreased adherence of pro-B cells to HOB. Chemotherapy or rTGF- $\beta$ treatment also lead to the diminished ability of $\mathrm{HOB}$ to support pluripotent OCT-4 positive stem cell colonies and microarray analysis of HOB treated with Melphlan, rTGF- $\beta$ or Conditioned Media from BMSC treated with Melphlan led to dramatic changes in the gene expression profiles of the HOB. This study elucidates the importance of osteoblasts in the marrow following ablative therapy and indicates how different components of the marrow are altered by chemotherapy. 
Our laboratory and others have previously shown that BMSC are able to protect tumor cells from chemotherapy however the mechanisms by which the bone marrow microenvironment regulates tumor cell survival are diverse. This study describes the novel observation that in addition to Philadelphia chromosome positive $(\mathrm{Ph}+)$ acute lymphoblastic leukemia $(A L L)$ cell lines, primary patient cells also express Vascular Endothelial Cadherin (VE-cadherin) which is regulated by Abl kinase and has been associated with aggressive phenotype and poor prognosis in other models. Targeted knockdown of VE cadherin rendered ALL cells more susceptible to chemotherapy, even in the presence of BMSC derived survival cues. Pre-treatment of Ph+ ALL cells with ADH100191, a VE-cadherin antagonist, resulted in increased apoptosis during in vitro chemotherapy exposure. Consistent with a role for VE-cadherin in modulation of leukemia cell viability, lentiviral-mediated expression of VE-cadherin in Ph- ALL cells resulted in increased resistance to treatment-induced apoptosis. Collectively, these data contribute to our understanding of the alterations that occur to the different supportive components of the bone marrow microenvironment during chemotherapy and the mechanisms that alter their ability to support both normal and neoplastic cells. 


\section{Dedication}

I dedicate this dissertation to my parents, David and J oAnn O'Leary who sacrificed for me because they believed I could do anything and to my husband and daughter, Adam and Layla Goodwill, because of whose love and support I know that it is true. 


\section{Acknowledgements}

I would like to thank my mentor, Dr. Laura Gibson for her support and for helping me to grow both personally and professionally during my time in her lab. I will be forever grateful for her time and friendship and appreciate the opportunity to learn from her.

I am very grateful to my committee members Dr. Solveig Ericson, Dr. Daniel Flynn, Dr. Karen Martin, Dr. William Petros and Dr. Scott Weed for all of their insight, encouragement, and support pertaining to both "real life" and science during my graduate career.

I would like to thank past and present members the Gibson laboratory especially, J im Fortney, Matt Akers, Stephanie Rellick, Debra Piktel, Cheryl Walton, Dr. Sreekumar Othumpugnat, Audrey Jajoski, and Dr. Gerry Higa for both their support as well as their friendships. Even the worst day seems ok when you are surrounded by friends.

Finally, I would like to thank the people closest to me whom I would not be successful in any way without. My husband and daughter, my parents, my wonderful in-laws and my awesome close group of friends I have made at WVU. Although you are not mentioned by name I want you to know that I realize I would never have gotten this far without you. You have been there for me throughout the best and worst times, personally and professionally, and I appreciate that more than I can tell you. It isn't about whether you were there with me to laugh or cry, just that you were there, and for that I am eternally grateful and will always remember how lucky I am to have you in my life.

"Never lose sight of the fact that the most important yardstick of your success will be how you treat other people - your family, friends, and coworkers, and even strangers you meet along the way."- Barbara Bush 


\section{Abbreviations or Nomenclature}

2-oxoglutarate-dependent dioxygenase

(2-ODD)

Acute Lymphoblastic Leukemia

(ALL)

ADH10019 (VE-cadherin antagonist)

(ADH)

Acute Myeloid Leukemia

(AML)

Cytarabine

(Ara-C)

Aryl receptor nuclear translocator

(ARNT)

Basic-helix-loop-helix

(bHLH)

BMI1 polycomb ring finger oncogene

(BMI-1)

Bone marrow endothelial cells

(BMEC)

Bone marrow stromal cells

(BMSC)

Cluster of differentiation

(CD)

Colony forming unit

(CFU)

Chronic Myelogenous Leukemia

(CML)

Ckit

(also known as CD117)

Central Nervous System

(CNS)

C-terminal transactivation domain

(CTAD)

Chemokine (CXC motif) ligand 12,

(CXCL12, SDF-1)

also known as, Stromal Cell

Derived Factor-1)

Epithelial to mesenchymal transition

(EMT)

Endothelial-selectin

Etoposide

(E-selectin, also known as CD62E)

(VP-16)

Factor inhibiting HIF-1

$(\mathrm{FIH}-1)$

Fibroblast growth factor

(FGF)

FMS-like tyrosine kinase 3

(FLT-3 ligand)

Granulocyte colony-stimulating factor

(G-CSF)

Granulocyte-macrophage colony stimulating factor (GM-CSF)

Hematopoietic inductive microenvironment

(HIM)

Hematopoietic stem cells

(HSC)

Hypoxia Inducible Factor 2 •

$(\mathrm{HIF}-2 \cdot)$

Histone deacetylases

(HDAC)

Histone deactylase inhibitors

(HDACl)

Hypoxia responsive elements

(HRE)

(HOB) 
Imatinib Mesylate

Insulin-like growth factor-1

Interferon-•

Interleukin

Leukemia inhibitory factor

Macrophage colony stimulating factor

Macrophage inflammatory protein-1 $\bullet$

Mesenchymal stem cells

Neuronal cadherin

Non obese diabetic/severe combined

immunodeficiency

$\mathrm{N}$-terminal transactivation domain

Octamer 4

oxygen dependent domain

Pax/Aryl hydrocarbon receptor/S im

Platelet endothelial cell adhesion molecule-1

Philadelphia chromosome

POU class 5 homeobox 1 family

proline-rich tyrosine kinase 2

Protein phosphatase- $2 \mathrm{~A}$

Recombinase-activating enzymes

Stem cell antigen 1

Severe combined immunodeficiency

Shaped $\mathrm{N}$-cadherin positive

Signaling lymphocyte activation molecules

Stem cell factor

Terminal deoxynucleotidyl transferase)

Transforming growth factor-•

Tumor initiating cells

Tumor necrosis factor-•

Vascular Cell Adhesion Molecule

Vascular Endothelial Cadherin

Very Late Antigen-4

Very Late Antigen-5
(Imatinib, Gleevec, STI571)

(IGF-1)

$(\mathrm{IFN}-\bullet)$

(IL)

(LIF)

$(\mathrm{M}-\mathrm{CSF})$

$(\mathrm{MIP}-1 \cdot)$

(MSC)

(N-cadherin, $\mathrm{CDH} 2)$

(NOD/SCID)

(NTAD)

(OCT-4)

(ODD)

(PAS)

(PECAM1, CD31)

(Bcr/ABI , Ph+, t(9;22))

(POU5F 1)

(Pyk-2)

(PP2A)

$(R A G 1 \& R A G 2)$

(Sca-1)

(SCID)

(SNO)

(SLAM)

(SCF)

(Tdt)

$(T G F-\bullet)$

(TIC)

$(\mathrm{TNF}-\bullet)$

(V-CAM)

(VE-cadherin, also known as

CD144)

(VLA-4)

(VLA-5) 


\section{TABLE OF CONTENTS:}

VE-Cadherin Expression and Regulation of Sensitivity to Apoptosis in Philadelphia Chromosome Positive Acute Lymphoblastic Leukemia.

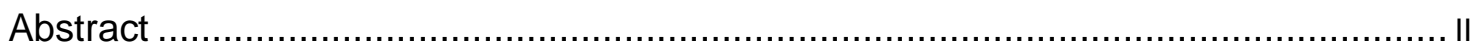

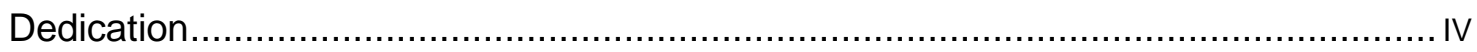

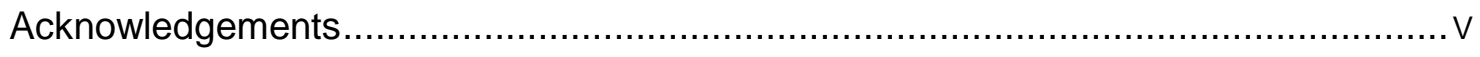

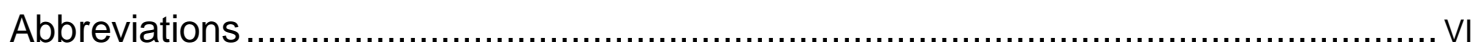

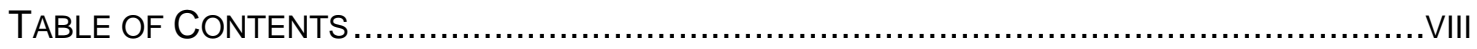

Architecture of the Bone Marrow Microenvironment: Hematopoesis \& Normal B-Cell

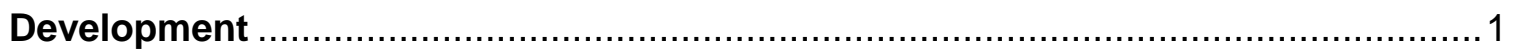

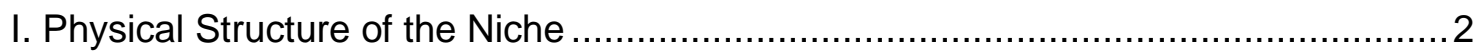

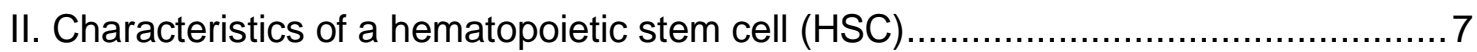

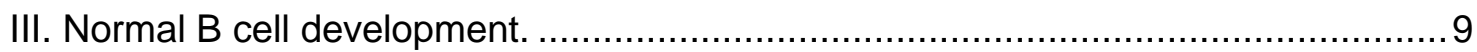

IV. Damage to the microenvironment alters support of stem and progenitor cells...... 12

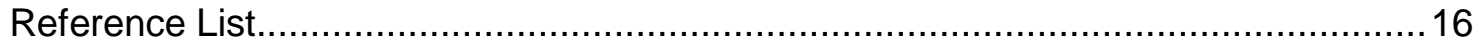

Critical Components of a Functional Stem Cell Niche are Damaged by Chemotherapy

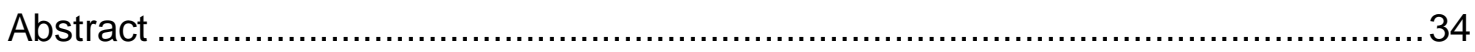

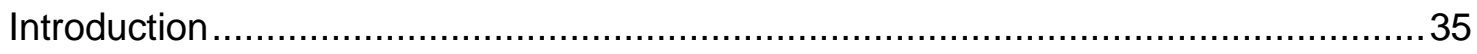

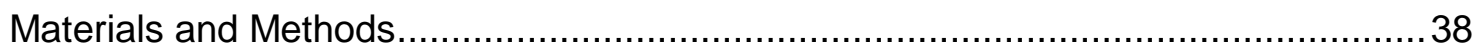

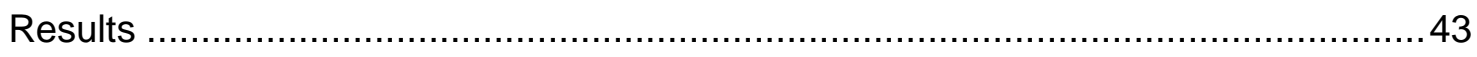

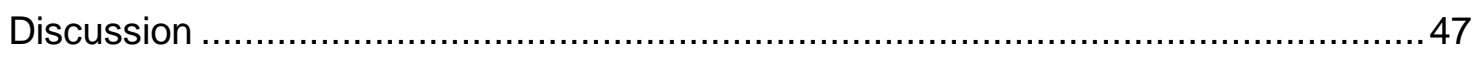

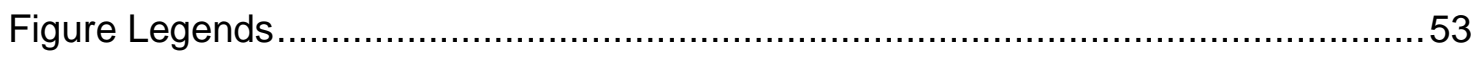




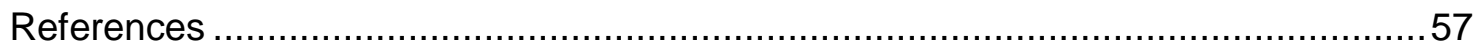

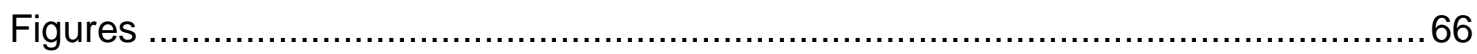

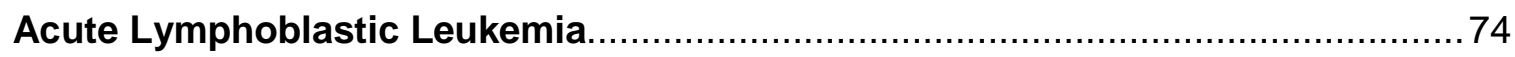

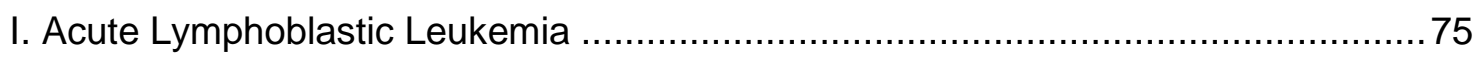

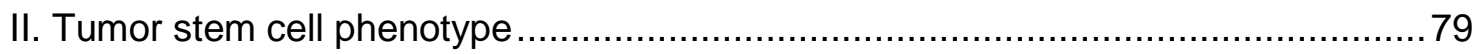

III. Rodent models of tumor stem cells and leukemia ......................................... 81

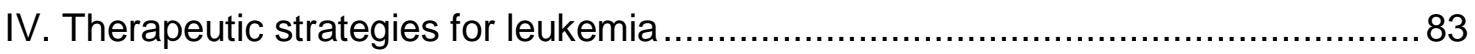

V. Bcr/Abl, Beta-catenin, HIF-2alpha, VE-cadherin, and Oct-4 in normal cells and leukemic

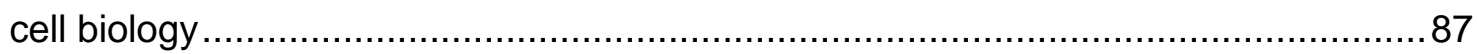

VI. Unique phenotype of leukemia cells utilized in our model and rationale for our studies

Reference List.

$\mathrm{Ph}^{+} / \mathrm{VE}$-cadherin ${ }^{+}$identifies a stem cell-like population of acute lymphoblastic leukemia

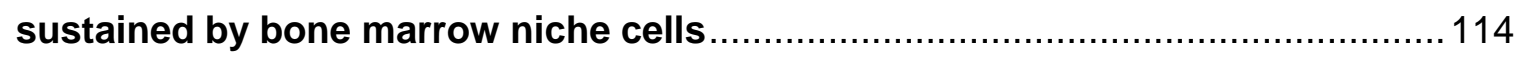

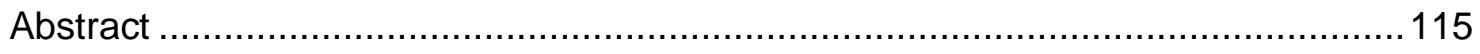

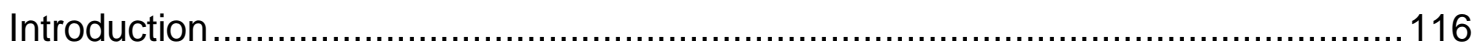

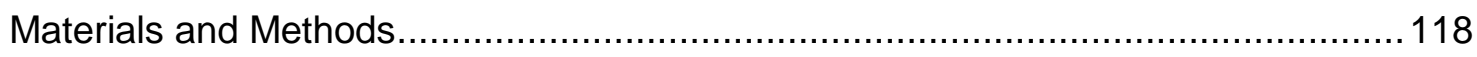

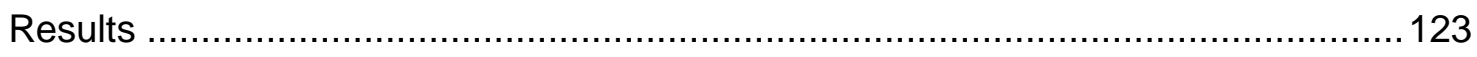

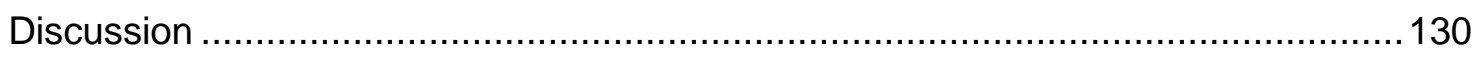

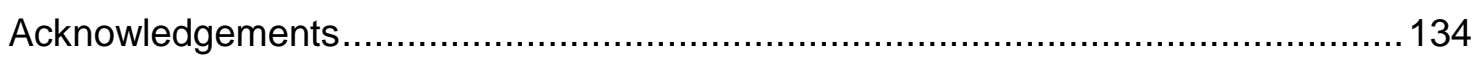

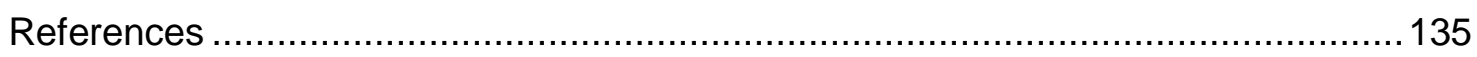

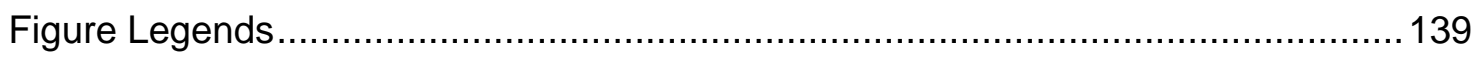

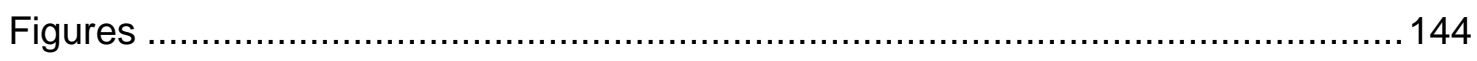




\section{VE-cadherin Regulates Philadelphia Chromosome Positive Acute Lymphoblastic}

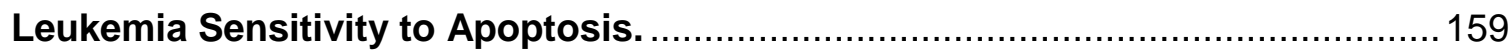

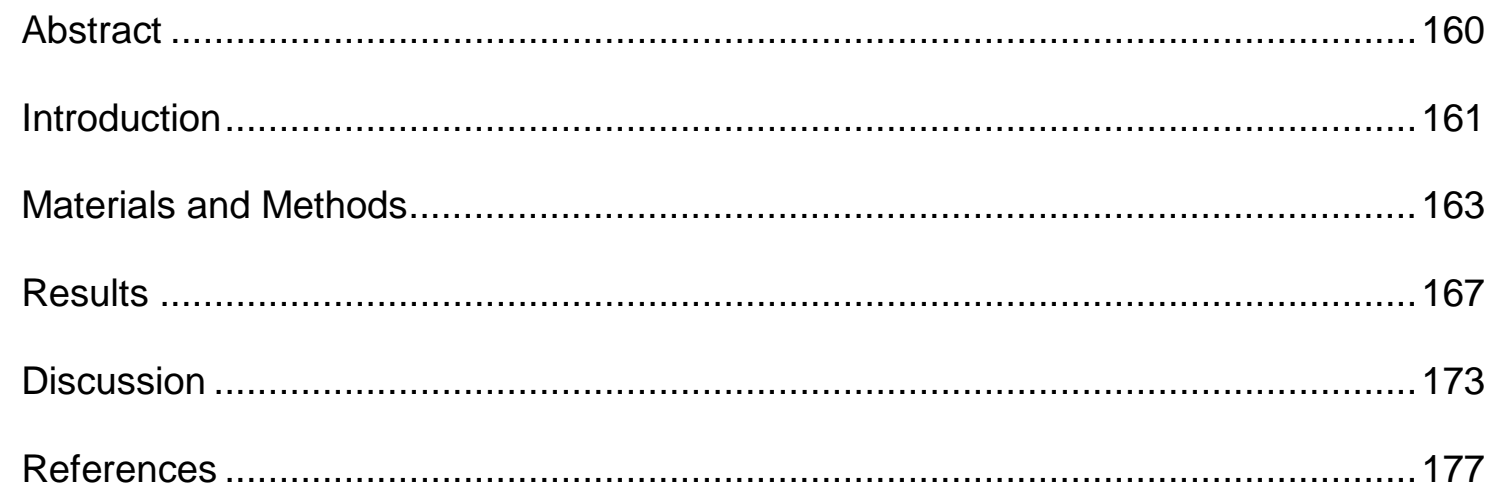

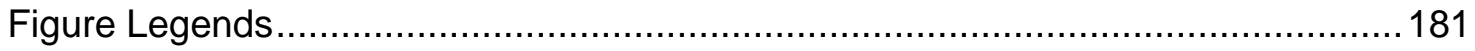

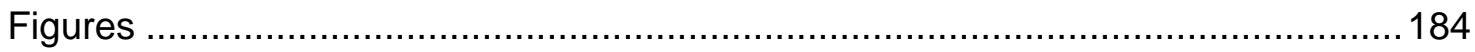

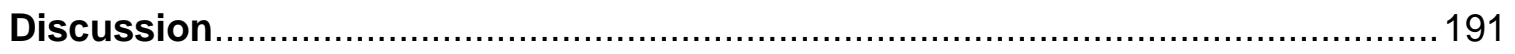

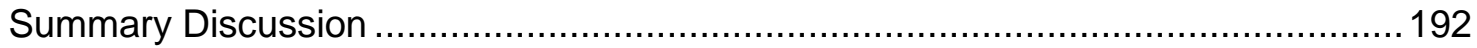

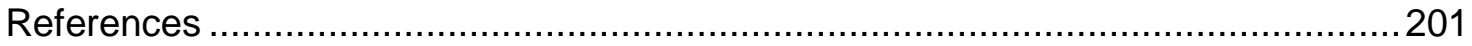




\section{Chapter 1}

\section{Architecture of the Bone Marrow Microenvironment: Hematopoesis \& Normal B-Cell Development}




\section{Architecture of the bone marrow microenvironment/ hematopoietic}

\section{niche, hematopoiesis and normal B cell development}

\section{Physical Structure of the Niche}

The stem cell niche can be characterized as a specialized environment which can vary in content and location based on the tissue and stem cell type that it supports. Early work of Curry and Trenton in 1966 first coined the phrase "hematopoietic inductive microenvironment" (HIM) and the first description of a stem cell niche was hypothesized by Shofield in 1978 who suggested that stem cells were in association with other cells that influence their behavior ${ }^{1 ; 2}$. More recently, the Scadden lab has proposed that the niche is a group of cells that allow a stem cell to maintain its identity ${ }^{3 ; 4}$. Our focus has been the bone marrow microenvironment which is anatomical space that houses the unique niche for hematopoietic stem cells (HSC) and is the primary site of post-natal hematopoiesis.

The primary function of the niche is to facilitate the anchorage, growth and expansion of stem cells. Early studies characterizing the progression and renewal of stem cells were completed in Drosophila and C. elegans models ${ }^{5-7}$. Further studies to characterize the expansion of stem cells in a mammalian model have shown that stem cell survival and self renewal is accomplished by supporting cells providing both physical and soluble cues to stem cells that hone towards, and bind to, the physical architecture of the stem cell niche ${ }^{8 ; 9 ; 10}$. Until recently, the composition and location of the stem cell niche components remained somewhat elusive. Shackney, followed by others, suggested a model of gradient hematopoiesis in the bone marrow with more primitive cells located near the endosteum, with differentiation and maturation increasing as the cells moved toward the vascularized bone marrow cavity to be mobilized to the periphery ${ }^{11 ; 12}$ (Figure 1).

Current studies have segregated the HSC niche into two main support systems, the osteoblastic or endosteal niche and the vascular niche 11;13;14. The supportive components of 
these stem cell niches are mesenchymal stem cells that differentiate into supportive lineages including osteoblasts (both spindle-shaped N-cadherin positive (SNO) and negative), fibroblastic cells (also known as bone marrow stromal cells, BMSC and mesenchymal stem cells, MSC), endothelial cells, chondrocytes, adipocytes, and myocytes ${ }^{15-19}$. Recent studies from the Taichman lab suggest an interesting role for HSC in the regulation of differentiation of supportive cells suggesting that HSC directly participate in niche activities ${ }^{20 ; 21}$. Our studies have focused on two of the main components of each niche, osteoblasts and bone marrow stromal cells.

The endostosteum, found lining the bone surface, consists mostly of osteoblasts and serves as the primary site in which quiescent HSC reside ${ }^{22-25}$. Osteoblasts are mononucleate cells that are responsible for the production of bone and are further separated into spindleshaped $\mathrm{N}$-cadherin positive, or SNO cells, or $\mathrm{N}$-cadherin negative ${ }^{16 ; 26}$. Prior to the knowledge of the specific architecture of the niche, Gong and Lord showed in 1975 that more primitive hematopoietic progenitor cells were in close proximity to the endosteal surface, while more differentiated cells were seen in the center of the bone marrow space ${ }^{24 ; 25}$. Literature summarized by the work of multiple groups ${ }^{14 ; 19 ; 26-28}$ then revealed the first true glimpses of the structure, in vivo location, function and signaling of the cells in the niche, showing the $\mathrm{N}$-cadherin positive osteoblasts that line the endosteal surface play a role in the regulation of HSC. Additionally, these studies showed that the number of osteoblasts, as well as HSC adhesion to them, directly regulate both the number and quiescence of the HSCs found in the niche ${ }^{26 ; 14}$.

There is a discrepancy in the literature regarding the importance of $\mathrm{N}$-cadherin regulating HSC in the niche. Zhang et al. showed that $\mathrm{N}$-cadherin expression on osteoblasts is critical to the regulation of the number of HSC in the niche ${ }^{26}$. Subsequent papers by Kiel et al., from the Morrision lab, deleted $\mathrm{N}$-cadherin from HSC using $\mathrm{Mx}-1-\mathrm{Cre}(+) \mathrm{N}$-cadherin(fl/-) mice and showed that $\mathrm{N}$-cadherin deficiency did not affect bone marrow cellularity or lineage composition, the numbers of colony-forming progenitors, the frequency of HSC, the ability of 
HSC to sustain hematopoiesis over time, or their ability to reconstitute irradiated mice in primary or secondary transplants ${ }^{29 ; 30}$. These observations confirm that the osteoblasts may be important, but that $\mathrm{N}$-cadherin expression is not critical for HSC development in the endosteal niche. Studies using the ability to inducibly ablate osteoblasts in transgenic mice expressing the herpes virus thymidine kinase gene, under the control of the osteoblast specific collagen a1 promoter, were performed by Visnjic et al. and showed that the loss of osteoblasts led to substantial decrease in the number of progenitor cells (lymphoid, myeloid and erythroid) in the bone marrow ${ }^{31 ; 32}$. Additionally, these studies showed a decrease in the total number of HSC and decreased bone marrow cellularity, all of which could be restored by the reconstitution of the osteoblasts ${ }^{31 ; 32}$. In parallel, the Taichman lab has shown that the in vitro survival of hematopoietic progenitor cells on osteoblasts is dependent upon the engagement of VLA-4 (Very Late Antigen) and VLA-5, and that HSC are able to regulate the osteoblast secretion of certain factors necessary for stem cell survival and differentiation suggesting an active reciprocal relationship between HSC and the supportive cells of the niche ${ }^{21 ; 33-35}$.

The second major physical component of the bone marrow niche includes stromal cells which are adherent, clonogenic, non-phagocytic cells that express a variety of molecules necessary for immune function ${ }^{36 ; 37}$. In 1968, Friedenstein, Owen, and colleagues were the first to determine that bone marrow stromal cells, or fibroblastic colony forming units (CFU-F) as they called them, were able to be derived and propagated from the bone marrow of post-natal animals ${ }^{38-43}$.

The bone marrow contains adventitial (outer) reticular marrow cells which line the sinus wall and fibroblastic reticular marrow cells (referred to as bone marrow stromal cells, BMSC) that are found scattered in the mid bone region, and form a three-dimensional cellular network integrating the underlying sinusoidal network and play a major role in regulation of hematopoiesis, specifically B cell development. These fibroblastic BMSC have classically been described as not expressing hematopoietic or co-stimulatory molecules but are able to express 
extracellular matrix proteins including collagen I, III, IV, V, VI, fibronectin, vitronectin, laminin, thrombospondin, hemonectin, and

tenascin ${ }^{44-46}$. They have the surface markers CD105 (SH2), CD73 (SH3/4), CD44, CD90(Thy1), CD71, and Stro-1 as well as adhesion molecules CD166 (activated leukocyte cell adhesion molecule [ALCAM]), intercellular adhesion molecule (ICAM)-1, CD29, Stro-1 and VCAM-1 (Vascular Cell Adhesion Molecule-1, CD106) which are important for hematopoiesis ${ }^{47-49}$. Additionally, they produce soluble factors, including CXCL12 (chemokine (CXC motif) ligand 12, also known as SDF-1 (Stromal Cell Derived Factor-1) and Interleukin-7, that are important for the differentiation and maturation of HSC ${ }^{50-52}$.

Interestingly, bone marrow stromal cells (BMSC) expression of physical and soluble factors allows them to both positively and negatively influence hematopoiesis, and multiple studies have suggested that they play an important role in both the osteoblastic and vascular niches ${ }^{53}$. Expression of cytokines which positively influence hematopoiesis include granulocytemacrophage colony stimulating factor (GM-CSF), interleukin-1 (IL-1), IL-3, IL-5, IL-6, IL-7, IL-11, IL-12, leukemia inhibitory factor (LIF), fibroblast growth factor (FGF), stem cell factor (SCF), Flt3 ligand (FMS-like tyrosine kinase 3), c-kit, macrophage colony stimulating factor (M-CSF), insulin-like growth factor-1 (IGF-1) and tumor necrosis factor- $\alpha$ (TNF- $\alpha)^{54-60}$. In contrast, interferon- $\gamma$ (INF- $\gamma$ ), transforming growth factor- $\beta$ (TGF- $\beta$ ), and macrophage inflammatory

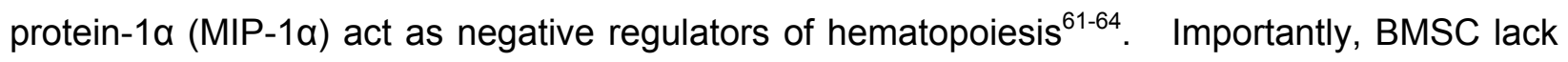
phenotypic markers of osteoblasts, such as osteopontin and osteocalcin, showing they are distinct from osteoblasts consistent with their documentation of performing unique functions ${ }^{65}$. Stromal cells were initially shown to support hematopoietic cells by Dexter, Whitelock, and Witte and have been shown to be crucial in the early stages of B cell development, or B lymphopoiesis. Additionally, stromal cells have the ability to protect of B-lineage leukemias, as well as other malignancies, from chemotherapy ${ }^{66-71}$. 
While not a focus of work presented in the current studies, it is important to touch on the endothelial, or vascular, niche. The endothelial niche is an environment which provides signals for HSC proliferation, differentiation into progenitors, and subsequently mature blood cells, as well as mobilization into the blood stream $^{72 ; 73}$. Bone marrow endothelial cells (BMEC) interact with HSC through constitutive expression of chemokines such as CXCL12 and through the expression of adhesion markers VCAM-1, PECAM1 (platelet endothelial cell adhesion molecule-1), E-selectin (endothelial-selectin) as well as others ${ }^{11 ; 18 ; 74}$. HSC vacillate between the osteoblastic and vascular niche, potentially by utilizing BMSC, during normal homeostatic conditions. This migration is increased during times of stress when the need for blood cells is increased. Endothelial cells have been shown to be a crucial component of the niche, as upon ablation of endothelial cells in vivo by utilizing anti-VE-cadherin antibody, hematopoietic failure ensued and the addition of endothelial cells has been shown to increased hematopoietic reconstitution ${ }^{75-77}$.

A close relationship between endothelial cells and HSC is not surprising as both lineages are derived from a common precursor, though there is discrepancy in the literature whether the common lineage is a hemangioblast, haemogenic endothelium or both ${ }^{78 ; 79}$. Hemangioblasts are mesodermal progenitors with both endothelial and haematopoietic potential while haemogenic endothelium is phenotypically differentiated endothelial cells with haematopoietic potential ${ }^{80}$. The hemangioblast theory initially arose from studies in the late 1990's identifying that during embryonic stem cell differentiation a clonal precursor, the blast colony-forming cell (BL-CFC), was able to give rise to blast colonies with both endothelial and haematopoietic components ${ }^{81 ; 82}$. Further research has provided evidence for the presence of this bipotential precursor, or BL-CFC in vivo, however, the mechanism by which hematopoietic cells are generated from the hemangioblast, and the role of the haemogenic endothelium, is still being investigated. 
Recently, to address this discrepancy, the Lacaud laboratory, and other groups, followed individual blasts cell development by time-lapse photography and demonstrated that the hematopoietic cells are generated from the hemangioblast, using the haemogenic endothelium as an intermediate step. They utilized the endothelial markers Tie2/Tek13, as well as the hematopoietic commitment markers CD41/allb integrin and c-kit to investigate the sequential, developmental steps, as well as identify transitional populations, and also determined that the transcription factors Scl/Tal110 and Runx1/AML1 are necessary for the establishment of the haemogenic endothelium and the generation of hematopoietic cells, respectively ${ }^{79 ; 80 ; 83 ; 84}$.

Another factor further solidifying the relationship between endothelial cell and HSC interactions are expression of cell surface receptors of the SLAM (signaling lymphocyte activation molecules) family. These molecules, expressed on the surface of HSC, consist of CD150, CD244 and CD48 and are commonly associated with the population of HSC that interacts directly with the endothelial cells and are self-renewing HSC that can be mobilized rapidly, if needed, and replaced by cells recruited from the endosteal niche ${ }^{72}$.

\section{Characteristics of a hematopoietic stem cell (HSC).}

In the early 1900's Alexander Maximow gave the first description of a hematopoietic stem cell stating that, "In the mammalian organism exists one cell type, the lymphocyte in the widest sense of the word, which may look different according to the site of residence as well as to the local conditions and which can produce different products of cellular differentiation ${ }^{85}$." The 1960's brought about the next phase in the investigation of the HSC with the work of Goodman and Hodgson who coined the term $\mathrm{HSC}^{86}$. Additionally, groups such as Till and McCulloch, Bradley and Metcalf, Pluznik and Sachs, and Castro-Malaspina and Moore clearly delineated the importance of the bone marrow in regulation of hematopoiesis ${ }^{87-93}$. Critical techniques were also developed in order to analyze HSC in vitro with spleen colony forming assays, and the growth of niche cells in vitro, respectively ${ }^{94 ; 95}$. 
More current studies of HSC characterize them as pluripotent, self-renewing, non-cycling cells with a surface marker phenotype of $\mathrm{CD} 34^{+}$, Lineage $, \mathrm{SCA}^{+}, \mathrm{KIT}^{+96 ; 97}$. HSC give rise to all cells of the immune system including lymphoid ( $T, B$, and Natural Killer (NK) cells) and myeloid lineage cells (monocytes, macrophages, neutrophils, basophils, eosinophils, erythrocytes, megakaryocytes/platelets, and dendritic cells) while maintaining their ability to self renew ${ }^{98 ; 99}$ (Figure 2, ${ }^{100}$ ). Many adhesion and soluble factors are necessary for the maintenance of the stem cell phenotype. The important adhesion molecules of the niche include $\mathrm{N}$-cadherin/ $\beta$ catenin, VCAM/integrin and osteopontin/ $\beta 1$ integrin ${ }^{5 ; 101}$. Though the exact functions of these adhesion molecules are largely unknown, studies blocking the function of integrins have shown their importance in the adhesion and homing of HSC to the niche. Soluble factors that have been shown to be important in the maintenance of HSC include CXCL12, which plays a role in homing, transendothelial migration, proliferation and survival, and G-CSF (Granulocyte colonystimulating factor) which induces HSC and progenitor mobilization. The most primitive HSC are quiescent and found in the endosteal niche interacting with osteoblasts and subsequently interacting with BMSC and BMEC as they differentiate into progenitors and mature into competent immune cells that will migrate into the peripheral blood.

Innovative mouse studies from Akashi and Weissman proved the existence of specific and restricted common lymphoid (CLP) and myeloid progenitor (CMP) stem cells that arose from the HSC population and specifically gave rise to $B, T$ and NK cells (CLP) and Monocyte/Granulocyte, Megakaryocyte/Erythrocyte progenitor lineages (CMP), respectively ${ }^{102-}$ 106. These studies were the first to prove the existence of these intermediate progenitor stem

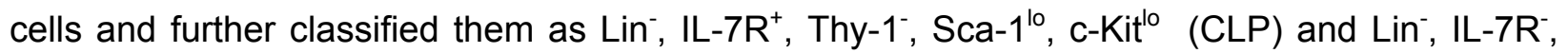
Thy-1', Sca-1 ${ }^{-}, \mathrm{c}-\mathrm{Kit}^{+}, \mathrm{Fc} \gamma \mathrm{R}^{\mathrm{lo}}$ (CMP). Further discussions of stem cell progenitor development will focus on the CLP, more specifically, its B-lineage progeny. 


\section{Normal B cell development.}

B (bursa or bone marrow derived) lymphocytes, both normal and malignant, were discovered and characterized throughout the mid 1960's and early 1970's by Max Cooper and Robert Good utilizing both patients with immune deficiencies as well as experimental animal models $^{107-110}$. B lymphocytes consist of a population of bone marrow derived cells that express clonally diverse cell surface immunoglobulin receptors recognizing specific antigenic epitopes 107. Early B cell development requires stromal cell physical contact and soluble factors in order to complete differentiation steps which involve rearrangement of immunoglobulin variable region gene segments to produce a mature, and functional, B lineage cell. B lymphopoiesis occurs initially in primary lymphoid tissue (fetal liver and then fetal/adult bone marrow), with functional maturation occurring in secondary lymphoid organs (lymph nodes and spleen) with the final endpoint being functional plasma cells that are terminally differentiated ${ }^{107 ; 111-114}$.

B lymphopoiesis occurs as HSC differentiate to a committed lymphoid progenitor stem cell (CLP) which then become pro-B, pre-B cells as their immunoglobulin variable region gene segments are rearranged (Figure $3,{ }^{100}$ ). This rearrangement occurs in both the heavy $(\mu)$ and light $(\lambda)$ chain variable regions by a tightly regulated process that utilizes the Tdt, or terminal deoxynucleotidyl transferase, and recombinase-activating enzymes (Rag1 and Rag2) leading to the expression of $\lg \mathrm{M}$, on the surface of the immature B cell. Immature B cells additionally express CD19, CD20, CD40, MHC class II and CD45R, and cells that exit the marrow acquire surface $\lg D$, as well as CD21 and CD22, and have functionally important changes in the density of other receptors ${ }^{107 ; 115 ; 116}$.

The crucial factors driving B lymphocyte development, in vivo, include Interluekin-7 (IL7), CXCL12/CXCR4, FIt-3L/FLT3, SCF, RANKL, and VCAM-1 and will be discussed below. IL-7 provides both survival/proliferation signals, promotes $\mathrm{V}$ to $\mathrm{DJ}$ heavy chain rearrangement by altering the accessibility of DNA substrates to the recombinase, and was the first cytokine 
shown to be essential for $B$ cell development ${ }^{117-119}$. IL-7 is secreted from the bone marrow stromal cells and binds to the IL-7R on the pre-B cell. Ligand binding stimulates maturation resulting in down-regulation of adhesion molecules on the pre-B cell so that it can proliferate and is no longer stromal, but still IL-7, dependent. The receptor for IL-7 is comprised of two chains: IL-7Ra and the cytokine-receptor common $\mathrm{Y}$-chain ( $\mathrm{Yc}$ ), and IL-7- and IL-7Ra-deficient mice have severe defects in the development of $B$ and $T$ cells ${ }^{120}$. IL-7 has been shown to play a vital role in the pro-B cell stage of development which has been confirmed by studies in IL-7- or IL-7Ra- deficient mice showing that their bone marrow is composed of normal numbers of prepro-B cells but has severe deficits of pro-B cells, pre-B cells and the more differentiated B cells with other studies suggesting the importance of IL-7 at the CLP stage of development ${ }^{107 ; 117-121}$.

CXCL12 and its receptor CXCR4 have been shown to be important in the retention of B lineage cells in primary lymphoid tissues and colonization in the bone marrow of B-lineage cells as well as $\mathrm{HSC}^{122 ; 123}$. Murine studies of CXCL12 deficient embryos or WT mice reconstituted with CXCR4 deficient fetal cells, show severely reduced numbers of very early B- precursors in the fetal liver as well as decreases in the pre-pro-B cells of the adult marrow, respectively, suggesting that CXCL12-CXCR4 axis is absolutely crucial for the earliest stages of B-cell development in the fetus and adult ${ }^{124 ; 125}$. CXCR4/CXCL12 signaling has also been shown to be important in the homing of end stage B cells to the bone marrow, however, the specific mechanisms by which CXCL12 functions in the regulation of B-cell development still remain unknown. Another receptor for CXCL12, CXCR7 has been identified and been shown to heterodimerize with CXCR4 to enhance CXCL12 signaling, and aid in transendothelial migration of B lineage ALL cells; however, a specific role for CXCR7 in B cell development has not yet been identified as conditionally deficient CXCR7-/- mice have normal B cell development ${ }^{126 ; 127}$.

FLT-3L/FLT3 is a ligand for the FLT-3 receptor which has sequence and structural homology to the class-III-receptor tyrosine kinases including the macrophage colony-stimulating 
factor (M-CSF) receptor (c-fms), the SCF receptor (KIT), and the $\alpha$ - and $\beta$-platelet-derived growth factor (PDGF) receptors ${ }^{128}$. Flt3 deficient mice have reductions in the number of pre-pro and pro-B cells with generally normal numbers of pre-B cells, immature B cells and mature B cells ${ }^{129}$. In contrast, FLT3L deficient mice have substantial reductions in the number of pre-proB-cells, marginally diminished numbers of pro-B cells and pre-B cells, and normal numbers of more differentiated B cells ${ }^{130}$. These data indicate that, similar to CXCL12, FLT3L is pivotal for the development of pre-pro-B cells but the phenotypic difference between FLT3 and FLT3L deficient mice suggests the potential for another receptor for FLT3L.

SCF binds to the KIT class-III-receptor tyrosine kinase and has been shown to play a role in the development of many cells types including hematopoietic cells ${ }^{131}$. SCF or c-kit deficient mice have been shown to have normal B cell development with significantly reduced numbers of CLP in mice younger than 4 weeks of age, and at 195 days (approximately 28 weeks), the numbers of pre-pro-B cells were normal but the numbers of pro-B and pre-B cells were severely reduced suggesting that in younger mice SCF/C-kit may be redundant but that it plays a critical role in adult B cell development and maintenance ${ }^{132-134}$. During B cell development, c-kit on the surface of the pro-B cell interacts with SCF on the surface of the stromal cell which activates the tyrosine kinase activity inducing pro-B to pre-B division and differentiation.

RANKL (receptor activator of nuclear factor-K B ligand) binds to the RANK receptor, and its expression on $B$ cells has been shown to be important for B cell development. Reconstitution of immunodeficient recombination-activating gene 1 (Rag1-/-) mice with Rankl-/- fetal liver cells led to reduced numbers of pre-B cells and $\mathrm{B} 220+\lg \mathrm{M}+$ immature $\mathrm{B}$ cells, where reconstitution of Rankl-/- mice with wild-type bone-marrow cells led to normal B-cell development ${ }^{135}$.

VCAM-1 provides physical interaction between pro and pre-B cells and allows for retention in the bone marrow. Additionally, interactions between VCAM-1 on the stromal cells 
and VLA-4 on the B cells hold them in close proximity to each other so that the B cells can interact with soluble factors being produced by the BMSC. Although some early studies suggested that VCAM-1 may not be essential to B lymphopoiesis, ${ }^{136}$ more recent studies have shown the importance of VCAM in both normal and neoplastic B cell survival ${ }^{137-141}$.

\section{Damage to the microenvironment alters support of stem and progenitor cells.}

As mentioned previously, in a healthy bone marrow microenvironment, the supportive cells of the niche, osteoblasts and bone marrow stromal cells, act as crucial mediators in both the survival of primitive stem cells as well as the maturation of these cells into functional cells of the immune system. As such, it is important to address the functional consequences and deficits that occur when supportive cells of the bone marrow microenvironment are damaged by myelosuppressive or ablative chemotherapy or radiation as a common complication in the setting of bone marrow transplantation.

Early studies from the Fried lab showed that both chemotherapy and irradiation led to lasting deficits in stromal cell function and subsequently to a decrease in the number of fibroblastic colony forming units (CFU-F $)^{142-144}$. Patient retrospective studies from the late 1990's show that even at 12 years, post-transplant patients' CFU-F frequencies were reduced by $60 \%$ $90 \%$ compared to controls ${ }^{145 ; 146}$. More recent studies show that Acute Lymphoblastic Leukemia $(A L L)$ patients who received ablative therapy prior to bone marrow transplantion were found to have diminished hematopoietic support that was attributed to an increase in transforming growth factor beta $(\mathrm{TGF}-\beta)^{147}$. In contrast, studies from Isaikinia et al. investigated the ability of mesenchymal stem cells (MSC) from both normal donors and patients exposed to chemotherapy and/or radiation (Non-Hodgkin's, Hodgkin's Lymphoma or Ewings sarcoma) to support CD34+ cells ${ }^{148}$. They saw no difference in expansion or differentiation of hematopoietic cells at 7,14 , or 21 days.

Further studies are clearly needed to better understand the mechanisms that underlie the damage that occurs with different chemotherapy regimens and how functional changes alter 
long term hematopoietic recovery. Previous publications of in vitro studies, from our laboratory, as well as others, established that chemotherapy increases the amount of active TGF- $\beta$ in bone marrow stromal cells and data shown in chapter 1 elucidates the functional consequences of chemotherapy mediated increases in TGF- $\beta$ in osteoblasts on their capacity to support human stem and hematopoietic progenitor cells ${ }^{149-151}$.

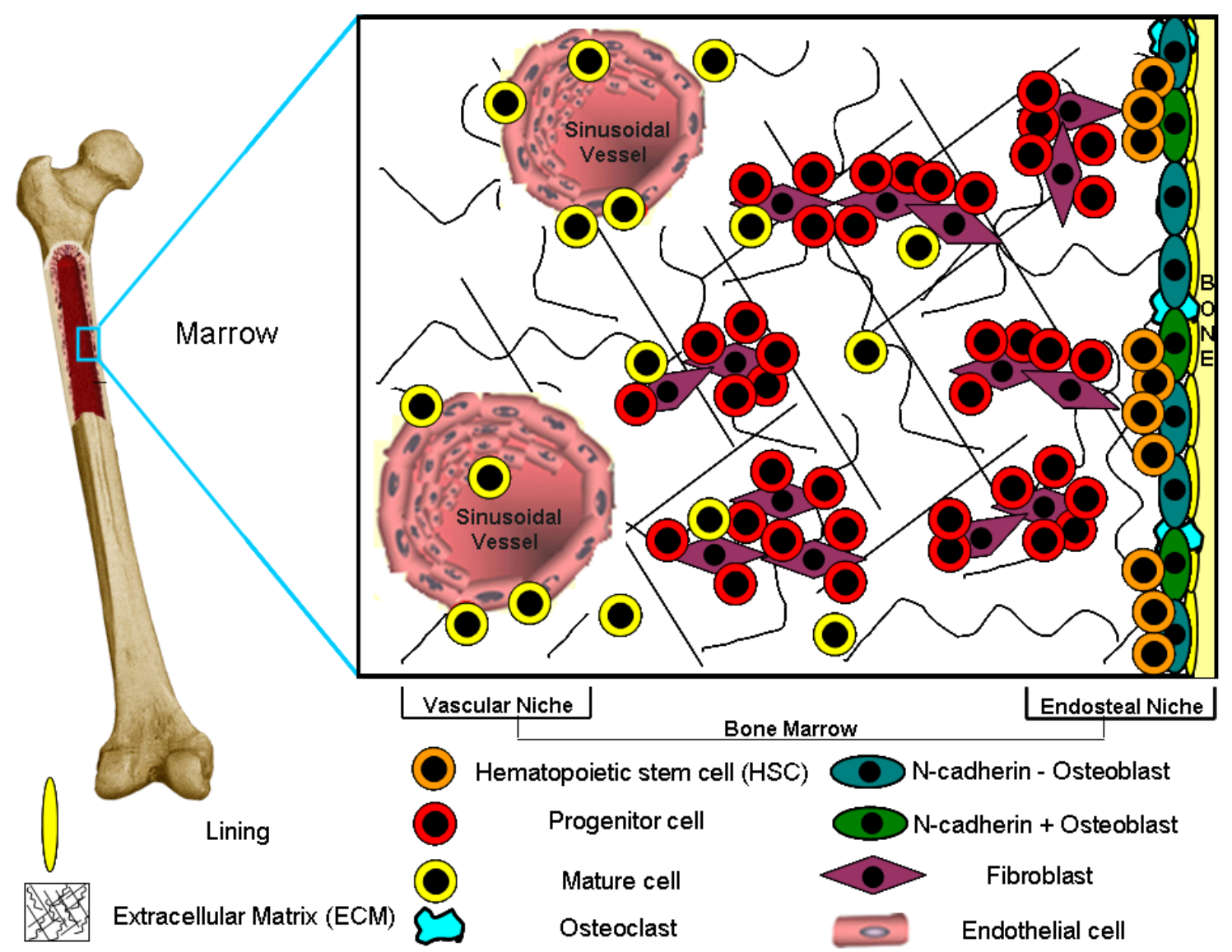

Figure 1: Architecture of the stem cell niche 


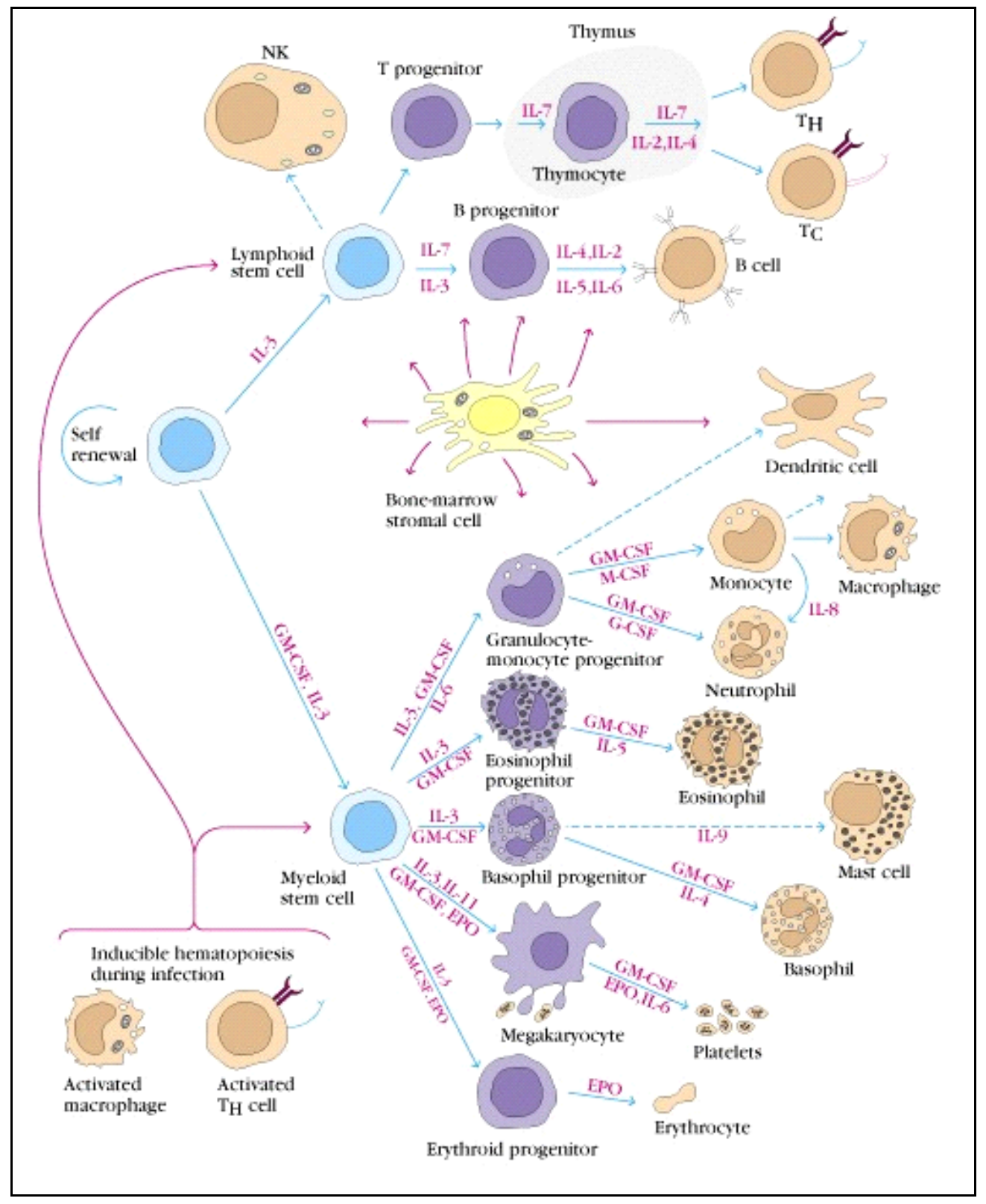

Figure 2: Hematopoiesis, Immunology, $5^{\text {th }}$ edition ${ }^{100}$ 


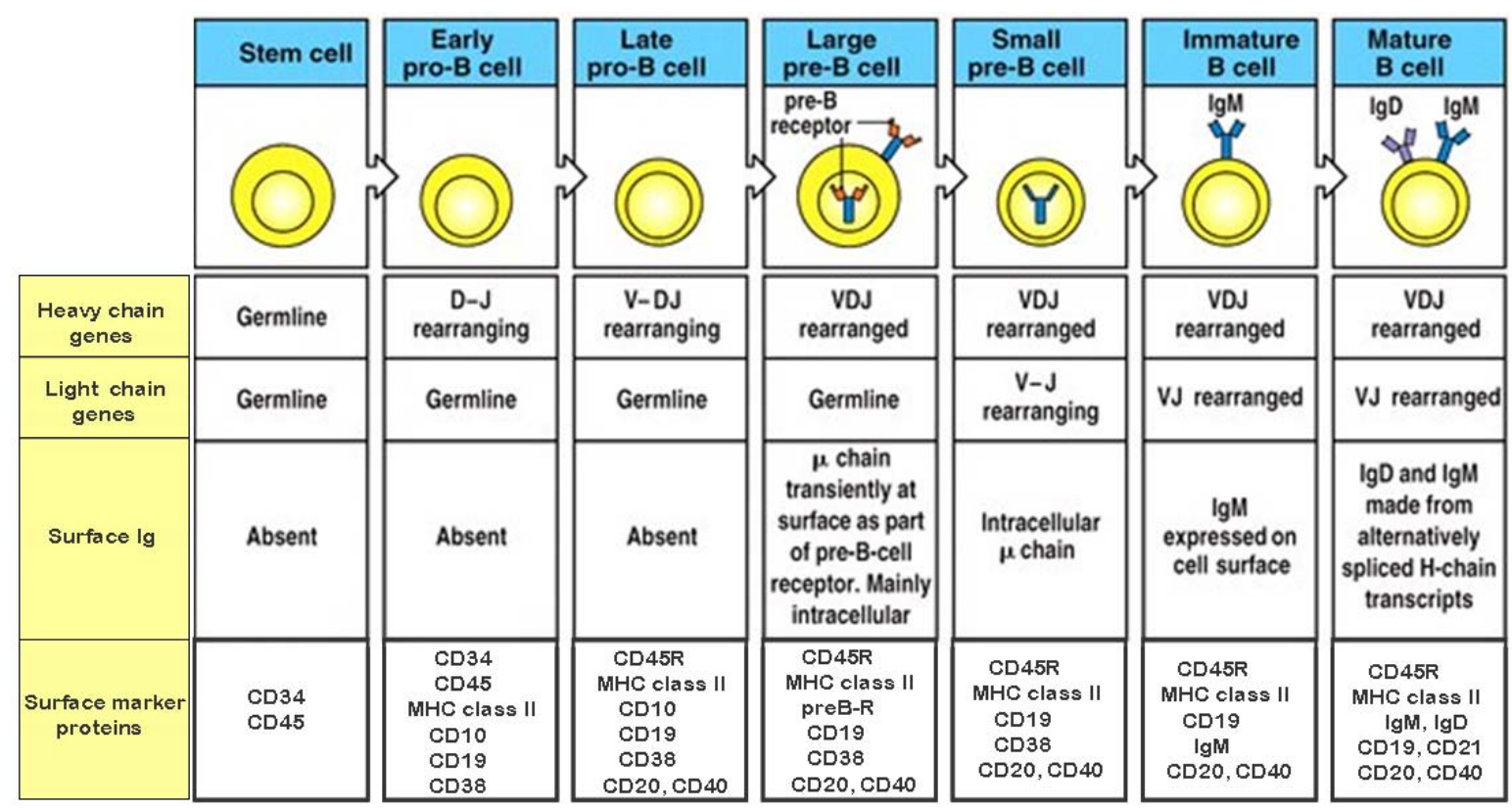

Figure 3: Normal B cell development (lymphopoiesis), Immunology $5^{\text {th }}$ edition ${ }^{100}$ 


\section{Reference List}

1. Curry JL, Trentin JJ. Hemopoietic spleen colony studies. I. Growth and differentiation. Dev.Biol. 1967;15:395-413.

2. Schofield R. The relationship between the spleen colony-forming cell and the haemopoietic stem cell. Blood Cells 1978;4:7-25.

3. Adams GB, Scadden DT. The hematopoietic stem cell in its place. Nat.Immunol. 2006; 7:333-337.

4. Scadden DT. The stem-cell niche as an entity of action. Nature $2006 ; 441: 1075-1079$.

5. Li L, Xie T. Stem cell niche: structure and function. Annu.Rev.Cell Dev.Biol. $2005 ; 21: 605-631$.

6. Spradling A, Drummond-Barbosa D, Kai T. Stem cells find their niche. Nature 2001;414:98-104.

7. Walker MR, Patel KK, Stappenbeck TS. The stem cell niche. J.Pathol. 2009;217:169180.

8. Yusuf RZ, Scadden DT. Homing of hematopoietic cells to the bone marrow. J.Vis.Exp. 2009

9. Kiger AA, White-Cooper H, Fuller MT. Somatic support cells restrict germline stem cell self-renewal and promote differentiation. Nature 2000;407:750-754.

10. Blank U, Karlsson G, Karlsson S. Signaling pathways governing stem-cell fate. Blood 2008;111:492-503. 
11. Kaplan RN, Psaila B, Lyden D. Niche-to-niche migration of bone-marrow-derived cells. Trends Mol.Med. 2007;13:72-81.

12. Shackney SE, Ford SS, Wittig AB. Kinetic-microarchitectural correlations in the bone marrow of the mouse. Cell Tissue Kinet. 1975;8:505-516.

13. Yin T, Li L. The stem cell niches in bone. J.Clin.Invest 2006;116:1195-1201.

14. Calvi LM, Adams GB, Weibrecht KW et al. Osteoblastic cells regulate the haematopoietic stem cell niche. Nature 2003;425:841-846.

15. Wang $\mathrm{X}$, Hisha $\mathrm{H}$, Taketani $\mathrm{S}$ et al. Characterization of mesenchymal stem cells isolated from mouse fetal bone marrow. Stem Cells 2006;24:482-493.

16. Muguruma $\mathrm{Y}$, Yahata $\mathrm{T}$, Miyatake $\mathrm{H}$ et al. Reconstitution of the functional human hematopoietic microenvironment derived from human mesenchymal stem cells in the murine bone marrow compartment. Blood 2006;107:1878-1887.

17. Frisch BJ, Porter RL, Calvi LM. Hematopoietic niche and bone meet. Curr.Opin.Support.Palliat.Care 2008;2:211-217.

18. Kopp HG, Avecilla ST, Hooper AT, Rafii S. The bone marrow vascular niche: home of HSC differentiation and mobilization. Physiology.(Bethesda.) 2005;20:349-356.

19. Xie $Y$, Yin $T$, Wiegraebe $W$ et al. Detection of functional haematopoietic stem cell niche using real-time imaging. Nature 2009;457:97-101.

20. Taichman RS. Blood and bone: two tissues whose fates are intertwined to create the hematopoietic stem-cell niche. Blood 2005;105:2631-2639. 
21. Jung $Y$, Song J, Shiozawa $Y$ et al. Hematopoietic stem cells regulate mesenchymal stromal cell induction into osteoblasts thereby participating in the formation of the stem cell niche. Stem Cells 2008;26:2042-2051.

22. Kiel MJ, Morrison SJ. Uncertainty in the niches that maintain haematopoietic stem cells. Nat.Rev.Immunol. 2008;8:290-301.

23. Nilsson SK, Johnston HM, Coverdale JA. Spatial localization of transplanted hemopoietic stem cells: inferences for the localization of stem cell niches. Blood 2001;97:22932299.

24. Lord BI, Testa NG, Hendry JH. The relative spatial distributions of CFUs and CFUc in the normal mouse femur. Blood 1975;46:65-72.

25. Gong JK. Endosteal marrow: a rich source of hematopoietic stem cells. Science 1978;199:1443-1445.

26. Zhang J, Niu C, Ye L et al. Identification of the haematopoietic stem cell niche and control of the niche size. Nature 2003;425:836-841.

27. Lo CC, Fleming HE, Wu JW et al. Live-animal tracking of individual haematopoietic stem/progenitor cells in their niche. Nature 2009;457:92-96.

28. Yahata T, Muguruma Y, Yumino S et al. Quiescent human hematopoietic stem cells in the bone marrow niches organize the hierarchical structure of hematopoiesis. Stem Cells 2008;26:3228-3236.

29. Kiel MJ, Acar M, Radice GL, Morrison SJ. Hematopoietic stem cells do not depend on Ncadherin to regulate their maintenance. Cell Stem Cell 2009;4:170-179. 
30. Kiel MJ, Radice GL, Morrison SJ. Lack of evidence that hematopoietic stem cells depend on $\mathrm{N}$-cadherin-mediated adhesion to osteoblasts for their maintenance. Cell Stem Cell 2007;1:204-217.

31. Visnjic D, Kalajzic I, Gronowicz G et al. Conditional ablation of the osteoblast lineage in Col2.3deltatk transgenic mice. J.Bone Miner.Res. 2001;16:2222-2231.

32. Visnjic D, Kalajzic Z, Rowe DW et al. Hematopoiesis is severely altered in mice with an induced osteoblast deficiency. Blood 2004;103:3258-3264.

33. Neiva K, Sun YX, Taichman RS. The role of osteoblasts in regulating hematopoietic stem cell activity and tumor metastasis. Braz.J.Med.Biol.Res. 2005;38:1449-1454.

34. Jung $\mathrm{Y}$, Wang J, Havens A et al. Cell-to-cell contact is critical for the survival of hematopoietic progenitor cells on osteoblasts. Cytokine 2005;32:155-162.

35. Taichman RS, Reilly MJ, Emerson SG. The Hematopoietic Microenvironment: Osteoblasts and The Hematopoietic Microenvironment. Hematology. 2000;4:421-426.

36. Lichtman MA. The ultrastructure of the hemopoietic environment of the marrow: a review. Exp.Hematol. 1981;9:391-410.

37. Dorshkind K. Regulation of hemopoiesis by bone marrow stromal cells and their products. Annu.Rev.Immunol. 1990;8:111-137.

38. Friedenstein AJ. Marrow stromal fibroblasts. Calcif. Tissue Int. 1995;56 Suppl 1:S17.

39. Friedenstein AJ, Petrakova KV, Kurolesova Al, Frolova GP. Heterotopic of bone marrow. Analysis of precursor cells for osteogenic and hematopoietic tissues. Transplantation 1968;6:230-247. 
40. Friedenstein AJ. Stromal mechanisms of bone marrow: cloning in vitro and retransplantation in vivo. Haematol.Blood Transfus. 1980;25:19-29.

41. Friedenstein AJ, Chailakhyan RK, Latsinik NV, Panasyuk AF, Keiliss-Borok IV. Stromal cells responsible for transferring the microenvironment of the hemopoietic tissues. Cloning in vitro and retransplantation in vivo. Transplantation 1974;17:331-340.

42. Owen M. Marrow stromal stem cells. J.Cell Sci.Suppl 1988;10:63-76.

43. Owen M, Friedenstein AJ. Stromal stem cells: marrow-derived osteogenic precursors. Ciba Found.Symp. 1988;136:42-60.

44. Haynesworth SE, Goshima J, Goldberg VM, Caplan AI. Characterization of cells with osteogenic potential from human marrow. Bone 1992;13:81-88.

45. Chamberlain G, Fox J, Ashton B, Middleton J. Concise review: mesenchymal stem cells: their phenotype, differentiation capacity, immunological features, and potential for homing. Stem Cells 2007;25:2739-2749.

46. Mayani H, Guilbert LJ, Janowska-Wieczorek A. Biology of the hemopoietic microenvironment. Eur.J.Haematol. 1992;49:225-233.

47. Haynesworth SE, Baber MA, Caplan AI. Cell surface antigens on human marrow-derived mesenchymal cells are detected by monoclonal antibodies. Bone 1992;13:69-80.

48. Conget PA, Minguell JJ. Phenotypical and functional properties of human bone marrow mesenchymal progenitor cells. J.Cell Physiol 1999;181:67-73.

49. Jones EA, Kinsey SE, English A et al. Isolation and characterization of bone marrow multipotential mesenchymal progenitor cells. Arthritis Rheum. 2002;46:3349-3360. 
50. Miyake K, Medina K, Ishihara K et al. A VCAM-like adhesion molecule on murine bone marrow stromal cells mediates binding of lymphocyte precursors in culture. J.Cell Biol. 1991;114:557-565.

51. Juneja HS, Schmalsteig FC, Lee S, Chen J. Vascular cell adhesion molecule-1 and VLA-4 are obligatory adhesion proteins in the heterotypic adherence between human leukemia/lymphoma cells and marrow stromal cells. Exp.Hematol. 1993;21:444-450.

52. Jacobsen K, Kravitz J, Kincade PW, Osmond DG. Adhesion receptors on bone marrow stromal cells: in vivo expression of vascular cell adhesion molecule-1 by reticular cells and sinusoidal endothelium in normal and gamma-irradiated mice. Blood 1996;87:73-82.

53. Sara Lamorte, Leonor Remédio, SergioDias. Communication between bone marrow niches in normal bone marrow function and during hemopathies progression. Hematology Reviews 2009;1:

54. Thalmeier K, Meissner P, Reisbach $\mathrm{G}$ et al. Constitutive and modulated cytokine expression in two permanent human bone marrow stromal cell lines. Exp.Hematol. 1996;24:110.

55. Silva WA, Jr., Covas DT, Panepucci RA et al. The profile of gene expression of human marrow mesenchymal stem cells. Stem Cells 2003;21:661-669.

56. Kittler EL, Peters SO, Crittenden RB et al. Cytokine-facilitated transduction leads to lowlevel engraftment in nonablated hosts. Blood 1997;90:865-872.

57. Kittler EL, McGrath H, Temeles D et al. Biologic significance of constitutive and subliminal growth factor production by bone marrow stroma. Blood 1992;79:3168-3178. 
58. Dormady SP, Bashayan O, Dougherty R, Zhang XM, Basch RS. Immortalized multipotential mesenchymal cells and the hematopoietic microenvironment. J.Hematother.Stem Cell Res. 2001;10:125-140.

59. Ryan DH, Nuccie BL, Ritterman I, Liesveld JL, Abboud CN. Cytokine regulation of early human lymphopoiesis. J.Immunol. 1994;152:5250-5258.

60. Hogan MB, Piktel D, Landreth KS. IL-5 production by bone marrow stromal cells: implications for eosinophilia associated with asthma. J.Allergy Clin.Immunol. 2000;106:329-336.

61. Snoeck HW, Van Bockstaele DR, Nys G et al. Interferon gamma selectively inhibits very primitive CD342+. J.Exp.Med. 1994;180:1177-1182.

62. Keller JR, Mantel C, Sing GK et al. Transforming growth factor beta 1 selectively regulates early murine hematopoietic progenitors and inhibits the growth of IL-3-dependent myeloid leukemia cell lines. J.Exp.Med. 1988;168:737-750.

63. Sing GK, Keller JR, Ellingsworth LR, Ruscetti FW. Transforming growth factor beta selectively inhibits normal and leukemic human bone marrow cell growth in vitro. Blood 1988;72:1504-1511.

64. Broxmeyer HE. Regulation of hematopoiesis by chemokine family members. Int.J.Hematol. 2001;74:9-17.

65. Balduino A, Hurtado SP, Frazao P et al. Bone marrow subendosteal microenvironment harbours functionally distinct haemosupportive stromal cell populations. Cell Tissue Res. 2005;319:255-266.

66. Dalton WS, Hazlehurst L, Shain K, Landowski T, Alsina M. Targeting the bone marrow microenvironment in hematologic malignancies. Semin.Hematol. 2004;41:1-5. 
67. Mudry RE, Fortney JE, York T, Hall BM, Gibson LF. Stromal cells regulate survival of Blineage leukemic cells during chemotherapy. Blood 2000;96:1926-1932.

68. Nefedova Y, Landowski TH, Dalton WS. Bone marrow stromal-derived soluble factors and direct cell contact contribute to de novo drug resistance of myeloma cells by distinct mechanisms. Leukemia 2003;17:1175-1182.

69. Neville-Webbe HL, Cross NA, Eaton CL et al. Osteoprotegerin (OPG) produced by bone marrow stromal cells protects breast cancer cells from TRAIL-induced apoptosis. Breast Cancer Res. Treat. 2004;86:269-279.

70. Nyambo R, Cross N, Lippitt J et al. Human bone marrow stromal cells protect prostate cancer cells from TRAIL-induced apoptosis. J.Bone Miner.Res. 2004;19:1712-1721.

71. Panayiotidis P, Jones D, Ganeshaguru K, Foroni L, Hoffbrand AV. Human bone marrow stromal cells prevent apoptosis and support the survival of chronic lymphocytic leukaemia cells in vitro. Br.J.Haematol. 1996;92:97-103.

72. Kiel MJ, Yilmaz OH, Iwashita T et al. SLAM family receptors distinguish hematopoietic stem and progenitor cells and reveal endothelial niches for stem cells. Cell 2005;121:11091121.

73. Arai F, Hirao A, Ohmura M et al. Tie2/angiopoietin-1 signaling regulates hematopoietic stem cell quiescence in the bone marrow niche. Cell 2004;118:149-161.

74. meida-Porada G, Ascensao JL. Isolation, characterization, and biologic features of bone marrow endothelial cells. J.Lab Clin.Med. 1996;128:399-407. 
75. Avecilla ST, Hattori K, Heissig B et al. Chemokine-mediated interaction of hematopoietic progenitors with the bone marrow vascular niche is required for thrombopoiesis. Nat.Med. 2004;10:64-71.

76. Chute JP, Muramoto GG, Salter AB et al. Transplantation of vascular endothelial cells mediates the hematopoietic recovery and survival of lethally irradiated mice. Blood 2007;109:2365-2372.

77. Salter AB, Meadows SK, Muramoto GG et al. Endothelial progenitor cell infusion induces hematopoietic stem cell reconstitution in vivo. Blood 2009;113:2104-2107.

78. Yoshimoto M, Yoder MC. Developmental biology: Birth of the blood cell. Nature 2009;457:801-803.

79. Lancrin C, Sroczynska P, Stephenson C et al. The haemangioblast generates haematopoietic cells through a haemogenic endothelium stage. Nature 2009;457:892-895.

80. Lancrin C, Sroczynska P, Serrano AG et al. Blood cell generation from the hemangioblast. J.Mol.Med. 2009

81. Choi K, Kennedy M, Kazarov A, Papadimitriou JC, Keller G. A common precursor for hematopoietic and endothelial cells. Development 1998;125:725-732.

82. Nishikawa SI, Nishikawa S, Kawamoto H et al. In vitro generation of lymphohematopoietic cells from endothelial cells purified from murine embryos. Immunity. 1998;8:761-769.

83. Chen MJ, Yokomizo T, Zeigler BM, Dzierzak E, Speck NA. Runx1 is required for the endothelial to haematopoietic cell transition but not thereafter. Nature 2009;457:887-891. 
84. Eilken HM, Nishikawa S, Schroeder T. Continuous single-cell imaging of blood generation from haemogenic endothelium. Nature 2009;457:896-900.

85. Maximow AA. Berlin lecture: The Lymphocyte as Common Stem Cell of the Different Blood Elements during Embryonic Development and in the Post-Fetal Life of Mammals (1909). Physiol Rev. 1924;4:533-563.

86. Goodman JW, HODGSON GS. Evidence for stem cells in the peripheral blood of mice. Blood 1962;19:702-714.

87. Wu AM, Siminovitch L, TILL JE, McCULLOCH EA. Evidence for a relationship between mouse hemopoietic stem cells and cells forming colonies in culture. Proc.Natl.Acad.Sci.U.S.A 1968;59:1209-1215.

88. Wu AM, TILL JE, Siminovitch L, McCULLOCH EA. Cytological evidence for a relationship between normal hemotopoietic colony-forming cells and cells of the lymphoid system. J.Exp.Med. 1968;127:455-464.

89. Wu AM, TILL JE, Siminovitch L, McCULLOCH EA. A cytological study of the capacity for differentiation of normal hemopoietic colony-forming cells. J.Cell Physiol 1967;69:177-184.

90. Metcalf $D$. Potentiation of bone marrow colony growth in vitro by the addition of lymphoid or bone marrow cells. J.Cell Physiol 1968;72:9-19.

91. Bradley TR, Metcalf $D$. The growth of mouse bone marrow cells in vitro. Aust.J.Exp.Biol.Med.Sci. 1966;44:287-299.

92. Pluznik $\mathrm{DH}$, Sachs $\mathrm{L}$. The induction of clones of normal mast cells by a substance from conditioned medium. Exp.Cell Res. 1966;43:553-563. 
93. Castro-Malaspina H, Gay RE, Resnick G et al. Characterization of human bone marrow fibroblast colony-forming cells (CFU-F) and their progeny. Blood 1980;56:289-301.

94. TILL JE. Radiosensitivity and chromosome numbers in strain L mouse cells in tissue culture. Radiat.Res. 1961;15:400-409.

95. TILL JE, McCULLOCH EA. A direct measurement of the radiation sensitivity of normal mouse bone marrow cells. Radiat.Res. 1961;14:213-222.

96. To LB, Haylock DN, Simmons PJ, Juttner CA. The biology and clinical uses of blood stem cells. Blood 1997;89:2233-2258.

97. To LB, Haylock DN, Dowse T et al. A comparative study of the phenotype and proliferative capacity of peripheral blood (PB) CD34+ cells mobilized by four different protocols and those of steady-phase PB and bone marrow CD34+ cells. Blood 1994;84:2930-2939.

98. Morrison SJ, Uchida N, Weissman IL. The biology of hematopoietic stem cells. Annu.Rev.Cell Dev.Biol. 1995;11:35-71.

99. Morrison SJ, Weissman IL. Heterogeneity of hematopoietic stem cells: implications for clinical applications. Proc.Assoc.Am.Physicians 1995;107:187-194.

100. Richard A.Goldsby, Thomas J.Kindt, Janis Kuby, Barbara A.Osborne. Cells of the immune system; B cell development and Maturation. Immunology.: W. H. Freeman; 5th edition (November 29, 2002); 2002:

101. Nilsson SK, Johnston HM, Whitty GA et al. Osteopontin, a key component of the hematopoietic stem cell niche and regulator of primitive hematopoietic progenitor cells. Blood 2005;106:1232-1239. 
102. Akashi K, Kondo M, Cheshier S et al. Lymphoid development from stem cells and the common lymphocyte progenitors. Cold Spring Harb.Symp.Quant.Biol. 1999;64:1-12.

103. Akashi K, Traver D, Miyamoto T, Weissman IL. A clonogenic common myeloid progenitor that gives rise to all myeloid lineages. Nature 2000;404:193-197.

104. Miyamoto T, Iwasaki $\mathrm{H}$, Reizis B et al. Myeloid or lymphoid promiscuity as a critical step in hematopoietic lineage commitment. Dev.Cell 2002;3:137-147.

105. Kondo M, Weissman IL, Akashi K. Identification of clonogenic common lymphoid progenitors in mouse bone marrow. Cell 1997;91:661-672.

106. Kondo M, Scherer DC, Miyamoto T et al. Cell-fate conversion of lymphoid-committed progenitors by instructive actions of cytokines. Nature 2000;407:383-386.

107. LeBien TW, Tedder TF. B lymphocytes: how they develop and function. Blood 2008;112:1570-1580.

108. GOOD RA, ZAK SJ. Disturbances in gamma globulin synthesis as experiments of nature. Pediatrics 1956;18:109-149.

109. Cooper MD, Peterson RD, Gabrielsen AE, GOOD RA. Lymphoid malignancy and development, differentiation, and function of the lymphoreticular system. Cancer Res. 1966;26:1165-1169.

110. Cooper MD, Peterson RD, GOOD RA. DELINEATION OF THE THYMIC AND BURSAL LYMPHOID SYSTEMS IN THE CHICKEN. Nature 1965;205:143-146.

111. Manz RA, Thiel A, Radbruch A. Lifetime of plasma cells in the bone marrow. Nature 1997;388:133-134. 
112. McGinnes K, Quesniaux V, Hitzler J, Paige C. Human B-lymphopoiesis is supported by bone marrow-derived stromal cells. Exp.Hematol. 1991;19:294-303.

113. Lee G, Namen AE, Gillis S, Kincade PW. Recombinant interleukin-7 supports the growth of normal B lymphocyte precursors. Curr.Top.Microbiol.Immunol. 1988;141:16-18.

114. Goodwin RG, Namen AE. The cloning and characterization of interleukin-7. Year Immunol. 1989;6:127-139.

115. Alt FW, Reth MG, Blackwell TK, Yancopoulos GD. Regulation of immunoglobulin variable-region gene assembly. Mt.Sinai J.Med. 1986;53:166-169.

116. Alt FW, Blackwell TK, DePinho RA, Reth MG, Yancopoulos GD. Regulation of genome rearrangement events during lymphocyte differentiation. Immunol.Rev. 1986;89:5-30.

117. Namen AE, Schmierer AE, March CJ et al. B cell precursor growth-promoting activity. Purification and characterization of a growth factor active on lymphocyte precursors. J.Exp.Med. 1988;167:988-1002.

118. Peschon JJ, Morrissey PJ, Grabstein $\mathrm{KH}$ et al. Early lymphocyte expansion is severely impaired in interleukin 7 receptor-deficient mice. J.Exp.Med. 1994;180:1955-1960.

119. von Freeden-Jeffry U, Vieira P, Lucian LA et al. Lymphopenia in interleukin (IL)-7 genedeleted mice identifies IL-7 as a nonredundant cytokine. J.Exp.Med. 1995;181:1519-1526.

120. Cao X, Shores EW, Hu-Li J et al. Defective lymphoid development in mice lacking expression of the common cytokine receptor gamma chain. Immunity. 1995;2:223-238.

121. Nagasawa T. Microenvironmental niches in the bone marrow required for B-cell development. Nat.Rev.Immunol. 2006;6:107-116. 
122. Nagasawa T, Kikutani H, Kishimoto T. Molecular cloning and structure of a pre-B-cell growth-stimulating factor. Proc.Natl.Acad.Sci.U.S.A 1994;91:2305-2309.

123. Ma $Q$, Jones $D$, Springer TA. The chemokine receptor $C X C R 4$ is required for the retention of $B$ lineage and granulocytic precursors within the bone marrow microenvironment. Immunity. 1999;10:463-471.

124. Zou YR, Kottmann AH, Kuroda M, Taniuchi I, Littman DR. Function of the chemokine receptor CXCR4 in haematopoiesis and in cerebellar development. Nature 1998;393:595-599.

125. Ma Q, Jones D, Borghesani PR et al. Impaired B-lymphopoiesis, myelopoiesis, and derailed cerebellar neuron migration in C. Proc.Natl.Acad.Sci.U.S.A 1998;95:9448-9453.

126. Sierro F, Biben C, Martinez-Munoz L et al. Disrupted cardiac development but normal hematopoiesis in mice deficient in the second CXCL12/SDF-1 receptor, CXCR7. Proc.Natl.Acad.Sci.U.S.A 2007;104:14759-14764.

127. Levoye A, Balabanian K, Baleux F, Bachelerie F, Lagane B. CXCR7 heterodimerizes with CXCR4 and regulates CXCL12-mediated G protein signaling. Blood 2009;113:6085-6093.

128. Lyman SD, James $\mathrm{L}$, Zappone $\mathrm{J}$ et al. Characterization of the protein encoded by the flt3 (flk2) receptor-like tyrosine kinase gene. Oncogene 1993;8:815-822.

129. Mackarehtschian K, Hardin JD, Moore KA et al. Targeted disruption of the flk2/flt3 gene leads to deficiencies in primitive hematopoietic progenitors. Immunity. 1995;3:147-161.

130. Sitnicka $\mathrm{E}$, Bryder D, Theilgaard-Monch $\mathrm{K}$ et al. Key role of flt3 ligand in regulation of the common lymphoid progenitor but not in maintenance of the hematopoietic stem cell pool. Immunity. 2002;17:463-472. 
131. Anderson DM, Lyman SD, Baird A et al. Molecular cloning of mast cell growth factor, a hematopoietin that is active in both membrane bound and soluble forms. Cell 1990;63:235-243.

132. Takeda S, Shimizu T, Rodewald HR. Interactions between c-kit and stem cell factor are not required for B-cell development in vivo. Blood 1997;89:518-525.

133. Waskow C, Rodewald HR. Lymphocyte development in neonatal and adult c-Kitdeficient (c-KitW/W) mice. Adv.Exp.Med.Biol. 2002;512:1-10.

134. Waskow C, Paul S, Haller C, Gassmann M, Rodewald HR. Viable c-Kit(W/W) mutants reveal pivotal role for c-kit in the maintenance of lymphopoiesis. Immunity. 2002;17:277-288.

135. Dougall WC, Glaccum M, Charrier $\mathrm{K}$ et al. RANK is essential for osteoclast and lymph node development. Genes Dev. 1999;13:2412-2424.

136. Friedrich C, Cybulsky MI, Gutierrez-Ramos JC. Vascular cell adhesion molecule-1 expression by hematopoiesis-supporting stromal cells is not essential for lymphoid or myeloid differentiation in vivo or in vitro. Eur.J.Immunol. 1996;26:2773-2780.

137. Ryan DH, Nuccie BL, Abboud CN, Winslow JM. Vascular cell adhesion molecule-1 and the integrin VLA-4 mediate adhesion of human B cell precursors to cultured bone marrow adherent cells. J.Clin.Invest 1991;88:995-1004.

138. Koni PA, Joshi SK, Temann UA et al. Conditional vascular cell adhesion molecule 1 deletion in mice: impaired lymphocyte migration to bone marrow. J.Exp.Med. 2001;193:741-754.

139. Zhu J, Garrett R, Jung Y et al. Osteoblasts support B-lymphocyte commitment and differentiation from hematopoietic stem cells. Blood 2007;109:3706-3712. 
140. Hall BM, Fortney JE, Taylor L et al. Stromal cells expressing elevated VCAM-1 enhance survival of B lineage tumor cells. Cancer Lett. 2004;207:229-239.

141. Zucchetto A, Benedetti D, Tripodo C et al. CD38/CD31, the CCL3 and CCL4 chemokines, and CD49d/vascular cell adhesion molecule-1 are interchained by sequential events sustaining chronic lymphocytic leukemia cell survival. Cancer Res. 2009;69:4001-4009.

142. Chamberlin W, Barone J, Kedo A, Fried W. Lack of recovery of murine hematopoietic stromal cells after irradiation-induced damage. Blood 1974;44:385-392.

143. Fried W, Chamberlin W, Kedo A, Barone J. Effects of radiation on hematopoietic stroma. Exp.Hematol. 1976;4:310-314.

144. Fried W, Kedo A, Barone J. Effects of cyclophosphamide and of busulfan on spleen colony-forming units and on hematopoietic stroma. Cancer Res. 1977;37:1205-1209.

145. del CC, Lopez N, Caballero D et al. Haematopoietic damage persists 1 year after autologous peripheral blood stem cell transplantation. Bone Marrow Transplant. 1999;23:901905.

146. Galotto M, Berisso G, Delfino L et al. Stromal damage as consequence of high-dose chemo/radiotherapy in bone marrow transplant recipients. Exp.Hematol. 1999;27:1460-1466.

147. Corazza F, Hermans C, Ferster A et al. Bone marrow stroma damage induced by chemotherapy for acute lymphoblastic leukemia in children. Pediatr.Res. 2004;55:152-158.

148. Isaikina $\mathrm{Y}$, Shman T. Influence of mesenchymal stem cells derived from bone marrow of children with oncohematological diseases on proliferation and self-renewal of hematopoietic progenitor cells in vitro. Exp.Oncol. 2008;30:121-128. 
149. Wang L, Clutter S, Benincosa J, Fortney J, Gibson LF. Activation of transforming growth factor-beta1/p38/Smad3 signaling in stromal cells requires reactive oxygen species-mediated MMP-2 activity during bone marrow damage. Stem Cells 2005;23:1122-1134.

150. Barcellos-Hoff MH, Derynck R, Tsang ML, Weatherbee JA. Transforming growth factorbeta activation in irradiated murine mammary gland. J.Clin.Invest 1994;93:892-899.

151. Tavassoli M, Soltaninia J, Rudnicka J et al. Tamoxifen inhibits the growth of head and neck cancer cells and sensitizes these cells to cisplatin induced-apoptosis: role of TGF-beta1. Carcinogenesis 2002;23:1569-1575. 


\title{
Chapter 2
}

\section{Critical Components of a Functional Stem Cell Niche are Damaged by Chemotherapy}

\author{
Heather O'Leary ${ }^{1,2}$, Stephanie L. Rellick ${ }^{1,2}$, Debra Piktel ${ }^{2}$, Cheryl \\ Walton ${ }^{4}$, James E. Fortney ${ }^{2}$, Stephen M. Akers ${ }^{1,2}$, Karen H. Martin ${ }^{2,5}$, \\ James Denvir ${ }^{6}$, Goran Boskovic ${ }^{7}$, Donald A. Primerano ${ }^{7}$, and Laura F. \\ Gibson $^{1,2,3}$ \\ ${ }^{1}$ Cancer Cell Biology Program, ${ }^{2}$ Mary Babb Randolph Cancer Center, ${ }^{3}$ Department of Microbiology, \\ Immunology and Cell Biology, ${ }^{4}$ Department of Pediatrics, ${ }^{5}$ Department of Neurobiology and Anatomy, ${ }^{6}$ \\ Department of Statistics, ${ }^{7}$ Marshall University Microarray Core Facility, \\ West Virginia University, School of Medicine, Morgantown, WV 26506
}




\begin{abstract}
:
Sustained long-term hematopoietic reconstitution, following bone marrow or stem cell transplantation, requires a microenvironment niche capable of supporting stem cells with the capacity to differentiate and expand to provide hematopoietic recovery, with osteoblasts comprising one important component of this niche. We determined that treatment of human osteoblasts $(\mathrm{HOB})$ with chemotherapy resulted in an increase in phospho-Smad2, consistent with increased TGF- $\beta$ activity coincident with reduced HOB capacity to support immature B lineage cell chemotaxis and adherence. The supportive deficit was not limited to committed progenitor cells, as human embryonic stem cells (hESC) co-cultured with chemotherapy or rTGF- $\beta$ pre-treated HOB had diminished Oct-4 expression when compared to hESC co-cultured with untreated $\mathrm{HOB}$. These functional deficits were downstream of significant changes in $\mathrm{HOB}$ gene expression profiles following chemotherapy. In addition, HOB gene expression patterns were impacted by either recombinant TGF- $\beta$, or conditioned media from Melphalan treated bone marrow stromal cells, suggesting response to direct genotoxic stress as well as to factors potentially elaborated by neighboring cells that would be found in the marrow. Chemotherapy induced damage of $\mathrm{HOB}$ suggests vulnerability of the stem cell niche to therapeutic agents frequently utilized in pre-transplant regimens and suggests that dose escalated chemotherapy may contribute to post-transplantation hematopoietic deficits by damage structural components of the stem cell niche.
\end{abstract}




\section{Introduction:}

The stem cell niche hypothesis was first presented in 1978 by Schofield who suggested that stem cells were associated with accessory cells that influence their behavior ${ }^{1}$. Studies from several labs have expanded our appreciation of the unique anatomical niches within the marrow microenvironment and have characterized areas of optimal stem cell support ${ }^{2-4}$. The niche structure and cellular components have been more recently elucidated to consist of osteoblasts (HOB), bone marrow stromal or mesenchymal stem cells (BMSC, MSC), and endothelial cells ${ }^{5-7}$. Recent work has demonstrated the importance of the interaction of osteoblasts and stem cells in the niche, suggesting that hematopoietic stem cells (HSC) can regulate MSC differentiation into osteoblasts and that they, in turn, play an important role in the support of B lymphocytes and differentiation of HSC ${ }^{8 ; 9}$. Additionally, it has been shown that resting HSC are maintained in a quiescent state as a result of their close proximity to osteoblasts and that the number of HSCs change as a result of the number and type of osteoblasts present ${ }^{10 ; 11}$. Studies describing BMSC have shown that damage by chemotherapy and radiotherapy can affect the ability of the BMSC to self-repair and leads to decreased numbers of functional immune system cells in the blood, with deficits persisting years after transplant ${ }^{12-14}$. The effects of chemotherapy on osteoblasts, and subsequently HSC support, have not been as well characterized as those on BMSC, and warrant further investigation.

The stem cell niche is characterized, in part, by expression of specific cytokines, including TGF- $\beta$ and CXCL12, to facilitate signaling between the niche components and HSC. Studies by our laboratory, and others, demonstrate that chemotherapy increases the levels of active TGF- $\beta$ resulting in decreased ability of BMSC to support HSC ${ }^{15 ; 16}$. It has also been shown that TGF- $\beta$ has potential crosstalk with $\mathrm{CXCL} 12$ and can stimulate the differentiation of progenitor cells to erythroid and myeloid cells resulting in a deficit of the primitive stem cell pool 17;18. The importance of CXCL12 is demonstrated by its requirement for homing of progenitor

cells to the bone marrow following transplantation ${ }^{19 ; 20}$. We have previously demonstrated that 
diminished levels of CXCL12 in the supernatants of VP-16 treated BMSC results in loss of an optimal chemokine gradient to which CXCR4+ pro-B cells respond and CXCL12 was subsequently shown to also be important in regulation of stem cell phenotype by Guo et al. ${ }^{21 ; 22}$. Sugiyama et al showed that mice deficient in the CXCL12 receptor, CXCR4, had a reduction in HSC, in both vascular and endosteal niches, and increased sensitivity to myelotoxic stress compared to their wild-type counterparts ${ }^{23}$. Other studies of CXCR4 in the HSC niche have shown that CXCR4 is essential to maintain the quiescence, and retention, of stem cells in their specific niches ${ }^{24}$. In the current study we investigate chemotherapy-mediated damage of osteoblasts with emphasis on CXCL12 and TGF- $\beta$ levels following chemotherapy. HOB cells were evaluated for their ability to support maintenance of undifferentiated human embryonic stem cells as a model of one critical element of the stem cell niche.

In addition to soluble factors that define the stem cell niche, adhesion molecules are also known to be critical to physically tether immature cells in areas of concentrated cytokines and to initiate intracellular signaling following integrin engagement ${ }^{25}$. VCAM-1 has been shown to be one adhesion molecule that stem cells rely upon to anchor to the marrow stroma which plays a crucial role in lymphopoiesis ${ }^{26 ; 27}$. Animal studies have shown that VCAM-1 neutralizing antibodies, or VCAM-1 conditional knockout, block engraftment of HSC in mice ${ }^{28 ; 29}$.

In the current study, global changes in HOB gene expression in response to Melphalan, a clinically relevant pre-transplant agent, were investigated to determine the general vulnerability of this particular component of the stem cell niche to genotoxic stress. In addition, TGF- $\beta$, CXCL12 and VCAM-1 were investigated as representative osteoblast proteins involved in three critical functions of the endosteal niche; support of pluripotency, homing and stem cell retention ${ }^{30-32}$. Our results indicate diverse changes in gene expression profiles following HOB exposure to Melphalan, conditioned media from BMSC treated with Melphalan, and following exposure to rTGF- $\beta$ as one of the factors elaborated by chemotherapy damaged stroma ${ }^{15}$. HOB 
treated with chemotherapy had increased levels of active TGF- $\beta$, consistent with the earlier documented effect on BMSC ${ }^{15}$. Melphalan, VP-16, or rTGF- $\beta$ pre-treated HOB demonstrated reduced ability to support OCT-4 positive embryonic stem cell colonies. Additionally, HOB treatment with chemotherapy or $\mathrm{rTGF}-\beta$ resulted in decreased levels of CXCL12, and reduced chemotactic support and adhesion of CXCR4+ pro-B cells. In contrast to our earlier reports of decreased expression of VCAM-1 by BMSC exposed to VP-16, treatment of HOB with VP-16, Melphalan, or rTGF- $\beta$ did not lead to significant reductions in VCAM-1, suggesting that signaling through this adhesion molecule is maintained. These data suggest that while stem cells may be spared direct cytotoxic insult by chemotherapeutic agents, the niche in which they reside may be more vulnerable to damage than previously appreciated. 


\section{Materials and Methods:}

\section{Cell Lines and Reagents}

Human osteoblasts (HOB) were purchased from Promocell (Heidelberg, Germany) and maintained in osteoblast growth media. The CXCR4+/VLA-4+ pre-pro-B leukemic cell line JM-1 was purchased from the ATCC (CRL-10423, Manassas, VA). The BMSC and IL-7 dependent murine pro-B cell line $\mathrm{C} 1.92$ was kindly provided by Dr. Kenneth Landreth and has been described in detail ${ }^{33}$. Melphalan (Sigma-Aldrich, St. Louis, MO) was reconstituted at a stock concentration of $2.5 \mathrm{mg} / \mathrm{ml}$ or $50 \mathrm{mg} / \mathrm{ml}$ immediately prior to use. VP-16 (Etoposide, Bristol Myers Squibb, New York, NY) was stored at a concentration of $33.98 \mathrm{mM}$ and diluted immediately prior to use. Human rTGF- $\beta$ (R\&D, Minneapolis, MN) was used at a concentration of $10 \mathrm{ng} / \mathrm{ml}$. In all experiments that include rTGF- $\beta$, it was added to the culture every 6 hours based on its short half-life. Human embryonic stem cells (H9, WiCell, Madison WI) were maintained on irradiated mouse embryo fibroblasts (MEF) and grown in DMEM-F12 media (Mediatech, Manassas, VA) supplemented with Knockout Serum Replacement (Gibco/Invitrogen, Carlsbad, CA) 2 mM Lglutamine (Mediatech), $0.05 \mu \mathrm{M}$ 2-mercaptoethanol (Sigma-Aldrich), non-essential amino acids and B-FGF solution. $\mathrm{H} 9$ cells were moved to $\mathrm{HOB}$ feeder layers where indicated.

\section{Adhesion assay}

HOB were pre-treated with $50 \mu \mathrm{g} / \mathrm{ml}$ Melphalan, $50 \mu \mathrm{M}$ VP-16, or $10 \mathrm{ng} / \mathrm{ml}$ rTGF- $\beta$ for 24 hours. C1.92 pro-B cells were stained with Cell Tracker Green (Invitrogen) according to the manufacturer's instructions. The HOB adherent layer was thoroughly rinsed following treatment and $1 \times 10^{5}$ fluorescently labeled $\mathrm{C} 1.92$ pro-B cells were added in co-culture for 24 hours. Subsequently, the media containing non-adherent C1.92 was aspirated and the cultures were gently rinsed. Remaining $\mathrm{HOB}$ and adherent $\mathrm{C} 1.92$ were trypsinized and $\mathrm{C} 1.92$ cells were enumerated using a FACSCalibur flow cytometer (BD, Franklin Lakes, NJ) with events counted for 30 seconds on high flow rate. Data were analyzed using WinMDI software. 


\section{Chemotaxis assays}

HOB were plated in the bottom chamber of a transwell at $100 \%$ confluence and were left either untreated or treated with $50 \mu \mathrm{g} / \mathrm{ml}$ Melphalan, $50 \mu \mathrm{M}$ VP-16, or $10 \mathrm{ng} / \mathrm{ml}$ rTGF- $\beta$ for 24 hours. After 24 hours, $350 \mu \mathrm{L}$ of supernatant was placed in the bottom of a transwell and $150 \mu \mathrm{L}$ of JM-1 cells $\left(1 \times 10^{6}\right.$ cells $\left./ \mathrm{mL}\right)$ were added to the top chamber, and incubated at $37^{\circ} \mathrm{C}$ for 4 hours. JM-1 cells migrated through the $5 \mu \mathrm{m}$ pores to the bottom chamber towards media supplemented with $100 \mathrm{ng} / \mathrm{mL}$ CXCL12 (positive control), towards media alone (negative control), or towards media conditioned by the chemotherapy treated or non-treated HOB. Migrated JM-1 cells were collected using a FACSCalibur flow cytometer (BD) with events counted for 30 seconds on high flow rate with data analyzed using WinMDI software.

\section{ELISA}

CXCL12 and TGF- $\beta$ ELISAs were purchased from R\&D. To complete the CXCL12 ELISA, HOB were plated at $100 \%$ confluence in a 96 well plate and left untreated or treated with $50 \mu \mathrm{g} / \mathrm{ml}$ Melphalan, $50 \mu \mathrm{M}$ VP-16, or $10 \mathrm{ng} / \mathrm{ml}$ rTGF- $\beta$ in complete media for 24 hours. The media was then removed, cells were rinsed and fresh serum-free media was added to each well. After 24 and 48 hours of incubation supernatants were collected and analyzed for CXCL12 following the manufacturer's instructions. The TGF- $\beta$ ELISA was completed using HOB plated at $100 \%$ confluence in a 96 well plate in serum free media and left untreated or treated with $10 \mathrm{ng} / \mathrm{ml}$ rTGF- $\beta$ every 6 hours for a total of 24 hours. The media was removed, cells were rinsed, and fresh serum-free media was added to each well. After 24 and 48 hours supernatants were collected and analyzed for TGF- $\beta$ secretion following the manufacturer's instructions.

\section{Fluorescent Microscopy}

$\mathrm{HOB}$ cells were cultured on coverslips and left untreated or treated with $50 \mu \mathrm{g} / \mathrm{ml}$ Melphalan, $50 \mu \mathrm{M}$ VP-16, or $10 \mathrm{ng} / \mathrm{ml}$ rTGF- $\beta$ for 24 hours, washed thoroughly with media and H9 stem cells added. Stem cell colony expansion and differentiation were monitored for 2 days 
before pictures were taken, counts based on colony morphology were completed, and cells were subsequently stained for Oct-4. To complete intracellular staining, cells were fixed in $4 \%$ formaldehyde for 15 minutes at room temperature (RT) and permeabilized with $0.5 \%$ Triton-X100 at RT for 15 minutes. After blocking for 30 minutes in 5\% BSA/1X PBS, cells were incubated with mouse $\alpha$-human primary antibody $(1 \mu \mathrm{g})$, specific for human Oct-4 or the matched isotype control, in 5\% BSA/1X PBS for 1 hour at RT. Coverslips were washed three times with 1X PBS and incubated with Alexafluor 488 labeled secondary $\alpha$-mouse antibody (1 $\mu \mathrm{g}$ ) at RT for 1 hour. Coverslips were mounted on glass microscope slides with ProLong Gold plus DAPI (Invitrogen, Carlsbad, CA). Confocal images were acquired using a Zeiss LSM510 confocal system connected to a Zeiss Axiolmager microscope (Thornwood, NY). Photographs of human embryonic stem cells and C1.92 pro-B cells were taken using a Nikon Coolpix 990 camera. To complete phospho-smad2 staining, HOB cells were plated on coverslips and left untreated or treated for 4 hours with $100 \mu \mathrm{g} / \mathrm{ml}$ Melphalan, $100 \mu \mathrm{M}$ VP-16, or with conditioned media from BMSC that were maintained in control media untreated or treated with $100 \mu \mathrm{g} / \mathrm{ml}$ Melphalan or $100 \mu \mathrm{M}$ VP-16 for 24 hours. Staining and imaging was completed as described

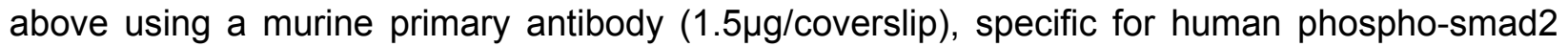
(Cell Signaling Technology Inc., Danvers, MA) or matched isotype control.

\section{Microarray}

HOB cells were left untreated, or treated with $50 \mu \mathrm{g} / \mathrm{ml}$ Melphalan, $10 \mathrm{ng} / \mathrm{ml} \mathrm{rTGF}-\beta$ or conditioned media from BMSC (treated with $50 \mu \mathrm{g} / \mathrm{ml}$ Melphalan for 24 hours) for 6 hours. Total RNA was isolated from HOB using the RNEasy RNA isolation kit (Qiagen,Valencia, CA) with quality assessed by electrophoretic analysis on an Agilent Model 2100 Bioanalyzer. RNA samples had integrity numbers greater than 8.0 (8.4-10). RNA (250 ng) was used as the template for synthesis of internally labeled cRNAs using the Agilent QuickAmp Labeling kit and cyanine 3-CTP and cyanine 5-CTP (Perkin Elmer, Waltham, MA) and a modified QuickAmp 
protocol ${ }^{34}$. A total of $825 \mathrm{ng}$ of cyanine 3- and cyanine5-labeled cRNAs was combined and hybridized onto Agilent Whole Human Genome $4 \times 44 \mathrm{~K}$ microarrays at $65^{\circ} \mathrm{C}$ for 17 hours and washed according to the manufacturer's protocol. Slides were scanned on an Agilent DNA Microarray Scanner. HOB treated with $\mathrm{rTGF}-\beta$ and conditioned media were competitively hybridized against untreated $\mathrm{HOB}$ in a balanced block design with six replicates. Melphalan treated $\mathrm{HOB}$ and untreated $\mathrm{HOB}$ were hybridized against Stratagene Universal Reference RNA (Agilent Technologies, Santa Clara, CA) in a universal reference design with four replicates.

Intersections of groups and corresponding statistically significant fold changes (details described in the supplemental section) for each experiment were imported into Ingenuity Pathway Analysis (IPA) software v 2.6 (Ingenuity Systems $®$, Redwood City, CA, www.ingenuity.com). We performed a core analysis in IPA, using default settings, to search for networks associated with these lists of genes. Complete microarray data may be accessed at the NCBI Gene Expression Omnibus (GEO) database (GSE17860).

\section{Real Time Reverse Transcriptase PCR}

Total cellular RNA was isolated from HOB using the RNAeasy RNA isolation kit (Qiagen). Real time RT-PCR was performed using 50ng RNA per reaction using the QuantiTech SYBR Green RT-PCR kit supplied by Qiagen. Primers specific for human CXCL12 were obtained from SuperArray (Frederick, MD) with $0.25 \mu$ l used per reaction. Primers specific for TGF- $\beta$ and the housekeeping gene (HPRT-1) were purchased from Real Time Primers, LLC (Elkins Park, PA). Samples were analyzed in triplicate using the Applied Biosystems 7500 Real-time PCR system (Foster City, CA). Amplification parameters included $50^{\circ} \mathrm{C}$ for 30 minutes, $95^{\circ} \mathrm{C}$ for 15 minutes, $94^{\circ} \mathrm{C}$ for 15 seconds (x 45 cycles), $58^{\circ} \mathrm{C}$ for 30 seconds, and $72^{\circ} \mathrm{C}$ for 45 seconds. Changes in gene expression were determined using the Comparative $\mathrm{Ct}$ method and analysis of relative gene expression data using real-time quantitative PCR and the 2(-Delta Delta C(T)) Method. 


\section{Statistics}

Data were analyzed using the Students-t test or ANOVA where appropriate with statistical significance of $p \leq .05$ denoted by an asterisk (*). Microarray data analysis is described in the supplemental section. 


\section{Results:}

\section{Direct Melphalan exposure or factors from chemotherapy damaged BMSC affect HOB.}

Observations from our laboratory, and others, have demonstrated that BMSC treated with chemotherapy have higher levels of active TGF- $\beta$ and a diminished capacity to support proB cells and normal hematopoiesis ${ }^{15-17 ; 35}$. Additionally, retrospective studies of patients that received allogeneic bone marrow transplants showed that they have serious and irreversible stromal damage as measured by CFU-F frequencies that did not recover to the levels of normal control patients even after 12 years, suggesting that the damage done to the supportive cells of the bone marrow is irreversible ${ }^{36}$.

To determine if direct chemotherapy damage to HOB cells results in increased active TGF- $\beta$, HOB were treated with Melphalan or VP-16 and the expression of total and active TGF$\beta$ was assessed. Data shown in Figures $1 A$ and $B$ show that direct exposure to chemotherapy (left panels) does not alter the expression of TGF- $\beta$ mRNA or protein respectively. However, direct treatment with rTGF- $\beta$ (right panels) does increase both TGF- $\beta$ mRNA and protein expression. In contrast to total TGF- $\beta$ mRNA and protein expression, chemotherapy exposure does result in increases in the levels of active TGF- $\beta$ capable of cell signaling reflected as increased phosphorylation of Smad2 protein (Figure 1C). Additionally, to mimic the indirect effects of soluble cues elaborated by damaged stroma on HOB, BMSC were treated with Melphalan or VP-16, rinsed, and allowed to condition media that was then placed on HOB that had not been exposed to chemotherapy. HOB exposed to conditioned media from damaged BMSC have higher levels of phosphorylated Smad2 than their counterparts exposed to conditioned media from untreated stroma. 


\section{Chemotherapy or rTGF- $\beta$ treatment diminishes the ability of osteoblasts to support}

\section{human stem cells and diminishes the physical interaction of HOB and pro-B cells}

One of the critical functions of osteoblasts in the endosteal niche is to support stem cells, and post-transplantation, osteoblasts are crucial to efficient and sustained hematopoietic reconstitution ${ }^{37 ; 38}$. Therefore, we investigated how chemotherapy or rTGF- $\beta$ modulates the ability of osteoblasts to support human stem cells. Figure 2 shows that in the absence of treatment, osteoblasts are able to support undifferentiated stem cell colonies characterized by morphology of dense round colonies with definitive, regular, cell borders. In contrast, after HOB pre-treatment with Melphalan, VP-16 or rTGF- $\beta$, there is an increase in the number of differentiated stem cell colonies with irregular borders and a decrease in the number of undifferentiated colonies (Figure 2A) supported by the pre-treated feeder layers. OCT-4 staining was completed on stem cell colonies as a measure of pluripotency potential, with a decrease in the ability to support OCT-4 positive colonies observed in HOB that had been pre-treated with chemotherapy or rTGF- $\beta$ (Figure 2B).

Alterations in osteoblast function after aggressive treatment could impact transplant engraftment and hematopoietic reconstitution ${ }^{11 ; 30 ; 39}$. For technical ease we utilized CXCR4+/VLA-4+ C1.92 and JM-1 pro-B cells to investigate the effects of chemotherapy on the ability of $\mathrm{HOB}$ to support immature hematopoietic progenitor cells. $\mathrm{HOB}$ were pre-treated with Melphalan, VP-16 or rTGF- $\beta$ and C1.92 adhesion to HOB was analyzed as described. Data shown in Figure $2 \mathrm{C}$ indicates that following $\mathrm{HOB}$ pre-treatment with chemotherapy or rTGF- $\beta$, C1.92 pro-B cells did not adhere to the pre-treated HOB as efficiently as their untreated control counterparts. To determine if alterations in adhesion molecule expression were associated with decreased adhesion between C1.92 and HOB, VCAM-1, CD44 and Hyaluronan expression were evaluated on the $\mathrm{HOB}$ in the presence and absence of chemotherapy. No modulation of these proteins was detected on the HOB during chemotherapy exposure suggesting that, 
changes in expression of classical adhesion proteins does not appear to be responsible for decreased pro-B cell adhesion to Melphalan treated HOB (data not shown).

\section{Chemotherapy or rTGF- $\beta$ diminishes HOB expression of CXCL12 coincident with reduced} support of pro-B cell chemotaxis

Inhibition of CXCL12 in the bone marrow has been shown to have a negative impact on chemotaxis leading to deficits in HSC homing and engraftment ${ }^{19 ; 40 ; 41}$. To further investigate the impact of chemotherapy and rTGF- $\beta$ treatment on expression of osteoblast derived CXCL12, real time RT-PCR and ELISA were completed as described. Pre-treatment of HOB with chemotherapy or rTGF- $\beta$ decreased the amount of CXCL12 mRNA and protein detected by real

time RT-PCR and ELISA, respectively (Figure $3 \mathrm{~A}$ and B) ${ }^{42}$. Additionally, as a functional readout of a potential CXCL12 deficit in our model, chemotaxis of JM-1 cells toward HOB that were untreated or pre-treated with chemotherapy or rTGF- $\beta$ was completed. Figure $3 \mathrm{C}$ summarizes data suggesting that chemotaxis of progenitor cells toward adherent layers of HOB was impaired by Melphalan or rTGF- $\beta$ treatment.

\section{Direct and indirect chemotherapy induced damage result in global changes to osteoblast} gene expression

To elucidate the global changes that occur in osteoblasts with direct and indirect insult from chemotherapy, HOB were exposed to either rTGF- $\beta$ to mimic increased active TGF- $\beta$ released by neighboring, damaged stroma or Melphalan to investigate direct insult of osteoblasts by chemotherapy. In addition, HOB were exposed to conditioned media from BMSC that had been pre-treated with Melphalan (drug removed prior to collection of conditioned media) to recapitulate signaling that may occur in response not only to active TGF- $\beta$ elaborated by BMSC, but also in response to the collective soluble factors elaborated by BMSC in response to chemotherapy induced stress. Microarray analysis of gene expression was performed as described. The genes for which expression changed in each group individually, 
and common gene targets that overlap between treatment groups, are indicated in the Venn diagram (Figure 4A). HOB exposure to recombinant TGF- $\beta$ resulted in the most pronounced effect on gene expression for the treatment groups compared, the highest number of genes influenced across the treatment groups evaluated, with Melphalan exposure also resulting in a robust effect. Twenty-five common genes significantly changed when the intersection of all treatment groups was considered. The Venn and network diagrams show the modulations of genes due to treatment, and potential relationships between some of the responsive genes. BCL2A1, which has been shown to be regulated by $N F \kappa B$ and up-regulated during stress to prevent apoptosis, emerges as one point of convergence in the pathway analysis shown (Figures 4-7). The genes that were commonly up-regulated (indicated in red) or down-regulated (in green) between treatment groups are shown and numerically were: 4 up-regulated, 2 downregulated (Figure 4, Intersection of all 3 treatments), 16 up-regulated, 3 down-regulated (Figure 5, CMM:Melphalan), 26 up-regulated, 11 down-regulated (Figure 6, TGF:CMM), and 97 upregulated, 188 down-regulated (Figure 7, TGF:Melphalan). This summary can be compared with those genes that were influenced, but in opposing directions, between groups (Supplemental Figure 1). 


\section{Discussion:}

Ablative therapy followed by stem cell reinfusion is used to treat hematopoietic, and brain tumors as well as childhood sarcomas, and immune deficiencies ${ }^{43-45}$. As the primary site of postnatal hematopoiesis, the functional integrity of the bone marrow microenvironment is critical for hematopoietic recovery subsequent to stem cell transplantation. Earlier reports have suggested that BMSC are vulnerable to functional damage imposed by aggressive chemotherapeutic agents ${ }^{46 ; 47}$. These studies have focused largely on the ability of stromal cells to generate fibroblastic colonies (CFU-F) or to support survival or expansion of committed progenitor cells when isolated from patients following treatment of subsequent to in vivo drug exposures $^{48}$.

Murine models of ablative treatment and stem cell transplant have shown long-term deficits in hematopoietic recovery and in vitro models have paralleled these documenting the inability of transplanted cells to migrate efficiently to the necessary anatomical niches for engraftment ${ }^{49}$. Observations of long-term hematopoietic deficits in bone marrow of transplantation patients suggest that the functionality of the developmental niches required for appropriate support of stem cells may have been compromised by aggressive pre-transplant therapies. One study observed that at 1 year post transplant $61 \%$ of patients have subnormal values in one or more hematopoietic lineages ${ }^{50}$. Further, Nieboer et al. showed that at 5 years post transplant $15 \%$ of the patient population analyzed had low values in one or more hematopoietic cell lineages ${ }^{51}$. Investigation of the mechanisms that underlie damage of the hematopoietic and stem cell niche is further encouraged by retrospective studies of patients that received allogeneic bone marrow transplants in which patient HSC did not recover to the levels of control patients, even after 12 years, as measured by CFU-F frequencies, suggesting that the damage of the structural, hematopoietic supportive cells of the bone marrow can be sustained 36. 
In the current study we characterized the impact of direct and indirect damage on osteoblasts and their subsequent ability to support progenitor and stem cells. Following transplantation and during development, HSC home to the endosteal niche which acts as a critical regulator of stem cell quiescence, proliferation, and conservation of the stem cell pool. Direct contact between osteoblasts and HSC is required for HSC survival ${ }^{52-54}$ with a dynamic relationship demonstrated by the ability of HSC to regulate the cytokines expressed by osteoblasts in order to enhance their own survival. Studies by Calvi et al., and others, have shown that number of osteoblasts present in the niche directly modulates the numbers of HSC that can be supported by the niche ${ }^{10 ; 11 ; 30}$.

In light of the delicate balance between osteoblasts and HSCs, it is not surprising that either direct, or indirect damage via factors elaborated by other populations of cells within the niche, to osteoblasts results in a deficit in the HSC pool. Our data has shown that both direct exposure to chemotherapy as well as exposure to conditioned media from chemotherapy damaged BMSC increases the activity of osteoblast derived TGF- $\beta$, one of the known negative regulators of HSCs (Figure 1C) ${ }^{15-17}$. Consistent with the literature suggesting that TGF- $\beta$ activity leads to decreased expression of HSC surface cytokine receptors and a deficit in the stem cell pool, ${ }^{55 ; 56}$ Figures 2 and 3 summarize data that show the decreased ability of chemotherapy damaged osteoblasts to interact with, and support, both human embryonic stem cells as well as more differentiated pro-B cells. Direct treatment of HOB with active TGF- $\beta$ results in a comparable reduction in pro-B cell adhesion and chemotaxis as well as diminished ability to support Oct-4 positive stem cells. Collectively, these data suggest that chemotherapy induced increases in active TGF- $\beta$, from damaged BMSC and $\mathrm{HOB}$, could contribute to deficits in the stem cell pool

Another consideration when evaluating the dynamic balance of the niche is the role of adhesion molecules physically tethering progenitor cells to supportive cells of bone marrow, 
which provides signals for their maturation and survival ${ }^{57}$. Earlier reports have described the role of the VCAM-1/VLA-4 interaction in hematopoiesis. Ryan et al demonstrated that adhesion of B cell precursors to BMSC was dependent on this interaction and Dittel et al elucidated how cytokines could alter the surface expression of VCAM-1 ${ }^{26 ; 27}$. Studies in murine models showed that a VCAM-1 knockout was embryonic lethal, while a conditional deletion led to decreases in immature B cells found in the bone marrow with a subsequent impairment in immune response 28.

In addition to the VCAM-1/ VLA-4 interaction, the CD44/ hyaluronan (HA) interaction has also been recognized for its role in hematopoiesis and homing of primitive cells to the bone marrow ${ }^{58 ; 59}$. Avigdor et al demonstrated the important roles of CXCL12 with respect to the migration and anchorage of progenitors to the bone marrow through CD44/ $\mathrm{HA}{ }^{60}$. It was based on these observations that we investigated the effects of chemotherapy on VCAM-1, CD44, and $\mathrm{HA}$ in our model of osteoblast damage. Figure $2 \mathrm{C}$ shows that pro-B cells co-cultured with chemotherapy or rTGF- $\beta$ pre-treated osteoblasts are unable to adhere to the osteoblasts efficiently. However, investigation of the adhesion molecules VCAM-1, CD44 and Hyaluronan indicated no altered expression with either chemotherapy or rTGF- $\beta$ exposure. These observations suggest that the deficit in hematopoietic support, in our model, is the result of changes in a soluble factor acting in either an autocrine or paracrine manner to diminish optimal cell:cell interaction. Paracrine effects could be modulated, in part, through alteration of integrin activity, which would not have been detected in our assay. These observations also suggest very specific effects of chemotherapy on stromal and osteoblast components of the niche, emphasizing the need to understand each population individually to understand the total response of the niche to therapy.

In light of the data suggesting that decreased expression of specific adhesion molecules was not obviously responsible for the inability of damaged osteoblasts to support stem and progenitor cells, we examined the effect of chemotherapy damage on osteoblast derived 
CXCL12. Data in Figure 3 shows that both chemotherapy and rTGF- $\beta$ decrease CXCL12 mRNA and protein in osteoblasts ${ }^{42}$. The decrease in CXCL12 correlated with a decrease in chemotaxis of CXCR4+ cells towards osteoblasts pre-treated with either Melphalan or rTGF- $\beta$. However, in contrast to previous experiments in which we reported chemotactic deficits in VP16 treated BMSC ${ }^{21}$, no significant reduction in chemotactic support of CXCR4+ cells was noted in the VP-16 treated HOB groups, even though they exhibited the decrease in CXCL12. These data suggest potential drug specific effects in which Melphalan may target CXCL12 expression as well as other critical chemotactic factors in HOB while VP-16 does not as globally affect chemotaxis regulators, allowing some maintenance of chemotactic support. One such factor for future investigation would include stem cell factor, SCF, which has been shown to synergize with CXCL12 in homing of stem cells and retention in their developmental niche ${ }^{61 ; 62}$.

Collectively, these data suggest that generation of active TGF- $\beta$ in the endosteal niche

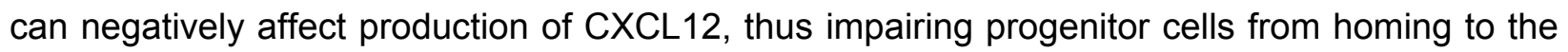
bone marrow, engrafting, and reconstituting the patient's immune system. This observation of vulnerability of gene expression to genotoxic stress in HOB prompted us to attempt to understand the magnitude of direct and indirect chemotherapy-induced damage to osteoblasts by microarray analysis. After only 6 hours of treatment the diverse changes observed in $\mathrm{HOB}$ gene expression alone allow for a better understanding of the significance of the potential damage to the niche and the subsequent impact on hematopoietic reconstitution that relies on

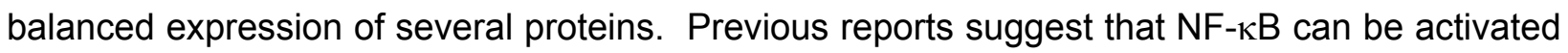
by both TGF- $\beta$ and TNF- $\alpha$ leading to the transcription of BCL2A1, to suppress chemotherapy induced apoptosis ${ }^{63 ; 64}$. Interestingly, all 3 HOB treatments (rTGF- $\beta$, Melphalan and conditioned media from Melphalan pre-treated BMSC) evaluated in the microarray analysis had the convergence point of increased BCL2A1 mRNA, suggested by the network analysis to be regulated by NF-kB (Figures 4-7). As with all gene expression pathway analysis, in the 
absence of targeted genetic manipulation or biochemical analysis, the interactions remain hypothetical. The most pronounced value of these data in the current study is to provide a sense of the responsiveness of osteoblasts to genotoxic stress as well as to factors from other structural components in the stem cells niche. Points of convergence, such as BCL2A1 as just a single example, may then provide the focus for a more mechanistic understanding of cell signaling downstream of stress in the bone marrow microenvironment.

Central to our investigation was an interest in the influence of active TGF- $\beta$ released from chemotherapy treated $\mathrm{HOB}$ as well as TGF- $\beta$ that may be released from neighboring BMSC in a damaged microenvironment as just two potential sources of this growth factor. Understanding the role of TGF- $\beta$ in the bone marrow microenvironment is extremely important when attempting to modulate therapeutic intervention to reconstitute the niche post-transplant. Studies by Batard et al have described the importance of low levels of TGF- $\beta$ in the bone marrow microenvironment for maintenance of the stem cell pool through up-regulation of the CD34 antigen, a marker of primitive HSC ${ }^{55}$. Consistent with the need for rigorous control of total TGF- $\beta$ levels, a number of studies have shown the benefit of TGF- $\beta$ neutralization in cases where TGF- $\beta$ levels are increased in response to therapy ${ }^{65 ; 66}$. Lagneaux et al showed that stromal cells isolated from B-CLL patients had increased TGF- $\beta$ production correlated with decreased colony-stimulating activity which was corrected by neutralizing TGF- $\beta$ activity ${ }^{17}$. Using a murine model of breast cancer, Biswas et al showed that radiation or doxorubicin treatment increased levels of TGF- $\beta$ which correlated with increased circulating tumor cells and increased metastasis ${ }^{67}$. These effects were abrogated by anti-TGF- $\beta$ antibodies providing rationale for utilization of TGF- $\beta$ inhibitors, such as GC1008 in clinical trials in the setting of renal cell carcinoma and malignant melanoma ${ }^{68}$. Based on our observations, application of TGF- $\beta$ neutralizing antibodies may have utility in restoration of the stem cell pool as well, through influence on both stem cells and the niche in which they develop. 
Our observations indicate that $\mathrm{HOB}$, a critical regulator of stem cell development, are susceptible to genotoxic stress documented by both functional deficits and broad alteration of gene expression profiles. Further investigation will identify targets that may prove useful in augmenting hematopoietic recovery through "balancing" the stem cell niche following therapyinduced damage. Long-term hematopoietic deficits may, in fact, derive in part from the immediate changes in the stem cell niche that are imposed by aggressive therapeutic regimens. This aspect of marrow function may highlight an area in which better understanding could identify new therapeutic strategies to augment efficient patient recovery follow bone marrow transplantation. 


\section{Figure legends:}

Figure 1: Direct and indirect damage increase HOB levels of active TGF- $\beta$. A) HOB were treated with $50 \mu \mathrm{g} / \mathrm{ml}$ Melphalan, $50 \mu \mathrm{M}$ VP-16, or $10 \mathrm{ng} / \mathrm{ml}$ rTGF- $\beta$ for 24 hours and real time RT-PCR for TGF- $\beta$ was performed. B) HOB were treated with $50 \mu \mathrm{g} / \mathrm{ml}$ Melphalan, $50 \mu \mathrm{M}$ VP-16 (left panel), or $10 \mathrm{ng} / \mathrm{ml}$ rTGF- $\beta$ (right panel) for 24 hours. The HOB layer was rinsed and new media was added and allowed to condition for 24 hours before being evaluated by ELISA to quantitate the amount

of secreted TGF- $\beta$. C) HOB were treated directly for 4 hours with chemotherapy (100 $\mu \mathrm{M} \mathrm{VP-16,}$ $100 \mu \mathrm{g} / \mathrm{ml}$ Melphalan) or with media from BMSC that had been left untreated (BMSC CM control) or pretreated with $50 \mu \mathrm{g} / \mathrm{ml}$ Melphalan (BMSC CM Melphalan) or 50 $\mu \mathrm{M}$ VP-16 (BMSC CM VP-16) for 24 hours. HOB cells were then fixed and stained for detection of phospho-Smad2 (green) and DAPI (blue).

\section{Figure 2: Chemotherapy or rTGF- $\beta$ exposure diminished the ability of HOB to support}

Oct-4 positive human embryonic stem cells and diminish HOB interaction with pro-B cells HOB were pre-treated with $10 \mathrm{ng} / \mathrm{ml}$ rTGF- $\beta, 50 \mu \mathrm{g} / \mathrm{ml}$ Melphalan or $50 \mu \mathrm{M}$ VP-16 for 24 hours. HOB were rinsed thoroughly and embryonic stem cells were co-cultured in complete media as recommended by WiCell. After 2 days of co-culture, stem cell colonies were counted and designated as undifferentiated or differentiated based on classic morphology of well defined borders (A) and were stained for Oct-4 as an indicator of potential for pluripotency (B). HOB were treated with $10 \mathrm{ng} / \mathrm{ml}$ rTGF- $\beta, 50 \mu \mathrm{g} / \mathrm{ml}$ Melphalan or $50 \mu \mathrm{M}$ VP-16 for 24 hours. Adherent layers of $\mathrm{HOB}$ were rinsed thoroughly and co-cultured with $1 \times 10^{5}$ fluorescently labeled pro-B cells. After 24 hours the media was aspirated and non-adherent pro-B cells were gently rinsed. Remaining $\mathrm{HOB}$ and pro-B cells adherent to the HOB layer were then trypsinized and events within the easily distinguishable lymphoid gate, based on fluorescence and forward/side scatter, were counted on high flow rate for 30 seconds to enumerate number of pro-B cells attached to the HOB (C). 
Figure 3: Chemotherapy or rTGF- $\beta$ diminishes HOB expression of CXCL12 and support of pro-B cell chemotaxis. A) $\mathrm{HOB}$ were treated with $10 \mathrm{ng} / \mathrm{ml} \mathrm{rTGF}-\beta, 50 \mu \mathrm{g} / \mathrm{ml}$ Melphalan or $50 \mu \mathrm{M}$ VP-16 for 24 hours. RNA was isolated and Real Time RT-PCR was performed for CXCL12. B) HOB were treated with $10 \mathrm{ng} / \mathrm{ml}$ rTGF- $\beta, 50 \mu \mathrm{g} / \mathrm{ml}$ Melphalan or $50 \mu \mathrm{M}$ VP-16 for 24 hours. Growth factor or chemotherapy was removed and fresh media was added, allowed to condition for 24 or 48 hours, and then evaluated in a CXCL12 specific ELISA. C) HOB were treated with rTGF- $\beta, 50 \mu \mathrm{g} / \mathrm{ml}$ Melphalan or $50 \mu \mathrm{M}$ VP-16 for 24 hours. 350ul of the supernatant was then removed and placed into the bottom chamber of a transwell. $1 \times 10^{5} \mathrm{JM}-1$ progenitor cells were placed in the top chamber and allowed to migrate for 4 hours. After 4 hours the cells migrated were read on high flow rate for 30 seconds on a flow cytometer.

Figure 4: Intersection of global gene changes during direct and indirect chemotherapy. HOB cells were treated for 6 hours with $10 \mathrm{ng} / \mathrm{ml}$ rTGF- $\beta, 50 \mu \mathrm{g} / \mathrm{ml}$ Melphalan, or conditioned media from BMSC (CMM) pre-treated with $50 \mu \mathrm{g} / \mathrm{ml}$ Melphalan for 24 hours. BMSC exposed to Melphalan were rinsed and fresh media was place on adherent layers to condition and to remove drug prior to stimulating HOB. After the 6 hour treatment, HOB RNA was isolated and microarray analysis was completed to evaluate global changes in gene expression. A) The Venn diagram summarizes the number of $\mathrm{HOB}$ genes that changed within each group as well as the changes between the groups. B) A gene summary was made of the genes that commonly were up-regulated (4, red) or down-regulated (2, green) for the intersection of all 3 treatments (rTGF- $\beta$ :CMM:Melphalan). C) A network diagram was generated that highlight potential paths that converged upon the commonly increased gene, BCL2A1, for the intersection of all 3 groups. All genes listed were generated using a $2.5 \%$ FDR and 1.5 fold significant cut off. 
Figure 5: Soluble factors in BMSC exposed to chemotherapy induce HOB gene expression changes in common with those subsequent to Melphalan exposure. HOB cells were treated for 6 hours with $50 \mu \mathrm{g} / \mathrm{ml}$ Melphalan, or conditioned media from BMSC pre-treated with $50 \mu \mathrm{g} / \mathrm{ml}$ Melphalan for 24 hours. BMSC exposed to Melphalan were rinsed and fresh media was place on adherent layers to condition and to remove drug prior to stimulating HOB. After the 6 hour treatment, HOB RNA was isolated and microarray analysis was completed to evaluate global changes in gene expression. A) Gene changes for the intersections of the CMM:Melphalan groups were analyzed based on the genes that commonly increased (16, red) or decreased (3, green). B) A network diagram was generated that highlight potential paths that converged upon the commonly increased gene, BCL2A1, for the intersection of CMM:Melphalan groups. All genes listed were generated using a $2.5 \%$ FDR and 1.5 fold significant cut off.

Figure 6: Soluble factors in BMSC exposed to chemotherapy induce HOB gene expression changes in common with those subsequent to rTGF- $\beta$ exposure. HOB cells were treated for 6 hours with $10 \mathrm{ng} / \mathrm{ml}$ rTGF- $\beta$, or conditioned media from BMSC pre-treated with $50 \mu \mathrm{g} / \mathrm{ml}$ Melphalan for 24 hours. BMSC exposed to Melphalan were rinsed and fresh media was place on adherent layers to condition and to remove drug prior to stimulating HOB. After the 6 hour treatment, HOB RNA was isolated and microarray analysis was completed to evaluate global changes in gene expression. A) Gene changes for the intersections of the TGF- $\beta$ :CMM groups were analyzed based on the genes that commonly increased (26, red) or decreased (11, green). B) A network diagram was generated that highlight potential paths that converged upon the commonly increased gene, BCL2A1, for the intersection of TGF- $\beta$ :CMM groups. All genes listed were generated using a $2.5 \%$ FDR and 1.5 fold significant cut off. 
Figure 7: rTGF- $\beta$ exposure induces HOB gene expression changes in common with those subsequent to Melphalan exposure. HOB cells were treated for 6 hours with $10 \mathrm{ng} / \mathrm{ml}$ rTGF- $\beta$, or with $50 \mu \mathrm{g} / \mathrm{ml}$ Melphalan for 24 hours. After the 6 hour treatment, HOB RNA was isolated and microarray analysis was completed to evaluate global changes in gene expression. A) Gene changes for the intersections of the TGF- $\beta$ :Melphalan groups were analyzed based on the genes that commonly increased $(97$, red) or decreased (188, green). B) A network diagram was generated that highlight potential paths that converged upon the commonly increased gene, BCL2A1, for the intersection of TGF- $\beta$ :Melphalan groups. All genes listed were generated using a $2.5 \%$ FDR and 1.5 fold significant cut off. 


\section{Reference List:}

1. Schofield R. The relationship between the spleen colony-forming cell and the haemopoietic stem cell. Blood Cells 1978;4:7-25.

2. Taichman RS, Emerson SG. The role of osteoblasts in the hematopoietic microenvironment. Stem Cells 1998;16:7-15.

3. Kiel MJ, Yilmaz OH, Iwashita T et al. SLAM family receptors distinguish hematopoietic stem and progenitor cells and reveal endothelial niches for stem cells. Cell $2005 ; 121: 1109-1121$.

4. Moore KA, Ema H, Lemischka IR. In vitro maintenance of highly purified, transplantable hematopoietic stem cells. Blood 1997;89:4337-4347.

5. Boskey AL, Posner AS. Bone structure, composition, and mineralization. Orthop.Clin.North Am. 1984;15:597-612.

6. Nilsson SK, Johnston HM, Coverdale JA. Spatial localization of transplanted hemopoietic stem cells: inferences for the localization of stem cell niches. Blood 2001;97:2293-2299.

7. Xie $Y$, Yin $T$, Wiegraebe $W$ et al. Detection of functional haematopoietic stem cell niche using real-time imaging. Nature 2009;457:97-101.

8. Jung $\mathrm{Y}$, Song J, Shiozawa $\mathrm{Y}$ et al. Hematopoietic stem cells regulate mesenchymal stromal cell induction into osteoblasts thereby participating in the formation of the stem cell niche. Stem Cells 2008;26:2042-2051.

9. Zhu J, Garrett R, Jung $Y$ et al. Osteoblasts support B-lymphocyte commitment and differentiation from hematopoietic stem cells. Blood 2007;109:3706-3712. 
10. Calvi LM, Adams GB, Weibrecht $\mathrm{KW}$ et al. Osteoblastic cells regulate the haematopoietic stem cell niche. Nature 2003;425:841-846.

11. Zhang J, Niu C, Ye L et al. Identification of the haematopoietic stem cell niche and control of the niche size. Nature 2003;425:836-841.

12. Ben-Ishay Z, Prindull G, Yankelev S, Sharon S. Cumulative bone marrow stromal damage caused by $\mathrm{X}$-irradiation and cytosine-arabinoside in leukemic mice. Med.Oncol.Tumor Pharmacother. 1990;7:55-59.

13. Guest I, Uetrecht J. Drugs toxic to the bone marrow that target the stromal cells. Immunopharmacology 2000;46:103-112.

14. Tauchmanova L, Serio B, Del PA et al. Long-lasting bone damage detected by dualenergy x-ray absorptiometry, phalangeal osteosonogrammetry, and in vitro growth of marrow stromal cells after allogeneic stem cell transplantation. J.Clin.Endocrinol.Metab 2002;87:5058-5065.

15. Wang L, Clutter S, Benincosa J, Fortney J, Gibson LF. Activation of transforming growth factor-beta1/p38/Smad3 signaling in stromal cells requires reactive oxygen speciesmediated MMP-2 activity during bone marrow damage. Stem Cells 2005;23:1122-1134.

16. Corazza F, Hermans C, Ferster A et al. Bone marrow stroma damage induced by chemotherapy for acute lymphoblastic leukemia in children. Pediatr.Res. 2004;55:152158.

17. L.Lagneaux, A.Delforge, C D, D.Bron, P.Stryckmans. Comparative analysis of cytokines released by bone marrow stromal cells from normal donors and B-cell chronic lymphocytic leukemic patients. Blood 1993;82:2379-2385. 
18. Zermati $\mathrm{Y}$, Fichelson $\mathrm{S}$, Valensi $\mathrm{F}$ et al. Transforming growth factor inhibits erythropoiesis by blocking proliferation and accelerating differentiation of erythroid progenitors. Exp.Hematol. 2000;28:885-894.

19. Peled A, Petit I, Kollet $\mathrm{O}$ et al. Dependence of human stem cell engraftment and repopulation of NOD/SCID mice on CXCR4. Science 1999;283:845-848.

20. Chabanon A, Desterke C, Rodenburger E et al. A cross-talk between stromal cellderived factor-1 and transforming growth factor-beta controls the quiescence/cycling switch of $\mathrm{CD} 34(+)$ progenitors through $\mathrm{FoxO} 3$ and mammalian target of rapamycin. Stem Cells 2008;26:3150-3161.

21. Hall BM, Fortney JE, Gibson LF. Human bone marrow stromal cell CXCL12 production is reduced following exposure to topoisomerase II inhibitors, etoposide or doxorubicin. Analytical Pharmacology 2003;4:21-29.

22. Guo Y, Hangoc G, Bian H, Pelus LM, Broxmeyer HE. SDF-1/CXCL12 enhances survival and chemotaxis of murine embryonic stem cells and production of primitive and definitive hematopoietic progenitor cells. Stem Cells 2005;23:1324-1332.

23. Sugiyama $T$, Kohara $H$, Noda $M$, Nagasawa T. Maintenance of the hematopoietic stem cell pool by CXCL12-CXCR4 chemokine signaling in bone marrow stromal cell niches. Immunity. 2006;25:977-988.

24. Nie Y, Han YC, Zou YR. CXCR4 is required for the quiescence of primitive hematopoietic cells. J.Exp.Med. 2008;205:777-783.

25. Arai F, Hirao A, Suda T. Regulation of hematopoiesis and its interaction with stem cell niches. Int.J.Hematol. 2005;82:371-376. 
26. Dittel BN, LeBien TW. Reduced expression of vascular cell adhesion molecule-1 on bone marrow stromal cells isolated from marrow transplant recipients correlates with a reduced capacity to support human B lymphopoiesis in vitro. Blood 1995;86:2833-2841.

27. Ryan DH, Nuccie BL, Abboud CN, Winslow JM. Vascular cell adhesion molecule-1 and the integrin VLA-4 mediate adhesion of human B cell precursors to cultured bone marrow adherent cells. J.Clin.Invest 1991;88:995-1004.

28. Leuker CE, Labow M, Muller W, Wagner N. Neonatally induced inactivation of the vascular cell adhesion molecule 1 gene impairs B cell localization and T cell-dependent humoral immune response. J.Exp.Med. 2001;193:755-768.

29. Peled A, Kollet $\mathrm{O}$, Ponomaryov $\mathrm{T}$ et al. The chemokine SDF-1 activates the integrins LFA-1, VLA-4, and VLA-5 on immature human CD34(+) cells: role in transendothelial/stromal migration and engraftment of NOD/SCID mice. Blood 2000;95:3289-3296.

30. Visnjic D, Kalajzic Z, Rowe DW et al. Hematopoiesis is severely altered in mice with an induced osteoblast deficiency. Blood 2004;103:3258-3264.

31. Suzuki N, Ohneda O, Minegishi N et al. Combinatorial Gata2 and Sca1 expression defines hematopoietic stem cells in the bone marrow niche. Proc.Natl.Acad.Sci.U.S.A 2006;103:2202-2207.

32. Taichman RS. Blood and bone: two tissues whose fates are intertwined to create the hematopoietic stem-cell niche. Blood 2005;105:2631-2639.

33. Gibson LF, Piktel D, Landreth KS. Insulin-like growth factor-1 potentiates expansion of interleukin-7-dependent pro-B cells. Blood 1993;82:3005-3011. 
34. Syed HA, Threadgill DW. Enhanced oligonucleotide microarray labeling and hybridization. Biotechniques 2006;41:685-686.

35. Gibson LF, Fortney J, Landreth KS et al. Disruption of bone marrow stromal cell function by etoposide. Biol.Blood Marrow Transplant. 1997;3:122-132.

36. Galotto M, Berisso G, Delfino $L$ et al. Stromal damage as consequence of high-dose chemo/radiotherapy in bone marrow transplant recipients. Exp.Hematol. 1999;27:14601466.

37. El-Badri NS, Wang BY, Cherry, Good RA. Osteoblasts promote engraftment of allogeneic hematopoietic stem cells. Exp.Hematol. 1998;26:110-116.

38. Balduino A, Hurtado SP, Frazao $P$ et al. Bone marrow subendosteal microenvironment harbours functionally distinct haemosupportive stromal cell populations. Cell Tissue Res. 2005;319:255-266.

39. Fleming HE, Janzen V, Lo CC et al. Wnt signaling in the niche enforces hematopoietic stem cell quiescence and is necessary to preserve self-renewal in vivo. Cell Stem Cell 2008;2:274-283.

40. Jo DY, Rafii S, Hamada T, Moore MA. Chemotaxis of primitive hematopoietic cells in response to stromal cell-derived factor-1. J.Clin.Invest 2000;105:101-111.

41. Ma $Q$, Jones $D$, Borghesani $P R$ et al. Impaired B-lymphopoiesis, myelopoiesis, and derailed cerebellar neuron migration in C. Proc.Natl.Acad.Sci.U.S.A 1998;95:9448-9453.

42. Jung $\mathrm{Y}$, Wang J, Schneider $\mathrm{A}$ et al. Regulation of SDF-1 (CXCL12) production by osteoblasts; a possible mechanism for stem cell homing. Bone 2006;38:497-508. 
43. de Vries EG, de GH, Boonstra A, van der Graaf WT, Mulder NH. High-dose chemotherapy with stem cell reinfusion and growth factor support for solid tumors. Stem Cells 1995;13:597-606.

44. Cohen Y, Nagler A. Treatment of refractory autoimmune diseases with ablative immunotherapy. Autoimmun.Rev. 2004;3:21-29.

45. Jabbour E, Cortes J, Kantarjian $\mathrm{HM}$ et al. Allogeneic stem cell transplantation for patients with chronic myeloid leukemia and acute lymphocytic leukemia after Bcr-Abl kinase mutation-related imatinib failure. Blood 2006;108:1421-1423.

46. Banfi A, Podesta M, Fazzuoli L et al. High-dose chemotherapy shows a dose-dependent toxicity to bone marrow osteoprogenitors: a mechanism for post-bone marrow transplantation osteopenia. Cancer 2001;92:2419-2428.

47. Li J, Law HK, Lau YL, Chan GC. Differential damage and recovery of human mesenchymal stem cells after exposure to chemotherapeutic agents. Br.J.Haematol. $2004 ; 127: 326-334$.

48. Cao J, Tan $\mathrm{MH}$, Yang $\mathrm{P}$ et al. Effects of adjuvant chemotherapy on bone marrow mesenchymal stem cells of colorectal cancer patients. Cancer Lett. 2008;263:197-203.

49. Neben S, Hellman S, Montgomery M, Ferrara J, Mauch P. Hematopoietic stem cell deficit of transplanted bone marrow previously exposed to cytotoxic agents. Exp.Hematol. 1993;21:156-162.

50. Nieboer $P$, de Vries EG, Vellenga $E$ et al. Factors influencing haematological recovery following high-dose chemotherapy and peripheral stem-cell transplantation for haematological malignancies; 1-year analysis. Eur.J.Cancer 2004;40:1199-1207. 
51. Nieboer P, de Vries EG, Mulder $\mathrm{NH}$ et al. Long-term haematological recovery following high-dose chemotherapy with autologous bone marrow transplantation or peripheral stem cell transplantation in patients with solid tumours. Bone Marrow Transplant. 2001;27:959-966.

52. Gillette JM, Lippincott-Schwartz J. Hematopoietic progenitor cells regulate their niche microenvironment through a novel mechanism of cell-cell communication. Commun.Integr.Biol. 2009;2:305-307.

53. Askmyr M, Sims NA, Martin TJ, Purton LE. What is the true nature of the osteoblastic hematopoietic stem cell niche? Trends Endocrinol.Metab 2009;20:303-309.

54. Weber JM, Calvi LM. Notch signaling and the bone marrow hematopoietic stem cell niche. Bone 2009

55. Batard P, Monier MN, Fortunel N et al. TGF-(beta)1 maintains hematopoietic immaturity by a reversible negative control of cell cycle and induces CD34 antigen up-modulation. J.Cell Sci. 2000;113 ( Pt 3):383-390.

56. Lagneaux L, Delforge A, Dorval C, Bron D, Stryckmans P. Excessive production of transforming growth factor-beta by bone marrow stromal cells in B-cell chronic lymphocytic leukemia inhibits growth of hematopoietic precursors and interleukin-6 production. Blood 1993;82:2379-2385.

57. Mendez-Ferrer S, Frenette PS. Hematopoietic stem cell trafficking: regulated adhesion and attraction to bone marrow microenvironment. Ann.N.Y.Acad.Sci. 2007;1116:392413. 
58. Legras S, Levesque JP, Charrad R et al. CD44-mediated adhesiveness of human hematopoietic progenitors to hyaluronan is modulated by cytokines. Blood 1997;89:1905-1914.

59. Matrosova VY, Orlovskaya IA, Serobyan N, Khaldoyanidi SK. Hyaluronic acid facilitates the recovery of hematopoiesis following 5-fluorouracil administration. Stem Cells $2004 ; 22: 544-555$.

60. Avigdor A, Goichberg P, Shivtiel S et al. CD44 and hyaluronic acid cooperate with SDF1 in the trafficking of human CD34+ stem/progenitor cells to bone marrow. Blood 2004;103:2981-2989.

61. Dutt P, Wang JF, Groopman JE. Stromal cell-derived factor-1 alpha and stem cell factor/kit ligand share signaling pathways in hemopoietic progenitors: a potential mechanism for cooperative induction of chemotaxis. J.Immunol. 1998;161:3652-3658.

62. Driessen RL, Johnston HM, Nilsson SK. Membrane-bound stem cell factor is a key regulator in the initial lodgment of stem cells within the endosteal marrow region. Exp.Hematol. 2003;31:1284-1291.

63. Zong WX, Edelstein LC, Chen C, Bash J, Gelinas C. The prosurvival Bcl-2 homolog Bfl1/A1 is a direct transcriptional target of NF-kappaB that blocks TNFalpha-induced apoptosis. Genes Dev. 1999;13:382-387.

64. Wang CY, Guttridge DC, Mayo MW, Baldwin AS, Jr. NF-kappaB induces expression of the $\mathrm{Bcl}-2$ homologue $\mathrm{A} 1 / \mathrm{Bfl}-1$ to preferentially suppress chemotherapy-induced apoptosis. Mol.Cell Biol. 1999;19:5923-5929. 
65. Anscher MS, Thrasher B, Zgonjanin L et al. Small molecular inhibitor of transforming growth factor-beta protects against development of radiation-induced lung injury. Int.J.Radiat.Oncol.Biol.Phys. 2008;71:829-837.

66. Muraoka RS, Dumont N, Ritter CA et al. Blockade of TGF-beta inhibits mammary tumor cell viability, migration, and metastases. J.Clin.Invest 2002;109:1551-1559.

67. Biswas S, Guix M, Rinehart C et al. Inhibition of TGF-beta with neutralizing antibodies prevents radiation-induced acceleration of metastatic cancer progression. J.Clin.Invest 2007;117:1305-1313.

68. J.C.Morris, G.I.Shapiro, A.R.Tan et al. Phase I/ll study of GC1008: A human antitransforming growth factor-beta (TGFß) monoclonal antibody (MAb) in patients with advanced malignant melanoma (MM) or renal cell carcinoma (RCC). [abstract]. J Clin Oncol 26: 2008 (May 20 suppl; abstr 9028) 2008;

69. Saeed Al, Sharov V, White J et al. TM4: a free, open-source system for microarray data management and analysis. Biotechniques 2003;34:374-378.

70. Tusher VG, Tibshirani R, Chu G. Significance analysis of microarrays applied to the ionizing radiation response. Proc.Natl.Acad.Sci.U.S.A 2001;98:5116-5121. 
Figure 1

A.

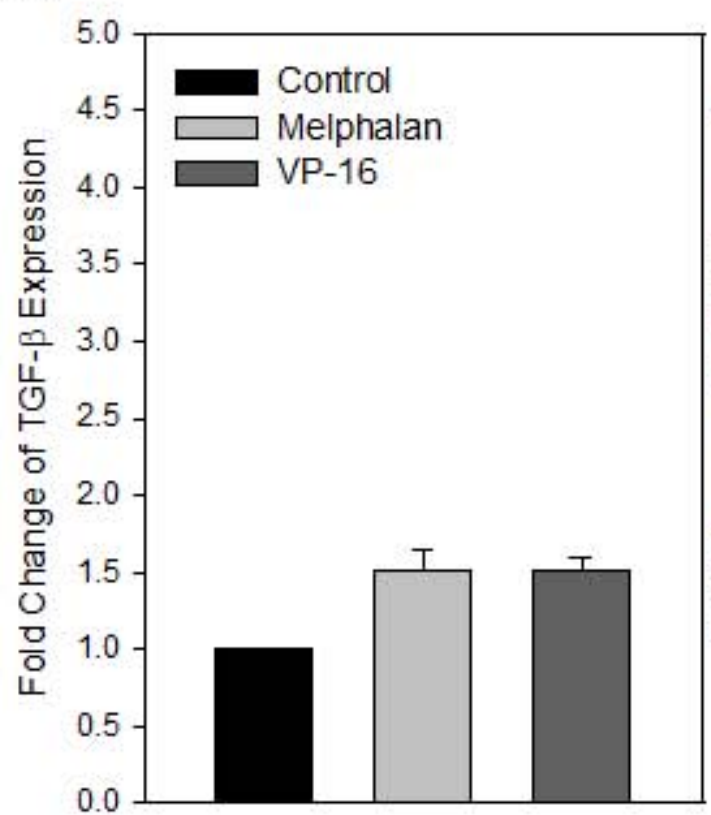

B.

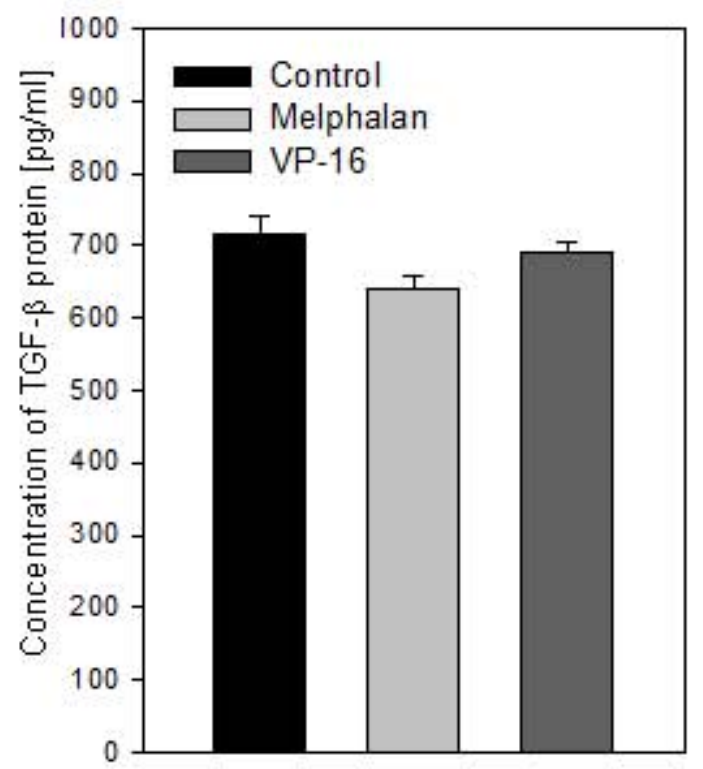

C. pSmad2/DAPI
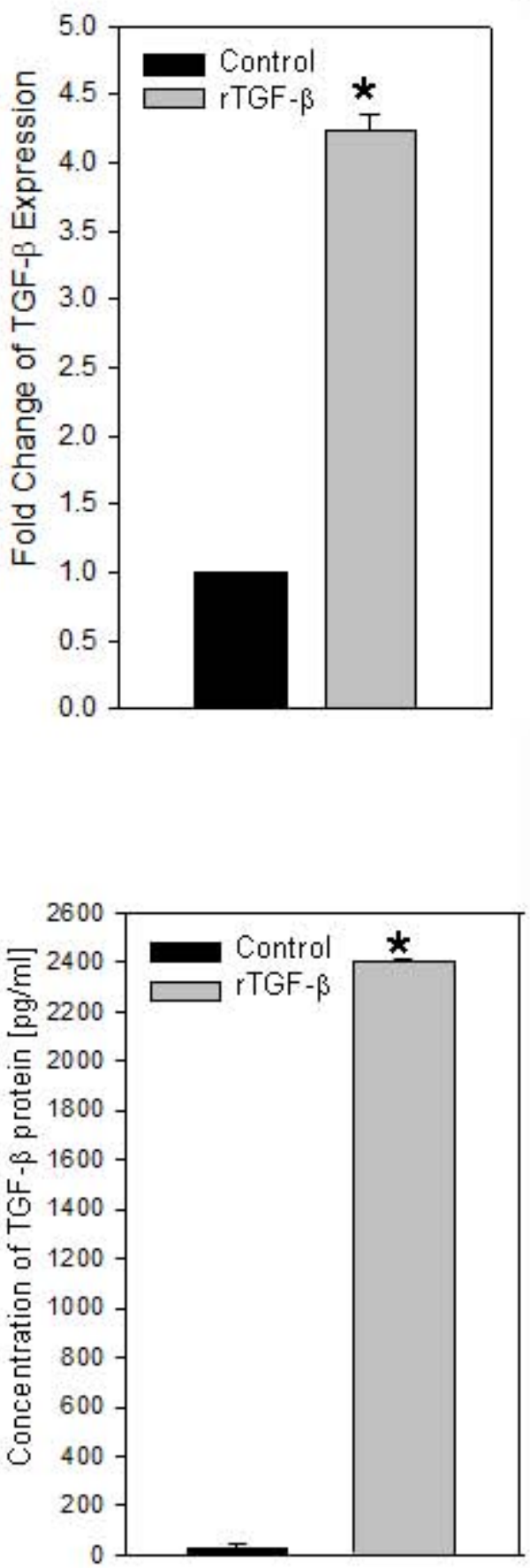

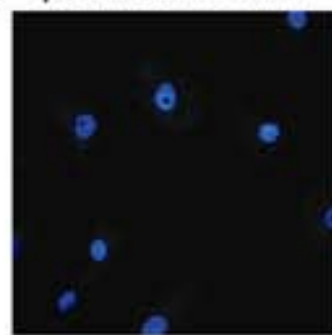

Control

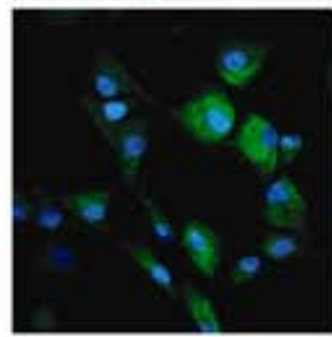

Melphalan

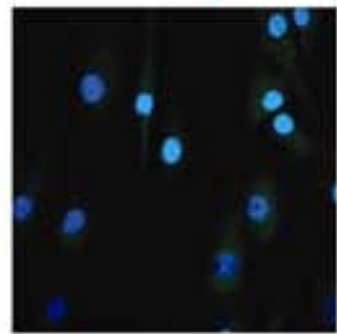

VP-16

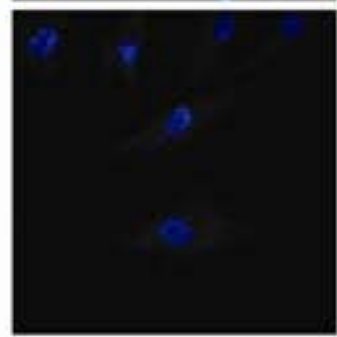

BMSC CM Control

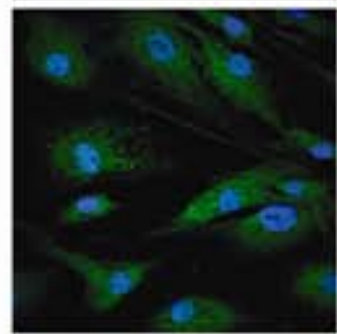

BMSC CM Melphalan

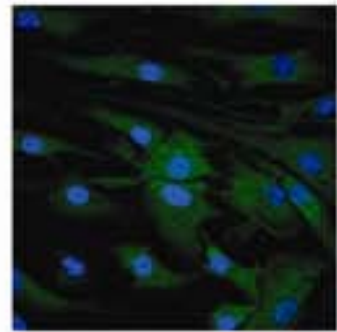

BMSC CM VP-16 
Figure 2 A.

Brightfield
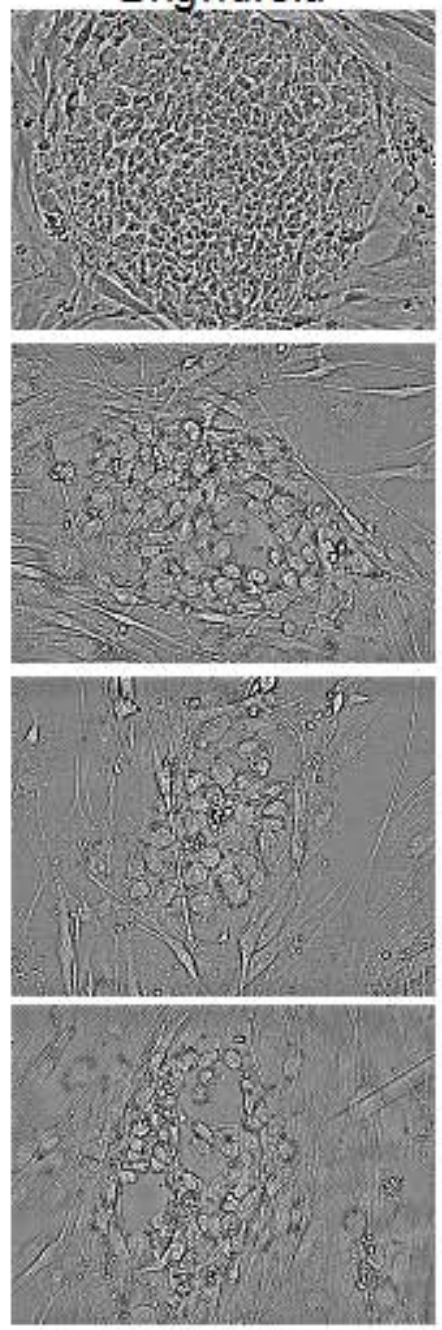

B.

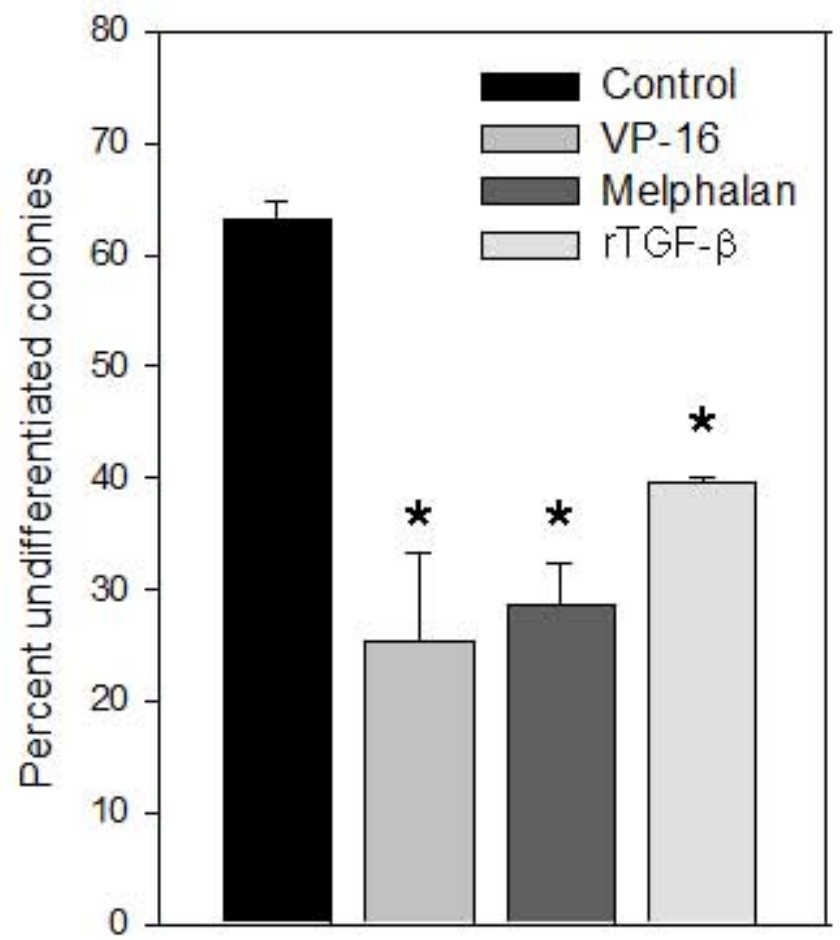

Oct-4

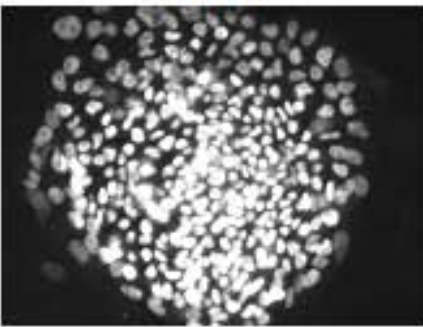

Control

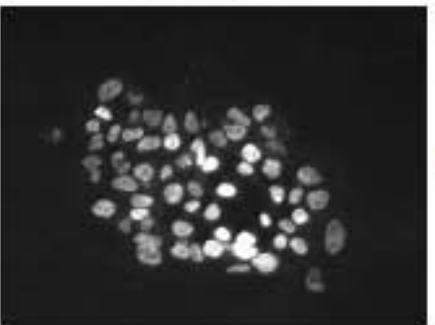

VP-16

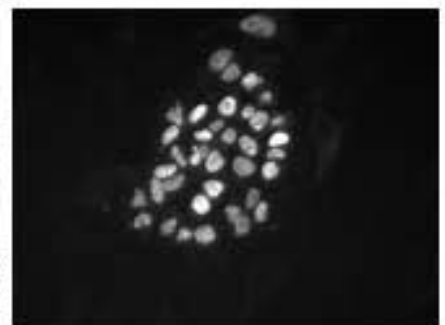

Melphalan

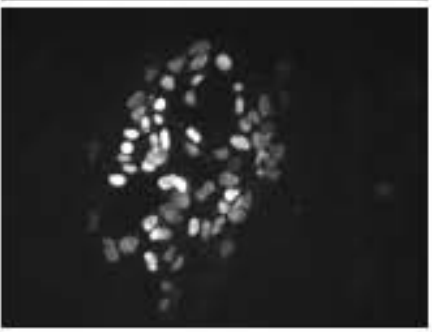

rTGF- $\beta$

c.

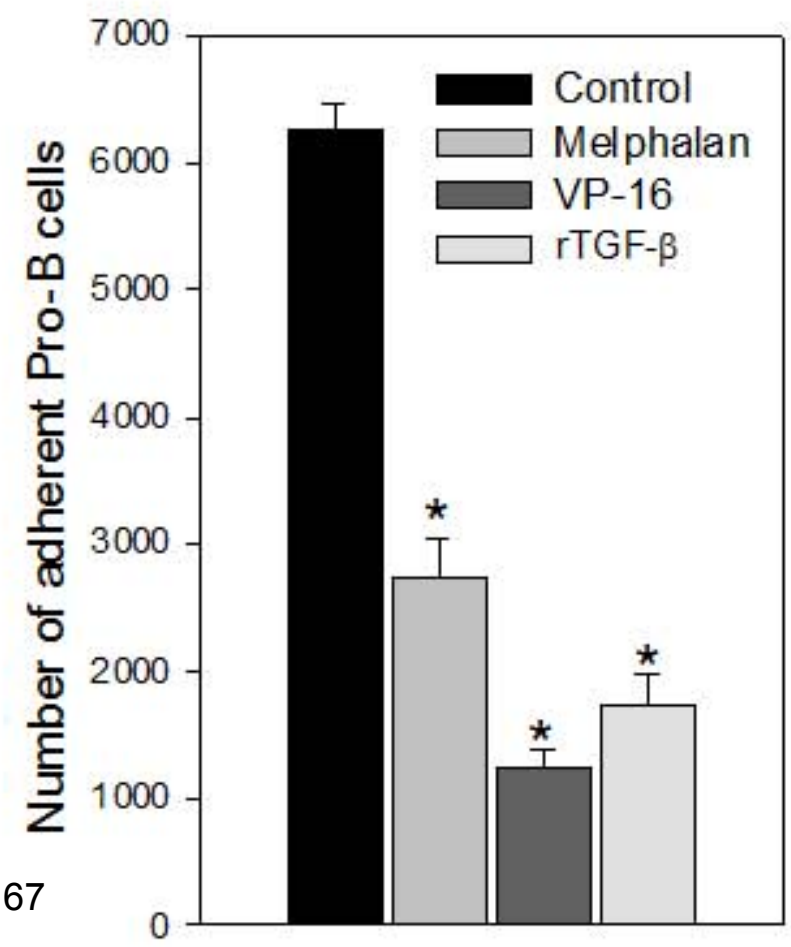


A.

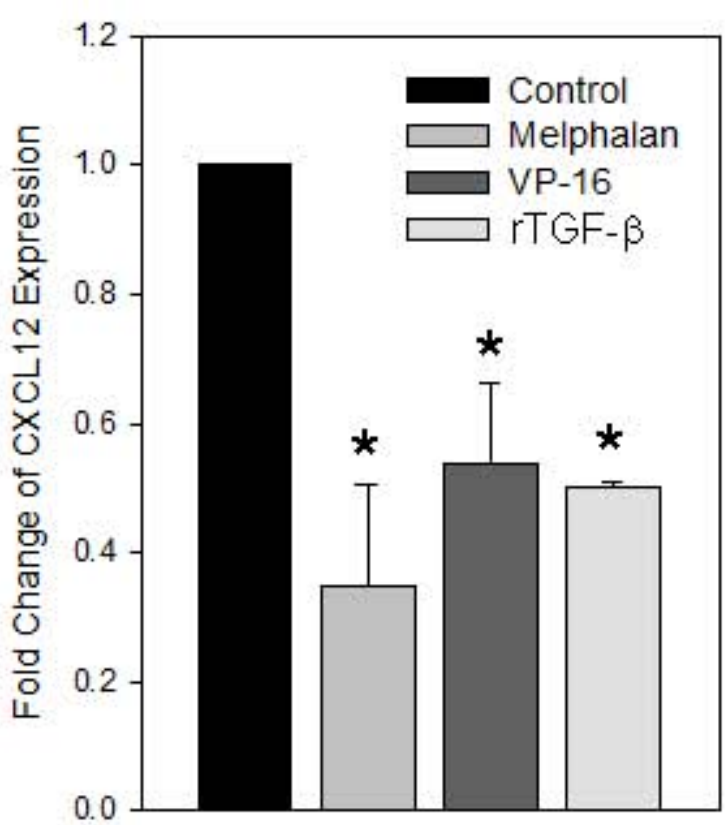

B.
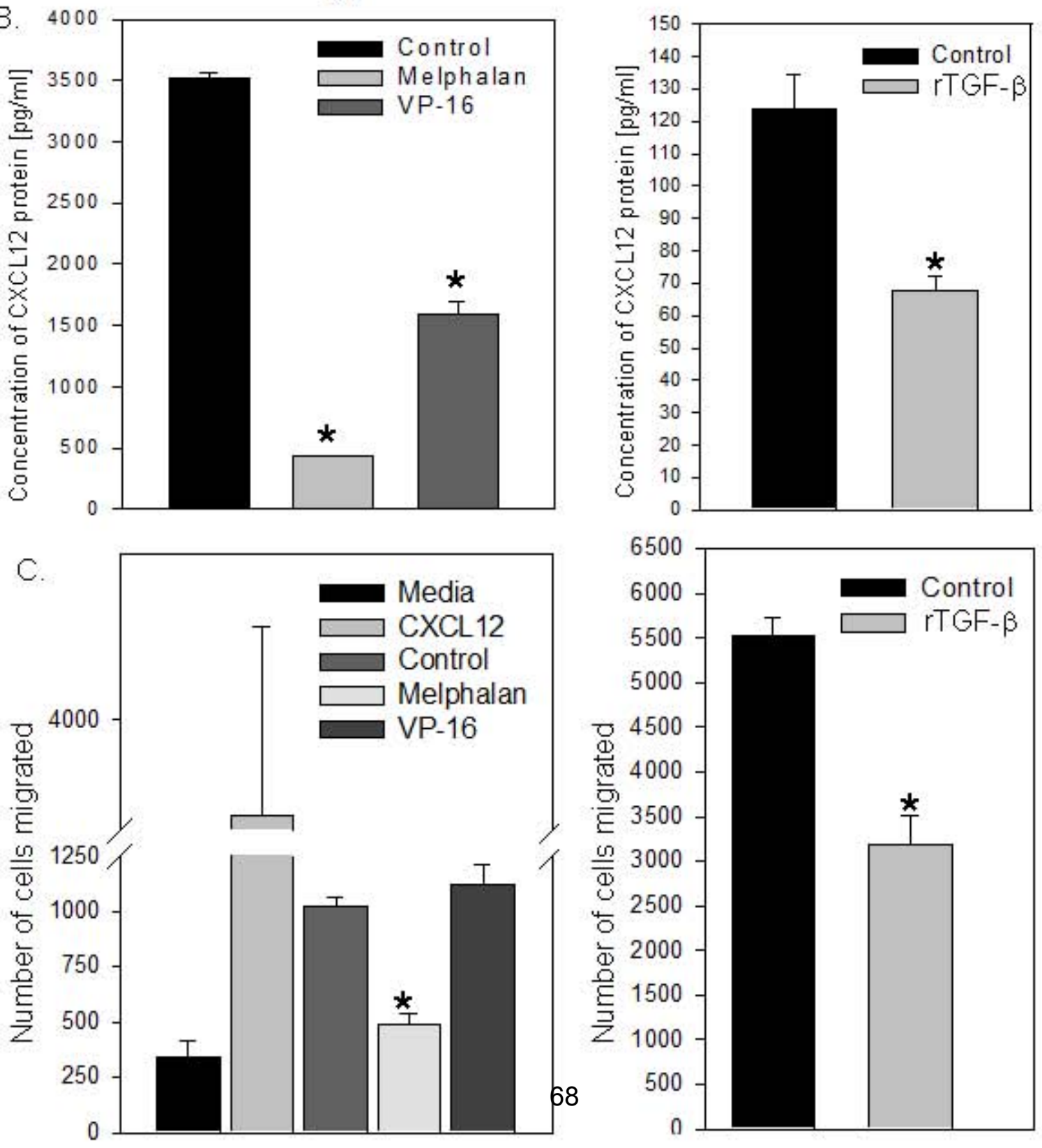
Figure 4

A.

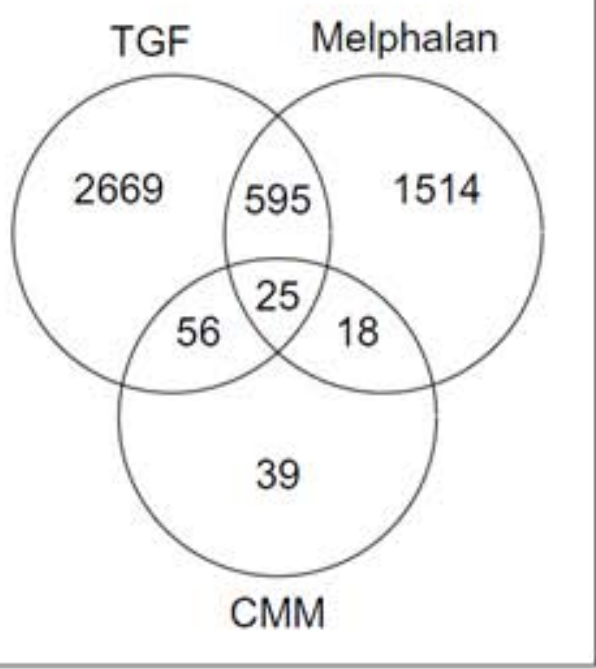

\section{B. Intersection of all 3 Same direction}

\begin{tabular}{|l|l|}
\hline \multicolumn{1}{|c|}{ GeneName } & \multicolumn{1}{c|}{ Description } \\
\hline TFPI2 & tissue factor pathway inhibitor 2 \\
\hline AA837799 & CDNA clone IMAGE:1385153, mRNA sequence [AA837799] \\
\hline BCL2A1 & BCL2-related protein A1, transcript variant 1 \\
\hline THC2727302 & (P39193) Alu subfamily SP \\
\hline EEPD1 & endonuclease/exonuclease/phosphatase family domain containing 1 \\
\hline RNF128 & ring finger protein 128 (RNF128), transcript variant 1 \\
\hline
\end{tabular}

C.

Network 1 : Observation 1 : intersection 1.5 fold : Observation 1

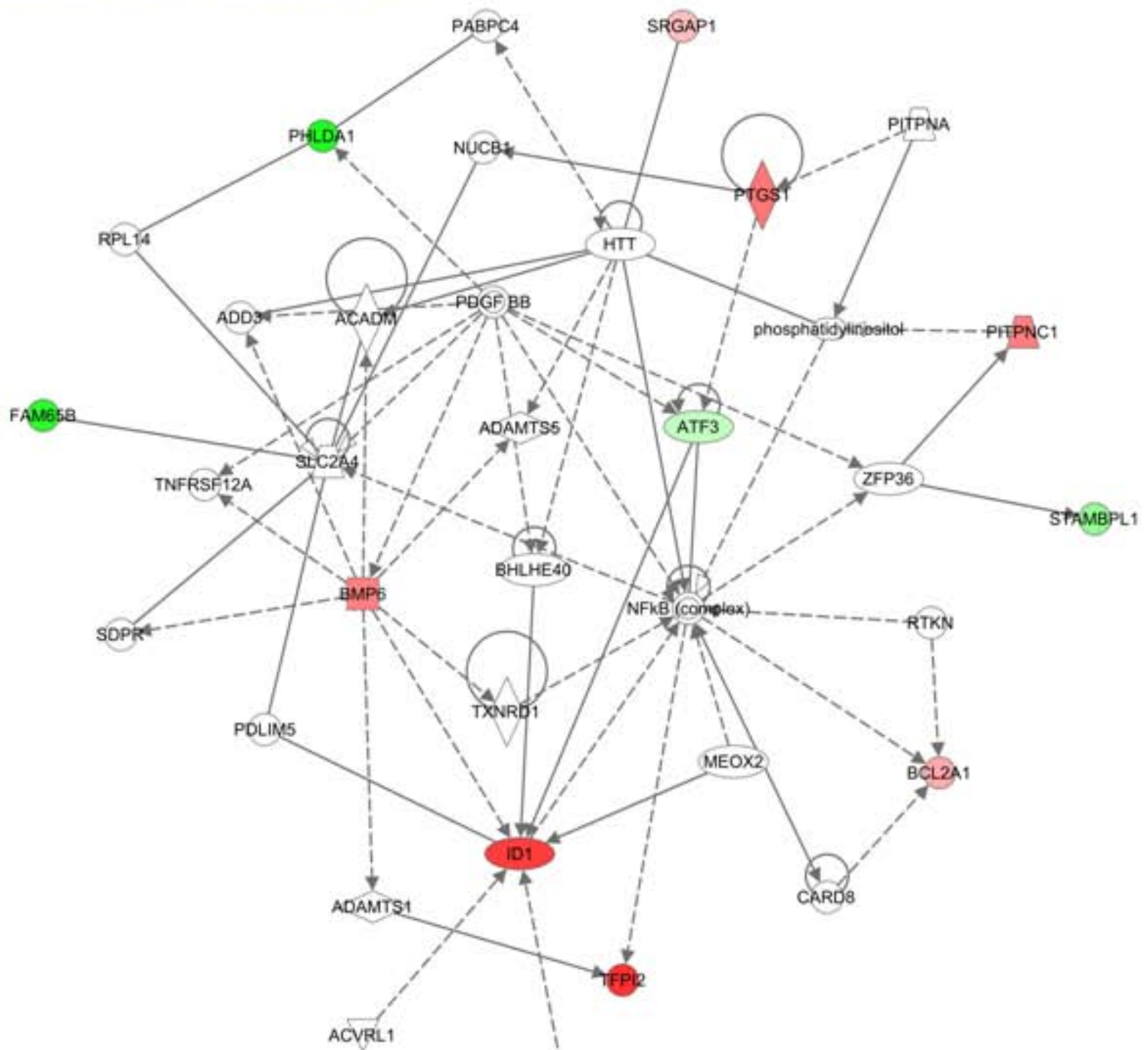




\section{Figure 5}

A. CMM:Melphalan Same direction

\begin{tabular}{|l|l|}
\hline \multicolumn{1}{|c|}{ GeneName } & \multicolumn{1}{c|}{ Description } \\
\hline THC2673554 & Alu subfamily 3 sequence \\
\hline AF227517 & Sprouty-4C mRNA, complete cds. [AF227517] \\
\hline IL.1B & interleukin 1, beta (IL1B) \\
\hline BCL2A1 & BCL2-related protein A1 (BCL2A1), transcript variant 1, \\
\hline A_32_P206561 & Unknown \\
\hline CCL20 & chemokine (C-C motif) ligand 20 (CCL.20) \\
\hline NR4A3 & nuclear receptor subfamily 4, group A, member 3, transcript variant 2 \\
\hline RASD1 & RAS, dexamethasone-induced 1 \\
\hline THC2674068 & Q4S8B2_TETNG (Q4S8B2) Chromosome undetermined SCAF14706 \\
\hline AA837799 & CDNA clone IMAGE:1385153, mRNA sequence [AA837799] \\
\hline THC2560068 & High mobility group protein HMGI-C (High mobility group AT-hook protein 2) \\
\hline THC2727302 & HUMAN (P39193) Alu Subfamily SP \\
\hline LOC390595 & cDNA FL13740 fis, clone PLACE3000199 \\
\hline PHLDA1 & pleckstrin homology-like domain, family A, member 1 \\
\hline ANKRD10 & ankyrin repeat domain 10 \\
\hline AY831680 & HC1 (HC1) mRNA, complete cds. [AY831680] \\
\hline NUAK1 & NUAK family, SNF1-like kinase, 1 \\
\hline EEPD1 & endonuclease/exonuclease/phosphatase family domain containing 1 \\
\hline RNF128 & ring finger protein 128 (RNF128), transcript variant 1 \\
\hline
\end{tabular}

\section{B. "k1: : cMM: : CMM and Meph sane direction: : CMM}

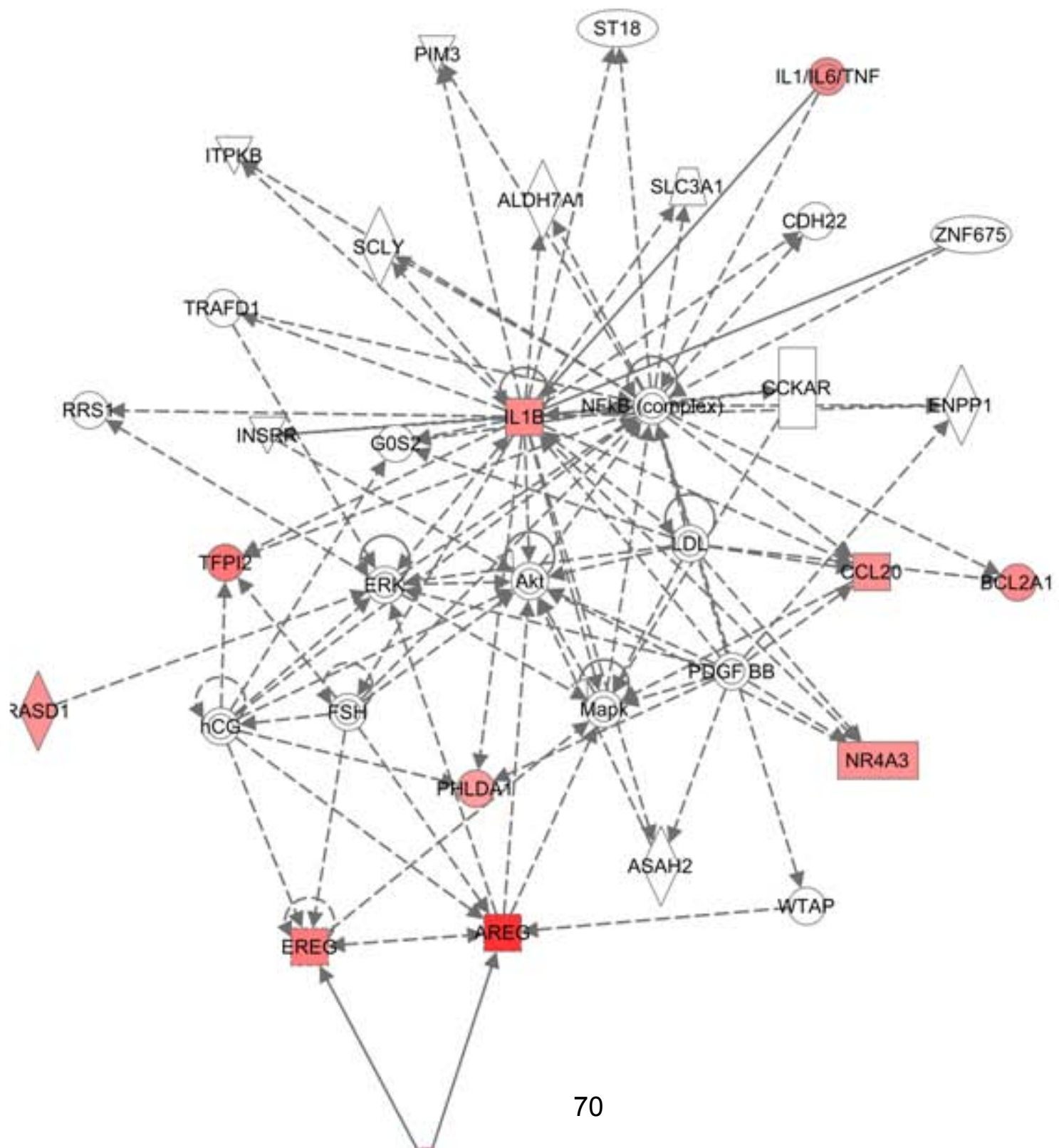




\begin{tabular}{|c|c|}
\hline GeneName & Description \\
\hline TFPI2 & tissue factor pathway inhibitor 2 \\
\hline AA837799 & CDNA clone IMAGE: 1385153 \\
\hline $1 D 1$ & Inhibitor of DNA binding 1, dominant negative helix-loop-helix protein (ID1) \\
\hline PTGS1 & prostaglandin-endoperoxide synthase 1 (prostaglandin $\mathrm{G} / \mathrm{H}$ synthase and cyclooxygenase) \\
\hline PITPNC1 & phosphatidylinositol transfer protein, cytoplasmic 1 (PITPNC1), transcript variant 2 \\
\hline BMP6 & bone morphogenetic protein 6 (BMP6) \\
\hline $\mathrm{CCL} 7$ & chernokine (C-C motif) ligand 7 \\
\hline GEM & GTP binding protein overexpressed in skeletal muscle (GEM), transcript variant 1 \\
\hline FU14213 & protor-2 (FU14213) \\
\hline DIRAS3 & DIRAS family, GTP-binding RAS-like 3 \\
\hline MMP13 & matrix metallopeptidase 13 (collagenase 3 ) \\
\hline HAS1 & hyaluronan synthase 1 \\
\hline BCLZA1 & BCL2-related protein A1 (BCL2A1), transcript variant 1 \\
\hline BDKRB1 & bradykinin receptor B1 \\
\hline D8381305 & CDNA clone PLACE $30004003^{\prime}$ \\
\hline MYB & v-myb myeloblastosis viral oncogene homolog \\
\hline IFNE1 & interferon epsilon 1 \\
\hline FGF16 & fibroblast growth factor 16 \\
\hline SRGAP1 & SLIT-ROBO Rho GTPase activating protein 1 \\
\hline THC272730 & ALU6_HUMAN (P39193) Alu subfamily SP \\
\hline AL 390214 & CDNA DKFZp56402423 (from clone DKFZp56402423) \\
\hline PRL & prolactin \\
\hline SPON1 & spondin 1, extracellular matrix protein \\
\hline GPRCSA & G protein-coupled receptor, family C, group 5, member A (GPRC5A), \\
\hline AA293788 & CDNA clone IMAGE:727217 5' similar to gb:X02761_cds1 FIBRONECTIN PRECURSOR; \\
\hline AF086511 & full length insert CDNA clone ZE03A08. [AF086511] \\
\hline GREM1 & gremlin 1, cysteine knot superfamily, homolog \\
\hline ATF3 & activating transcription factor 3 (ATF 3 ), transcript variant 4 , \\
\hline L3MBTL2 & CDNA FU32615 fis, clone STOMA2000148, [AK057177] \\
\hline CIQTNF7 & C19 and tumor necrosis factor related protein 7 (C1QTNF7), \\
\hline HSPB3 & heat shock $27 \mathrm{kDa}$ protein 3 (HSPB3) \\
\hline PRKAG3 & protein kinase, AMP-activated, gamma 3 non-catalytic subunit \\
\hline EEPD1 & endonuclease/exonuclease/phosphatase family domain containing 1 (EEPD1) \\
\hline RNF128 & ring finger protein 128 (RNF128), transcript variant 1 \\
\hline KIAA1199 & KIAA1 199 (KLAA1199) \\
\hline LOC283143 & CDNA FLJ33283 fis, clone ASTRO2009177. [AK090602] \\
\hline KLF5 & Kruppel-like factor 5 (Intestinal) \\
\hline
\end{tabular}

B.

ork 1 : TGF : TGF and CMM same direction. bet: TGF

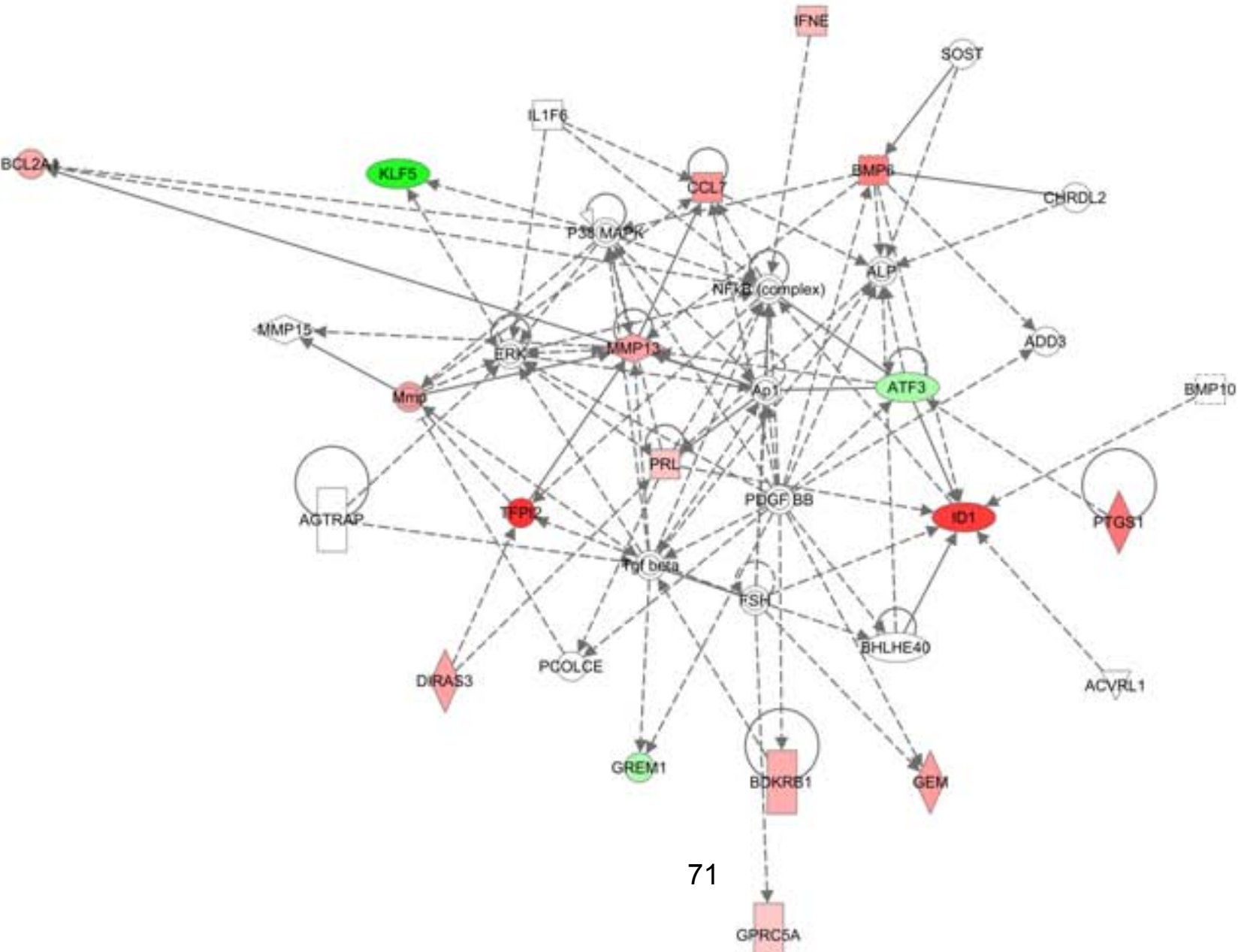


Figure 7

A.

\begin{tabular}{|c|c|c|}
\hline GeneName & Description & GeneName \\
\hline PTGS2 & prostaglandin-endoperoxide synthase 2 & AK022150 \\
\hline RASLI1B & RAS-like, family 11 , member B & AK095141 \\
\hline SIC19A2 & solute carrier family 19 , member 2 & C1orf203 \\
\hline TRIB1 & tribbles homolog 1 (Drosophila) & MKL2 \\
\hline LOH3CR2A & CDNA FU 30336 fis, clone BRACE2007358 & LOC653391 \\
\hline MEX3B & mex -3 homolog $B$ (C. elegans) & PRUNE2 \\
\hline CXCR7 & chemokine ( $\mathrm{C}-\mathrm{x}-\mathrm{C}$ motif) receptor 7 & SRGAP2 \\
\hline TFP12 & tissue factor pathway inhibitor 2 & ANKAR \\
\hline AA837799 & CDNA done IMAGE: 1385153 & C6orf 165 \\
\hline FOSB & FB) murine osteosarcoma viral oncogene homolog B & IKBKE \\
\hline SNF 1 LK & SNF1-llke kinase (SNF1LK) & ENST00000311275 \\
\hline RASLIOA & RAS-like, family 10 , member $A$, transcript variant 2 & C6orf 167 \\
\hline IER3 & immediate early response 3 & DENNDAC \\
\hline GRIN2C & glutamate receptor, ionotropic, $\mathrm{N}$-methyl D-aspartate $2 \mathrm{C}$ & RSPO2 \\
\hline TMFMS8 & transmembrane protein 88 & NFIA \\
\hline YRDC & & ENST 00000219090 \\
\hline RBM24 & RNA binding motif protein 24 & MYO1B \\
\hline IL12A & interleukin $12 \mathrm{~A}$ & REV3L \\
\hline RRAD & Ras-related associated with diabetes & KIAA1107 \\
\hline SGK1 & serum/glucocorticoid regulated kinase 1 & BC047111 \\
\hline A_32_P219704 & Unknown & PPM1H \\
\hline B3GNT2 & betaGal beta-1,3-N-acetylglucosaminyltransferase 2 & EMX2 \\
\hline RPL27A & ribosomal proteln $127 \mathrm{a}$ & FAM90A1 \\
\hline BCL2A1 & BCL2-related protein A1, transcript variant 1 & SPATA17 \\
\hline CITED4 & $\mathrm{Cbp} / \mathrm{p} 300$-interacting transactivator, Glu/Asp-rich c-term 4 & C9orf93 \\
\hline HOXD1 & homeobox D1 (HOXO1) & THSD4 \\
\hline DA116424 & CDNA clone BRACE3035779 & FUT10 \\
\hline SERPINB2 & serpin peptidase inhibitor, clade $\mathrm{B}_{\text {, member } 2}$ & EXOC6 \\
\hline C1orf107 & chromosome 1 open reading frame 107 & CPNE8 \\
\hline THC2619021 & CF066_HUMAN (Q9P032) UPF0240 protein C6orf66 & TMEM200A \\
\hline MIRHG1 & chromosome 13 open reading frame 25 & STAC \\
\hline RGS2 & regulator of $\mathrm{G}$-protein signaling 2 & BE893137 \\
\hline BU903025 & CDNA clone IMAGE:6528450 5, & POLIMS \\
\hline USP36 & ubiquitin specific peptids & THC2781306 \\
\hline NEBL & nebulette, transcript variant 1 , & DST \\
\hline MFSD2 & major facilitator superfamily domain containing 2 & SPRED1 \\
\hline CCDC64B & CDNA DKFZP666L166 & THC2664860 \\
\hline BX375060 & NEUROBLASTOMA COT 25-NORMALIZED & ZNF438 \\
\hline THC2727164 & Unknown & KIAA0922 \\
\hline THC2669419 & Alu subfamily SQ sequence & ZNF521 \\
\hline MESOC1 & mesoderm development candidate 1 & $\pi C 30 \mathrm{~B}$ \\
\hline YOD1 & YOD1 OTU deubiquinating enzyme 1 homolog & LYST \\
\hline ARC & activity-regulated cyloskeleton associated protein & ZSWIM5 \\
\hline ATG16L1 & $\begin{array}{l}\text { ATG16 autophagy reated } 16-4 k e 1 \\
\text {. }\end{array}$ & GRKS \\
\hline ZC3H12A & Enc finger CCCH-bpe containing 12A & HMGA2 \\
\hline THC2727302 & ALU6 HUMAN (P39193) Alu subtamily SP & PAG1 \\
\hline TUFT1 & tuffeln 1 (TUFT1) & CF552909 \\
\hline C13orf27 & chromosome 13 open reading trame 27 & RGMB \\
\hline MEX3A & x.3 hemolog A & PHF21A \\
\hline LOC100129406 & & \\
\hline BC063641 & cDNA clone IMAGE 4745832 & \\
\hline $\mathrm{DBF} 4$ & DEF 4 homolog (S cerensiae) (DBF4) & BC034285 \\
\hline RGS16 & regulator of G-protein signating 16 & ARHGAP18 \\
\hline KLHDCS & kelch domain cortaining 5 (KLLDCC5) & PXK \\
\hline CV570707 & Human keratoconus cornea & CXorf57 \\
\hline CUL3 & cillin 3 (CUL 3 ) & TBLIXR1 \\
\hline AMMECR1L & AMME chromosonal tegion gene 1 -tke & CC2D2A \\
\hline BU561469 & CDNA clone IMAGE 65925255 & SNX29 \\
\hline NOL5A & A (56kDa with KKED repeat) & FAM108C1 \\
\hline C7ort40 & chromosome 7 open reading frame 40 & TLRA \\
\hline LOC338756 & $10 \mathrm{C} 339756010 \mathrm{OC}$ & PHF3 3 \\
\hline THC26 & 15 & IKZF2 \\
\hline RG9MTL & meltivtransterase dom: & \\
\hline BTG2 & mber? 2 . & FA \\
\hline LOC285535 & CDNAFL.J33738 fis, clone BRAWH2018527. & TNRC6B \\
\hline EAF1 & ELL associated factor 1 & OSBP \\
\hline THC2713715 & A clone UE.EJ1 an-0.13.0U 5 & C10rf190 \\
\hline B3GNTS & a Gal beta. $1,3-\mathrm{N}$ - acelyblucosaminytransferase 5 & \\
\hline BC032716 & CDNA clone IMAGE 5518697 & ZNF214 \\
\hline SNORA70 & II nucleolar RNA. HACA box 70 & M133 \\
\hline A_ 32 P 109645 & nown & \\
\hline THC2525241 & Q3S759 BOVIN (Q23S759) Ribos & \\
\hline BM475547 & CDNA Clot & \\
\hline & & \\
\hline SNORD22 & st & \\
\hline PDIF & & \\
\hline LOCBS: & omosome 11 & \\
\hline A 3 . & & \\
\hline & & \\
\hline & & \\
\hline NKi & 8 repressing factor (NKRF) & \\
\hline THC2537217 & & \\
\hline SPTY2D1 & 2. Suppressor of Ty, domain containing 1 & KIAADB \\
\hline ABT1 & ator of basal transc & C14 \\
\hline THC2729109 & 1 HUMAN (P3918B) Alu sibfamily J & $\mathrm{K} 3 \mathrm{R}^{3}$ \\
\hline$B C 035666$ & CDNA clone IMAGE 5724430 & TCF7L1 \\
\hline T05215 & T05215 EST03104 Fetal brain & MLLT3 \\
\hline AF339771 & $\begin{array}{l}\text { done IMAGE } 1257951 \text {. } \\
\text { cidin }\end{array}$ & ZNF618 \\
\hline cyp27 & 0, tamily 27,3 & \\
\hline PLK & & \\
\hline & & \\
\hline & & \\
\hline & A) & \\
\hline BF575152 & cDNA done IMAGE $42885475^{\circ}$ & PLEKHAS \\
\hline BM726940 & cDNA done U. E.EJO-ait-121-0.U 5 & $\mathrm{BICC1}$ \\
\hline
\end{tabular}


Figure 7

B.

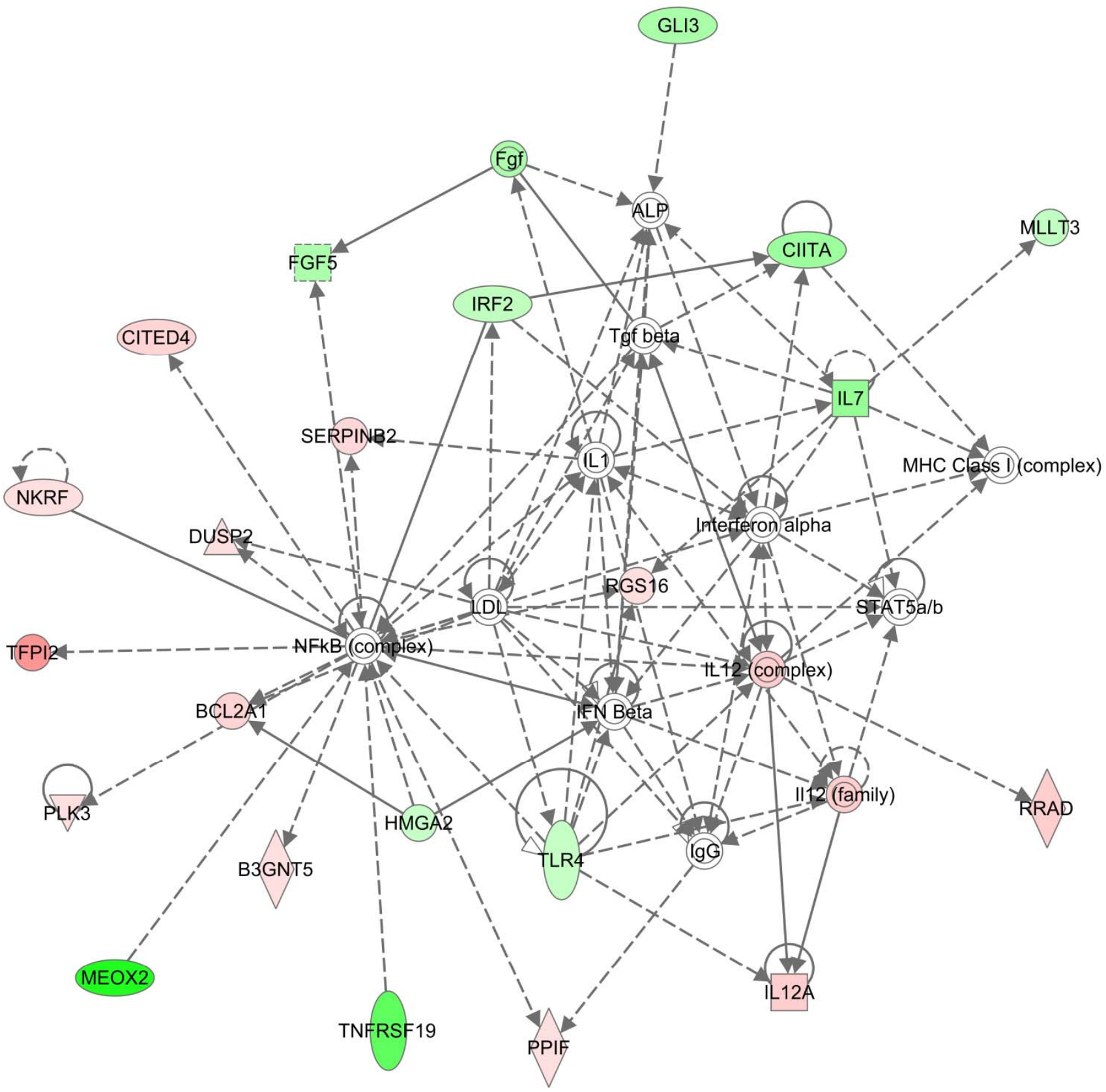




\section{Chapter 3}

\section{Acute Lymphoblastic Leukemia}




\section{Acute Lymphoblastic Leukemia}

\section{Acute Lymphoblastic Leukemia}

As previously mentioned, normal B lymphopoiesis occurs in the bone marrow and gives rise to mature $B$ cells that express immunoglobulin and are responsible for humoral immunity. In some cases, normal B cells acquire stage specific mutation(s) and undergo developmental arrest, while continuing to proliferate and expand, without being functional modulators of immunity. This leads to an accumulation of blasts, or immature B cells, in the bone marrow and subsequently in the periphery, that are indistinguishable from their normal counterparts and are representative of the disease clinically classified as Acute Lymphoblastic Leukemia.

Acute lymphoblastic leukemia (ALL) is the most common malignancy in children, with the peak incidence being ages 2-5, and approximately 5,700 new cases will be diagnosed this year in the United States ${ }^{1 ; 2}$. Although a direct cause of leukemia is not known, exposure to chemicals such as benzene, high levels of radiation or chemotherapeutic agents increases the chance of leukemia, as do certain viruses, and inherited diseases such as Down's syndrome, but it is believed that these represent less than $5-10 \%$ of diagnosed leukemias. Literature suggesting high birth weight being associated with leukemia is becoming more prevalent, but much more research is needed to attempt to determine the causation of the disease ${ }^{3}$. The start of the disease is unknown, and it has been suggested that some leukemias may start in utero while others state that the first mutation in the multistep pathway may start in a hematopoietic stem cell (HSC) with multi-lineage developmental capacity or a progenitor cell committed to specific lineage ${ }^{4}$.

Additionally, the presence of chromosomal abnormalities is relevant to the disease but is ruled out as the sole causation since screening of neonatal cord blood has shown that potential leukemic clones with the TEL-AML fusion gene (aka ETV6-RUNX1) has been found in $1 \%$ of newborn babies which is a frequency 100 times higher than the incidence of ALL with this fusion 
gene in childhood ${ }^{5}$. The Philadelphia chromosome (Bcr/ABI, $\mathrm{Ph}+$ ) has also been detected in circulating cells of healthy people who never develop leukemia further substantiating that the single translocations are not enough to cause the full disease ${ }^{6-11}$. At diagnosis, risk assessment is based on age, white blood cell count, and the presence of chromosomal abnormalities ${ }^{12}$. Diagnosis is further classified by surface expression of $\mathrm{T}$ or B-lineage markers, and prognostic significance is based on these classifications as well as initial response to therapy. Further discussion will focus specifically on B-lineage ALL.

B-lineage Acute Lymphoblastic Leukemia is responsible for $75-80 \%$ of ALL and is a malignant disease characterized by an accumulation of blasts, or immature cells, that undergo clonal expansion resulting in suppression of normal hematopoiesis and potential infiltration of extramedullary sites ${ }^{13}$. Clinically it is seen as fever, effects of anemia such as severe fatigue and malaise, an absence of functioning granulocytes (proneness to infection and inflammation), and thrombocytopenia (hemorrhagic diathesis) ${ }^{12}$. The 5 year overall survival rates for B-lineage ALL are 60-70 percent overall; 90.9 percent for children under $5^{14-16}$. However, these numbers are altered by expression of negative cytogenetic markers. Chromosomal abnormalities detected at diagnosis are used for both risk assessment as well as deciding on treatment regimens ${ }^{12 ; 17 ; 18}$. Common translocations found in B-Lineage ALL are high hyperploidy (51-65 chromosomes) and TEL/AML1 fusion; $t(12 ; 21)$ which are typically associated with younger patients (1-10yrs old, $22-50 \%$ of ALL children, $2-10 \%$ of ALL adults) with low leukocyte counts and are correlated with a favorable prognosis ${ }^{18}$. Other common alterations and translocations include: hypodiploidy (fewer than 44-45 chromosomes), intra-chromosomal amplification of the AML1 gene on chromosome 21 (lamp21), and rearrangements of the Mixed Lineage Leukemia gene (MLL, 11q23), E2A-PBX1 $t(1: 19)$. These alterations are all associated with a poor prognosis and high risk of relapse. MLL $(4 ; 11$, most common and significantly poor prognosis in children under 1 with overall survival $\sim 50 \%$ ) and the Bcr/Abl t(9;22) (poor prognosis in children and adults) $)^{17 ; 18}$. 
The Philadelphia chromosome $(\mathrm{Ph}+, \mathrm{t}(9 ; 22)(\mathrm{q} 34 ; 911)$ is a reciprocal translocation of the long arms of chromosomes 9 and 22 . It was discovered in 1960 by Peter C. Nowell in Chronic Myelogenous Leukemia $(\mathrm{CML}){ }^{19 ; 20}$ but it was not until the early 1970's that improved cytogenetics techniques allowed the origin of the translocation, chromosomes 9 and 22, to be $\mathrm{known}^{21}$. The $\mathrm{Ph}+$ increases in frequency with age, from 3-5 percent in children to 20 percent in adults to more than 50 percent in patients older than 50 years ${ }^{22}{ }^{18}$. Interestingly, in patients with ALL who have $t(9 ; 22)$, the Philadelphia chromosome, children one to nine years of age have a better prognosis than adolescents with the same disease, who in turn fare better than adults ${ }^{22}$.

Treatment for ALL typically consists of 3 phases: remission induction, consolidation or intensification and maintenance therapy ${ }^{12 ; 17 ; 22 ; 23}$. The goal of remission induction is to eradicate $99 \%$ of the leukemia burden and to restore normal hematopoiesis and performance status. Patients with $1 \%$ or greater leukemic blasts at the end of 4-6 weeks of remission induction therapy fare nearly as poorly as those who do not achieve clinical remission by the accepted morphological standard ( $\geq 5 \%$ leukaemic cells), where people who achieve molecular or immunological remission $\left(<0 \cdot 01 \%\right.$ leukemic cells) have an excellent outcome ${ }^{17 ; 24-27}$. Children that have high risk or very high risk ALL, as well as most adults, tend to receive four or more chemotherapeutic drugs during this aggressive therapy.

Remission induction usually lasts approximately a month and typically includes HyperCVAD. Hyper refers to hyperfractionated nature of the chemotherapy, which is given in smaller doses, more frequently, to minimize side-effects and CVAD is an acronym for the chemotherapeutic agents utilized: Cyclophosphamide, Vincristine, Daunorubicin (Adriamycin, Ara-C, or Doxorubicin) and Dexamethasone (Prednisone) ${ }^{25 ; 28}$. Additionally, based on the patient's prognostic factors, some regimens may also include L-asparaginase, etoposide, and/or high doses of methotrexate or cytarabine (Ara-C) as part of the induction phase. During remission induction, prophylactic treatment is also given to keep the leukemia from spreading to 
the CNS (Central Nervous System). This treatment may include intrathecal chemotherapy (injected directly into the spinal fluid), high dose methotexate IV, high dose Ara-C or cranial irradiation. The number of rounds of therapy depends on age and tolerability of therapy, but generally consists of 8 cycles of treatment ${ }^{12 ; 29}$. For Ph+ ALL disease, patients also receive Imatinib or Dasatinib as part of therapy and throughout maintenance.

Consolidation therapy occurs when a patient is considered to be in remission (both cytogeneic and hematopoietic recovery) and is a short course (a few months) of the same chemotherapy as remission induction, CNS treatment. Patients with a high risk phenotype $(\mathrm{Ph}+)$, or that had a poor initial response to treatment, may have allogeneic bone marrow transplants after the induction of remission. Transplant is decided in the first remission based on several factors: 1. age at diagnosis, 2- chromosome abnormalities at diagnosis (ie $\mathrm{Ph}+$, 11q23 abnormalities, etc a 'poor risk), - 3- WBC at diagnosis, 4- availability of a donor (do they have a matched sibling available) ${ }^{17 ; 29}$. If patients are going to transplant in first remission, they generally complete 4 cycles of therapy, then go to transplant. If patients are staying on treatment, they generally proceed through therapy. If they relapse, they get further therapy to try to get into remission, then go through transplant (in second remission) ${ }^{17 ; 29}$. After the initial 8 cycles, patients then receive maintenance therapy with methotrexate, vincristine, prednisone, and 6-MP, on a monthly schedule for 2 more years.

These treatments, though aggressive in nature, often do not result in eradication of disease. Minimal residual disease (MRD) and subsequent relapse typically occur in the bone marrow and monitoring of patient disease status has been revolutionized by the Campana laboratory, and others ${ }^{24 ; 30 ; 31}$. MRD could previously be detected only by morphological microscopic analysis and did not allow for efficient detection of relapse or monitoring of response to treatment. Approximately 30 years ago, Janossy and colleagues were one of the first groups to attempt to identify residual tumor cells using more than morphology, and they observed that T-lineage ALL cells co-expressed both TdT and T-cell marker, which normal 
blood and bone marrow cells did not ${ }^{32 ; 33}$. The most widely used techniques for detection of MRD are PCR and flow cytometry which allow for the detection of chromosomal translocations and immunoglobulin gene rearrangements and are able to observe a single tumor cell in the background of thousands to millions of normal cells ${ }^{34 ; 35}$. Currently, the ability to utilize immunologic markers allows for the detection of the unique tumor phenotypes that cause MRD in both $\mathrm{T}$ and $\mathrm{B}$ lineage ALL.

\section{Tumor stem cell phenotype}

Tumor cells with diverse phenotypes have been shown to both interact with, and alter, their microenvironment with leukemia cells also having the potential to change the ability of normal HSC to proliferate and function in shared niches ${ }^{36 ; 37}$. Although many microenvironments have been shown to be protective to multiple types of tumors, numerous studies from the Dalton and Campana laboratories laid the seminal ground work for the hypothesis of the bone marrow microenvironment being protective to hematopoietic tumors, as well as a key site of metastasis for solid tumors ${ }^{25 ; 38}$. Therefore, the bone marrow microenvironment has unique biological relevance and its interaction with tumors with a stem- like phenotype is the focus of the following section.

On the surface, leukemic cells express identical proteins to their normal immature hematopoietic cell counterparts. This stems from the fact that a B-lineage, acute lymphoblastic leukemia (ALL) cell is, for all intents and purposes, a normal B cell that is arrested in a pre-pro progenitor stage and is unable to differentiate to become a mature, functional B cell but has extreme proliferative capacity. Blunted differentiation leads to the rapid accumulation of immature B-lineage cells, or leukemic blasts in the acute phase. The hallmark difficulties in treatment then become not only eradicating the proliferative leukemic blasts, but also their ability to be protected by the microenvironment by utilizing normal $\mathrm{B}$ cell/stromal microenvironment interactions resulting in residual tumor that can contribute to relapse of disease. As mentioned previously, normal B cells interact with the microenvironment through 
physical interactions (Integrins, VLA-4/VCAM-1 interactions) as well as through soluble cues (CXCL12, SCF, IL-7, TGF-B). Although it is hypothesized that leukemic cells have a stage of stromal cell dependence, ${ }^{39}{ }^{40}$ blast cells are commonly found in the blood and periphery at advanced stages of disease, suggesting that part of the evolution of this malignancy is a loss of stromal cell dependence that would normally control expansion of pre-pro-B cells. Our laboratory, as well as others, have focused on the factors that influence survival of B-lineage ALL during chemotherapy with respect to the protection given by the bone marrow microenvironment ${ }^{41-45}$.

The data presented in Chapters 2 and 3 summarizes our investigation of specific aspects of Philadelphia chromosome positive ALL cells that may help them survive chemotherapy exposure more efficiently than their Ph- counterparts. In addition to having the Bcr/Abl translocation leading to high Abl kinase activity, these cells also express vascular endothelial cadherin (VE-cadherin) and high levels of $\beta$-catenin, a pro-survival protein. These cells additionally have a stem-like phenotype, expressing markers expressed in pluripotent stem cells including Oct-4, HIF-2 $\alpha$, CD133, TRA-1-61, and TRA-1-80. Stem cell properties are sustained by co-culture with BMSC contact during chemotherapy leading to the survival of these $\mathrm{Ph}+$ cells during treatment.

The existence of a cancer stem cell was first suggested in the 1960 's ${ }^{46 ; 47}$ and has been thoroughly investigated by the Weinberg, Dick, Lapidot and Weissman labs, as well as others $^{41 ; 48-55}$. Tumor initiating cells $($ TIC) or tumor stem cells have been found in both hematopoietic tumors, with the foundational work being done in AML (Acute Myeloid Leukemia) ${ }^{51 ; 56}$, and in solid tumors including breast cancer, ovarian cancer, pancreatic cancer, colon cancer, prostate cancer, hepatocellular carcinoma, melanoma, lung cancer, glioblastoma, other brain tumors, and neuroblastoma ${ }^{43 ; 48 ; 57-67}$. The initial classification of a cancer stem cell was that it could be isolated from the tumor of one animal, transferred to an 
immuno-compromised recipient animal and subsequently establish disease. This has been expanded upon to include a panel of markers that are in common with embryonic and adult hematopoietic stem cells and that slightly differ between tumor types. These makers typically consist of CD133, CD34, CD44 as well as Oct-4, BMI-1, and other markers of pluripotentcy, although in different cancers there is a slightly different stem cell profile ${ }^{68-71}$. For example, breast cancer stem cells are CD44+ and CD24- ${ }^{72}$. Leukemic stem cells tend to be lineage -, cKit ${ }^{\text {high }}$, Sca-1-, CD34+, CD38-, (AC) CD133+. John Dick's lab found that in Acute Myeloid Leukemia (AML) a CD34+ CD38- (leukemic stem cell, LSC) fraction was always able to give rise to leukemia when transplanted into immunodeficient mice and that targeting of CD44 led to a diminished ability of these cells to interact with supportive niches and evade treatmentinduced apoptosis ${ }^{51 ; 73}$. In addition to their unique phenotype, cancer stem cells from multiple tumor types are able to interact with the bone marrow microenvironment and utilize cues derived from it to evade treatment leading to both minimal residual disease as well as relapse $74 ; 75$

Although controversy remains regarding the relevance of cancer stem cell markers in murine models as well as the potential for species incompatibility, leading to cancer stem cells that are unable to engraft, it is consistent that these markers give insight on the progress of the disease and allow for in vivo therapeutic manipulation ${ }^{76 ; 77}$.

\section{Rodent models of tumor stem cells and leukemia}

In the late 1970's mouse models of ALL consisted of subcutaneous injection of primary patient cells or cell lines into nude mice which result in solid tumors that were uncharacteristic of the disease. A study in 1978 by Watanabe et al. documented the ability of ALL patient cells to grow in the hematopoietic tissues of a nude mouse ${ }^{78}$. This study, however, was done using an aneuploid T ALL originally established and maintained as an ascites tumor in nude mice; the animals died within 2 to 4 weeks and growth as an ascites does not reflect the normal course of the disease ${ }^{78}$. In 1989 Dick and colleagues revolutionized the study of ALL by creating an in 
vivo model of B-lineage ALL that progressed with the same clinco-pathology as patient disease $^{79}$. They demonstrated the ability to engraft patient samples of pre-B-lineage ALL into irradiated SCID (Severe Combined Immunodeficiency) mice through intraperitoneal or intraveneous injection.

SCID mice are homozygous for an autosomal recessive mutation on chromosome 16 resulting in disruption of the protein kinase DNA activated catalytic polypeptide $(P r k d c)$ gene loci preventing the activation of a DNA recombinase enzyme, which in turn leads to impaired immunoglobulin and T-cell receptor gene rearrangements and consistent apoptosis of $\mathrm{T}$ and $\mathrm{B}$ cells ${ }^{80 ; 81}$. These mice are therefore deficient in both humoral and cellular immunity but retain a virtually fully functional innate immune system with normal levels of tissue macrophages, natural killer (NK) cells, marginal zone B-cells, serum complement activity and myelopoiesis ${ }^{80 ; 81 .}$ Additionally, despite the immune deficiencies, the haematopoietic microenvironment of SCID, including the thymic stroma, remains intact. These properties result in the mice being unable to reject allogeneic or xenogeneic organ grafts. Unfortunately, one of the major limitations of SCID mice as hosts for xenotransplantation is due to the incomplete penetrance or 'leakiness' of the SCID mutation ${ }^{82}$. Although strain dependent, leakiness results in the spontaneous development of partial immune reactivity, with up to $90 \%$ of old (>1 year) mice exhibiting high levels of immunoglobulin and functional lymphocytic rearrangements which has the potential to interfere with graft acceptance in the host ${ }^{82}$.

Currently, the most widely used mouse model of ALL is the NOD/SCID (Non Obese Diabetic/ Severe Combined Immunodeficiency) model, which in addition to the immunological deficits of the SCID, also exhibits multiple defects in adaptive and innate immunologic function including lack of functional lymphoid cells, exhibiting little or no serum immunoglobulin with age, lack of C5 and complement activation, lack of NK cell activity and a poor macrophage secretion of IL-1 ${ }^{83 ; 84}$. This results in a functionally less mature macrophage population in comparison to the parental SCID and therefore has been proven to be the better host, with or 
without additional immune suppression, for human hematopoietic cells and leukemic blasts than SCID mice ${ }^{83 ; 85 ; 86}$

More recent studies have been done comparing, even further, the engraftment of NOD/SCID mice to their NOD/scid/b2 null (lack of MHC class I expression and decreased NKcell function) and NOD/scid/IL-2Rcnull (IL-2Rg-chain deficiency impairs the signaling through multiple cytokine receptors blocking NK development and results in additional defects in innate immunity) counterparts. Engraftment of malignant cells (primary and cell line ALL, AML and $\mathrm{CML}$ ) was measured using clinico-pathological criteria, PCR, flow cytometry and immunohistochemistry. Interestingly, the NOD/scid/IL-2Rcnull had the greatest engraftment in both cell lines and patient samples (31/39 and 15/22) followed by the NOD/scid/b2 null (19/38 and 9/28) and finally the NOD/SCID (13/38 and $7 / 25)^{87}$.

In addition to the murine models of leukemia, a 2005 paper by Bernard et al. demonstrated the ability to chemically induce leukemia in a rat model ${ }^{88}$. This paper was the first time a chemically induced model of leukemia was used, and although it isn't a widely used model, they did prove that through administration of $\mathrm{N}$-butylnitrosourea (BNU), an alkylating agent for 24 weeks that the rats would develop B lineage ALL that could be serially transplanted into healthy rats. Murine models of leukemia are currently not only being used to study the dissemination of disease but are also being utilized as models of drug efficacy in pre-clinical studies. In this context, the microenvironment warrants careful consideration as a novel therapeutic target.

\section{Therapeutic strategies for leukemia.}

Acquired resistance of tumor cells to treatment can develop over time as a result of sequential genetic changes that ultimately culminate in complex therapy-resistant phenotypes. De novo resistance occurs typically in two ways, through both physical interactions (VLA4/VCAM-1) and soluble factor interaction (CXCL12, VEGF, TGF-B) of the tumor cells and their 
surrounding microenvironment. This allows for protection of the tumor cells during chemotherapy and has been found to be especially prominent in the leukemia stem cell pool.

Studies have shown that not only can leukemia cells respond to the microenvironment as a protective force during treatment, but additionally the microenvironment supports selection of those cells inherently resistant to treatment. A study from Mishra et al. demonstrated that exogenous SDF-1 (CXCL12) in the absence of bone marrow stromal cells, or bone marrow stromal cell co-culture, resulted in selection of Imatinib-resistant Bcr/Abl P190 lymphoblasts with less dependence on Bcr/Abl tyrosine kinase activity ${ }^{89}$. This selection of resistant cells and protection has also been shown by Mudry et al. and others, who showed that physical interaction between VCAM-1 on the stromal cell and VLA-4 on the leukemic cell alone is enough to confer protection during chemotherapy ${ }^{44 ; 90 ; 91}$. Although some treatments such as AMD3100 (inhibitor of the CXCR4 receptor for the CXCL12 ligand) allow for inhibition of tumor cell interaction with the microenvironment, it also inhibits the required physical interactions that normal hematopoietic cells need for the microenvironment to promote their survival ${ }^{92 ; 93}$.

Other mechanisms that underlie leukemic cell survival during chemotherapy include alterations in leukemic cell surface molecule expression or activity. The Weissman lab has recently shown that leukemic cells express high levels of CD47, an immunoglobulin-like protein that is known to interact with integrins and thrombospondin-1, to function as an anti-phagocytic signal $^{53}$. CD47 is typically found on normal hematopoietic cells to ensure that autologous cells are not inappropriately phagocytosed. Therefore CD47 may serve as a useful therapeutic target if inappropriately up-regulated at high levels on tumor targets on which it could be more readily interrupted than on the normal hematopoietic cells.

In order to identify more efficacious therapeutic targets an in depth understanding of the biology of specific subclasses of leukemia, in our studies, or specific tumor types in general other categories of malignancies is required to allow therapeutic strategies that target from multiple angles. For example, autophagy is usually thought of as an alternative death 
mechanism distinct from apoptosis or necrosis. It is defined as is a degradative process in eukaryotic cells that results in the breakdown of intracellular material within lysosomes under homeostatic conditions or in response to stress signals, allowing cells to adapt to environmental and/or developmental signals. It is a genetically controlled process, which progresses through definite steps, leading to the engulfment of long-lived proteins and whole organelles into multimembraned vacuoles, called autophagosomes, that fuse with lysosomes for final destruction and recycling ${ }^{94}$. However, autophagy is also a process by which cells can adapt their metabolism to starvation caused by a decrease in metabolite concentrations or extracellular nutrients, a typical consequence of loss of growth factor signaling, allowing cells to evade programmed cell death ${ }^{95}$. Bellodi et al. showed that Imatinib treatment rapidly activates an autophagic process, which follows the induction of ER stress and relies on intracellular Ca2+. More importantly, inhibition of autophagy by pharmacological inhibitors potentiates Imatinibinduced cell death in CML cell lines and primary CML cells, including those carrying partially IMresistant $B C R / A B L$ mutants ${ }^{94}$. This study suggests that induction of autophagy provides a survival mechanism to IM-treated BCR/ABL-expressing cells, including the stem cell population, and that inhibition of autophagy may improve the therapeutic efficacy of Imatinib. These results were also seen by the Adachi lab with the Abl kinase inhibitor INNO-406 (NS-187), which is a specific dual Bcr-Abl/Lyn kinase inhibitor ${ }^{96}$.

Currently, dual kinase inhibitors, proteasome inhibitors, histone deactylase inhibitors $(\mathrm{HDACl})$ and aurora kinase inhibitors are becoming therapeutic options for leukemia ${ }^{12 ; 22 ; 23}$. Abl kinase inhibitors such as Imatinib (Imatinib Mesylate, Gleevec) are currently being used to treat $\mathrm{Ph}+\mathrm{ALL}$ and $\mathrm{CML}$. Do to the high level of mutations of the Abl kinase domain and resistance to therapy, new more effective single abl kinase inhibitors, as well as dual inhibitors and the use of multiple types of inhibitors together are currently being investigated ${ }^{97}$.

Dasatinib (BMS-354825, Sprycel) is a dual Src family kinase, Abl kinase inhibitor that also targets PDGFR, kit and Ephrin receptor kinases. It has been through phase I and II clinical 
trials and has been shown to be approximately 300 -fold more effective than Imatinib, potentially due to its ability to bind both the active and inactive conformation of Bcr/Abl ${ }^{98}$. Dasatinib is unable to inhibit the T315I mutation but is capable of suppressing many of the Imatinib resistant mutations. Bosutinib (SKI-606) is an inhibitor of both Src and Abl kinases but does not have the off-target PDGFR and Kit effects of Imatinib or Dasatinib ${ }^{99}$. It has been shown to be well tolerated in Phase I trials, can bind to both the active and inactive conformation of Abl, but is not effective against all Bcr/Abl mutations. Nilotinib (Tasigna, AMN107) is an Abl kinase (and other, not Src) inhibitor that has been shown to an efficacy 20 fold higher than Imatinib and more readily crosses the blood brain barrier ${ }^{100}$.

Proteasome inhibitors act to disrupt the degradation of ubiquitinated proteins with small molecule inhibitors against one or more catalytic $\beta$-subunit ${ }^{101}$. They induce cell cycle arrest and function to induce apoptosis by inhibition of NF-KB and by endoplasmic reticulum stress and subsequent generation of reactive oxygen species. Additionally, they stabilize pro-apoptotic proteins such as p53, Bax, Bik, and Bim while reducing levels of anti-apoptotic proteins such as Bcl-2 and have been shown to be more effective against leukemic cells than normal cells ${ }^{102}$. Bortezomib is currently in Phase 1 and 2 clinical trials for CML and other hematologic malignancies.

Histone deacetylases (HDAC) remove the acetyl groups from the lysine residues leading to the formation of a condensed and transcriptionally silenced chromatin ${ }^{103}$. Reversible modification of the terminal tails of core histones constitutes the major epigenetic mechanism for remodeling higher order chromatin structure and controlling gene expression. HDAC inhibitors (HDACl) block this action and can result in hyperacetylation of histones, therefore affecting gene expression ${ }^{104 ; 105}$. However, there are significant gaps regard specifically how HDI cause apoptosis of leukemic cells. HDAC inhibitors that are undergoing extensive clinical evaluation include the pan-HDAC inhibitors, such as vorinostat and panobinostat, and more selective 
inhibitors, such as R306465, romidepsin and MS-275 and are starting to be analyzed for their use in ALL.

The aurora kinases are a family of serine/threonine kinases involved in cellular processes including progression through mitosis via regulation of spindle formation, chromosome segregation and cytokenesis ${ }^{106}$. They are commonly over-expressed in leukemia and several aurora kinase inhibitors are currently in clinical trials such as VX680, MLN8054, AZD1152,R766, R763, PHA-739358. VX-680 (MK-0457) is a pan-aurora kinase inhibitor that has shown in vitro activity against wt and Bcr/ABI mutants including T3151 as well as against Imatinib and Dasatinib resistant clones. In a recent phase I/II study it was shown to be active in patients with the refractory T3151 phenotype.

All of the agents discussed will only realize their full utility when the influence of the marrow microenvironment on the leukemic target is understood well enough to delineate its effect on critical regulatory proteins in the survival or proliferative pathways that are targeted by the unique classes of drugs and inhibitors. While some of these proteins are generated by unique chromosomal translocations, others are best described as anti-apoptotic, with additional factors associated with maintenance of a stem cell phenotype that is coincident with chemoresistance. Examples of each are described in the following section in the context, predominantly, of $\mathrm{Ph}+\mathrm{ALL}$.

\section{BcrlAbl, Beta-catenin, HIF-2alpha, VE-cadherin, and Oct-4 in normal cells and leukemic cell biology}

In addition to the cytogenic changes seen in ALL (Bcr/Abl, TEL-AML, MLL etc.) alterations in protein expression as well as activity have been shown to influence both the tumor stem cell phenotype as well as survival during treatment. The proteins that will be discussed in this section are relevant to the aggressive nature of Ph+ Acute Lymphoblastic Leukemia or the stem cell phenotype and consist of Bcr/Abl, Beta-catenin, VE-cadherin, HIF-2 alpha and OCT-4. 
The Bcr/Abl fusion protein (also known as the Philadelphia Chromosome, $\mathrm{Ph}+$ ) occurs due to a reciprocal translocation of the long arms (q) of chromosomes 9 and 22 . This translocation results in a fusion protein that has 2 forms, 190 and 210, named so due to their molecular weight. The proteins have the same regions of $\mathrm{Abl}$ but differ in their regions of $\mathrm{BCR}^{107}$. The hallmark of this disease is that the $\mathrm{Bcr} / \mathrm{Abl}$ translocation results in constitutive, high levels of Abl kinase activity (regardless of 190 or 210) resulting in abnormal and promiscuous signaling cascades ${ }^{108-110}$. There is literature to suggest that the different fusion proteins (190 vs 210) have both conserved (P-CrkL, Src family members, Ras, PI3K, Erk, CyclinD2 ${ }^{111-114}$ ) and specific downstream targets (Rho, Rac and CDC42 ${ }^{115}$ ) but more studies are needed to confirm and elaborate on these findings. In addition to turning on a multitude of signaling cascades, studies have shown that Bcr/Abl can also turn off regulatory phosphatases such as Protein phosphatase-2A (PP2A) ${ }^{116}$. The PP2A activator FTY720 is currently in clinical trials and murine in vivo data suggests that it is effective against Imatinib and Dasatinib resistant $\mathrm{Ph}+\mathrm{ALL}$ and CML stem cells carrying the T1351 mutation without negative consequence to the normal CD34+ and CD34+/CD19+ bone marrow cells ${ }^{117-119}$.

The Bcr/Abl fusion gene and subsequent fusion protein is commonly seen in Chronic Myelogenous Leukemia (CML, 210) and in Acute Lymphoblastic Leukemia (mostly 190 but some 210) and in ALL is associated with poor prognosis, aggressive disease, and relapse. The frequency of the $\mathrm{Bcr} / \mathrm{Abl}$ translocation is almost $100 \%$ in $\mathrm{CML}$ and lack of this fusion protein is actually a poor prognostic indicator for CML. In ALL the fusion protein occurs in approximately $3-5 \%$ of pediatric and $25-50 \%$ of adult ALL cases. Imatinib (Imatinib Mesylate, Gleevec) is an Abl kinase inhibitor used clinically to treat $\mathrm{Ph}+\mathrm{ALL}$ and $\mathrm{CML}$. It acts by binding to ATP pocket and inhibits the activity of the Abl kinase ${ }^{120}$. Unfortunately, mutations in the Abl kinase pocket (M244V, G250E, Y253F/H, E255K/V, T315I, M351T, and F359V) ${ }^{121}$ result in resistance to this treatment and therefore combined therapies such as Dasatinib and Nilotinib (Src/Abl inhibitor and more potent Abl inhibitor, respectively) along with proteasome inhibitors, HDAC inhibitors 
and aurora kinase inhibitors, are currently in clinical trials in attempts to improve outcome and survival. While elevated Abl kinase activity has been associated with diverse impacts on tumor cells including altered cytoskeletal dynamics and proliferation in addition to altered cell survival, other types of proteins impact on tumor phenotype through predominantly regulation of antiapoptotic pathways specifically, with one that is relevant to the work being currently described being beta-catenin.

Beta-catenin is a protein that is classically known for being a transcription factor that influences, predominantly, the expression of survival proteins and can be regulated via ubiquitination and proteasomal degradation ${ }^{122 ; 123}$. It is from a family of proteins that contain 6 armadillo repeat domains which are specialized for protein binding. Beta-catenin has been shown to bind to cadherins (VE-cadherin etc.) as well as be regulated by phosphorylation for stabilization (tyrosine) or targeted for degradation (serine/threonine) in the proteasome ${ }^{124-130}$. When beta-catenin is phosphorylated at tyrosine 86 and 654 it can translocate to the nucleus to act as a transcription factor for proteins such as c-myc, cyclin D1, and survivin ${ }^{131}$. It has been shown to not only be important in the survival of $\mathrm{Ph}+$ leukemia, as well as other cancer, but has also been shown to physically interact with, and be stabilized by, the Bcr/Abl fusion protein due to phosphorylation at $\mathrm{Y} 86$ and $\mathrm{Y} 654$ residues $^{126}$. A recent publication by the Li lab has shown that Beta-catenin is essential for the survival of leukemia stem cells and that it, not resistance to Bcr/Abl, was responsible for leukemic stem cell survival during treatment ${ }^{132}$. Additionally, Betacatenin has been shown in both normal cells, such as endothelial cells, as well as cells that have undergone EMT (epithelial to mesenchymal transition) to be able to bind to the cytoplasmic tail of cadherins as well as other proteins. This binding results in stabilization of beta-catenin and allows it to act as a scaffold for other proteins to bind which initiate signaling cascades that promote both metatstasis and survival ${ }^{123 ; 129 ; 133}$.

VE-cadherin (Vascular Endothelial cadherin, aka CD144 and Cadherin 5) is one of the cadherins to which beta-catenin can bind and is a protein that our laboratory has shown to be 
important in $\mathrm{Ph}+\mathrm{ALL}$. VE-cadherin is calcium-dependent and interacts homotypically with itself through the $\mathrm{N}$-terminal five extracellular cadherin repeats to form adherens junctions between endothelial cells, regulate vascular permeability and leukocyte extravasation ${ }^{134 ; 135}$. VE-cadherin also contains a transmembrane region and a highly conserved cytoplasmic tail to which proteins such as beta-catenin, plakoglobin, p120 can bind ${ }^{134 ; 135}$. These proteins are important to the regulation of VE-cadherin and their phosphorylation status can alter the stability of VE-cadherin on the surface of endothelial cells.

The main mechanism of regulation for VE-cadherin, in endothelial cells in which it has been most thoroughly studied, is clathrin coated endocytosis, via p120, and recycling of VEcadherin back to the membrane surface ${ }^{136}$. More recent potential mechanisms of VE-cadherin regulation suggest that in response to VEGF, a Src dependent phosphorylation of the guanine exchange factor Vav2 occurs, leading to the activation of the GTPase Rac and subsequent phosphorylation of serine 665 of VE-cadherin ${ }^{137 ; 138}$. This phosphorylation results in the recruitment of $\beta$-arrestin2, thereby promoting internalization of VE-cadherin. Additionally, studies have shown that the tyrosine phosphorylation status of VE-cadherin at $y 731$, and potentially 658, can be altered by a process that required Src and the proline-rich tyrosine kinase 2 (Pyk2), and that the phosphorlyation status could further be altered by the VE-cadherin specific receptor type protein tyrosine phosphatase VE-PTP in normal endothelial cells ${ }^{139-141 .}$

An elegant study from the Cheresh lab, using $\mathrm{CHO}$ cells lacking endogenous cadherins, showed that tyrosine phosphorylation of VE-cadherin at 731 or 658 was sufficient to prevent the binding of $\mathrm{p} 120-$ and $\beta$-catenin, respectively, to the cytoplasmic tail of VE-cadherin ${ }^{142}$. Phosphorylation at either site led to the inhibition of cell barrier function and mutants of 731 or 658 that were not able to be phosphorylated resulted in enhanced cell migration and an invasive phenotype $^{142}$. Interestingly, VE-cadherin has been shown to be unexpectedly expressed in a variety of cancers such as melanoma, ewings sarcoma, breast cancer, prostate cancer and our laboratory has shown the expression, and functional significance, of VE-cadherin in $\mathrm{Ph}+\mathrm{Acute}$ 
Lymphoblastic leukemia ${ }^{41 ; 143-145}$. Studies in both endothelial cells, as well as cancer cells, have been varied on the mechanisms by which VE-cadherin surface expression is regulated. Recent studies have focused on the potential for VE-cadherin regulation at the level of transcription potentially by the hypoxia sensitive transcription factor HIF-2 alpha (Hypoxia inducible factor 2 alpha) ${ }^{146}$ which, in our model of ALL was shown to be modulated by Abl kinase activity as well as bone marrow microenvironment signals.

HIF-2 $\alpha$ is a transcription factor composed of a constitutively expressed $\beta$ subunit (HIF $\beta$, also known as aryl receptor nuclear translocator, ARNT) and an oxygen-regulated a subunit $(\mathrm{HIF \alpha})^{147}$. Both subunits are basic-helix-loop-helix $(\mathrm{bHLH})$ transcription factors and contain a Pax/Aryl hydrocarbon receptor/Sim (PAS) domain. HIF $\beta$ is not regulated by oxygen and interacts with several bHLH factors other than HIFa ${ }^{148 ; 149}$. Although there are 3 isoforms of the alpha subunit (1, 2/EPAS, and 3$)$ only 1 and 2 are commonly studied. ${ }^{150}$

The regulation of the HIF proteins occurs through both the $\mathrm{C}$ terminal oxygen dependent domain (ODD) and the $\mathrm{N}$ terminal transactivation domain. During high levels of oxygen, or normoxia, an ODD specific proline residue (p531) within the LXXLAP cores are hydroxylated and this posttranslational modification is an absolute requirement for its degradation ${ }^{150 ; 151}$. When hydroxylation occurs this proline residue is recognized by the protein $\mathrm{pVHL}$, the substrate recognition component of an E3 ubiquitin ligase complex that targets HIF for proteosomal degradation ${ }^{152-154}$. During hypoxia the alpha subunits are stabilized and HIF can translocate to the nucleus where they heterodimerize with ARNT and bind to the HRE (hypoxia responsive elements) within the HIF target genes ${ }^{155 ; 155}$. Regulation of transcription via the Nterminal transactivation domain (NTAD) occurs via hydroxylation of an asparagine residue within the NTAD that inhibits its interaction with the transcriptional co-activator p300. Interestingly, the enzymes that catalyze both of these reactions are from the family of 2oxoglutarate-dependent dioxygenase (2-ODD) which require molecular oxygen as a cosubstrate for their catalytic reactions ${ }^{156}$. The interaction between HIF and p300/CBP is also 
regulated in an oxygen-dependent manner by factor inhibiting HIF-1 (FIH-1). FIH hydroxylates asparagine residues located within the HIF-a C-terminal transactivation domain (CTAD) and prevents $\mathrm{p} 300 / \mathrm{CBP}$ binding ${ }^{155}$. Thus, full activation of HIF transcriptional activity requires both HIFa stabilization and CTAD activation.

HIF-2 $\alpha$ shares approximately $48 \%$ amino acid homology with HIF-1 but HIF-2 alpha, unlike HIF-1, is less ubiquitously expressed and is thought to be limited to cells in the CNS, lung, heart and endothelium ${ }^{149}$. Expression of HIF-2 alpha is found in hypoxic environments such as the bone marrow and within tumors and has been shown to have distinct targets ${ }^{156} 157$, compared to HIF-1, such as OCT-4, VE-cadherin, c-myc, flk-1, tie2, VEGF, CXCR4, TWIST and has been shown to regulate VE-cadherin in normoxia ${ }^{146 ; 158-162}$. In more recent literature HIF-2 alpha's mechanism of regulation in normoxia has become of interest to many groups based on studies showing that it can be expressed during normoxia and has been found at high levels in many tumor models such as colorectal, lung, melanoma, bladder and neuroblastoma ${ }^{67}{ }^{163-166}$. Murine knockout models of HIF-2 alpha lead to midgestation lethality (E9-E13.5) and defective vascular remodeling during embryonic development. Additionally, HIF-2 alpha knockout mice died from irregularities in cardiac hypertrophy, hepatic steatosis, retinopathy, lung maturation, hypocellular bone marrow and mitochondrial dysfunctions 167;168 compared to neural tube defects, lack of cephalic vascularization and cardiovascular malformations in the HIF-1 mice suggesting further the distinct target genes of these proteins ${ }^{169-171}$. Additionally, HIF-2 alpha has been shown to be critical for normal hematopoiesis and our interest in the potential stem-celllike characteristics of $\mathrm{Ph}+$ cells compelled us to look at Oct-4, which is a transcriptional target of HIF-2 alpha shown to be crucial in the maintenance of pluripotentcy ${ }^{158 ; 172}$.

OCT-4 (Octamer-4) is a transcription factor of the POU class 5 Homeobox 1 family (POU5F1) that is critically involved in stem cell renewal and pluripotentcy ${ }^{173 ; 174}$. It was originally investigated in the context of embryonic stem cells where it was found to maintain them in an undifferentiated state and since then has become associated with tumors and is a regulator of 
the tumor "stem cell" phenotype ${ }^{173}$. In embryonic stem cells a delicate balance of Oct-4 is needed as, too much can lead to differentiation into primitive endoderm and mesoderm ${ }^{175}$. In contrast, repression of Oct-4 results in failure to form the inner mass and induces loss of pluripotency and dedifferentiation to trophectoderm ${ }^{176}$. OCT-4 has been shown to be a single factor that is capable of reprogramming differentiated cells back into a stem-cell state and is thought to be responsible for treatment resistance in some tumor stem cell models ${ }^{177}$. Many of these critical proteins described up to this point were uniquely found to be co-expressed in the Ph+ ALL cells that were utilized in our some of our studies, elaborated on below.

\section{Unique phenotype of leukemia cells utilized in our model and rationale for our studies}

Seminal work from the Hendrix lab showed the unexpected expression VE-cadherin on aggressive melanoma cells and additional labs have shown the expression of VE-cadherin on other cancers such as breast and Ewing Sarcoma ${ }^{41 ; 143-145}$. This prompted our lab to investigate VE-cadherin expression, as well as stem cell marker expression, in our ALL cells that were $\mathrm{Bcr} / \mathrm{Abl}+$, or $\mathrm{Ph}+$, and $\mathrm{Ph}$ - cells. In the manuscripts listed below we show the expression of both VE-cadherin and PECAM-1 on the surface of BCR/ABL positive cells. Additionally, we show that these cells have a stem-like phenotype, expressing HIF-2 alpha as well as markers of pluripotentcy such as OCT-4, SSEA-1, TRA-1-80 etc in addition to normal B lineage markers such as CD19. The publications also show that VE-cadherin expression can be regulated by BMSC, potentially through Abl kinase activity, HIF-2 $\alpha$, and beta-catenin and that knockdown or inhibition of VE-cadherin can sensitize cells to treatment even in the presence of BMSC. The relevance of these proteins (Bcr/Abl, Beta-catenin, VE-cadherin, HIF-2 alpha and Oct-4) in normal and leukemic cells were previously discussed. 


\section{Reference List}

1. Leukemia and Lymphoma Society. 2010.

Ref Type: Internet Communication

2. Pui CH, Relling MV, Downing JR. Mechanisms of disease: Acute lymphoblastic leukemia. N.Engl.J.Med. 2004;350:1535-1548.

3. Hjalgrim LL, Westergaard T, Rostgaard K et al. Birth weight as a risk factor for childhood leukemia: a meta-analysis of 18 epidemiologic studies. Am.J.Epidemiol. 2003;158:724-735.

4. Mori $\mathrm{H}$, Colman SM, Xiao Z et al. Chromosome translocations and covert leukemic clones are generated during normal fetal development. Proc.Natl.Acad.Sci.U.S.A 2002;99:8242-8247.

5. Hong D, Gupta R, Ancliff $P$ et al. Initiating and cancer-propagating cells in TEL-AML1associated childhood leukemia. Science 2008;319:336-339.

6. Bennett M, Stroncek DF. Recent advances in the bcr-abl negative chronic myeloproliferative diseases. J.Transl.Med. 2006;4:41.

7. Biernaux C, Loos M, Sels A, Huez G, Stryckmans P. Detection of major bcr-abl gene expression at a very low level in blood cells of some healthy individuals. Blood 1995;86:31183122.

8. Biernaux C, Sels A, Huez G, Stryckmans P. Very low level of major BCR-ABL expression in blood of some healthy individuals. Bone Marrow Transplant. 1996;17 Suppl 3:S45-S47.

9. Bose S, Deininger M, Gora-Tybor J, Goldman JM, Melo JV. The presence of typical and atypical BCR-ABL fusion genes in leukocytes of normal individuals: biologic significance and implications for the assessment of minimal residual disease. Blood 1998;92:3362-3367. 
10. Butt NM, Wang L, bu-Eisha HM, Christmas SE, Clark RE. BCR-ABL-specific T cells can be detected in healthy donors and in chronic myeloid leukemia patients following allogeneic stem cell transplantation. Blood 2004;103:3245.

11. Butt NM, Rojas JM, Wang $L$ et al. Circulating bcr-abl-specific CD8+ $T$ cells in chronic myeloid leukemia patients and healthy subjects. Haematologica 2005;90:1315-1323.

12. Carroll WL, Bhojwani D, Min DJ et al. Pediatric acute lymphoblastic leukemia. Hematology Am.Soc.Hematol.Educ.Program. 2003102-131.

13. Cobaleda C, Sanchez-Garcia I. B-cell acute lymphoblastic leukaemia: towards understanding its cellular origin. Bioessays 2009;31:600-609.

14. Pui $\mathrm{CH}$, Sandlund JT, Pei D et al. Improved outcome for children with acute lymphoblastic leukemia: results of Total Therapy Study XIIIB at St Jude Children's Research Hospital. Blood 2004;104:2690-2696.

15. Pui CH. Recent advances in childhood acute lymphoblastic leukemia. J.Formos.Med.Assoc. 2004;103:85-95.

16. Silverman LB, Stevenson KE, O'Brien JE et al. Long-term results of Dana-Farber Cancer Institute ALL Consortium protocols for children with newly diagnosed acute lymphoblastic leukemia (1985-2000). Leukemia 2009

17. Pui CH. Acute lymphoblastic leukemia: introduction. Semin.Hematol. 2009;46:1-2.

18. Vrooman LM, Silverman LB. Childhood acute lymphoblastic leukemia: update on prognostic factors. Curr.Opin.Pediatr. 2009;21:1-8. 
19. Nowell p, Hungerford D. A minute chromosome in human chronic granulocytic leukemia. Science 1960;132:1497.

20. NOWELL PC, HUNGERFORD DA. Chromosome studies on normal and leukemic human leukocytes. J.Natl.Cancer Inst. 1960;25:85-109.

21. Rowley JD. Letter: A new consistent chromosomal abnormality in chronic myelogenous leukaemia identified by quinacrine fluorescence and Giemsa staining. Nature 1973;243:290293.

22. Ravandi F, Kebriaei P. Philadelphia chromosome-positive acute lymphoblastic leukemia. Hematol.Oncol.Clin.North Am. 2009;23:1043-63, vi.

23. Bhojwani D, Howard SC, Pui CH. High-risk childhood acute lymphoblastic leukemia. Clin.Lymphoma Myeloma. 2009;9 Suppl 3:S222-S230.

24. Coustan-Smith E, Gajjar A, Hijiya $\mathrm{N}$ et al. Clinical significance of minimal residual disease in childhood acute lymphoblastic leukemia after first relapse. Leukemia 2004;18:499-504.

25. Meads MB, Hazlehurst LA, Dalton WS. The bone marrow microenvironment as a tumor sanctuary and contributor to drug resistance. Clin.Cancer Res. 2008;14:2519-2526.

26. Pui $\mathrm{CH}$, Campana D, Evans WE. Childhood acute lymphoblastic leukaemia--current status and future perspectives. Lancet Oncol. 2001;2:597-607.

27. Pui $\mathrm{CH}$, Campana D. New definition of remission in childhood acute lymphoblastic leukemia. Leukemia 2000;14:783-785.

28. Pui $\mathrm{CH}$, Campana D, Pei D et al. Treating childhood acute lymphoblastic leukemia without cranial irradiation. N.Engl.J.Med. 2009;360:2730-2741. 
29. Michael Craig, MD. 2010.

Ref Type: Personal Communication

30. Campana D. Role of minimal residual disease monitoring in adult and pediatric acute lymphoblastic leukemia. Hematol.Oncol.Clin.North Am. 2009;23:1083-98, vii.

31. Campana D. Molecular determinants of treatment response in acute lymphoblastic leukemia. Hematology Am.Soc.Hematol.Educ.Program. 2008366-373.

32. Janossy G, Thomas JA, Pizzolo G. The analysis of lymphoid subpopulations in normal and malignant tissues by immunofluorescence techniques. J.Cancer Res.Clin. Oncol. 1981;101:1-11.

33. Janossy G, Bollum FJ, Bradstock KF, Ashley J. Cellular phenotypes of normal and leukemic hemopoietic cells determined by analysis with selected antibody combinations. Blood $1980 ; 56: 430-441$.

34. Campana D, Neale GA, Coustan-Smith E, Pui $\mathrm{CH}$. Detection of minimal residual disease in acute lymphoblastic leukemia: the St Jude experience. Leukemia 2001;15:278-279.

35. Campana D, Coustan-Smith E. Detection of minimal residual disease in acute leukemia by flow cytometry. Cytometry 1999;38:139-152.

36. Colmone A, Amorim M, Pontier AL et al. Leukemic cells create bone marrow niches that disrupt the behavior of normal hematopoietic progenitor cells. Science 2008;322:1861-1865.

37. Bewry NN, Nair RR, Emmons MF et al. Stat3 contributes to resistance toward BCR-ABL inhibitors in a bone marrow microenvironment model of drug resistance. Mol.Cancer Ther. 2008;7:3169-3175. 
38. Iwamoto S, Mihara K, Downing JR, Pui CH, Campana D. Mesenchymal cells regulate the response of acute lymphoblastic leukemia cells to asparaginase. J.Clin.Invest 2007;117:10491057.

39. LeBien TW. Fates of human B-cell precursors. Blood 2000;96:9-23.

40. Manabe A, Murti KG, Coustan-Smith E et al. Adhesion-dependent survival of normal and leukemic human B lymphoblasts on bone marrow stromal cells. Blood 1994;83:758-766.

41. Wang L, O'Leary H, Fortney J, Gibson LF. Ph+/VE-cadherin+ identifies a stem cell like population of acute lymphoblastic leukemia sustained by bone marrow niche cells. Blood $2007 ; 110: 3334-3344$.

42. Wang L, Fortney JE, Gibson LF. Stromal cell protection of B-lineage acute lymphoblastic leukemic cells during chemotherapy requires active Akt. Leuk.Res. 2004;28:733-742.

43. Gibson LF. Survival of B lineage leukemic cells: signals from the bone marrow microenvironment. Leuk.Lymphoma 2002;43:19-27.

44. Mudry RE, Fortney JE, York T, Hall BM, Gibson LF. Stromal cells regulate survival of Blineage leukemic cells during chemotherapy. Blood 2000;96:1926-1932.

45. Fortney JE, Zhao W, Wenger SL, Gibson LF. Bone marrow stromal cells regulate caspase 3 activity in leukemic cells during chemotherapy. Leuk.Res. 2001;25:901-907.

46. Goldberg GM, Rubenstone Al, Saphir O. A study of malignant lymphomas and leukemias. III. Stem cell, blast cell, and monocytic leukemias (with reference to their lymphogenous or myelogenous origin). Cancer 1961;14:21-29. 
47. Fiala S. The cancer cell as a stem cell unable to differentiate. A theory of carcinogenesis. Neoplasma 1968;15:607-622.

48. Mani SA, Guo W, Liao MJ et al. The epithelial-mesenchymal transition generates cells with properties of stem cells. Cell 2008;133:704-715.

49. Polyak K, Weinberg RA. Transitions between epithelial and mesenchymal states: acquisition of malignant and stem cell traits. Nat.Rev.Cancer 2009;9:265-273.

50. Dick JE, Lapidot T. Biology of normal and acute myeloid leukemia stem cells. Int.J.Hematol. 2005;82:389-396.

51. Lapidot T, Sirard C, Vormoor J et al. A cell initiating human acute myeloid leukaemia after transplantation into SCID mice. Nature 1994;367:645-648.

52. Tavor S, Petit I, Porozov S et al. CXCR4 regulates migration and development of human acute myelogenous leukemia stem cells in transplanted NOD/SCID mice. Cancer Res. 2004;64:2817-2824.

53. Jaiswal S, Jamieson $\mathrm{CH}$, Pang WW et al. CD47 is upregulated on circulating hematopoietic stem cells and leukemia cells to avoid phagocytosis. Cell 2009;138:271-285.

54. Park CY, Tseng D, Weissman IL. Cancer stem cell-directed therapies: recent data from the laboratory and clinic. Mol.Ther. 2009;17:219-230.

55. Chan KS, Espinosa I, Chao M et al. Identification, molecular characterization, clinical prognosis, and therapeutic targeting of human bladder tumor-initiating cells. Proc.Natl.Acad.Sci.U.S.A 2009;106:14016-14021. 
56. Bonnet D, Dick JE. Human acute myeloid leukemia is organized as a hierarchy that originates from a primitive hematopoietic cell. Nat.Med. 1997;3:730-737.

57. Al-Hajj M, Wicha MS, ito-Hernandez A, Morrison SJ, Clarke MF. Prospective identification of tumorigenic breast cancer cells. Proc.Natl.Acad.Sci.U.S.A 2003;100:3983-3988.

58. Li C, Heidt DG, Dalerba P et al. Identification of pancreatic cancer stem cells. Cancer Res. 2007;67:1030-1037.

59. Dalerba P, Dylla SJ, Park IK et al. Phenotypic characterization of human colorectal cancer stem cells. Proc.Natl.Acad.Sci.U.S.A 2007;104:10158-10163.

60. Ma S, Chan KW, Hu L et al. Identification and characterization of tumorigenic liver cancer stem/progenitor cells. Gastroenterology 2007;132:2542-2556.

61. Schatton T, Murphy GF, Frank NY et al. Identification of cells initiating human melanomas. Nature 2008;451:345-349.

62. Kim CF, Jackson EL, Woolfenden AE et al. Identification of bronchioalveolar stem cells in normal lung and lung cancer. Cell 2005;121:823-835.

63. Beier D, Hau P, Proescholdt M et al. CD133(+) and CD133(-) glioblastoma-derived cancer stem cells show differential growth characteristics and molecular profiles. Cancer Res. 2007;67:4010-4015.

64. Singh SK, Hawkins C, Clarke ID et al. Identification of human brain tumour initiating cells. Nature 2004;432:396-401.

65. Hirschmann-Jax C, Foster AE, Wulf GG et al. A distinct "side population" of cells with high drug efflux capacity in human tumor cells. Proc.Natl.Acad.Sci.U.S.A 2004;101:14228-14233. 
66. Clarke MF, Dick JE, Dirks PB et al. Cancer stem cells--perspectives on current status and future directions: AACR Workshop on cancer stem cells. Cancer Res. 2006;66:9339-9344.

67. Pietras A, Hansford LM, Johnsson AS et al. HIF-2alpha maintains an undifferentiated state in neural crest-like human neuroblastoma tumor-initiating cells. Proc.Natl.Acad.Sci.U.S.A 2009;106:16805-16810.

68. Monsef N, Soller M, Isaksson M, Abrahamsson PA, Panagopoulos I. The expression of pluripotency marker Oct $3 / 4$ in prostate cancer and benign prostate hyperplasia. Prostate 2009;69:909-916.

69. Ong CW, Kim LG, Kong $\mathrm{HH}$ et al. CD133 expression predicts for non-response to chemotherapy in colorectal cancer. Mod.Pathol. 2010

70. Kemper K, Sprick MR, de BM et al. The AC133 epitope, but not the CD133 protein, is lost upon cancer stem cell differentiation. Cancer Res. 2010;70:719-729.

71. Shimono Y, Zabala M, Cho RW et al. Downregulation of miRNA-200c links breast cancer stem cells with normal stem cells. Cell 2009;138:592-603.

72. Wright $\mathrm{MH}$, Calcagno AM, Salcido $\mathrm{CD}$ et al. Brca1 breast tumors contain distinct CD44+/. Breast Cancer Res. 2008;10:R10.

73. Jin L, Hope KJ, Zhai Q, Smadja-Joffe F, Dick JE. Targeting of CD44 eradicates human acute myeloid leukemic stem cells. Nat.Med. 2006;12:1167-1174.

74. Fortunato L, Mascaro A, Baldi A et al. Positive bone marrow biopsy is associated with a decreased disease-free survival in patients with operable breast cancer. Ann.Surg.Oncol. 2009;16:3010-3019. 
75. Kuroda T, Morikawa N, Matsuoka K et al. Prognostic significance of circulating tumor cells and bone marrow micrometastasis in advanced neuroblastoma. J.Pediatr.Surg. 2008;43:21822185.

76. Fillmore C, Kuperwasser C. Human breast cancer stem cell markers CD44 and CD24: enriching for cells with functional properties in mice or in man? Breast Cancer Res. 2007;9:303.

77. Krause DS, Lazarides K, von Andrian UH, Van Etten RA. Requirement for CD44 in homing and engraftment of BCR-ABL-expressing leukemic stem cells. Nat.Med. 2006;12:1175-1180.

78. Watanabe S, Shimosato $\mathrm{Y}$, Kameya $\mathrm{T}$ et al. Leukemic distribution of a human acute lymphocytic leukemia cell line (Ichikawa strain) in nude mice conditioned with whole-body irradiation. Cancer Res. 1978;38:3494-3498.

79. Kamel-Reid S, Letarte M, Sirard C et al. A model of human acute lymphoblastic leukemia in immune-deficient SCID mice. Science 1989;246:1597-1600.

80. Bosma GC, Custer RP, Bosma MJ. A severe combined immunodeficiency mutation in the mouse. Nature 1983;301:527-530.

81. McCune JM, Namikawa R, Kaneshima $\mathrm{H}$ et al. The SCID-hu mouse: murine model for the analysis of human hematolymphoid differentiation and function. Science 1988;241:1632-1639.

82. Nonoyama S, Smith FO, Bernstein ID, Ochs HD. Strain-dependent leakiness of mice with severe combined immune deficiency. J.Immunol. 1993;150:3817-3824.

83. Greiner DL, Shultz LD, Yates J et al. Improved engraftment of human spleen cells in NOD/LtSz-scid/scid mice as compared with C.B-17-scid/scid mice. Am.J.Pathol. 1995;146:888902. 
84. Shultz LD, Schweitzer PA, Christianson SW et al. Multiple defects in innate and adaptive immunologic function in NOD/LtSz-scid mice. J.Immunol. 1995;154:180-191.

85. Lock RB, Liem N, Farnsworth $\mathrm{ML}$ et al. The nonobese diabetic/severe combined immunodeficient (NOD/SCID) mouse model of childhood acute lymphoblastic leukemia reveals intrinsic differences in biologic characteristics at diagnosis and relapse. Blood 2002;99:41004108.

86. Baersch G, Mollers T, Hotte A et al. Good engraftment of B-cell precursor ALL in NOD-SCID mice. Klin.Padiatr. 1997;209:178-185.

87. Agliano A, Martin-Padura I, Mancuso P et al. Human acute leukemia cells injected in NOD/LtSz-scid/IL-2Rgamma null mice generate a faster and more efficient disease compared to other NOD/scid-related strains. Int.J.Cancer 2008;123:2222-2227.

88. Bernard N, Devevey L, Jacquemont C et al. A new model of pre-B acute lymphoblastic leukemia chemically induced in rats. Exp.Hematol. 2005;33:1130-1139.

89. Mishra S, Zhang B, Cunnick JM, Heisterkamp N, Groffen J. Resistance to imatinib of bcr/abl p190 lymphoblastic leukemia cells. Cancer Res. 2006;66:5387-5393.

90. Hall BM, Fortney JE, Taylor L et al. Stromal cells expressing elevated VCAM-1 enhance survival of B lineage tumor cells. Cancer Lett. 2004;207:229-239.

91. Matsunaga $\mathrm{T}$, Takemoto $\mathrm{N}$, Sato $\mathrm{T}$ et al. Interaction between leukemic-cell VLA-4 and stromal fibronectin is a decisive factor for minimal residual disease of acute myelogenous leukemia. Nat.Med. 2003;9:1158-1165. 
92. Broxmeyer HE, Orschell CM, Clapp DW et al. Rapid mobilization of murine and human hematopoietic stem and progenitor cells with AMD3100, a CXCR4 antagonist. J.Exp.Med. 2005;201:1307-1318.

93. Liesveld JL, Bechelli J, Rosell K et al. Effects of AMD3100 on transmigration and survival of acute myelogenous leukemia cells. Leuk.Res. 2007;31:1553-1563.

94. Bellodi C, Lidonnici MR, Hamilton A et al. Targeting autophagy potentiates tyrosine kinase inhibitor-induced cell death in Philadelphia chromosome-positive cells, including primary CML stem cells. J.Clin.Invest 2009;119:1109-1123.

95. Salomoni P, Calabretta B. Targeted therapies and autophagy: new insights from chronic myeloid leukemia. Autophagy. 2009;5:1050-1051.

96. Kamitsuji Y, Kuroda J, Kimura $S$ et al. The Bcr-Abl kinase inhibitor INNO-406 induces autophagy and different modes of cell death execution in Bcr-Abl-positive leukemias. Cell Death.Differ. 2008;15:1712-1722.

97. Grant S, Dent P. Simultaneous interruption of signal transduction and cell cycle regulatory pathways: implications for new approaches to the treatment of childhood leukemias. Curr.Drug Targets. 2007;8:751-759.

98. Porkka K, Koskenvesa P, Lundan T et al. Dasatinib crosses the blood-brain barrier and is an efficient therapy for central nervous system Philadelphia chromosome-positive leukemia. Blood 2008;112:1005-1012.

99. Boschelli DH, Wang YD, Ye F et al. Synthesis and Src kinase inhibitory activity of a series of 4-phenylamino-3-quinolinecarbonitriles. J.Med.Chem. 2001;44:822-833. 
100. Weisberg E, Manley PW, Breitenstein W et al. Characterization of AMN107, a selective inhibitor of native and mutant Bcr-Abl. Cancer Cell 2005;7:129-141.

101. Almond JB, Cohen GM. The proteasome: a novel target for cancer chemotherapy. Leukemia 2002;16:433-443.

102. An B, Goldfarb RH, Siman R, Dou QP. Novel dipeptidyl proteasome inhibitors overcome $\mathrm{Bcl}-2$ protective function and selectively accumulate the cyclin-dependent kinase inhibitor p27 and induce apoptosis in transformed, but not normal, human fibroblasts. Cell Death.Differ. 1998;5:1062-1075.

103. Peterson CL, Laniel MA. Histones and histone modifications. Curr.Biol. 2004;14:R546R551.

104. Marks PA, Miller T, Richon VM. Histone deacetylases. Curr.Opin.Pharmacol. 2003;3:344351.

105. Mitsiades CS, Mitsiades NS, McMullan CJ et al. Transcriptional signature of histone deacetylase inhibition in multiple myeloma: biological and clinical implications. Proc.Natl.Acad.Sci.U.S.A 2004;101:540-545.

106. Carvajal RD, Tse A, Schwartz GK. Aurora kinases: new targets for cancer therapy. Clin.Cancer Res. 2006;12:6869-6875.

107. Radich JP. Philadelphia chromosome-positive acute lymphocytic leukemia. Hematol.Oncol.Clin.North Am. 2001;15:21-36.

108. Hazlehurst LA, Bewry NN, Nair RR, Pinilla-Ibarz J. Signaling networks associated with BCR-ABL-dependent transformation. Cancer Control 2009;16:100-107. 
109. Jilani I, Kantarjian H, Gorre M et al. Phosphorylation levels of BCR-ABL, CrkL, AKT and STAT5 in imatinib-resistant chronic myeloid leukemia cells implicate alternative pathway usage as a survival strategy. Leuk.Res. 2008;32:643-649.

110. Alvarez RH, Kantarjian H, Cortes JE. The biology of chronic myelogenous leukemia: implications for imatinib therapy. Semin.Hematol. 2007;44:S4-14.

111. Uemura N, Salgia $\mathrm{R}$, Li JL et al. The BCR/ABL oncogene alters interaction of the adapter proteins CRKL and CRK with cellular proteins. Leukemia 1997;11:376-385.

112. Ptasznik A, Urbanowska E, Chinta $S$ et al. Crosstalk between BCR/ABL oncoprotein and CXCR4 signaling through a Src family kinase in human leukemia cells. J.Exp.Med. 2002;196:667-678.

113. Deininger MW, Vieira SA, Parada $Y$ et al. Direct relation between BCR-ABL tyrosine kinase activity and cyclin D2 expression in lymphoblasts. Cancer Res. 2001;61:8005-8013.

114. Steelman LS, Pohnert SC, Shelton JG et al. JAK/STAT, Raf/MEK/ERK, PI3K/Akt and BCR-ABL in cell cycle progression and leukemogenesis. Leukemia 2004;18:189-218.

115. Harnois T, Constantin B, Rioux A et al. Differential interaction and activation of Rho family GTPases by p210bcr-abl and p190bcr-abl. Oncogene 2003;22:6445-6454.

116. Neviani P, Santhanam R, Trotta $R$ et al. The tumor suppressor PP2A is functionally inactivated in blast crisis CML through the inhibitory activity of the BCR/ABL-regulated SET protein. Cancer Cell 2005;8:355-368.

117. Perrotti D, Neviani P. Protein phosphatase 2A (PP2A), a drugable tumor suppressor in Ph1(+) leukemias. Cancer Metastasis Rev. 2008;27:159-168. 
118. Perrotti D, Neviani P. Protein phosphatase 2A (PP2A), a drugable tumor suppressor in Ph1(+) leukemias. Cancer Metastasis Rev. 2008;27:159-168.

119. Perrotti D, Neviani P. ReSETting PP2A tumour suppressor activity in blast crisis and imatinib-resistant chronic myelogenous leukaemia. Br.J.Cancer 2006;95:775-781.

120. Druker BJ, Tamura S, Buchdunger E et al. Effects of a selective inhibitor of the Abl tyrosine kinase on the growth of Bcr-Abl positive cells. Nat.Med. 1996;2:561-566.

121. Soverini S, Colarossi S, Gnani A et al. Contribution of $A B L$ kinase domain mutations to imatinib resistance in different subsets of Philadelphia-positive patients: by the GIMEMA Working Party on Chronic Myeloid Leukemia. Clin.Cancer Res. 2006;12:7374-7379.

122. Aberle H, Bauer A, Stappert J, Kispert A, Kemler R. beta-catenin is a target for the ubiquitin-proteasome pathway. EMBO J. 1997;16:3797-3804.

123. Polakis P. The oncogenic activation of beta-catenin. Curr.Opin.Genet.Dev. 1999;9:15-21.

124. Yost C, Torres M, Miller JR et al. The axis-inducing activity, stability, and subcellular distribution of beta-catenin is regulated in Xenopus embryos by glycogen synthase kinase 3 . Genes Dev. 1996;10:1443-1454.

125. Ikeda S, Kishida S, Yamamoto $\mathrm{H}$ et al. Axin, a negative regulator of the Wnt signaling pathway, forms a complex with GSK-3beta and beta-catenin and promotes GSK-3betadependent phosphorylation of beta-catenin. EMBO J. 1998;17:1371-1384.

126. Coluccia AM, Vacca A, Dunach M et al. Bcr-Abl stabilizes beta-catenin in chronic myeloid leukemia through its tyrosine phosphorylation. EMBO J. 2007;26:1456-1466. 
127. Aberle H, Butz S, Stappert J et al. Assembly of the cadherin-catenin complex in vitro with recombinant proteins. J.Cell Sci. 1994;107 ( Pt 12):3655-3663.

128. Huber $\mathrm{AH}$, Weis WI. The structure of the beta-catenin/E-cadherin complex and the molecular basis of diverse ligand recognition by beta-catenin. Cell 2001;105:391-402.

129. Navarro P, Caveda L, Breviario F et al. Catenin-dependent and -independent functions of vascular endothelial cadherin. J.Biol.Chem. 1995;270:30965-30972.

130. Huber AH, Nelson WJ, Weis WI. Three-dimensional structure of the armadillo repeat region of beta-catenin. Cell 1997;90:871-882.

131. Piedra J, Martinez D, Castano J et al. Regulation of beta-catenin structure and activity by tyrosine phosphorylation. J.Biol.Chem. 2001;276:20436-20443.

132. Hu Y, Chen Y, Douglas L, Li S. beta-Catenin is essential for survival of leukemic stem cells insensitive to kinase inhibition in mice with BCR-ABL-induced chronic myeloid leukemia. Leukemia 2009;23:109-116.

133. Daugherty RL, Gottardi CJ. Phospho-regulation of Beta-catenin adhesion and signaling functions. Physiology.(Bethesda.) 2007;22:303-309.

134. Vincent PA, Xiao K, Buckley KM, Kowalczyk AP. VE-cadherin: adhesion at arm's length. Am.J.Physiol Cell Physiol 2004;286:C987-C997.

135. Dejana E, Bazzoni G, Lampugnani MG. Vascular endothelial (VE)-cadherin: only an intercellular glue? Exp.Cell Res. 1999;252:13-19.

136. Xiao K, Garner J, Buckley KM et al. p120-Catenin regulates clathrin-dependent endocytosis of VE-cadherin. Mol.Biol.Cell 2005;16:5141-5151. 
137. Komarova YA, Mehta D, Malik AB. Dual regulation of endothelial junctional permeability. Sci.STKE. 2007;2007:re8.

138. Gavard J, Gutkind JS. VEGF controls endothelial-cell permeability by promoting the betaarrestin-dependent endocytosis of VE-cadherin. Nat.Cell Biol. 2006;8:1223-1234.

139. Allingham MJ, van Buul JD, Burridge K. ICAM-1-mediated, Src- and Pyk2-dependent vascular endothelial cadherin tyrosine phosphorylation is required for leukocyte transendothelial migration. J.Immunol. 2007;179:4053-4064.

140. Vestweber D, Winderlich M, Cagna G, Nottebaum AF. Cell adhesion dynamics at endothelial junctions: VE-cadherin as a major player. Trends Cell Biol. 2009;19:8-15.

141. Gavard J. Breaking the VE-cadherin bonds. FEBS Lett. 2009;583:1-6.

142. Potter MD, Barbero S, Cheresh DA. Tyrosine phosphorylation of VE-cadherin prevents binding of p120- and beta-catenin and maintains the cellular mesenchymal state. J.Biol.Chem. 2005;280:31906-31912.

143. Alvero $\mathrm{AB}, \mathrm{Fu} \mathrm{HH}$, Holmberg $\mathrm{J}$ et al. Stem-like ovarian cancer cells can serve as tumor vascular progenitors. Stem Cells 2009;27:2405-2413.

144. Smith ME, Brown JI, Fisher C. Epithelioid sarcoma: presence of vascular-endothelial cadherin and lack of epithelial cadherin. Histopathology 1998;33:425-431.

145. Hendrix MJ, Seftor EA, Meltzer PS et al. Expression and functional significance of VEcadherin in aggressive human melanoma cells: role in vasculogenic mimicry. Proc.Natl.Acad.Sci.U.S.A 2001;98:8018-8023. 
146. Le BA, Lionneton F, Mattot V et al. HIF-2alpha specifically activates the VE-cadherin promoter independently of hypoxia and in synergy with Ets-1 through two essential ETS-binding sites. Oncogene 2007;26:7480-7489.

147. Reyes H, Reisz-Porszasz S, Hankinson O. Identification of the Ah receptor nuclear translocator protein (Arnt) as a component of the DNA binding form of the Ah receptor. Science 1992;256:1193-1195.

148. Wang GL, Jiang BH, Rue EA, Semenza GL. Hypoxia-inducible factor 1 is a basic-helixloop-helix-PAS heterodimer regulated by cellular $\mathrm{O} 2$ tension. Proc.Natl.Acad.Sci.U.S.A $1995 ; 92: 5510-5514$

149. Ema M, Taya S, Yokotani $\mathrm{N}$ et al. A novel bHLH-PAS factor with close sequence similarity to hypoxia-inducible factor 1alpha regulates the VEGF expression and is potentially involved in lung and vascular development. Proc.Natl.Acad.Sci.U.S.A 1997;94:4273-4278.

150. Fedele AO, Whitelaw ML, Peet DJ. Regulation of gene expression by the hypoxia-inducible factors. Mol.Interv. 2002;2:229-243.

151. Fong GH, Takeda K. Role and regulation of prolyl hydroxylase domain proteins. Cell Death.Differ. 2008;15:635-641.

152. Ivan M, Kondo K, Yang $\mathrm{H}$ et al. HIFalpha targeted for VHL-mediated destruction by proline hydroxylation: implications for O2 sensing. Science 2001;292:464-468.

153. Jaakkola P, Mole DR, Tian YM et al. Targeting of HIF-alpha to the von Hippel-Lindau ubiquitylation complex by O2-regulated prolyl hydroxylation. Science 2001;292:468-472.

154. Min JH, Yang H, Ivan M et al. Structure of an HIF-1alpha -pVHL complex: hydroxyproline recognition in signaling. Science 2002;296:1886-1889. 
155. Lisy K, Peet DJ. Turn me on: regulating HIF transcriptional activity. Cell Death.Differ. 2008;15:642-649.

156. Hu CJ, Sataur A, Wang L, Chen H, Simon MC. The N-terminal transactivation domain confers target gene specificity of hypoxia-inducible factors HIF-1alpha and HIF-2alpha. Mol.Biol.Cell 2007;18:4528-4542.

157. Hu CJ, Wang LY, Chodosh LA, Keith B, Simon MC. Differential roles of hypoxia-inducible factor 1alpha (HIF-1alpha) and HIF-2alpha in hypoxic gene regulation. Mol.Cell Biol. 2003;23:9361-9374.

158. Covello KL, Kehler J, Yu H et al. HIF-2alpha regulates Oct-4: effects of hypoxia on stem cell function, embryonic development, and tumor growth. Genes Dev. 2006;20:557-570.

159. Liu YL, Yu JM, Song XR et al. Regulation of the chemokine receptor CXCR4 and metastasis by hypoxia-inducible factor in non small cell lung cancer cell lines. Cancer Biol.Ther. 2006;5:1320-1326.

160. Gordan JD, Bertout JA, Hu CJ, Diehl JA, Simon MC. HIF-2alpha promotes hypoxic cell proliferation by enhancing c-myc transcriptional activity. Cancer Cell 2007;11:335-347.

161. Gort EH, van HG, Verlaan I et al. The TWIST1 oncogene is a direct target of hypoxiainducible factor-2alpha. Oncogene 2008;27:1501-1510.

162. Takeda N, Maemura K, Imai $\mathrm{Y}$ et al. Endothelial PAS domain protein 1 gene promotes angiogenesis through the transactivation of both vascular endothelial growth factor and its receptor, Flt-1. Circ.Res. 2004;95:146-153. 
163. Cleven AH, Wouters BG, Schutte B et al. Poorer outcome in stromal HIF-2 alpha- and CA9-positive colorectal adenocarcinomas is associated with wild-type TP53 but not with BNIP3 promoter hypermethylation or apoptosis. Br.J.Cancer 2008;99:727-733.

164. Kim WY, Perera S, Zhou B et al. HIF2alpha cooperates with RAS to promote lung tumorigenesis in mice. J.Clin.Invest 2009;119:2160-2170.

165. Giatromanolaki A, Sivridis E, Kouskoukis C et al. Hypoxia-inducible factors 1alpha and 2alpha are related to vascular endothelial growth factor expression and a poorer prognosis in nodular malignant melanomas of the skin. Melanoma Res. 2003;13:493-501.

166. Xia G, Kageyama Y, Hayashi T et al. Positive expression of HIF-2alpha/EPAS1 in invasive bladder cancer. Urology 2002;59:774-778.

167. Peng J, Zhang L, Drysdale L, Fong GH. The transcription factor EPAS-1/hypoxia-inducible factor 2alpha plays an important role in vascular remodeling. Proc.Natl.Acad.Sci.U.S.A 2000;97:8386-8391.

168. Compernolle V, Brusselmans K, Acker T et al. Loss of HIF-2alpha and inhibition of VEGF impair fetal lung maturation, whereas treatment with VEGF prevents fatal respiratory distress in premature mice. Nat.Med. 2002;8:702-710.

169. Tian H, Hammer RE, Matsumoto AM, Russell DW, McKnight SL. The hypoxia-responsive transcription factor EPAS1 is essential for catecholamine homeostasis and protection against heart failure during embryonic development. Genes Dev. 1998;12:3320-3324.

170. Iyer NV, Kotch LE, Agani F et al. Cellular and developmental control of $\mathrm{O} 2$ homeostasis by hypoxia-inducible factor 1 alpha. Genes Dev. 1998;12:149-162. 
171. Ryan HE, Lo J, Johnson RS. HIF-1 alpha is required for solid tumor formation and embryonic vascularization. EMBO J. 1998;17:3005-3015.

172. Scortegagna M, Morris MA, Oktay Y, Bennett M, Garcia JA. The HIF family member EPAS1/HIF-2alpha is required for normal hematopoiesis in mice. Blood 2003;102:1634-1640.

173. Loh $\mathrm{YH}, \mathrm{Wu} \mathrm{Q}$, Chew JL et al. The Oct4 and Nanog transcription network regulates pluripotency in mouse embryonic stem cells. Nat.Genet. 2006;38:431-440.

174. Looijenga LH, Stoop $\mathrm{H}$, de Leeuw HP et al. POU5F1 (OCT3/4) identifies cells with pluripotent potential in human germ cell tumors. Cancer Res. 2003;63:2244-2250.

175. Friel R, van der SS, Mee PJ. Embryonic stem cells: understanding their history, cell biology and signalling. Adv.Drug Deliv.Rev. 2005;57:1894-1903.

176. Hochedlinger K, Yamada Y, Beard C, Jaenisch R. Ectopic expression of Oct-4 blocks progenitor-cell differentiation and causes dysplasia in epithelial tissues. Cell 2005;121:465-477.

177. Yu J, Vodyanik MA, Smuga-Otto $\mathrm{K}$ et al. Induced pluripotent stem cell lines derived from human somatic cells. Science 2007;318:1917-1920. 


\title{
Chapter 4
}

\section{$\mathrm{Ph}^{+} / \mathrm{VE}$-cadherin ${ }^{+}$identifies a stem cell-like population of acute lymphoblastic leukemia sustained by bone marrow niche cells Lin Wang, ${ }^{1}$ Heather O'Leary, ${ }^{2}$ James Fortney, ${ }^{1}$ and Laura F. Gibson $^{1-3}$}

\author{
${ }^{1}$ Department of Pediatrics, ${ }^{2}$ Department of Microbiology and Immunology, and ${ }^{3}$ Mary Babb \\ Randolph Cancer Center, \\ West Virginia University, School of Medicine, Morgantown, WV 26506
}

"This research was originally published in Blood. Wang L, O'Leary H, Fortney J, Gibson LF. Ph+/VEcadherin+ identifies a stem cell like population of acute lymphoblastic leukemia sustained by bone marrow niche cells. Blood. 2007;110(9):3334-44. @ the American Society of Hematology." 


\begin{abstract}
:
Although leukemic stem cells (LSCs) demonstrate a symbiotic relationship with bone marrow microenvironmental niches, the mechanism by which the marrow microenvironment contributes to self-renewal and proliferation of LSCs remains elusive. In the present study, we identified a unique subpopulation of $\mathrm{Ph}+\mathrm{ALL}$ cells co-expressing markers of endothelial cells (including VE-cadherin, PECAM-1 and Flk-1) and committed B-lineage progenitors. Following long-term co-culture with bone marrow stromal cells, tumor cells formed hematopoietic colonies and cords, expressed early stem cell markers, and demonstrated endothelial sprouting. Gene expression profiles of LSCs were altered in the presence of stromal cell contact. Stromal cell contact promoted leukemic cell VE-cadherin expression, stabilized $\beta$-catenin and upregulated Bcr-abl fusion gene expression. Our study indicates that these specific tumor cells are uniquely positioned to respond to microenvironment-derived selfrenewing and proliferative cues. $\mathrm{Ph}+/ \mathrm{VE}$-cadherin+ tumor subpopulation circumvents the requirement of exogenous Wnt signaling for self-renewal through stromal cell support of leukemic cell VE-cadherin expression and upregulated Bcr-abl tyrosine kinase activity. These data suggest that strategies targeting signals in the marrow microenvironment that amplify Bcr-abl/VE-cadherin/ $\beta$-catenin axis may have utility in sensitizing drug-resistant leukemic stem cells.
\end{abstract}




\section{Introduction:}

The bone marrow microenvironment plays an important role in maintaining the quiescence and plasticity of hematopoietic stem cells (HSCs). The stem cell properties are controlled by ligandreceptor signaling and cell-cell adhesion molecules within microenvironmental niches. These anatomical sites predominantly consist of spindle-shaped, $\mathrm{N}$-cadherin positive endosteal osteoblasts at the bone surface and VE-cadherin positive sinusoidal endothelium at the thin-walled blood vessels (sinusoids). ${ }^{1,2}$ The molecular mechanisms underlying interactions between stem cells and their niche are better understood in the context of Drosophila germ stem cells and mouse bone marrow than in humans. In Drosophila ovary, the molecular hinge that anchors germ stem cells to cap cells (niche stromal cells) is E-cadherin and $\beta$-catenin. ${ }^{3}$ In the mouse model of HSC microenvironment, $\mathrm{N}$ cadherin is expressed in both quiescent HSCs and osteoblasts, and an increase in the number of $\mathrm{N}$ cadherin+ osteoblasts is correlated with an increase in N-cadherin+ HSCs. ${ }^{1,4}$

While the impact of bone marrow niches on normal hematopoietic stem/progenitor cells has been extensively investigated, less is known about how the same microenvironment influences leukemic stem cells (LSCs). Although LSCs demonstrate a symbiotic relationship with the specialized bone marrow microenvironment, ${ }^{5}$ the role of bone marrow fibroblastic stromal cells in supporting selfrenewal of acute lymphoblastic leukemia (ALL) LSCs remains largely unclear. Recent studies indicated that the canonical $W n t / \beta$-catenin signaling pathway plays a pivotal role in B-lineage hematopoietic stem/progenitor cell development. ${ }^{6}$ In addition to the destruction and transcription complexes involved in Wnt signaling pathway, $\beta$-catenin also exists in the cadherin-catenin-actin cellcell adhesion complex. ${ }^{7}$ VE-cadherin (vascular-endothelial cadherin) is one of the classic $\mathrm{Ca}^{2+}$ dependent, homophilic adhesion molecules primarily expressed in endothelial cell adherens junctions. The intracellular domain of VE-cadherin physically interacts with $p 120$ catenin, $\beta$-catenin, $\alpha$ catenin and the actin cytoskeleton. Tyrosine phosphorylation of the C-terminus of $\beta$-catenin at Tyr142, or the VE-cadherin intracellular domain at Tyr $658 / 731$ by Src family kinases, alters the binding affinity of $\beta$-catenin to VE-cadherin. ${ }^{8,9}$ 
Interplay between $\beta$-catenin and cadherin family proteins may modulate the stem cell properties of normal HSCs. Whether this interaction influences LSC maintenance and progression, and how this interaction contributes to sustained leukemic cell self-renewal warrant further investigation. We present data showing that a putative LSC subset of ALL utilizes Bcr-abl/VEcadherin/ $\beta$-catenin axis to bypass the requirement of externally stimulated $\mathrm{Wnt} / \beta$-catenin. While dependence on microenvironment cues for self-renewal is lost, the ability of leukemic cells to respond to stromal signals is maintained. Stromal cells regulate self-renewal and proliferation of this $\mathrm{Ph}+\mathrm{NE}-$ cadherin+ LSC-like subpopulation by upregulation of VE-cadherin and Bcr-abl expression. 


\section{Materials and methods:}

\section{Cells and reagents}

Ph+ ALL cell line Sup-B15 (p185 Bcr-abl+) was obtained from ATCC. Nalm27 (p210 Bcrabl+). Nalm20 and Nalm29 ALL cell lines were kindly provided by the Fujisaki Cancer Center. Control cell lines JM1, RS4;11, REH, Jurkat, HL60, K562 were also from ATCC. Ph+ OP-1 was a gift from Dr. Dario Campana (St. Judes Children's Research Hospital). Maintenance of human bone marrowderived stromal cell line PatX and murine stromal cell line S-10 (provided by Dr. Kenneth Dorshkind of the University of California) has been previously described in detail. ${ }^{10}$ To establish long-term coculture of stromal and leukemic cells, Sup-B15 and Nalm27 cells were seeded onto $70 \%$ confluent stromal cells, and maintained by subculture of a portion of Sup-B15 or Nalm27 cells onto new stromal cells weekly for more than 12 months. Bcr-abl kinase inhibitors imatinib mesylate (IM) and AG957 were obtained from Novartis (Basel, Switizerland) and Sigma (St. Louis, MO), respectively. Src kinase inhibitor PP2 and proteosome inhibitor MG132 were purchased from Calbiochem (San Diego, CA). All recombinant cytokines and growth factors were purchased from R \& D systems (Minneapolis, $\mathrm{MN})$.

\section{Plasmid constructs, lentiviral and retroviral vectors}

Human VE-cadherin (referred to as CDH5/wild type, wt), VE-cadherin lacking the C-terminal 222-nt $\beta$-catenin binding domain (referred as $\Delta$ bcat) and VE-cadherin lacking the C-terminal 449-nt cytoplasmic domain (referred to as $\Delta$ cyto) coding DNA sequences (CDSs) were amplified with highfidelity DNA polymerase $p f x$ (Invitrogen, Carlsbad, CA) from a HUVEC cDNA library and subsequently ligated into the pENTR-D/TOPO entry vector using the TOPO cloning strategy (Invitrogen). The two truncated derivates and the wt VE-cadherin pENTR entry plasmid constructs were recombined with the pLenti6.2-Dest/V5 lentiviral vector via LR recombination using the Gateway cloning technology (Invitrogen). The pLenti6.2-Dest/V5 empty vector control (referred to as vect) was generated via recombination of the destination lentiviral vector with a circularized empty pENTRD/TOPO plasmid to replace the attR1-CmR-ccdB-attR2 toxic protein from the pLenti6.2-Dest/V5 vector. 
The murine stem cell retroviral (MSCV) vectors pMigR1-210 and pMigR1-185 carrying the Bcr-abl (p210 and p185) full-length fusion gene cDNAs were kindly provided by Dr. Pendergast of Duke University. Both plasmid constructs are bicistronic with an internal ribosomal entry site (IRES) upstream of the enhanced green fluorescent protein (eGFP) coding sequence. To generate the matched empty vector control pMSCV-IRES-eGFP (pMiG), the 7.2-kb EcoRI fragment coding for p210 Bcr-abl fusion protein was released and the vector re-ligated with T4 DNA ligase.

To construct the $\beta$-catenin/Tcf reporter gene system, the synthetic sense and antisense strands of the Tcf-binding sites 1 (TBS-1) and Tcf-binding sites 2 (TBS-2) were denatured at $94^{\circ} \mathrm{C}$ and annealed at room temperature. ${ }^{11,12}$ The ds-TBS-1/2 were $3^{\prime}$ adenine-tailed with Taq DNA polymerase at $72^{\circ} \mathrm{C}$ for 15 minutes followed by in vitro phosphorylation of the $5^{\prime}-\mathrm{OH}$ ends with T4 polynucleotide kinase. The resultant double-stranded ds-TBS-1/2 were inserted into pGEM/Tesay vector (Promega, Madison, $\mathrm{WI}$ ) via T/A cloning. The TBS-1/2 inserts flanked by Xho I and Hind III sites were excised from the T/A vector and the released TBS-1/2 oligonucleotides were ligated into the Xho I-Hind III site of the multiple cloning site in phRL-null Renilla luciferase vector (Promega). To construct the Tcf optimal promoter (TOP)/ minimal thymidine kinase (mTK) chermic promoter upstream of the Renilla luciferase coding sequence, a 531-bp Bgl II-Pvu II cohesive-blunt fragment of the thymidine kinase promoter region was deleted from the phRL-TK vector (Promega) and replaced with the Bgl II-Sma I cohesive-blunt fragment containing the TBS-1/2 fragments released from the phRL-TBS-1/2.

To construct the Bcr-abl promoter reporter, the pMigR1-210 was first digested with BamH I. The resulting BamH I 5'-overhangs were fill-in blunted with Klenow. A 640-bp EcoR I-BamH I fragment (pp210S) and an approximately 1.5-kb BamH I-EcoR I fragment (pp210L), spanning the putative Bcr-abl promoter region and part of the first exon, ${ }^{13}$ was further released from the linearized pMigR1-210 and inserted directionally (for pp210S) and in reverse direction (for pp210L) into the EcoR I-Sma I site of the phRL-null Renilla luciferase vector. 
All the synthetic oligonucleotides for long and accurate-PCR (LA-PCR) amplification of relevant gene CDSs, or for construction of TOP-mTK chimeric promoters, are indicated in Table 1 (Data supplement). At the 5'-end of each forward primer, a CACC 5'-overhang was added to the primer to ensure directional ligation into pENTR-D/TOPO vector and to constitute the Kozak consensus sequence (CACCATGC/G) for efficient translational initiation. At the 3'-end of each reverse primer, the TGA/TAG stop codons were site-directedly mutated into AGA to allow downstream V5 epitope expression. For the Tcf binding sites 1 and 2, the Xho I and Hind III restriction sites are underlined, respectively.

\section{Production of lentiviral and retroviral stocks}

To generate replication-incompetent lentiviral particles carrying the $C D H 5$-wt, $\Delta$ bcat, $\Delta$ cyto and vect, the pLenti6.2-Dest/V5 vectors containing the gene CDSs described were co-transfected with pLP1 (gag/pol), pLP2 (rev) and pLP3 (VSV-G, Vesicular Stomatitis Virus-G pseudotype) plasmids (Invitrogen) into 293FT packaging cells (Invitrogen). To generate the replicationincompetent murine stem cell retroviruses expressing the p210/p185 Bcr-abl fusion protein, the pMigR1-210, pMigR1-185 or pMiG empty vector constructs were transfected into the RetroPack PT67 packing cells (BD-Clontech), in which the gag/pol, rev and the pseudotyped VSV-G envelope coding sequences have been stably integrated into the PT67 genome. For detailed protocols of collection, titration and cell infection, see data supplement.

\section{Dual-luciferase Reporter (DLR) assay}

To evaluate transactivation of the $\beta$-catenin/Tcf signaling and Bcr-abl transcription activity initiated by long-term stromal cell co-culture or enforced expression of VE-cadherin in Sup-B15 cells, cells were transiently co-transfected in triplicate with pGL4.13-CMV/Luc2 (Promega) firefly luciferase expression vector (as an internal transfection efficiency control) and the Renilla luciferase TOP1/2mTK or Bcr-abl pp210S/pp210L promoter reporter constructs. For collection, cell lysis and bioluminescence assay, see data supplement. 


\section{Knockdown of VE-cadherin expression by RNAi}

SmartPool short interfering RNAs (siRNAs) corresponding to coding sequences of VEcadherin was obtained from Dharmacon (Lafayette, CO). Transient siRNA transfection of Sup-B15 cells was completed as previously described with use of scrambled siRNA sequence controls. ${ }^{10}$

\section{Endothelial differentiation}

Evaluation of endothelial cell differentiation (i.e. sprouting) of Sup-B15 and Nalm27 cells was completed as recommended by the manufacturer (Stemcell technologies, Toronto, Canada). Briefly, LTCC Ds-Red labeled Sup-B15 or eGFP labeled Nalm27 were collected and incubated in the EndoCult liquid medium supplemented with EndoCult supplements on coverslips. 48 hours following induction of differentiation, cells were fixed in formaldehyde and analyzed by confocal microscopy.

\section{Microarray analysis}

Wnt, Notch, HSC and CSM (cell surface marker) pathway-focused microarray analyses of mRNA transcripts in Sup-B15 LTMC/LTCC were performed according to the manufacturer's instructions (SuperArray, Frederick, MD). For a brief protocol, see data supplement.

\section{In vitro poly-ubiquitination of $\beta$-catenin}

In vitro poly-ubiquitination was performed as described previously. ${ }^{14}$ Briefly, $\beta$-catenin was immunoprecipitated either from 293FT expressing eGFP-210 or eGFP alone, or from Ph+ Sup-B15 or $\mathrm{Ph}-\mathrm{REH}$ leukemic cells. The ubiquitin-protein conjugation reaction was performed at $37^{\circ} \mathrm{C}$ waterbath for 3.5 hours in a volume of $20 \mu \mathrm{L}$ containing $50 \mathrm{mM}$ HEPES, pH 7.5, 2mM DTT, $5 \mathrm{mM} \mathrm{MgCl}_{2}, 5 \mathrm{mM}$ ATP, Fraction A (including human E1 and E2 enzymes), Fraction B (containing human E3 enzyme), $10 \mu \mathrm{g}$ of recombinant ubiquitin (BostonBiochem, Boston, MA) and immunoprecipitated $\beta$-catenin in the presence of $2 \mu \mathrm{M}$ ubiquitin C-terminal hydrolase $(\mathrm{UCH})$ inhibitor ubiquitin aldehyde (Ub-ald). The reaction was terminated by the addition of $10 \mu \mathrm{L} 3 \mathrm{x}$ SDS sample buffer and boiling at $100^{\circ} \mathrm{C}$ for 5 minutes. 


\section{Confocal microscopy, immunoprecipitation, immunoblotting and flow cytometry}

All the antigen-antibody based evaluations were completed as described previously. ${ }^{10,15}$ Antibodies are described in detail in data supplement. 


\section{$\underline{\text { Results: }}$}

Identification and characterization of a leukemic stem-cell like population that expresses both endothelial and hematopoietic progenitor cell surface markers.

Both p185 (Sup-B15) and p210 (Nalm27) Bcr-abl positive ALL cells exhibit either as floating aggregates or adherent patches, distinct from $\mathrm{Ph}$ - leukemic cells during in vitro culture. Screening a panel of adhesion molecules including VCAM-1, PECAM-1, ICAM-1 and the cadherin family of proteins (data not shown) in $\mathrm{Ph}+\mathrm{ALL}$ cells revealed that Bcr-abl positive cells uniquely express VEcadherin. Leukemic cell VE-cadherin was calcium-sensitive and predominantly localized on the cell surface (Fig 1A). Pretreatment of cells with the calcium chelator EGTA diminished the VE-cadherin fluorescent signal on leukemic cells, whereas addition of $\mathrm{Ca}^{2+}$ enhanced the calcium-mediated fluorescent signals (Fig 1A). Expression of VE-cadherin is absent on Ph-negative ALL cells, while all the Ph+ ALL cell lines tested, including K562 Ph+ CML (blast crisis), express VE-cadherin (Fig 1B). RT-PCR confirmed VE-cadherin expression in Ph+ leukemic cells, but not in Ph- leukemic cells, at the mRNA level (data not shown). Immunophenotypic characterization of the $\mathrm{Ph}+/ \mathrm{VE}$-cadherin+ subset of ALL cells indicated that hematopoietic stem/progenitor cell surface markers CD34, CD38 and c-kit, mature B-cell lymphoid markers CD19, CD45, and the endothelial antigens Flk-1, PECAM-1 and VE-cadherin are co-expressed on Sup-B15 cell surface (Fig 1C). Approximately 12\% of Sup-B15 cells also expressed the early endothelial marker CD133 (Fig 1C). Thus, Ph+/VE-cadherin+ identifies a unique subpopulation of ALL cells distinctive from Ph-negative ALL cell population.

$\mathrm{Ph}+/ \mathrm{VE}-\mathrm{cadherin+}$ leukemic cells form hematopoietic colonies/cords on bone marrow niche stromal cells and differentiate into endothelial cells in vitro.

Long-term co-culture (LTCC) of Sup-B15 or Nalm27 leukemic cells on either S10 or PatX stromal cells supported the formation of hematopoietic colonies ("hemospheres", Fig 2A), resembling neurospheres generated by neural stem cells or mamospheres formed by breast cancer stem cells. $^{16,17}$ Hemospheres formed on stromal cells morphologically resembled both type I (compact colony, Fig 2A upper right) and type II (colony with a dense center surrounded by migrating cells, Fig 2A lower right) but not type III (diffuse colonies of mobile differentiating cells) as characterized 
previously. ${ }^{18,19}$ However, unlike cancer stem cell colonies derived from solid tumors, formation of hemospheres from $\mathrm{Ph}+/ \mathrm{VE}$-cadherin+ leukemic cells are stromal-cell dependent, with hemospheres only initiated in physical association with a monolayer of VCAM-1-positive stromal cells. Of all the ALL cell lines tested, only the $\mathrm{Ph}+$ subset was capable of hemosphere formation, whereas $\mathrm{Ph}-\mathrm{ALL}$ cell lines did not form hemospheres during LTCC for up to 6 months (data not shown). Moreover, hemospheres are resistant to EDTA-free trypsin digestion during regular subculture, while leukemic cell aggregates in long-term medium culture (LTMC) can be disrupted by mechanic vibration.

Formation of flame-like, finger-shaped hematopoietic cords from Ph+/VE-cadherin+ LTCC on both human and murine stromal cells follows formation and growth of hemospheres (Fig 2B, supplementary video clips 1-6). Hematopoietic cords were characterized by a bamboo shoot-like structure comprised of distinct cellular constituents localized to the peripheral or central regions (Fig 2B). In a typical hematopoietic cord, the inner column is comprised of CD133+VE-cadherin+ cells with the periphery of the cord constituted by more differentiated CD133-VE-cadherin+ leukemic cells (Fig 2B, supplementary video clip 3\&4). To further examine the stem-cell potential of the leukemic cells that comprised the hemospheres and hematopoietic cords, we stained the hemosphere and hematopoietic cord cells with early stem cell (ESC) markers (Fig 2C \& 2D). Confocal microscopy revealed distinct expression and distribution patterns of ESC markers. Oct-4 was uniquely expressed in the peripheral region of the hemospheres (Fig 2D), while SSEA-1, SSEA-3, SSEA-4, Tra-1-61 and Tra-1-80 positive cells were limited to the central region (Fig 2C). Migratory leukemic cells surrounding the hemospheres were negative for ESC marker staining (Fig 2C \& 2D).

When LTCC Ph+/VE-cadherin+ cells were incubated in EndoCult, we observed endothelial sprouting of Ph+VE-cadherin+ Sup-B15 or Nalm 27 cells (Fig 2E). Many Ph+VE-cadherin+ LTCC cells differentiated from round, floating cells to spindle-shaped, adherent cells within 2 days (Fig 2E). Thus, deprivation of stromal cell support in the presence of endothelial-trophic growth factors leads to a rapid endothelial switch of $\mathrm{Ph}+\mathrm{NE}$-cadherin+ cells following long-term stromal cell contact. 


\section{LTCC with bone marrow stromal cells promotes self-renewal activity of $\mathrm{Ph}+/ \mathrm{VE}-$ cadherin+ leukemic cells independent of the Wnt/ß-catenin signaling pathway.}

To investigate the signaling pathway(s) potentially involved in the stem-cell like phenotypes of Ph+/VE-cadherin+ ALL cells following LTCC with stromal cells, pathway-focused microarrays were completed to compare the gene expression profiles in LTMC and LTCC Sup-B15. Sup-B15 genes involved in the $\mathrm{Wnt} / \mathrm{\beta}$-catenin signaling pathway respond to $\mathrm{S} 10$ or PatX stromal cell signals differentially (Fig 3 \& Table 2, data supplement). Tcf/ß-catenin target genes, including Cyclin D1 (CCND1), Cyclin D3 (CCND3) and c-Myc (MYC), were increased by 2-2.5 fold, 2-2.5 fold and 3-3.5 fold following LTCC, respectively. The $\beta$-catenin transcriptional co-activator Bcl-9 (BCL9) was upregulated 1.5-2 fold while its transcriptional co-repressor Tcf (TCF7) and the Wnt inhibitory factor 1 (WIF1) were down-regulated 2 and 1.5 fold, respectively. However, expression of the intracellular signaling mediator $\beta$-catenin (CTNNB1) and $\beta$-catenin binding protein 1 (CTNNB1P1) remained unchanged. Further, the leukemic cell autocrine Wnts, including Wnt1, Wnt2 and Wnt3A, were downregulated by $2-2.3$ fold in LTCC Sup-B15 as compared to those of LTMC Sup-B15, which were coincident with down-regulation of the Wnt co-receptor Frizzled (FZD3, 1.5-fold) and the secretory Wnt precursor-processing protein (PORCN, 2-fold). Thus, Wnt signaling cascades downstream of ligand/receptor occupancy were aberrantly intercepted and reinforced while the extracellular component of the signaling pathway was attenuated or disabled in $\mathrm{Ph}+/ \mathrm{VE}-$ cadherin+ $\mathrm{ALL}$ cells during LTCC.

Stromal cells up-regulate VE-cadherin expression and stabilize $\beta$-catenin in Ph+/VE-cadherin+ cells.

The convergence of $\beta$-catenin in cadherin-catenin mediated cell-cell adhesion and morphogenesis, and as an intracellular mediator of the canonical Wnt signaling pathway, prompted us to hypothesize that VE-cadherin expression may contribute to self-renewal and proliferation of $\mathrm{Ph}+/ \mathrm{VE}$-cadherin+ cells. Following LTCC of Sup-B15 with both murine and human marrow stromal cells, VE-cadherin expression was upregulated, coincident with elevated Src expression and $\beta$ catenin accumulation (Fig 4A). Screening a panel of stromal cell soluble growth factors and cytokines 
showed that TGF- $\beta 1$, bFGF and VEGF stimulated VE-cadherin expression on Sup-B15 cells by 2.0, 1.5 and 1.8 fold, respectively (Fig 4B). To determine whether upregulated VE-cadherin contributes to stabilizing $\beta$-catenin in Ph+/VE-cadherin+ ALL cells, reciprocal co-immunoprecipitaton revealed that the amount of $\beta$-catenin complexed with VE-cadherin in tumor cells derived from either S10 or PatX LTCC were 2-3.5 fold higher than those from LTMC alone (Fig 4C). Because microarray data indicated that $\beta$-catenin expression is not influenced by stromal cell contact (Fig 3), we hypothesized that upregulated VE-cadherin plays a major role in sequestering and stabilizing $\beta$-catenin in Ph+/VEcadherin+ cells. T

To investigate this possibility, lentiviral transduction of Sup-B15 and 293FT cells with vectors carrying the wild type and two mutant forms of VE-cadherin, $\Delta$ bcat and $\Delta$ cyto, were established (Fig 4D). Expression of the wt VE-cadherin, but not VE-cadherin lacking either the cytoplasmic or $\beta$ catenin binding domains, led to approximately 4 fold more $\beta$-catenin accumulation in both 293FT (Figure 4D, upper) and Sup-B15 (Fig 4D, lower) cells. Thus, stabilization of $\beta$-catenin in the presence of VE-cadherin may be a common molecular event in non-endothelial cells. To further investigate the relationship between VE-cadherin and $\beta$-catenin in $\mathrm{Ph}+/ \mathrm{VE}$-cadherin+ leukemic cells, VE-cadherin siRNA or scrambled control dsRNA was transiently transfected into Sup-B15 cells. Knockdown of VEcadherin expression in Sup-B15 cells resulted in diminished $\beta$-catenin in a time- (Fig 4E, upper) and concentration-dependent manner (Fig 4E, lower). Therefore, bone marrow niche stromal cells may modulate $\mathrm{Ph}+\mathrm{VE}$-cadherin+ leukemic cell self-renewal activity, at least in part, by influencing VEcadherin expression and subsequent $\beta$-catenin stabilization.

$\beta$-catenin is constitutively activated in leukemic stem-like cells that over-express VE-cadherin during LTCC.

To examine the $\beta$-catenin/Tcf transcriptional activity, Sup-B15 LTMC or LTCC cells were transiently co-transfected with phRL-TOP1 or phRL-TOP2 (Renilla luciferase) with an internal control plasmid, pGL4.13-CMV-Luc2 (firefly luciferase). Stromal cell contact resulted in a 5 to 13 fold increase in relative luciferase activity in LTCC (Fig 5A). Moreover, enforced expression of the wt, but not $\Delta$ bcat and $\Delta$ cyto VE-cadherin, significantly promoted $\beta$-catenin/Tcf transcriptional activity in Sup- 
B15 cells (Fig 5B). In contrast, depletion of VE-cadherin expression by siRNA resulted in an unexpected, transient elevation of $\beta$-catenin activity during the first 8 hours after transfection, followed by a persistent declining in relative luciferase activities in a time- (Fig 5C, upper) and siRNA concentration-dependent manner (Fig 5C, lower). One interpretation of this interesting phenomenon is that the initial reduction of the docking protein VE-cadherin releases $\beta$-catenin capable of driving luciferase reporter expression due to the release of excessive, free $\beta$-catenin that cannot be efficiently targeted for proteosome mediated degradation. However, long-term reduction of VE-cadherin may diminish its capability to protect $\beta$-catenin from targeted ubiquitination and degradation that is typically achieved through physical interaction. Stromal cell signals also altered the intracellular distribution of $\beta$-catenin in $\mathrm{Ph}+/ \mathrm{VE}$-cadherin+ cells. Translocation of $\beta$-catenin from the cytoplasm to the nucleus in Sup-B15 cells was sporadically observed in actively dividing cells in LTMC (Fig 5D), however, longterm co-culture of Sup-B15 cells consistently promoted nuclear translocation of $\beta$-catenin in most of the leukemic cells on hematopoietic cords (Fig 5D).

\section{Bcr-abl fusion protein is essential for maintaining the VE-cadherin/ $\beta$-catenin axis in the} leukemic stem-like cells.

In 293FT cells transduced with various forms of VE-cadherin expressing lentiviral vectors, forced wild type VE-cadherin stabilized $\beta$-catenin as compared to vector control, $\Delta$ bcat or $\Delta$ cyto VEcadherin (Fig 4D, upper). However, the $\beta$-catenin/Tcf transcriptional activity did not dramatically change following transduction of vect, $\Delta$ bcat, $\Delta$ cyto or even wt VE-cadherin in 293FT cells (data not shown). Therefore, VE-cadherin expression alone is likely necessary, but not sufficient, to maintain enhanced $\beta$-catenin activity in VE-cadherin+ leukemic cells. We hypothesized that Bcr-abl fusion

protein, with constitutive tyrosine kinase activity, may synergize with VE-cadherin expression to contribute to the unique phenomenon of leukemic cell self-renewal and proliferation. To test this, we examined alteration of Bcr-abl protein expression in LTMC and LTCC leukemic cells and observed that stromal cell contact upregulated both Abl and Bcr-abl protein expression by $1.5-2$ fold (Fig 6A, upper). To confirm the observation at the transcriptional level, the Bcr-abl fusion gene promoter region was cloned into the phRL-null luciferase reporter vector. The relative luciferase activity was 
upregulated 2- to 4-fold in Sup-B15 LTCC with S10 or PatX as assayed by the pp210S, but not the pp210L reporter (Fig 6A, lower). To further investigate the role of the Bcr-abl fusion protein, Sup-B15 cells were infected with retroviruses carrying either the p185 or p210 Bcr-abl full-length cDNA. Retroviral transduction of both p185 and p210 Bcr-abl resulted in forced expression of p185 or p210 protein in Sup-B15 cells (Fig 6B, upper). In Sup-B15 cells over-expressing the p185-eGFP or p210eGFP proteins, upregulation of VE-cadherin was also detected as above the parental baseline (Fig $6 \mathrm{~B}$, lower). Consistent with upregulated VE-cadherin expression, $\beta$-catenin/Tcf activity was also increased 7 - to 14 fold in p185-eGFP and p210-eGFP expressing cells, as compared to eGFP expression alone (Fig 6C). In contrast, inhibition of Bcr-abl activity with the tyrosine kinase inhibitors imatinib mesylate (IM) or AG957 down-regulated VE-cadherin expression in a concentrationdependent fashion in Sup-B15 cells, coincident with $\beta$-catenin cleavage (Fig 6D). In contrast, treatment of $\mathrm{Ph}+\mathrm{NE}$-cadherin+ leukemic cells with the proteosome inhibitor MG132 diminished imatinib-induced cleavage of $\beta$-catenin in both Sup-B15 and Nalm27 cells (Fig 6E).

Tyrosine phosphorylation of $\beta$-catenin mediated by Bcr-abl kinase diminishes its ubiquitination-proteosome dependent degradation.

To dissect the signaling pathway by which constitutive Bcr-abl kinase activity maintains higher VE-cadherin/ $\beta$-catenin in $\mathrm{Ph}+/ \mathrm{VE}$-cadherin+ ALL cells, Ph-/VE-cadherin- 293FT cells were cotransduced with lentiviruses encoding VE-cadherin and retroviruses encoding p210 Bcr-abl fusion protein. VE-cadherin/p210 dual transduction resulted in the most pronounced stabilization of $\beta$ catenin in 293FT cells as compared to VE-cadherin transduction alone (Fig 7A). Immuoprecipitation of $\beta$-catenin from the same samples indicated that $\beta$-catenin and Src co-existed in the same immunocomplexes and $\beta$-catenin was tyrosine-phosphorylated following transduction with p210 Bcrabl kinase (Fig 7B). This was consistent with the most pronounced $\beta$-catenin transcriptional activity being detected in p210 and VE-cadherin co-transduced cells (Fig 7C). Inhibition of Src activity with PP2, or Bcr-abl with imatinib, was correlated with modest reduction of $\beta$-catenin recognized by a monoclonal antibody specific for its active form. The combinatory inhibition of Src and Bcr-abl kinase activity was associated with a further reduction in $\beta$-catenin (Fig 7D). VE-cadherin was 
immunoprecipitated from the same panel. While expression of Bcr-abl protein resulted in a number of tyrosine phosphorylated proteins, VE-cadherin appeared not to be affected by this constitutively active kinase (Fig 7E). To investigate whether tyrosine phosphorylated $\beta$-catenin is more stable or resistant to the ubiquitin-proteosome mediated protein degradation pathway, $\beta$-catenin that was immunoprecipitated from $\mathrm{Ph}+/$ - leukemia or 293FT expressing eGFP-p210/eGFP was subjected to an in vitro ubiquitination and degradation assay. In the presence of endogenous $(\mathrm{Ph}+)$ or exogenously expressed Bcr-abl (eGFP-Bcr-abl), $\beta$-catenin had less mono-, poly-ubiquitination and degraded fractions. This effect was demonstrated by comparison of Ph+ Sup-B15 or 293FT/eGFP-p210 to PhREH or 293FT/eGFP cells (Figure 7F).

Thus, consistent with the recent reports that Bcr-abl fusion protein promotes Src activation and that Bcr-abl mediates tyrosine phosphorylation and subsequent stabilization of $\beta$-catenin in $\mathrm{Ph}+$ ALL cells, ${ }^{20,21}$ our data indicated that upregulated Bcr-abl fusion protein contributes to constitutively active $\beta$-catenin activity by promoting VE-cadherin expression (physical stabilization) and subsequently converting VE-cadherin-stabilized $\beta$-catenin to the active form through Src-mediated tyrosine phosphorylation (functional stabilization). These data also suggest that tyrosine phosphorylation and serine/threonine phosphorylation may differentially influence the fate of $\beta$-catenin by affecting its subsequent ubiquitination. 


\section{Discussion:}

As compared to the LSC model of AML, the origin of ALL LSCs is less well characterized. Recent studies indicated that primitive HSCs were the target for ALL LSC transformation. ${ }^{22-24}$ In contrast, Castor and colleagues demonstrated that different genetic alterations may target different stages of hematopoiesis in ALL. ${ }^{25}$ The p210 Bcr-abl targeted primitive HSCs, whereas p185 and TELAML1 can transform CD34+CD19+ B-cell progenitors, ${ }^{25}$ raising the question whether LSCs for $\mathrm{Ph}+$ ALL may also derive from committed B-cell progenitors.

Our data support the hypothesis that LSCs of B-cell Ph+ ALL can originate from committed progenitor cells. In the current study, we identified a CD34+CD38+CD19+ Ph+-ALL subpopulation with leukemic stem-cell like properties (Fig 1 \& Fig 2). Formation of hematopoietic colonies (hemospheres) and cords, induction of endothelial sprouting and reactivation of early stem cell genes in this CD34+CD38+CD19+ subset during LTCC are consistent with a leukemic stem cell phenotype (Fig 2). Expression of a panel of endothelial cell surface markers, including VE-cadherin, does not necessarily imply hemangioblast origin. Rather it may represent one of the biological consequences of Bcr-abl expression in this unique setting (Fig 6). In agreement with this possibility, a recent report showed that Bcr-abl fusion transcripts can be detected in endothelial cells derived from transplanted bone marrow cells from a CML patient. ${ }^{26}$ This in vivo observation, together with our in vitro induction of endothelial differentiation of Ph+/VE-cadherin+ ALL cells (Fig 2), supports the conclusion that Bcrabl alone may promote VE-cadherin expression (Fig 6) and contribute to vascular endothelium potential. ${ }^{26}$ Intriguingly, normal myeloid progenitors can also differentiate into endothelial cells, ${ }^{27}$ further supporting the notion that determination of endothelial fate is not restricted to the hemangioblast or HSC stage, but rather reflects the close developmental relationship between the hematopoietic and vascular systems.

VE-cadherin expression in non-endothelial cells has been identified and characterized in two additional cell types to date. Increased VE-cadherin expression on cytotrophoblast stem cells was required for normal placentation and successful endovascular invasion. ${ }^{28}$ In addition, VE-cadherin was expressed in highly aggressive melanoma, and contributed to vascular mimicry. ${ }^{29}$ Notable are 
the observations that gestational trophoblastic neoplasia and aggressive melanoma are highly metastatic with frequent central nervous system involvement. ${ }^{30,31}$ It is also widely recognized that, as compared to acute non-lymphoblastic leukemia, non-Hodgkin's lymphoma or Hodgkin's lymphoma, ALL is clinically manifested with a much higher frequency of CNS involvement. Because nonendothelial cells with VE-cadherin expression identified so far share a common clinical feature, CNS involvement, it is tempting to speculate that VE-cadherin expression plays an important role in mediating invasion of $\mathrm{Ph}+\mathrm{NE}$-cadherin+ ALL cells into the CNS.

Identification of the importance of the Bcr-abl/VE-cadherin/ $\beta$-catenin axis, and lack of reliance upon Wnt initiated signals, indicates that this subset of tumor cells can circumvent the requirement of exogenous Wnts for sustained self-renewal activity (Fig 4 \& Fig 5). This self-renewal autonomy is sustained by stabilized $\beta$-catenin in the presence of VE-cadherin expression (Fig 4) coincident with high Bcr-Abl kinase activity. Thus, these Ph+/VE-cadherin+ cells can bypass the de novo signaling cascade initialized by Wnt ligands for self-renewal and proliferation. Therefore, our data characterize a novel model in which the molecular basis underlying the self-renewal autonomy of Ph+ ALL LSCs can be further investigated.

While Wnt/ß-catenin mediated self-renewal is similar in many tumor models, the epigenetic and genetic alterations imposed on the tumor by the microenvironment are diverse. Self-renewal autonomy conferred by intrinsically active $\beta$-catenin reflects one of the differences between normal hematopoietic stem cells and leukemic stem cells, since normal stem cells exquisitely rely on selfrenewal signals from supportive niches, ${ }^{32}$ whereas cancer stem cells can somewhat escape this dependency. However, a lack of reliance by tumor cells on niche-derived signals does not indicate a loss of ability to respond to these important microenvironmental cues. In our model, bone marrow stromal cells modulate the $\beta$-catenin mediated self-renewal capacity by up-regulating VE-cadherin and Bcr-abl expression (Fig 4 \& Fig 6). This observation is consistent with a recent report that upregulation of Bcr-abl transcripts, followed by nuclear translocation of $\beta$-catenin, plays an important role during LSC transformation to CML blast crisis. ${ }^{33}$ Co-expression of VE-cadherin and Bcr-abl are unique to the subset of putative LSCs utilized in this model, with our data suggesting that 
microenvironmental factors remain influential in augmenting the self-renewal potential of specific LSCs.

In addition, recent studies indicated that conditional expression of constitutively active $\beta$ catenin in knock-in mice led to the exhaustion of the long-term hematopoietic stem cell pool and loss of stem-cell repopulating activity. ${ }^{34,35}$ This raised the question whether constitutively active $\beta$-catenin also impairs the plasticity of leukemic stem cells. Although $\beta$-catenin is constitutively active in LTCC $\mathrm{Ph}+\mathrm{VE}$-cadherin+ cells, in the presence of stromal cells, many early stem cell genes were reactivated in $\mathrm{Ph}+\mathrm{ALL}$ leukemic cells physically located in hemospheres (Fig 2). These early stem cell markers were previously shown to be expressed in primitive embryonic stem cells, and serve as indicators of quiescence and pluripotency of embryonic stem cells. ${ }^{36}$ The observation that tumor cells expressed early stem cell markers in a very specific anatomical configuration, with hemosphere structure initiation supported by physical attachment to bone marrow stromal cells, was striking. This observation suggests that stromal cell dependency distinguishes primitive leukemic stem cells from more differentiated progeny leukemic cells. Further, our data also suggest that leukemic cells in longterm co-culture with stroma are highly heterogeneous, and in vitro LTCC may partially mimic the hierarchical differentiation of the hematopoietic stem/progenitor cells in the bone marrow microenvironment.

The concept of "re-programming" differentiated cells to a stem cell-like phenotype has been addressed by several groups, including a recent report that the combination of four transcriptional factors, Oct-3/4, Sox2, c-myc and klf4, can reprogram terminally differentiated mouse fibroblasts into pluripotent embryonic stem cells. ${ }^{37}$ Our data suggest that $\mathrm{Ph}+/ \mathrm{VE}-$-cadherin+ $\mathrm{ALL}$ cell gene expression profiles may be uniquely modified by stromal cells, and support the hypothesis that formation of hemospheres with distinct stem cell marker expression may reflect an attempt by bone marrow stromal cells to balance the proliferating pool with the primitive, quiescent pool of LSCs. Therefore, unlike their normal hematopoietic counterparts, ${ }^{34,35}$ the LSC subpopulation of Ph+VEcadherin+ ALL cells may not be exhausted even if constitutively active $\beta$-catenin is driving cell cycle entry, due to stromal cell conversion of a pool of LSCs to a quiescent state. Thus, self-renewal 
autonomy and stromal cell dependence of Ph+VE-cadherin+ ALL cells may be integrated in a way that positions them to contribute to relapse of disease through characteristics they share with normal HSCs. 


\section{Acknowledgements:}

The authors are grateful to Dr. Brett Hall of Ohio State University for kindly providing Ds-Red labeled Sup-B15 cells and to the additional investigators noted in the text for providing valuable cell lines and constructs. This work was supported by NIH grant R01 HL056888 (LFG), and NCRR16440 (LFG). The authors declare no competing financial interests.

Author contributions: L.W. and L.F.G., designed research; L.W., H.O.L. and J.F., performed research; L.W. and H.O.L., analyzed data; L.W. and L.F.G., prepared the manuscript. 


\section{References:}

1. Zhang J, Niu C, Ye L et al. Identification of the haematopoietic stem cell niche and control of the niche size. Nature 2003;425:836-841.

2. Kiel MJ, Yilmaz OH, Iwashita T et al. SLAM family receptors distinguish hematopoietic stem and progenitor cells and reveal endothelial niches for stem cells. Cell 2005;121:1109-1121.

3. Spradling A, Drummond-Barbosa D, Kai T. Stem cells find their niche. Nature 2001;414:98-104.

4. Arai F, Hirao A, Ohmura M et al. Tie2/angiopoietin-1 signaling regulates hematopoietic stem cell quiescence in the bone marrow niche. Cell 2004;118:149-161.

5. Li L, Neaves WB. Normal stem cells and cancer stem cells: the niche matters. Cancer Res. 2006;66:4553-4557.

6. Reya T, Clevers H. Wnt signalling in stem cells and cancer. Nature 2005;434:843-850.

7. Nelson WJ, Nusse R. Convergence of Wnt, beta-catenin, and cadherin pathways. Science 2004;303:1483-1487.

8. Piedra J, Miravet S, Castano J et al. p120 Catenin-associated Fer and Fyn tyrosine kinases regulate beta-catenin Tyr-142 phosphorylation and beta-catenin-alpha-catenin Interaction. Mol.Cell Biol. 2003;23:2287-2297.

9. Potter MD, Barbero S, Cheresh DA. Tyrosine phosphorylation of VE-cadherin prevents binding of $\mathrm{p} 120$ - and beta-catenin and maintains the cellular mesenchymal state. J.Biol.Chem. 2005;280:31906-31912.

10. Wang L, Clutter S, Benincosa J, Fortney J, Gibson LF. Activation of transforming growth factor-beta1/p38/Smad3 signaling in stromal cells requires reactive oxygen species-mediated MMP-2 activity during bone marrow damage. Stem Cells 2005;23:1122-1134.

11. Maupas-Schwalm F, Robinet $\mathrm{C}$, Auge $\mathrm{N}$ et al. Activation of the $\{$ beta\}-catenin/T-cellspecific transcription factor/lymphoid enhancer factor-1 pathway by plasminogen activators in ECV304 carcinoma cells. Cancer Res. 2005;65:526-532. 
12. Ishitani T, Ninomiya-Tsuji J, Nagai $S$ et al. The TAK1-NLK-MAPK-related pathway antagonizes signalling between beta-catenin and transcription factor TCF. Nature 1999;399:798-802.

13. Mes-Masson AM, McLaughlin J, Daley GQ, Paskind M, Witte ON. Overlapping cDNA clones define the complete coding region for the P210c-abl gene product associated with chronic myelogenous leukemia cells containing the Philadelphia chromosome. Proc.Natl.Acad.Sci.U.S.A 1986;83:9768-9772.

14. Trotman LC, Wang X, Alimonti A, et al. Ubiquitination regulates PTEN nuclear import and tumor suppression. Cell. 2007;128(1):141-56.

15. Wang L, Chen L, Benincosa J, Fortney J, Gibson LF. VEGF-induced phosphorylation of Bcl-2 influences B lineage leukemic cell response to apoptotic stimuli. Leukemia 2005;19:344-353.

16. Vescovi AL, Galli R, Reynolds BA. Brain tumour stem cells. Nat.Rev.Cancer 2006;6:425-436.

17. Ponti D, Costa $\mathrm{A}$, Zaffaroni $\mathrm{N}$ et al. Isolation and in vitro propagation of tumorigenic breast cancer cells with stem/progenitor cell properties. Cancer Res. 2005;65:5506-5511.

18. Lavau C, Szilvassy SJ, Slany R, Cleary ML. Immortalization and leukemic transformation of a myelomonocytic precursor by retrovirally transduced HRX-ENL. EMBO J. 1997;16:4226-4237.

19. Somervaille TC, Cleary ML. Identification and characterization of leukemia stem cells in murine MLL-AF9 acute myeloid leukemia. Cancer Cell 2006;10:257-268.

20. Hu Y, Swerdlow S, Duffy TM, Weinmann R, Lee FY, Li S. Targeting multiple kinase pathways in leukemic progenitors and stem cells is essential for improved treatment of $\mathrm{Ph}+$ leukemia in mice. Proc Natl Acad Sci U S A. 2006;103:16870-5.

21. Coluccia AM, Vacca A, Dunach $M$, et al. Bcr-Abl stabilizes beta-catenin in chronic myeloid leukemia through its tyrosine phosphorylation. EMBO J. 2007;26 :1456-66.

22. Cobaleda C, Gutierrez-Cianca N, Perez-Losada J et al. A primitive hematopoietic cell is the target for the leukemic transformation in human philadelphia-positive acute lymphoblastic leukemia. Blood 2000;95:1007-1013. 
23. Cox CV, Evely RS, Oakhill A et al. Characterization of acute lymphoblastic leukemia progenitor cells. Blood 2004;104:2919-2925.

24. Hotfilder M, Rottgers S, Rosemann A et al. Leukemic stem cells in childhood high-risk $\operatorname{ALL} / \mathrm{t}(9 ; 22)$ and $\mathrm{t}(4 ; 11)$ are present in primitive lymphoid-restricted CD34+. Cancer Res. 2005;65:1442-1449.

25. Castor A, Nilsson L, strand-Grundstrom I et al. Distinct patterns of hematopoietic stem cell involvement in acute lymphoblastic leukemia. Nat.Med. 2005;11:630-637.

26. Gunsilius E, Duba HC, Petzer AL et al. Evidence from a leukaemia model for maintenance of vascular endothelium by bone-marrow-derived endothelial cells. Lancet 2000;355:1688-1691.

27. Bailey AS, Willenbring $\mathrm{H}$, Jiang $\mathrm{S}$ et al. Myeloid lineage progenitors give rise to vascular endothelium. Proc.Natl.Acad.Sci.U.S.A 2006;103:13156-13161.

28. Zhou Y, Fisher SJ, Janatpour $M$ et al. Human cytotrophoblasts adopt a vascular phenotype as they differentiate. A strategy for successful endovascular invasion? J.Clin.Invest 1997;99:2139-2151.

29. Hendrix MJ, Seftor EA, Meltzer PS et al. Expression and functional significance of VEcadherin in aggressive human melanoma cells: role in vasculogenic mimicry. Proc.Natl.Acad.Sci.U.S.A 2001;98:8018-8023.

30. Rustin GJ, Newlands ES, Begent RH, Dent J, Bagshawe KD. Weekly alternating etoposide, methotrexate, and actinomycin/vincristine and cyclophosphamide chemotherapy for the treatment of CNS metastases of choriocarcinoma. J.Clin.Oncol. 1989;7:900-903.

31. Khuntia D, Brown P, Li J, Mehta MP. Whole-brain radiotherapy in the management of brain metastasis. J.Clin.Oncol. 2006;24:1295-1304.

32. Yin T, Li L. The stem cell niches in bone. J.Clin.Invest 2006;116:1195-1201.

33. Jamieson $\mathrm{CH}$, Ailles LE, Dylla $\mathrm{SJ}$ et al. Granulocyte-macrophage progenitors as candidate leukemic stem cells in blast-crisis CML. N.Engl.J.Med. 2004;351:657-667. 
34. Kirstetter P, Anderson K, Porse BT, Jacobsen SE, Nerlov C. Activation of the canonical Wnt pathway leads to loss of hematopoietic stem cell repopulation and multilineage differentiation block. Nat.Immunol. 2006;7:1048-1056.

35. Scheller M, Huelsken J, Rosenbauer F et al. Hematopoietic stem cell and multilineage defects generated by constitutive beta-catenin activation. Nat.Immunol. 2006;7:1037-1047.

36. Thomson JA, Itskovitz-Eldor J, Shapiro SS et al. Embryonic stem cell lines derived from human blastocysts. Science 1998;282:1145-1147.

37. Takahashi K, Yamanaka S. Induction of pluripotent stem cells from mouse embryonic and adult fibroblast cultures by defined factors. Cell 2006;126:663-676. 


\section{Figure legends:}

Figure 1. Identification and characterization of a leukemic stem-cell like population that expresses both endothelial and hematopoietic progenitor cell surface markers.

(A) Confocal laser scanning microphotographs (LSMs) of Ph+ ALL Sup-B15 cells stained with antiVE-cadherin in the presence of $10 \mathrm{mM} \mathrm{EGTA}$ and $5 \mathrm{mM} \mathrm{CaCl}_{2}$. Cell nuclei were counterstained with propidium iodide (PI). (B) Cell lysates prepared from Ph-negative acute leukemia cell lines JM1, RS4;11, REH, Jurkat, HL60 and Ph+ acute leukemia cell lines K562, Sup-B15, OP-1, Nalm20, Nalm27 and Nalm29 were Western blotted with anti-VE-cadherin. The same membranes were stripped and re-probed with anti- $\beta$-tubulin as a loading control. (C) Immunophenotyping of Ph+/VEcadherin+ Sup-B15 cells by flow cytometry. Cells were surface stained to evaluate hematopoietic stem/progenitor cell and classic endothelial markers.

Figure 2. Ph+/VE-cadherin+ leukemic cells form hematopoietic colonies/cords on bone marrow niche stromal cells and differentiate into endothelial cells in vitro.

(A) Phase contrast micrographs of Ph+ ALL Sup-B15 (upper panel) and Nalm27 (lower panel) cells cultured in medium alone (Long-Term Medium Culture, LTMC) or long-term co-cultured (LTCC) on murine stromal cell line S10 (top \& bottom right). (B) Confocal LSM microphotographs of hematopoietic cords formed on stromal cells. Cells were surface stained with anti-CD34, CD19, VEcadherin, and CD133 respectively. Nucleic DNA dyes include Sytox (green), PI (red) and TO-PRO-3 (blue). Z-stacks were 3-D reconstructed with LSM510 software (Zeiss, version 3.2). The turning axis is the $\mathrm{Y}$ axis and turning angle for the displayed static pictures is $45^{\circ}$. (C) Confocal micrographs of hematopoietic colonies ("hemospheres") stained with a panel of early stem cell (ESC) markers. Stromal monolayer cells underneath hemospheres were counterstained with anti-VCAM-1. Cell nuclei were counterstained with DNA dyes PI (red fluorescence) or SYTOX Green (green fluorescence) to be compatible with the flurochrome tag of the secondary antibodies of anti-ESC antibody. Merged images of 3-channel colors are shown in the final column. (D) 3-dimensional reconstruction of z- 
stacks showing the distribution of transcriptional factor Oct-4 within a hematopoietic cord. Cell nuclei were counterstained with PI (red) and localization of Oct-4 was labeled with green fluorescence. The turning axis is the $\mathrm{Y}$ axis. The tip of the hematopoietic cord was pressed flat by the coverslip. (E) DsRed red fluorescent protein labeled Sup-B15 cells (top left) or eGFP labeled Nalm27 cells (bottom left) were cultured in standard medium, or in EndoCult endothelial-defined medium (top \& bottom right). White arrows denote individual endothelial sprouting observed for individual Ph+/VE-cadherin+ ALL cells.

Figure 3. LTCC with bone marrow stromal cells promotes self-renewal activity of Ph+/VEcadherin+ leukemic cells independent of the Wnt/B-catenin signaling pathway.

Clustering analysis of gene expression profiles in Sup-B15 cells following LTCC with S10 or PatX stromal cells. The hierarchical clusters were created with GEASuite software based on the similarity of gene expression. The green color at the farthest left end of the color scale corresponds to the minimal value; the red color at the farthest right end of the color scale corresponds to the maximum value, Black corresponds to the average value of expression. BAS2C, HSPCB, ACTB and GAPDH served as housekeeping gene controls. Analysis of the representative Wnt pathway is shown.

Figure 4. Stromal cells up-regulate VE-cadherin expression and stabilize $\beta$-catenin in Ph+/VEcadherin+ leukemic cells.

(A) Western blot analysis of Sup-B15 cells in LTMC (Med) or in LTCC with either S10 (S10) or PatX (PatX) stromal cells. The same membrane was probed with anti-VE-cadherin, anti- $\beta$-catenin and antiSrc, respectively. GAPDH was used as the lane loading control. (B) Western blot of cell lysates isolated from Sup-B15 cells exposed to recombinant human cytokines, chemokines, or growth factors compared to untreated control cells (Cont). (C) Reciprocal co-immunoprecipitation of Sup-B15 cell lysates from LTMC (Med) or LTCC (S10 and PatX) with anti-VE-cadherin or anti- $\beta$-catenin specific antibodies. Membranes were reciprocally probed with anti- $\beta$-catenin and anti-VE-cadherin, respectively. IgG heavy chains served as the loading control. "Input" denotes sample with antibody 
alone, lacking cell lysate. (D) Western blot analysis of cell lysates from 293FT (top panel) or Sup-B15 cells (bottom panel) transduced with lentiviruses carrying the wild type VE-cadherin (WT) or VEcadherin lacking either the cytoplasmic domain ( $\Delta$ cyto) or $\beta$-catenin binding domain ( $\Delta$ bcat) CDSs (Coding DNA Sequences). "Vect" denotes the empty lentiviral vector encoding the blasticidin resistance protein without a CDS insert. (E) Western blot analysis of Sup-B15 cells transiently transfected with VE-cadherin siRNA or scrambled (Scr) control siRNA sequence. Time-course (top panel) and dose-response (bottom panel) of VE-cadherin siRNA transfected samples were probed with anti-VE-cadherin and $\beta$-catenin specific antibodies.

Figure 5. $\beta$-catenin is constitutively activated in leukemic stem-like cells over-expressing VEcadherin during LTCC.

(A) Dual-luciferase reporter assays (DLR) of Sup-B15 LTMC (Med) or LTCC cells (S10 or PatX) transiently co-transfected with phRL-TOP1 or phRL-TOP2 Renilla luciferase reporters with an internal control pGL4.13-CMV-Luc2 firefly luciferase reporter. Experimental Renilla luciferase activity was normalized to that of control firefly luciferase and is shown as relative luciferase units (RLU). Data were presented as mean $+/-S D(n=3)$. (B) DLR assays of cell lysates from Sup-B15 cells transduced with wild type or the two truncated forms of VE-cadherin. Data were presented as mean $+/-S D(n=3)$. “*” denotes significant differences as compared to Vect controls $(p<0.01)$ based on the Student's $t$ test. (C) Sup-B15 cells transfected with 100nM VE-cadherin siRNA for 8-72 hours (top panel) or at a concentration of 50-200nM for 24 hours (bottom panel). Data are shown as the mean +/- SD $(n=3)$. (D) Confocal micrographs of LTMC or LTCC Sup-B15 cells stained with anti- active $\beta$-catenin antibody. Cell nuclei were counterstained with SYTOX Green. The photograph of LTMC was made from cytospin preparation and the photograph of LTCC Sup-B15 cells was taken from a portion of one hematopoietic cord. 
Figure 6. Bcr-abl fusion protein is essential for maintaining the VE-cadherin/ß-catenin axis in $P h+A L L$.

(A) Upper panel: Western blot analysis of Bcr-abl expression by Sup-B15 in LTMC (Med) or LTCC (S10 or PatX). Lower panel: DLR assays of LTMC (Med) and LTCC (S10 and PatX) Sup-B15 cells transiently co-transfected with the Bcr-abl promoter reporters phRL-pp210L or phRL-pp210S with an internal control pGL4.13-CMV-Luc2 firefly luciferase reporter. Data were shown as mean +/- SD $(n=3)$. "*” denotes statistically significant differences as compared to values from cells in media alone $(p<0.01)$ based on Student $t$ test. (B) Western blot analysis of Bcr-abl expression by Sup-B15 cells transduced with retroviruses containing p185-eGFP or p210-eGFP forms of Bcr-abl, or the empty vector control (MSCV-IRES-eGFP, MiG) alone (top western blot). Dual-color flow cytometric analysis of VE-cadherin expression in Sup-B15 cells over-expressing the exogenous Bcr-abl fusion proteins or empty retroviral control vector (bottom flow cytometry). Baseline VE-cadherin was set to "zero" for comparison of the net increases following retroviral transduction. (C) DLR assay of Sup-B15 cells infected with p185-eGFP, p210-eGFP or MiG vector control retroviruses. Data are shown as mean +/SD (n=3). "*” denotes significant differences as compared to MSCV empty vector controls $(p<0.01)$ based on Student $t$ test. (D) Western blot analysis of cell lysates from Sup-B15 cells treated with the Bcr-abl kinase inhibitors Imatinib Mesylate or AG957 at various concentrations. (E) Western blot of Sup-B15 or Nalm27 leukemic cells treated with $20 \mu \mathrm{M}$ Imatinib Mesylate, $10 \mu \mathrm{M}$ proteosome inhibitor MG132, or a combination of both inhibitors for 16 hours.

Figure 7. Tyrosine phosphorylation of $\beta$-catenin mediated by Bcr-abl kinase diminishes ß-catenin ubiquitination-proteosome-dependent degradation.

(A) Western blot analysis of cell lysates from 293FT cells co-transduced with lentiviral vector (LentiVect), lentiviruses carrying WT VE-cadherin (Lenti-VE-cad), retroviral vector (Retro-MiG) or retroviruses encoding p210-eGFP (Retro-MiG-p210). $\beta$-catenin was densitometrically normalized to 
GAPDH with the control value set at 1.0 and all other values shown relative to the control. (B) Immunoprecipitation of $\beta$-catenin was done using the above cell lysates and Western blots were probed with anti-P-Tyr (Phospho-Tyr102), anti-ß-catenin, anti-phospho-Src and anti-Src antibodies. IgG heavy chain served as the loading control. (C) DLR assays from the above 293FT cells transiently co-transfected with the phRL-TOP1 and phRL-TOP2 reporters and an internal pGL4.13CMV-Luc2 firefly luciferase reporter. Data are shown as mean +/- SD $(n=3)$. “*” denotes significant differences as compared to vector controls $(p<0.01)$ based on Student's $t$ test. (D) Western blot analysis of $\beta$-catenin stabilization from 293FT cells co-expressing VE-cadherin/eGFP-p210 or VEcadherin/eGFP treated with $10 \mu \mathrm{M}$ Src kinase inhibitor PP2, $10 \mu \mathrm{M}$ Bcr-abl inhibitor Imatinib Mesylate or both inhibitors for 16 hours. $\beta$-catenin was densitometrically normalized to VE-cadherin with the untreated control value of expressing MiG vector alone set to 1.0. All other ratios are normalized to this control value. (E) VE-cadherin was immunoprecipitated from 293FT cells co-expressing VEcadherin/eGFP-p210 or VE-cadherin/eGFP. The immunoprecipitates and cell lysates were loaded in parallel and probed with anti-phospho-Tyrosine (4G10) and VE-cadherin, c-Abl and eGFP antibodies. (F) $\beta$-catenin immunoprecipitated either from 293FT expressing eGFP-210 or eGFP alone, or from $\mathrm{Ph}+$ Sup-B15 or Ph- REH leukemic cells was in vitro labeled with recombinant ubiquitin and subjected to in vitro degradation assay as described in Materials and Methods. 
Figure 1

A
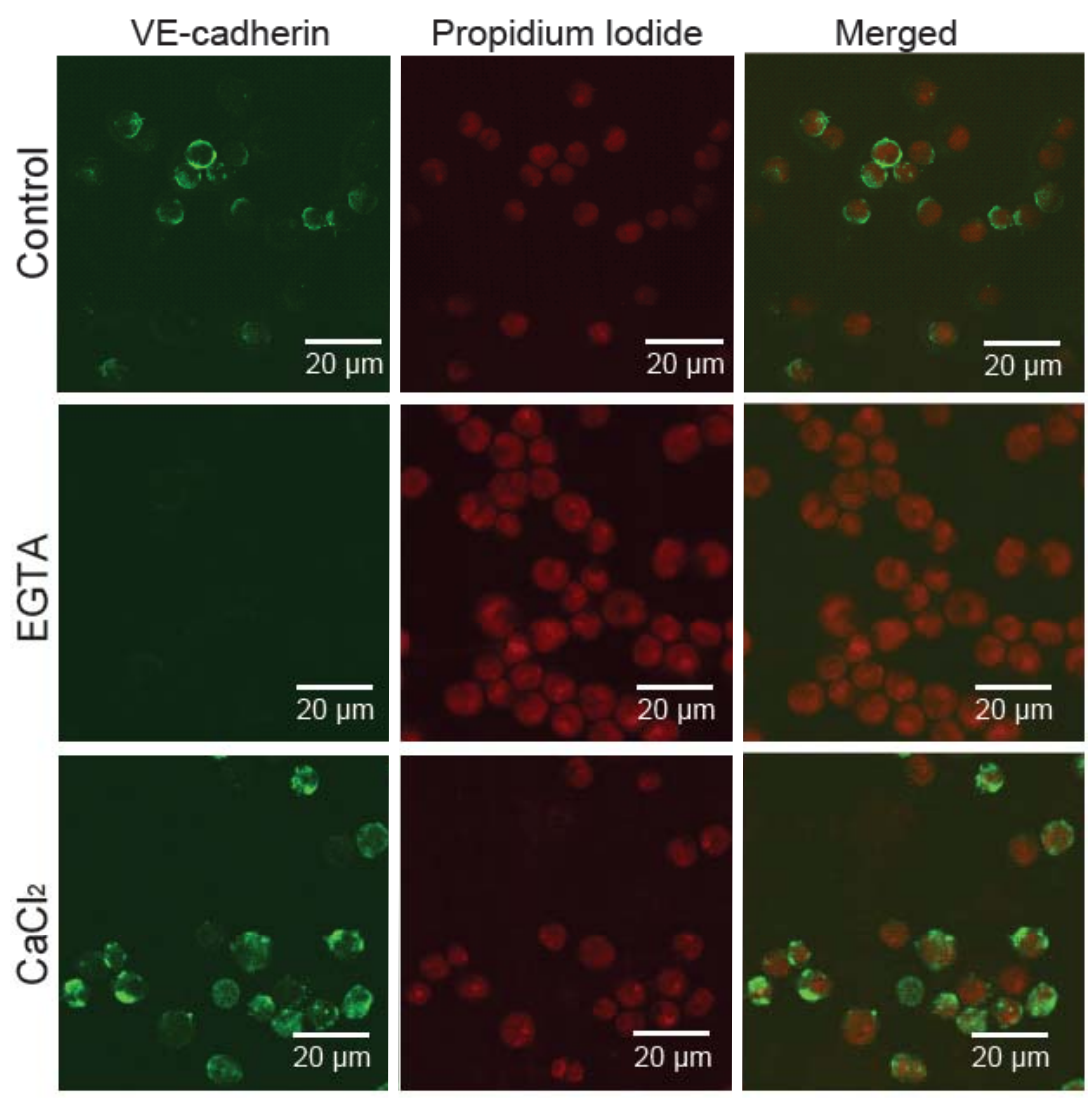

잉

B

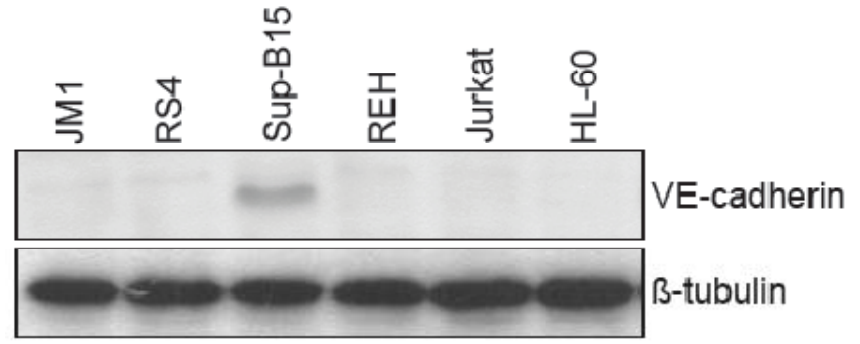

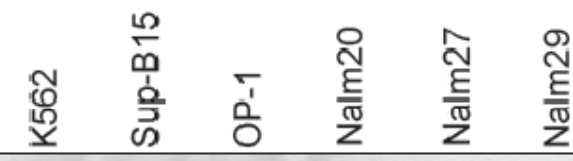
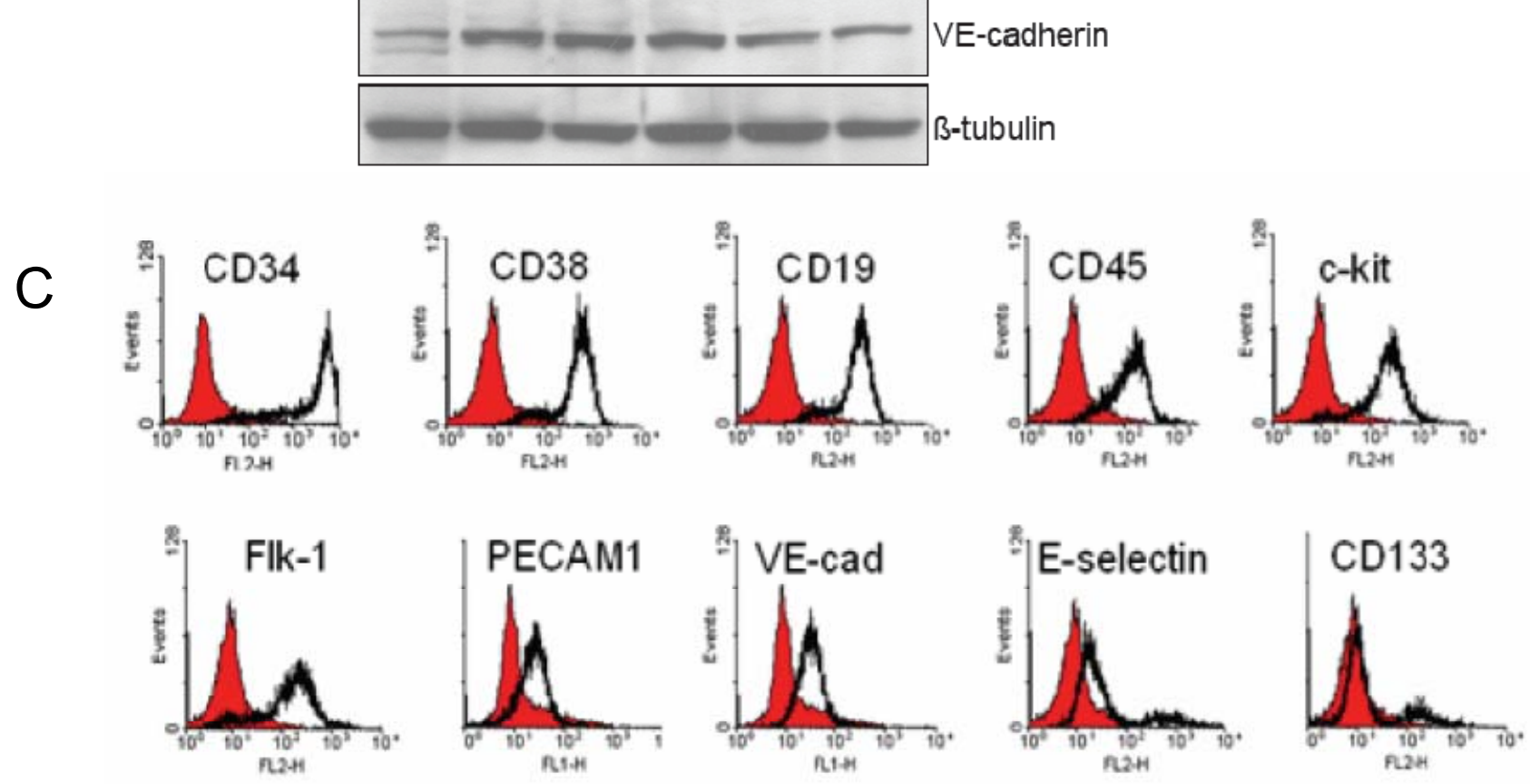
Figure 2

A

B
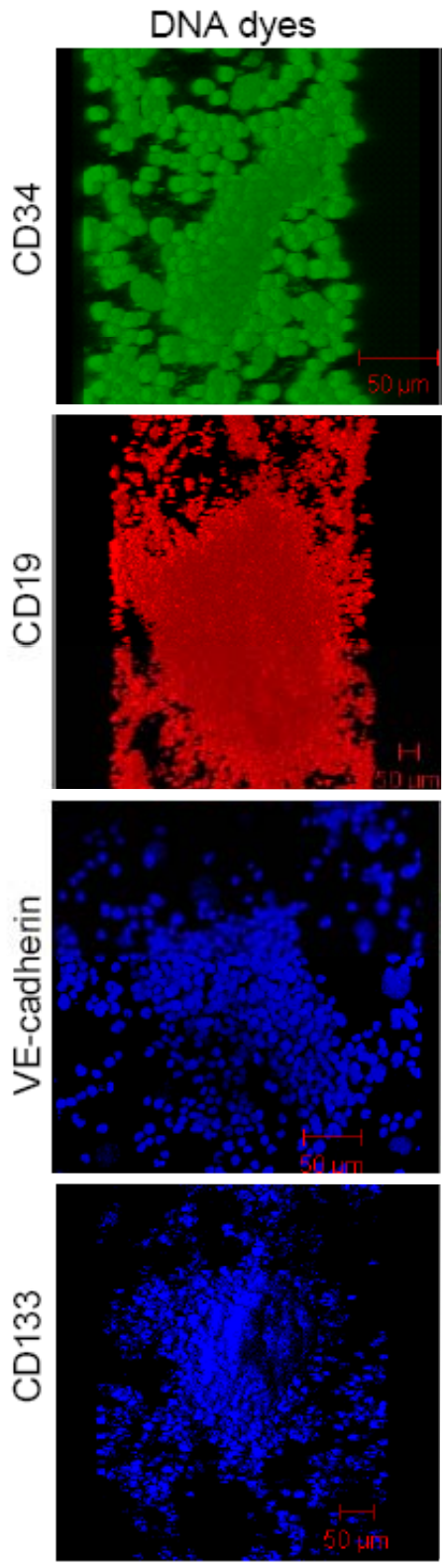

Sup-B15/LTMC

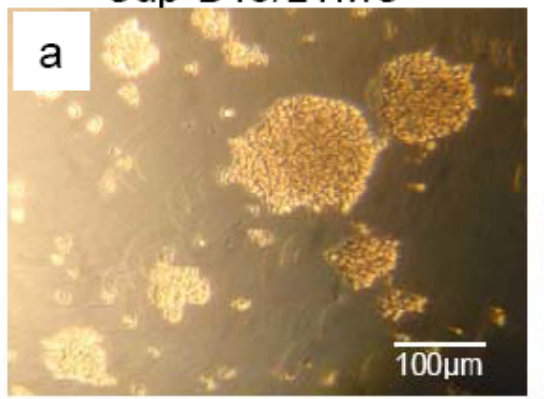

Nalm27/LTMC

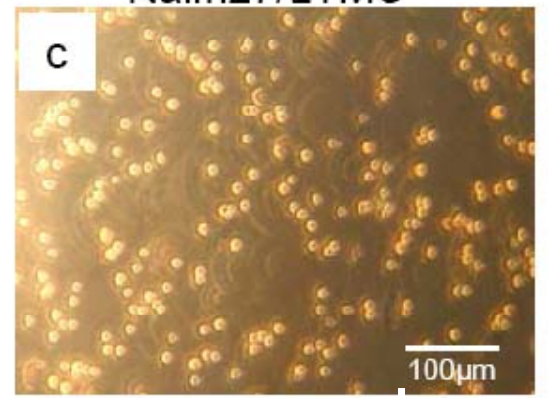

Cell surface markers
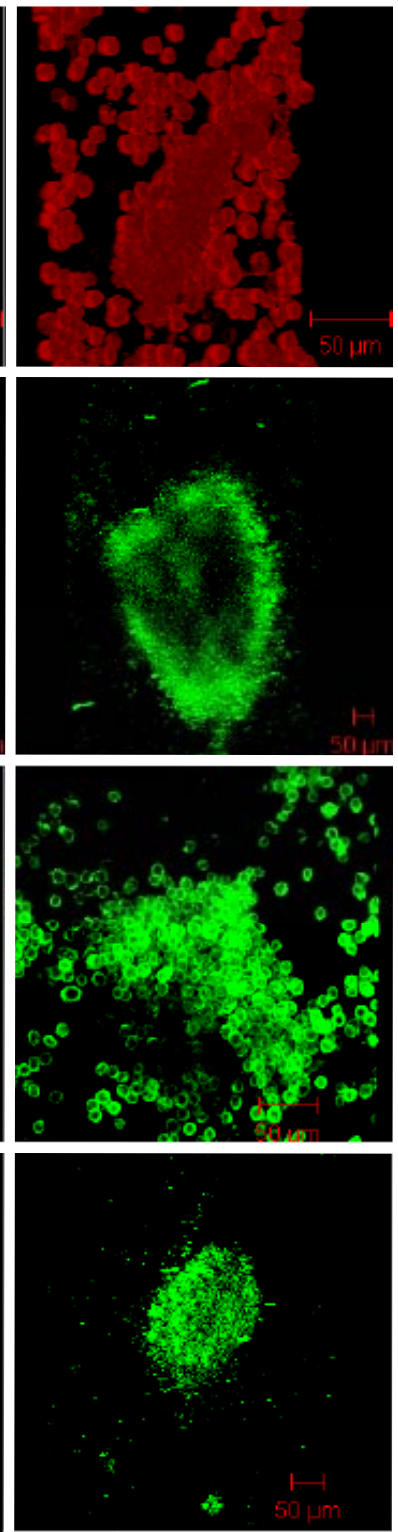

$100 \mu m$

Merged
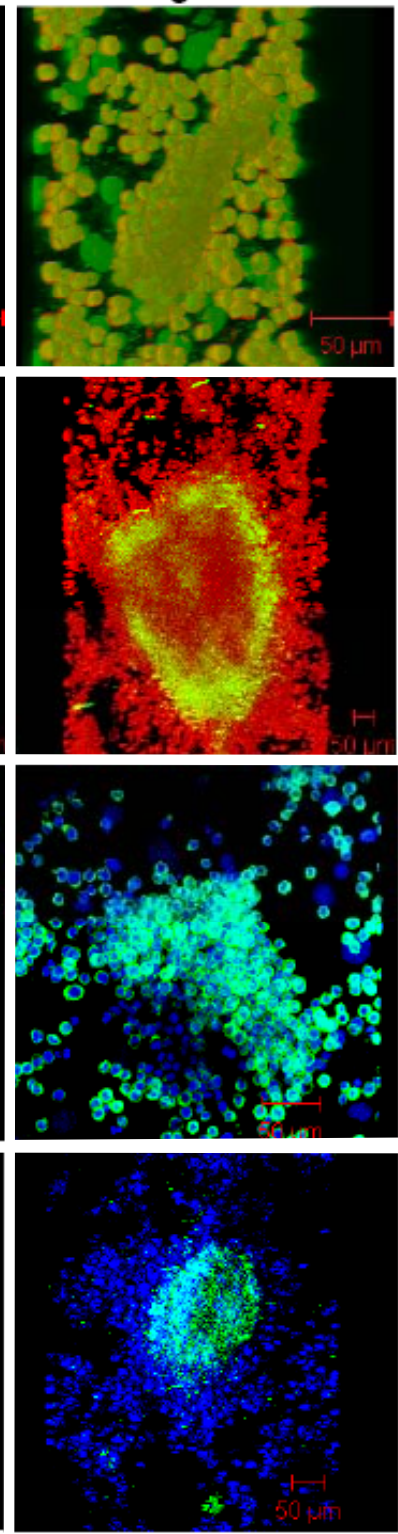
Figure 2

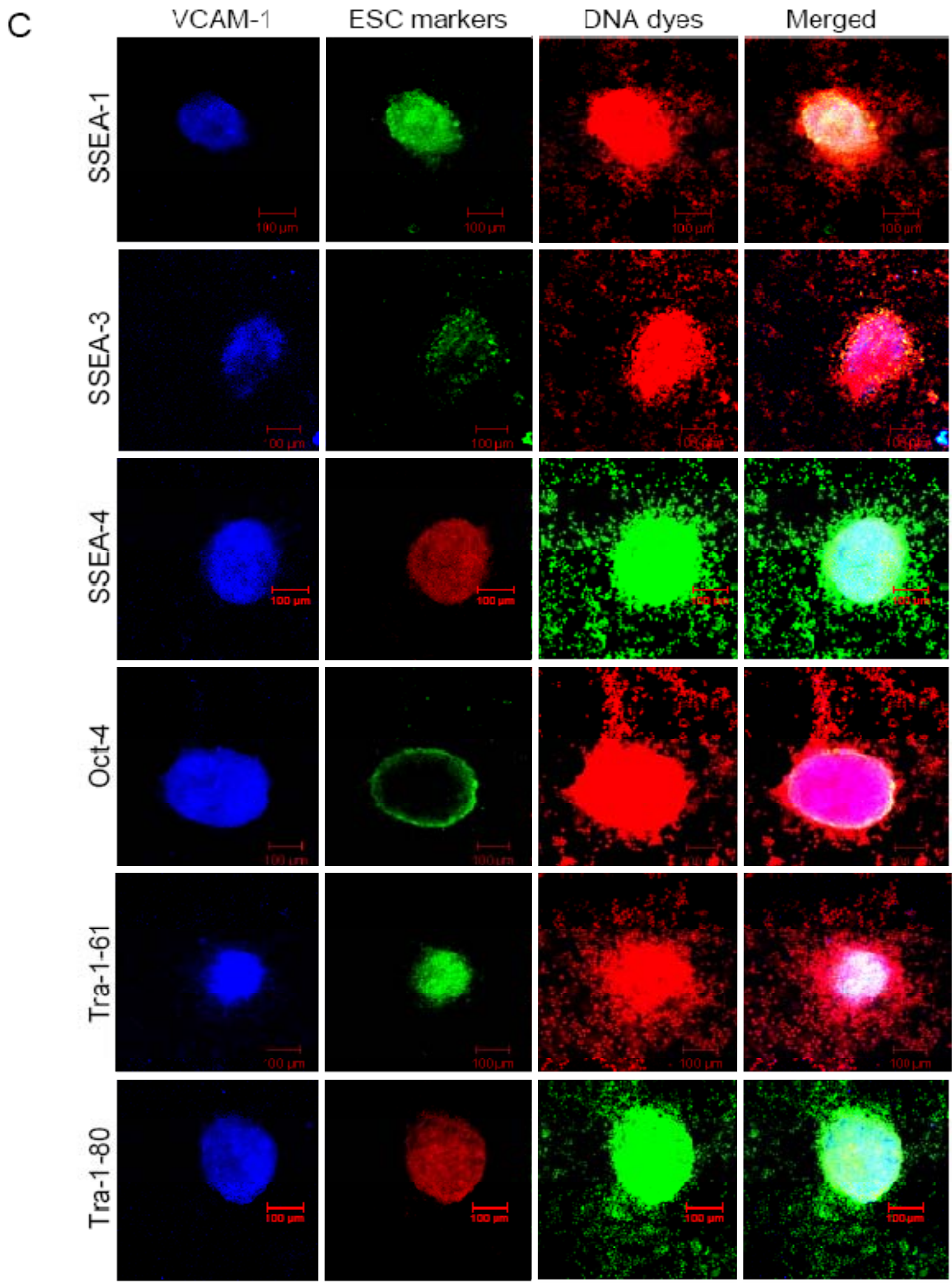




\section{Figure 2}

D

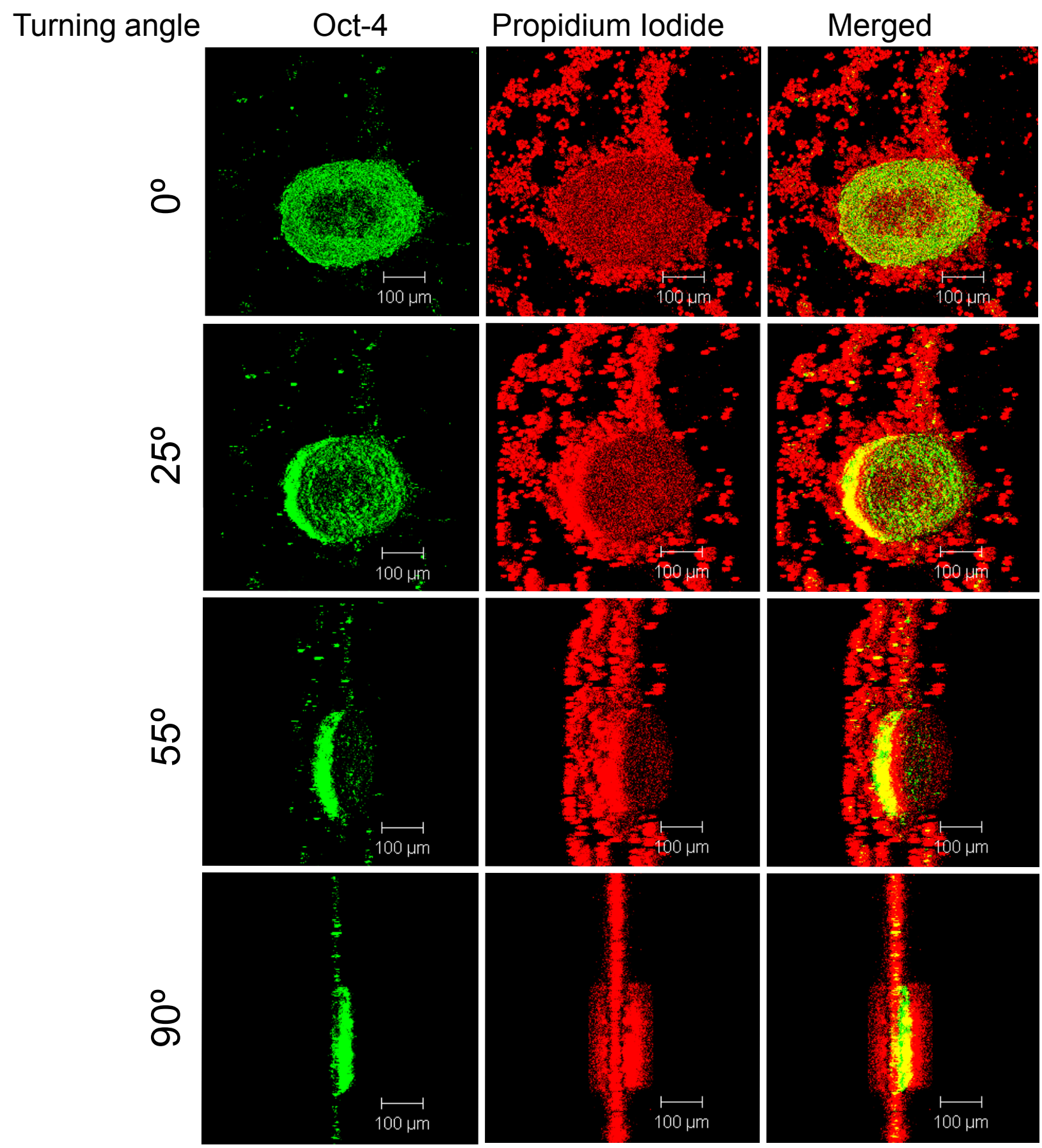


Figure 2

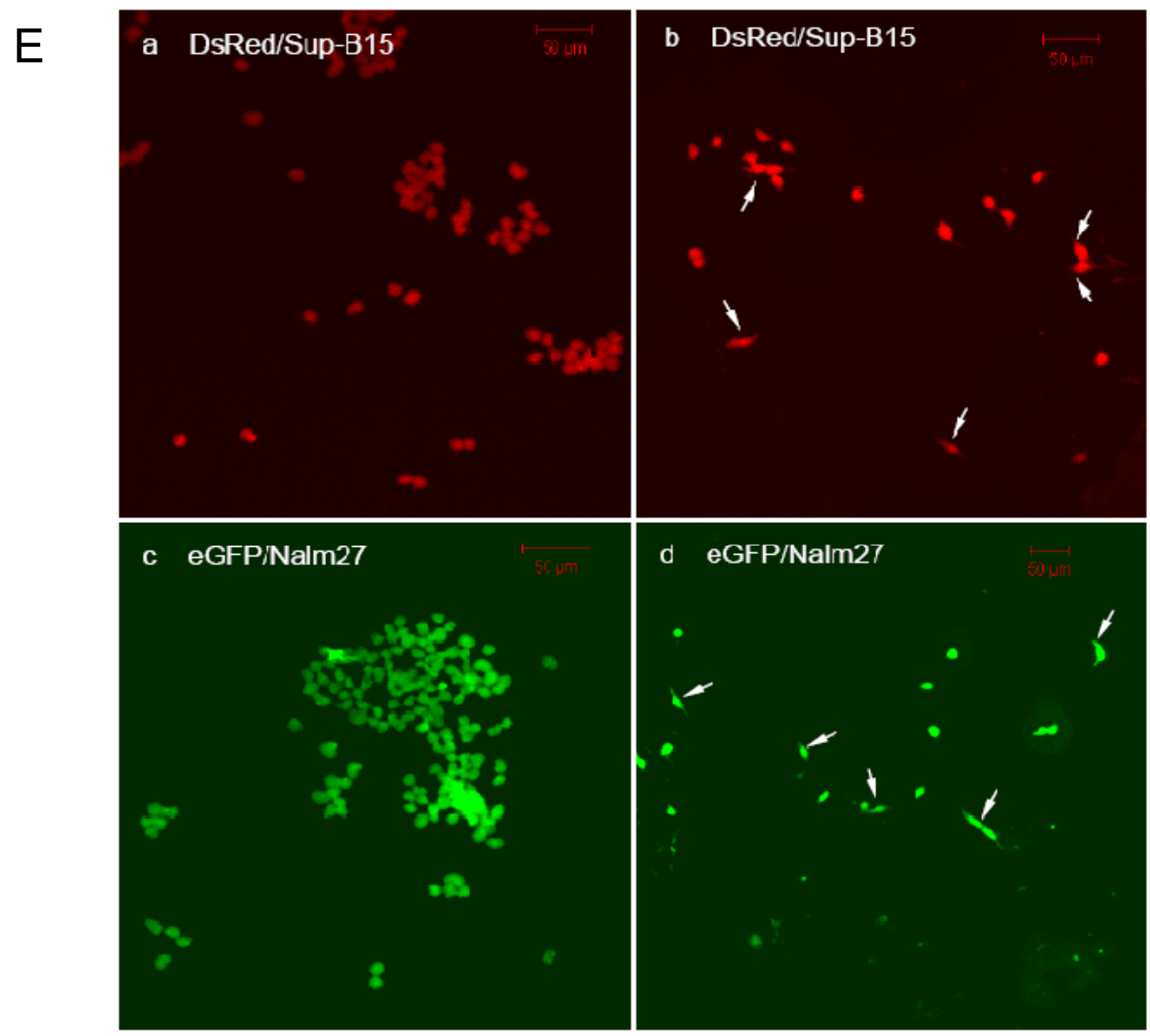


Figure 3

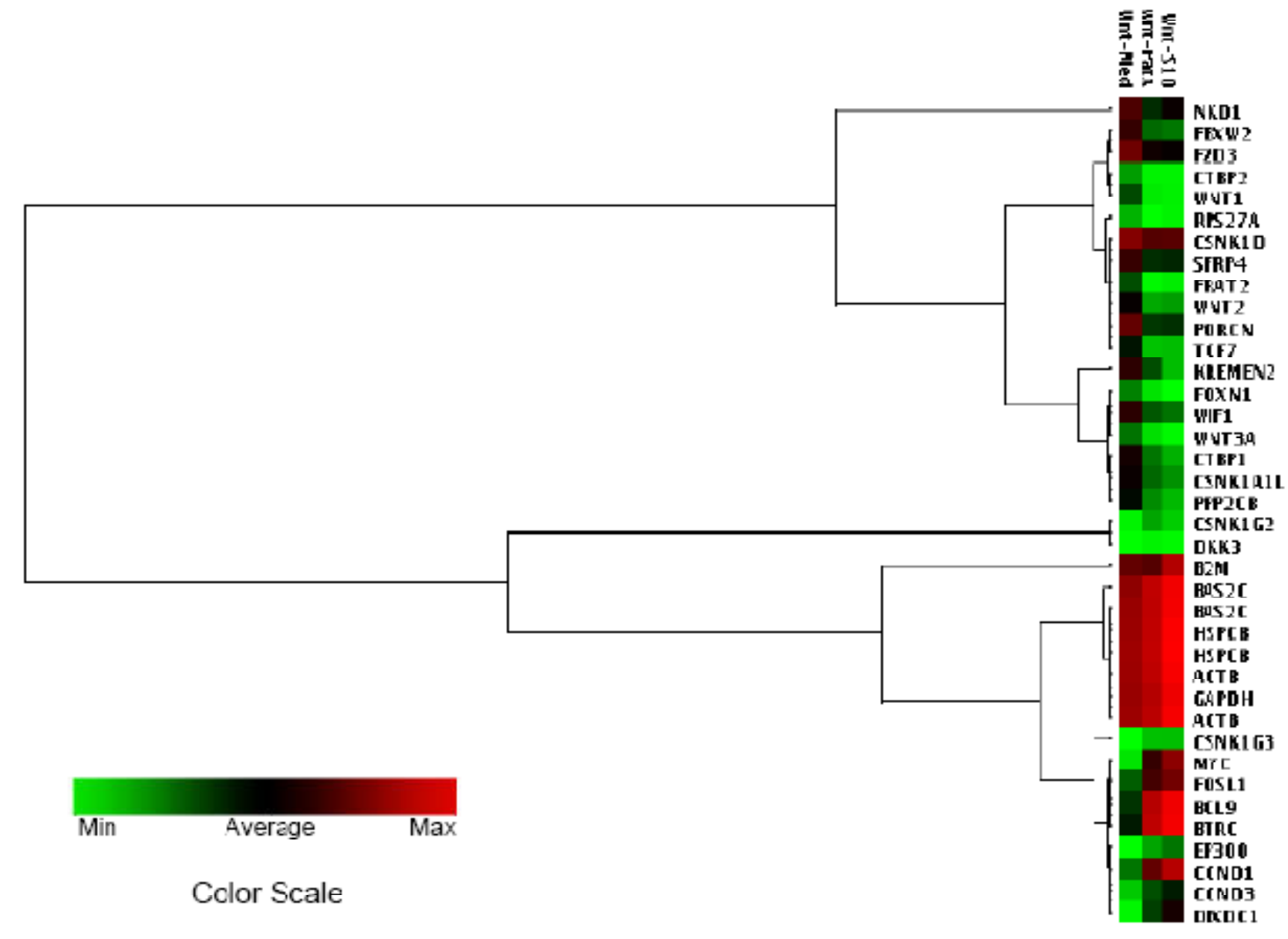


Figure 4

A

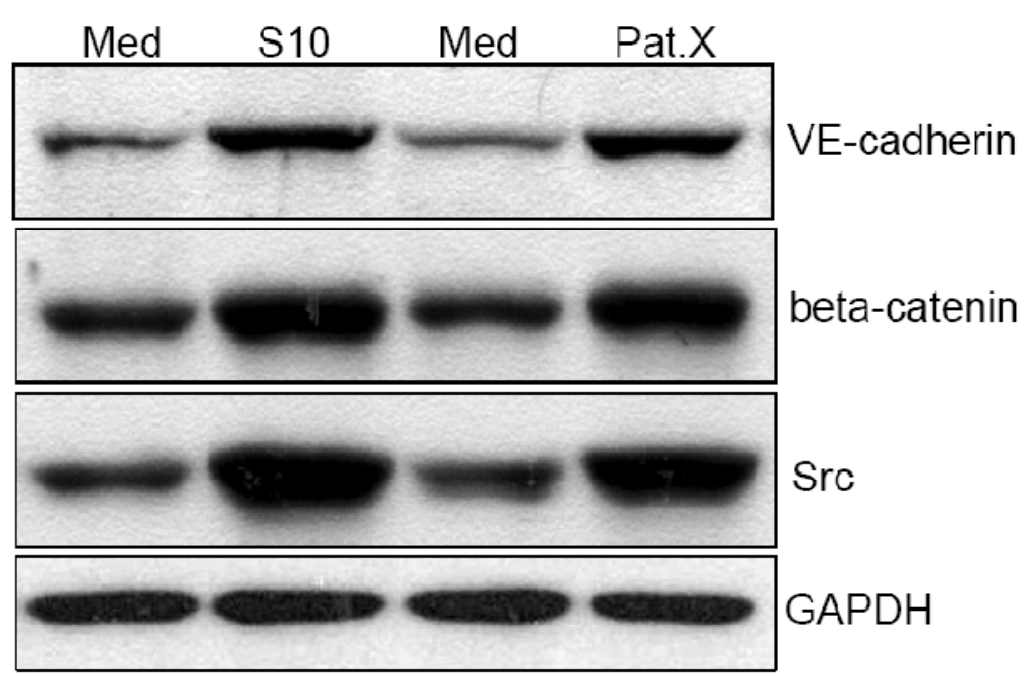

B
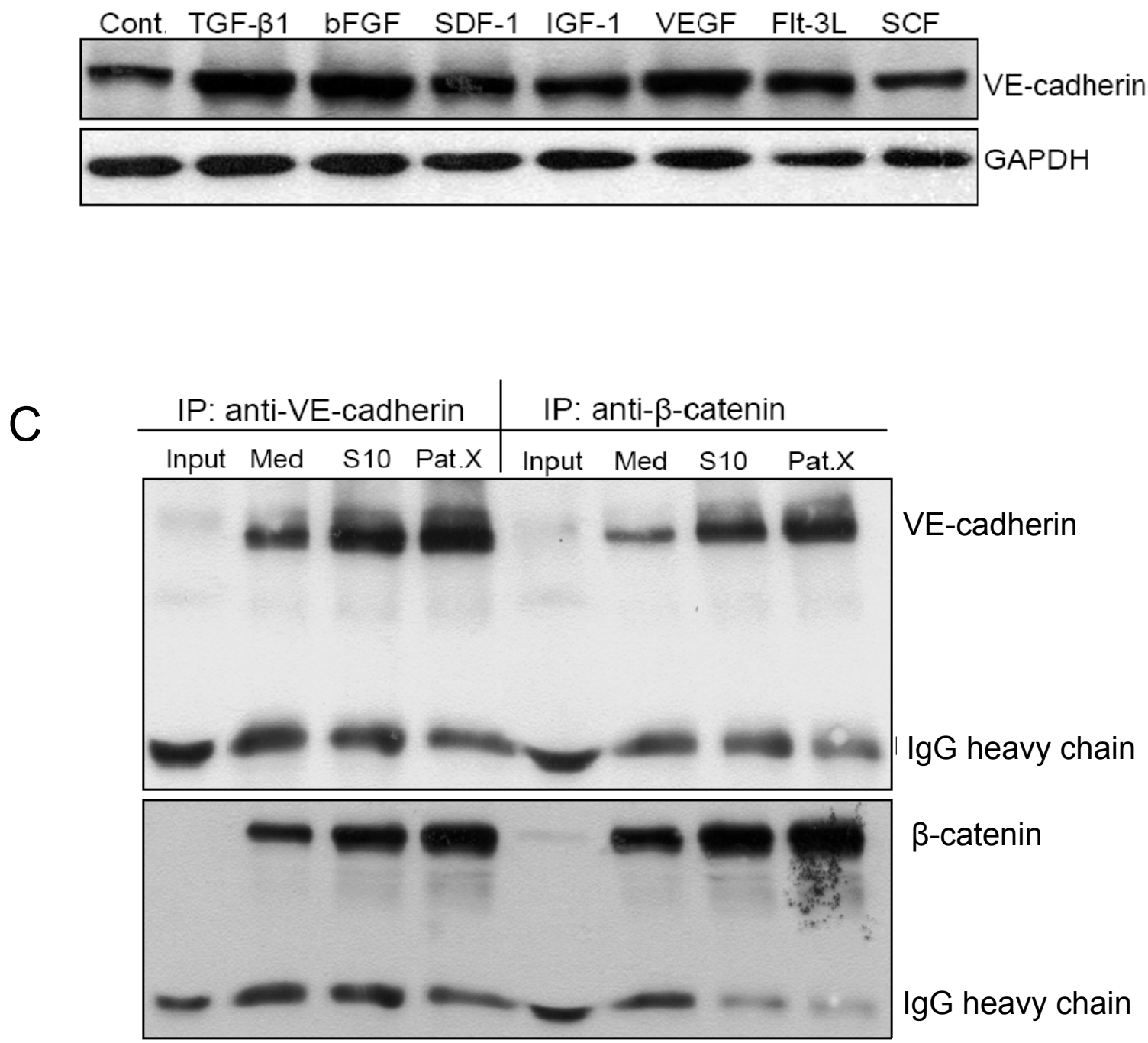
Figure 4

D
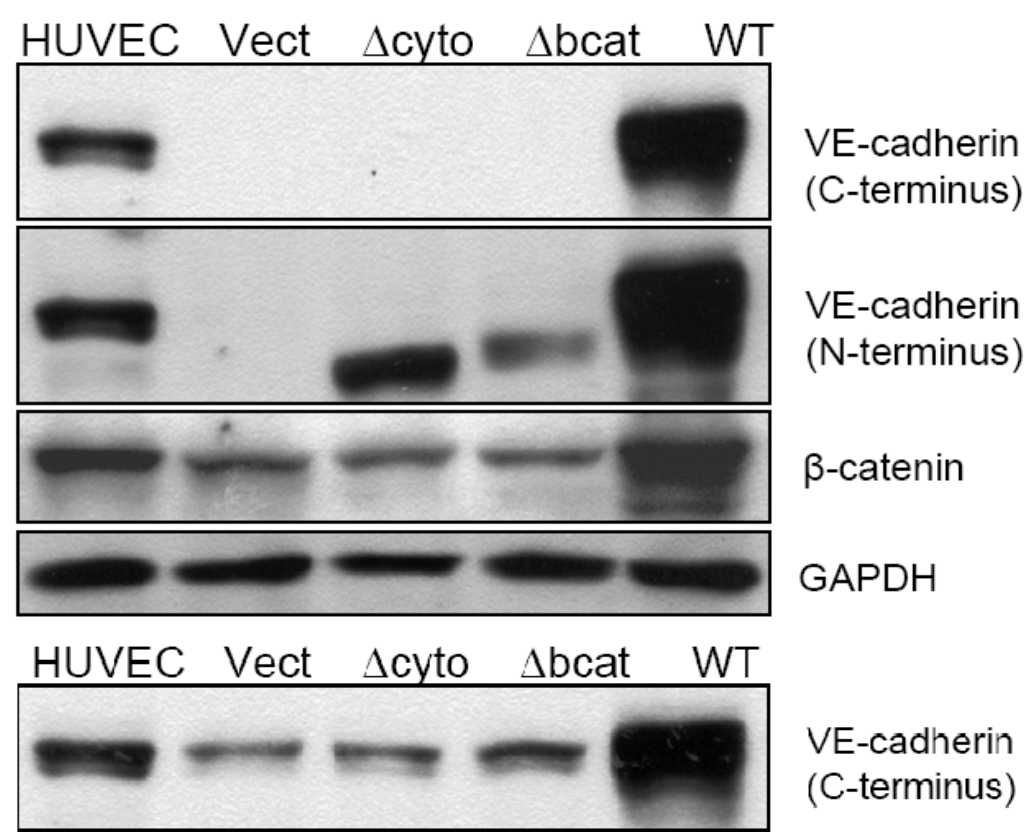

VE-cadherin

(C-terminus)

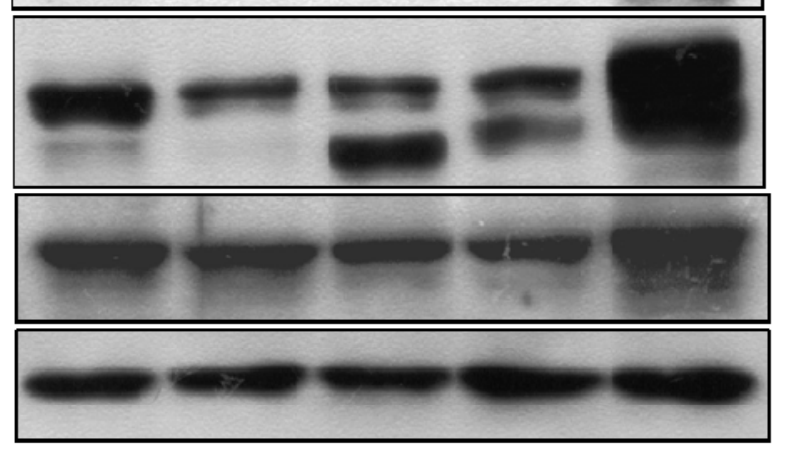

VE-cadherin

(N-terminus)

$\beta$-catenin

GAPDH

E
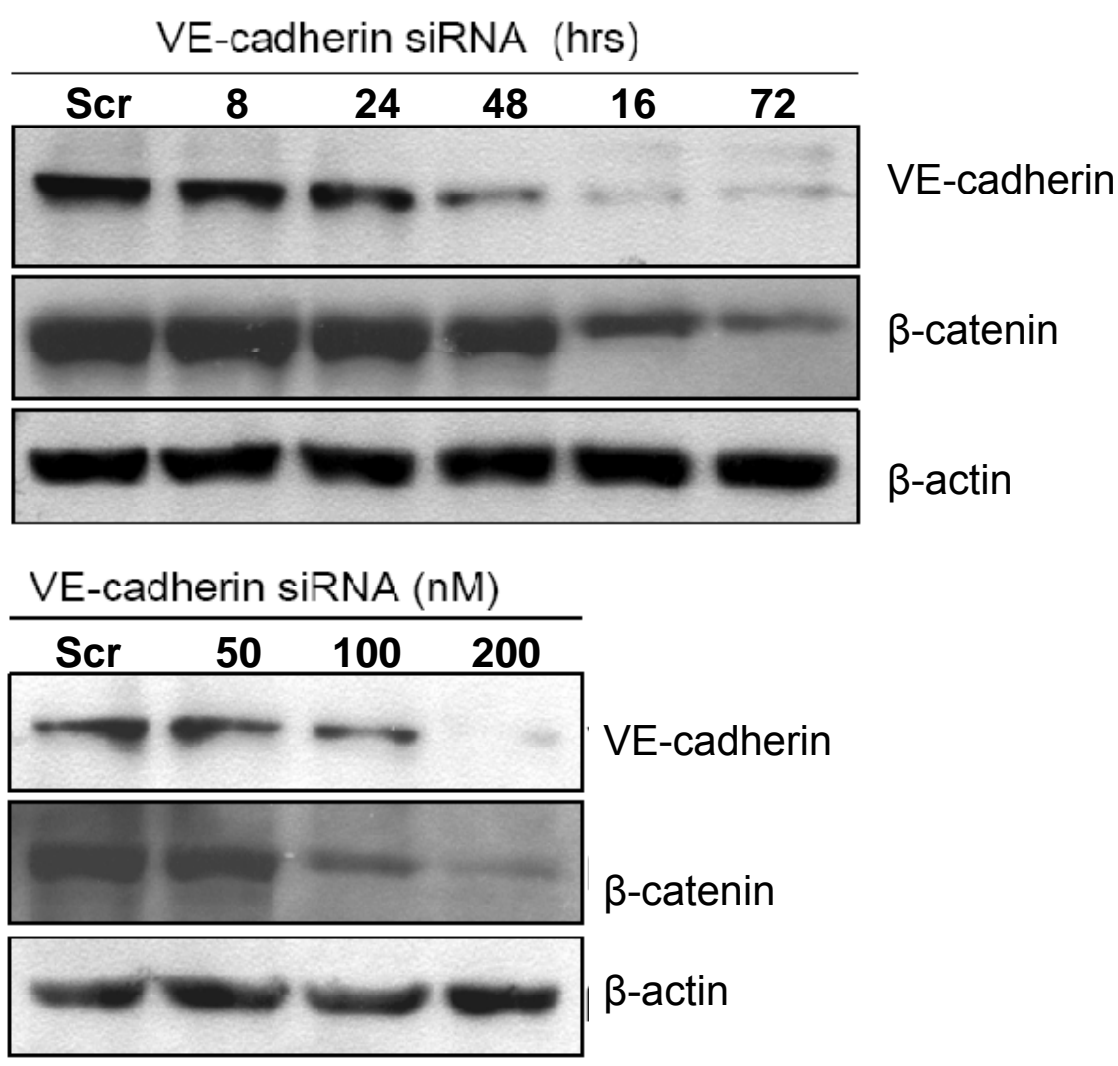
Figure 5

A

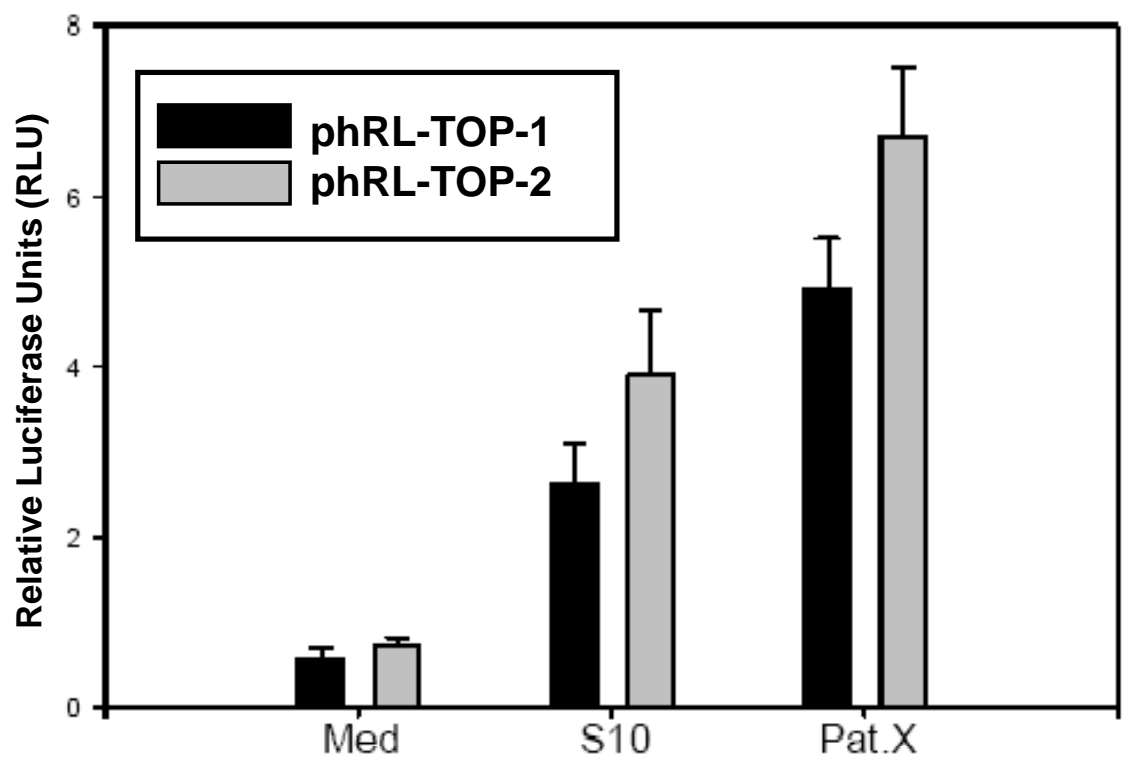

B

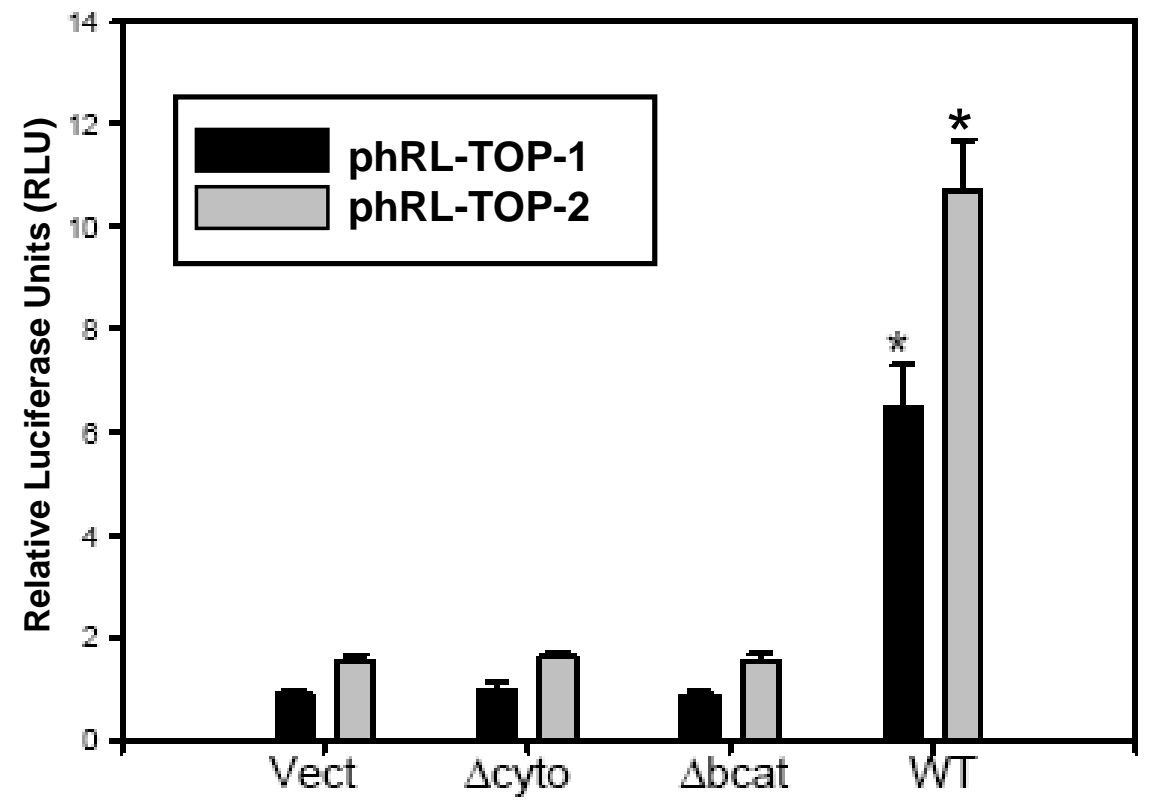


Figure 5
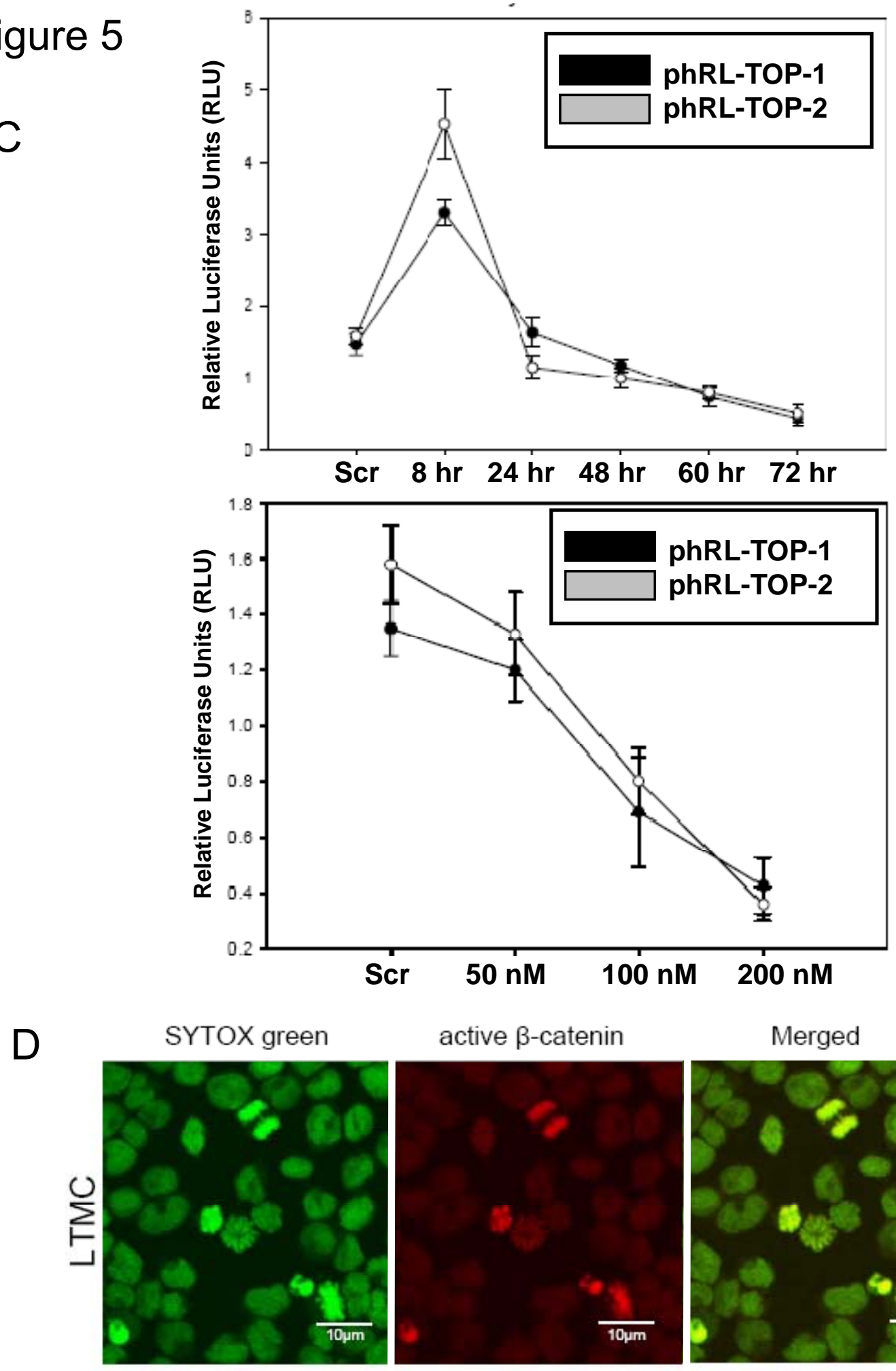

active $\beta$-catenin

Merged
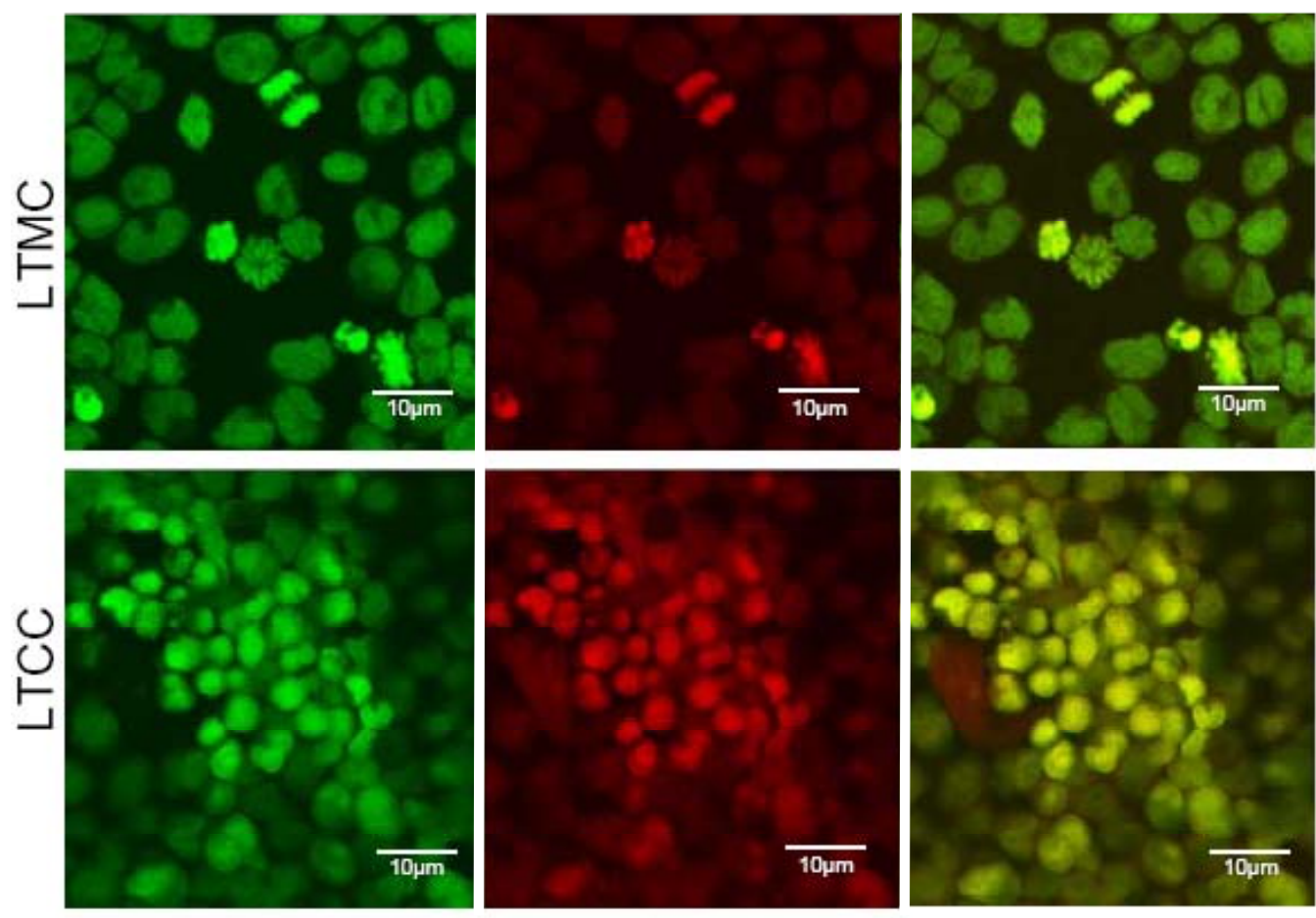
Figure 6 A

B
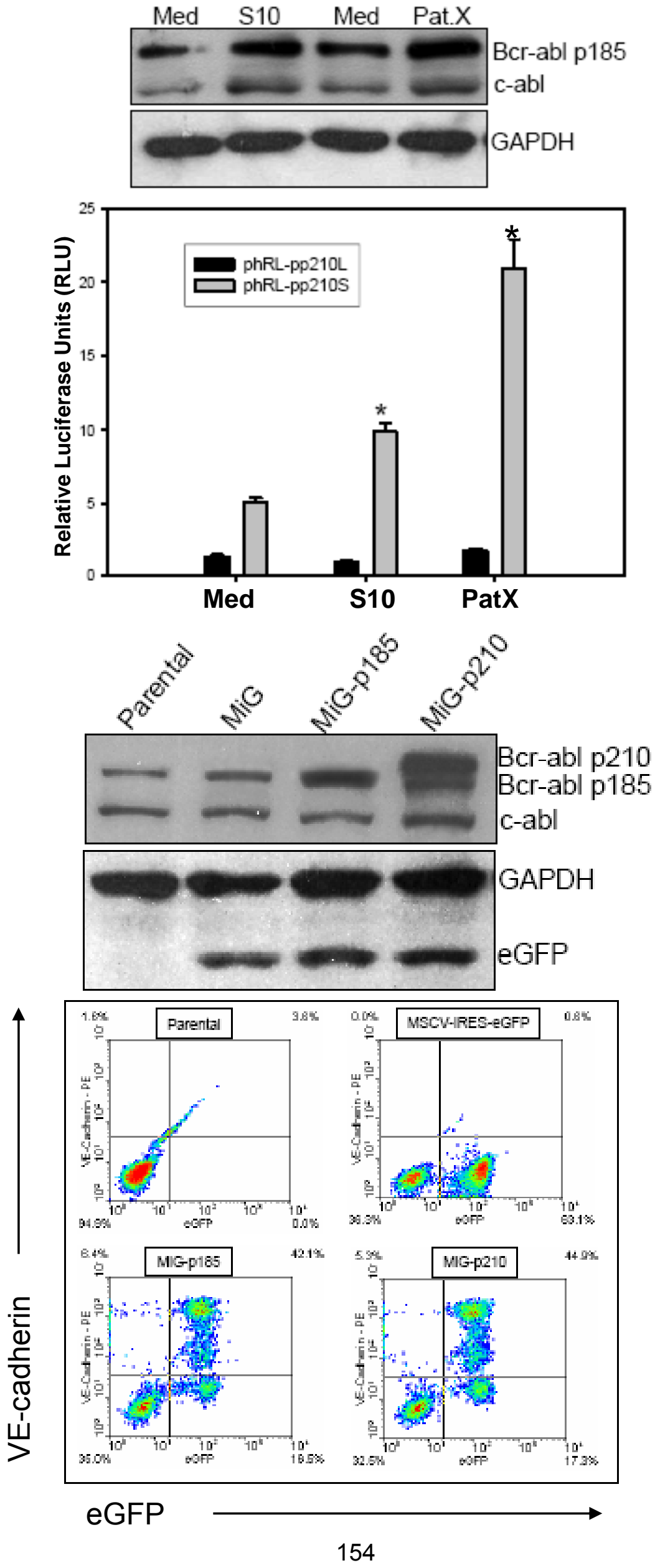
Figure 6

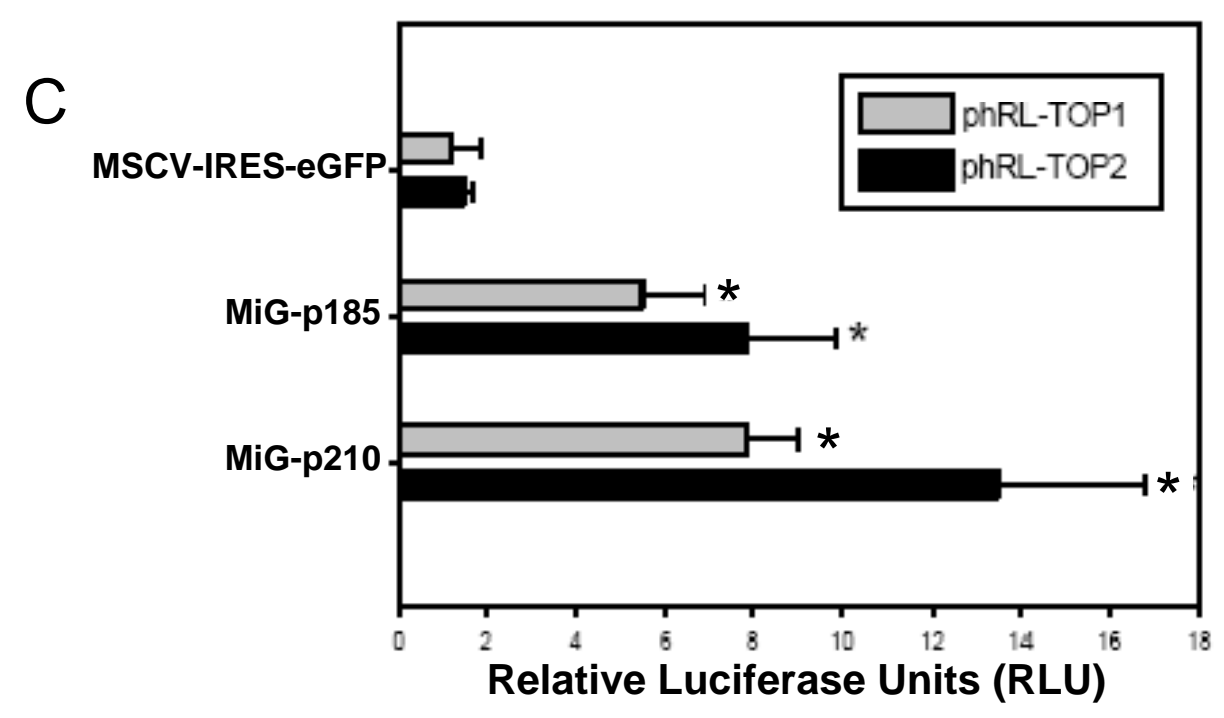

D

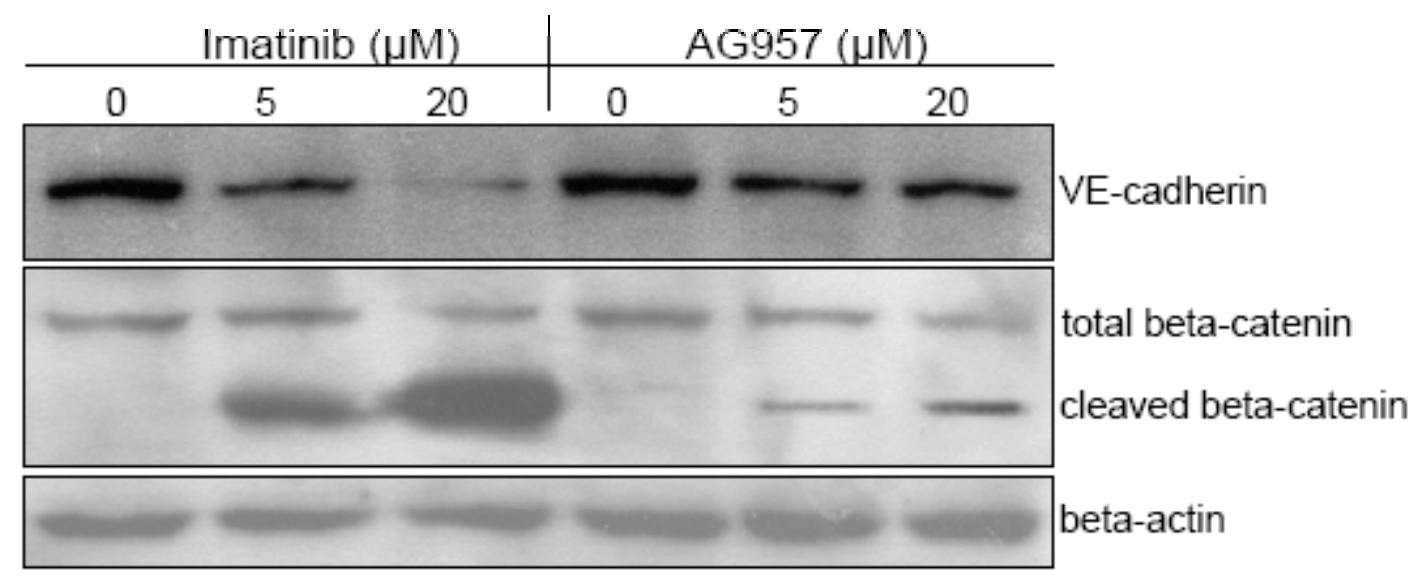

E

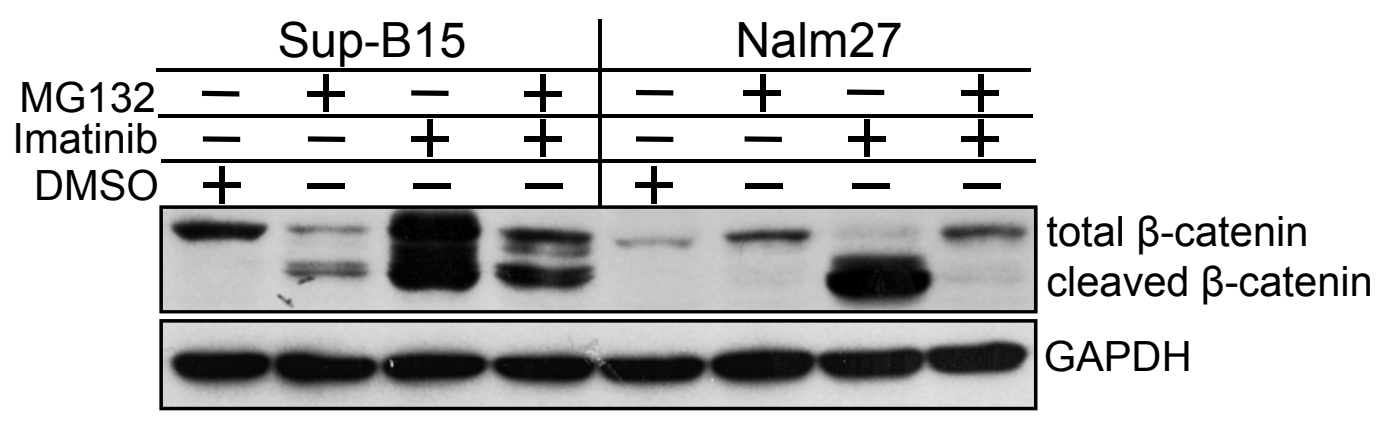


Figure 7

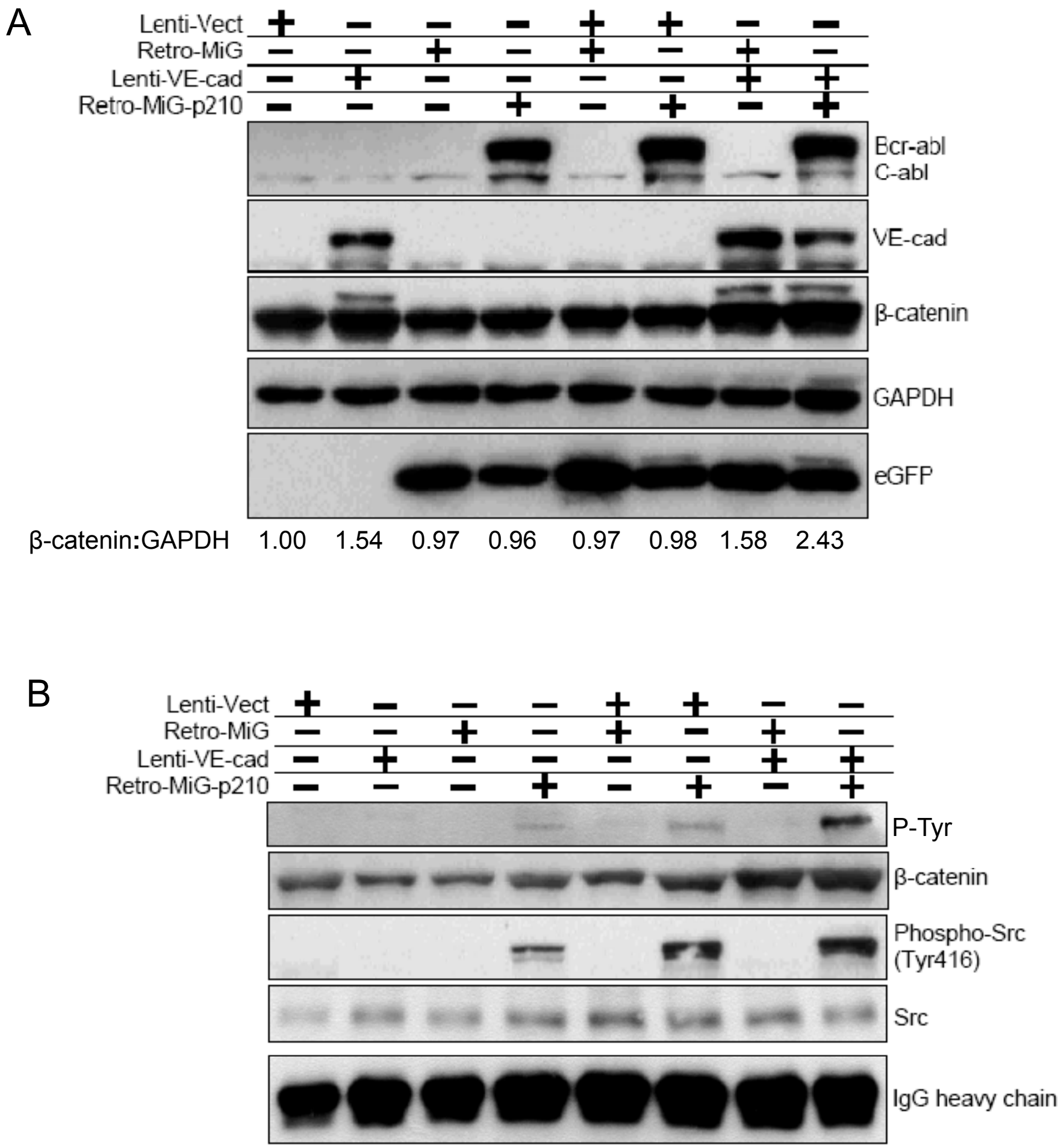


Figure 7

C

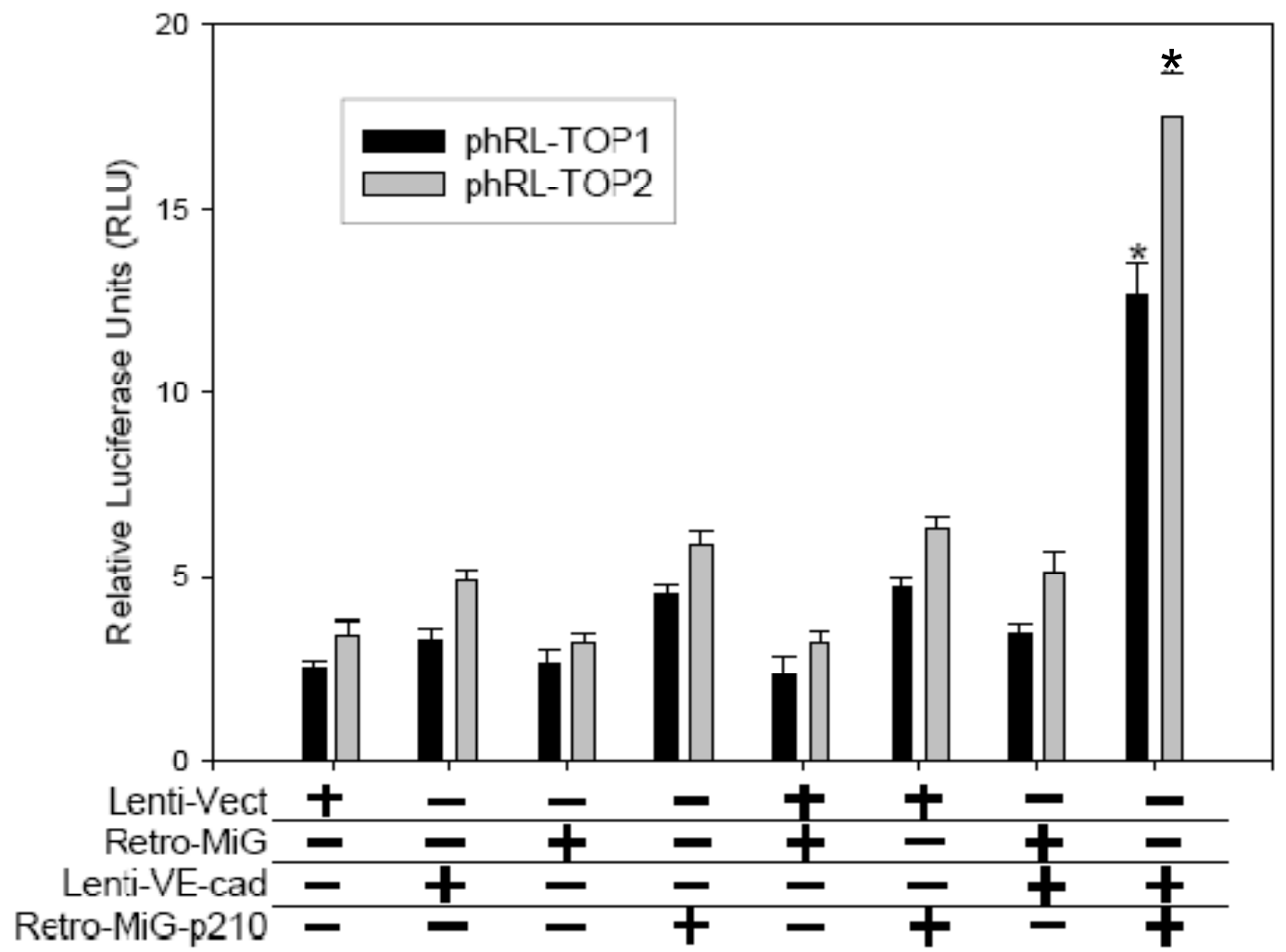

D

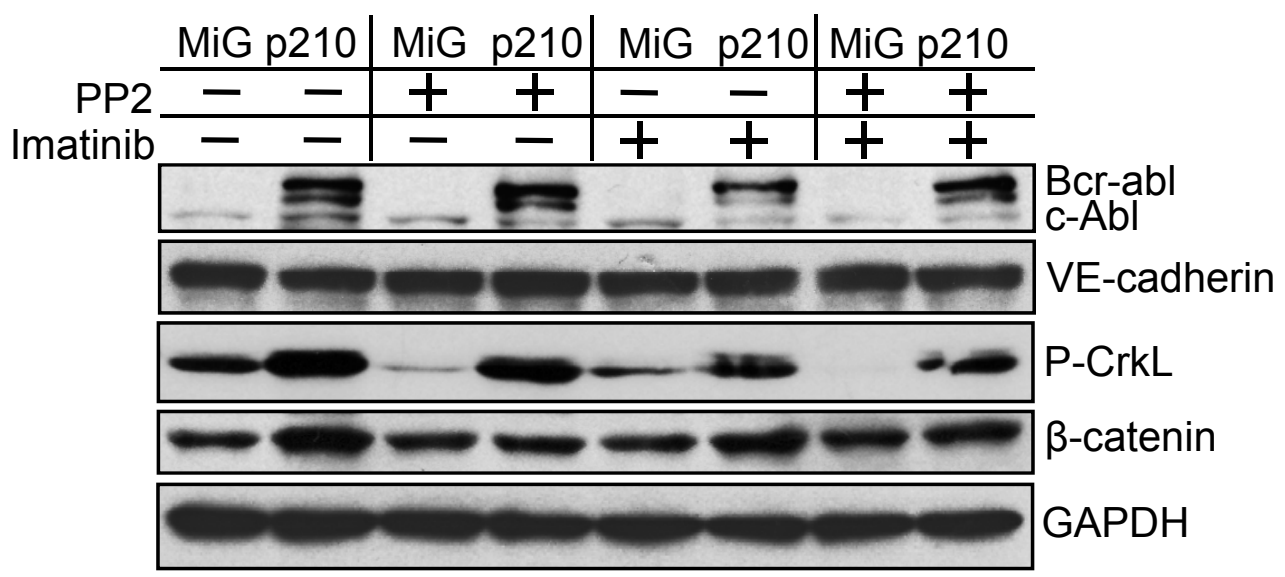

$\beta$-catenin:VE-cadherin $\begin{array}{lllllllll}1.00 & 2.93 & 0.98 & 1.35 & 0.97 & 2.14 & 0.96 & 0.97\end{array}$ 
Figure 7

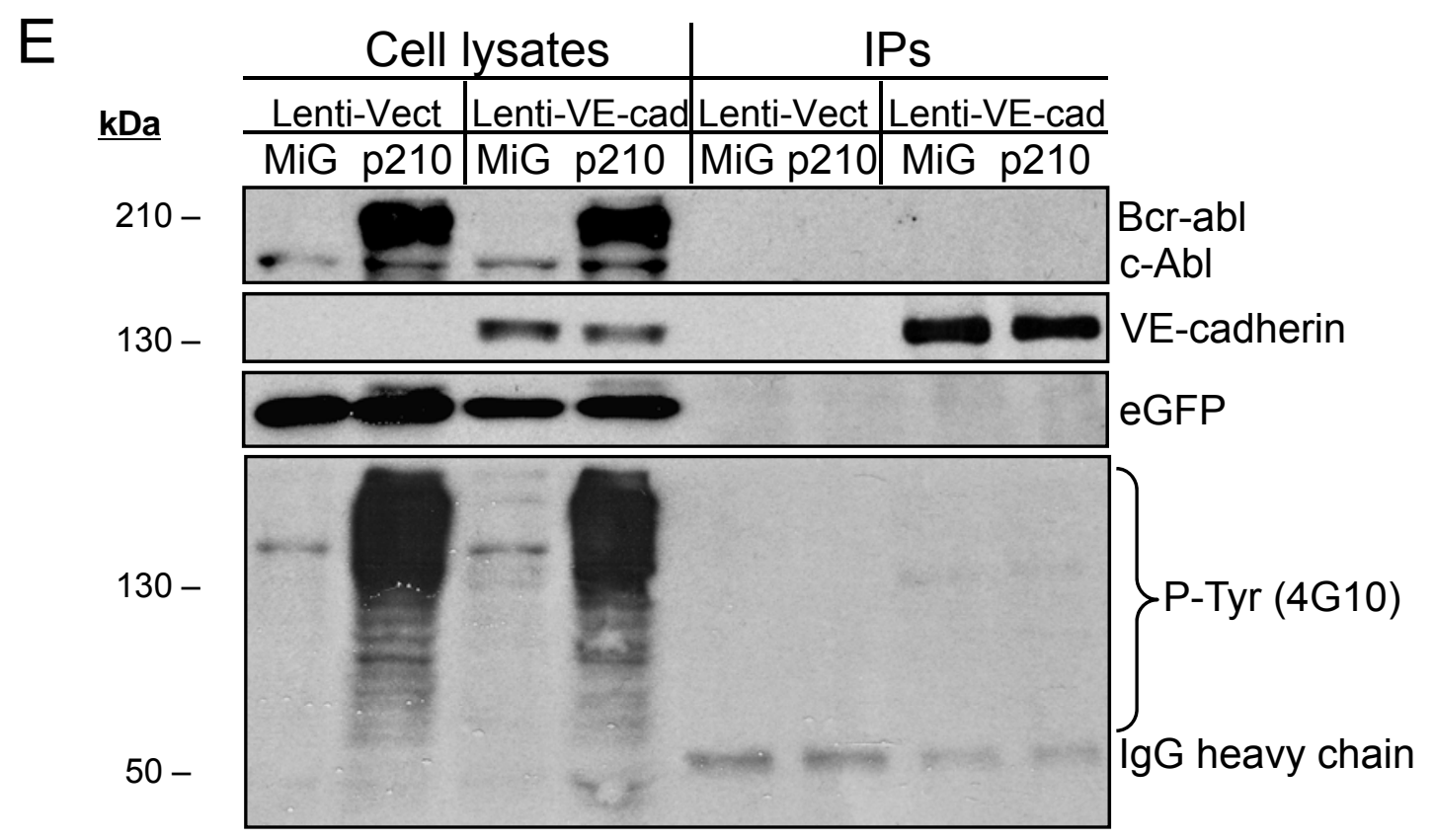

F

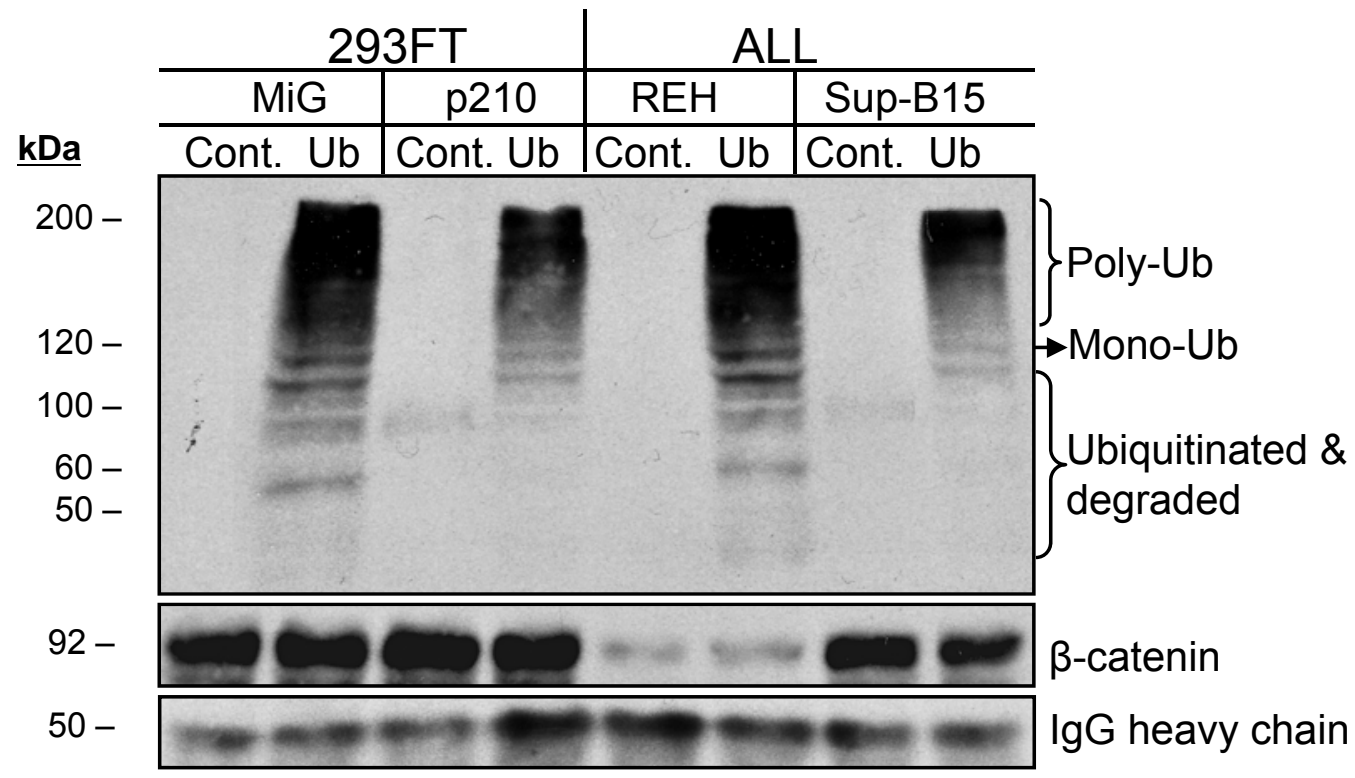




\title{
Chapter 5
}

\section{VE-cadherin Regulates Philadelphia Chromosome Positive Acute Lymphoblastic Leukemia Sensitivity to Apoptosis.}

\author{
Heather O'Leary ${ }^{1,2}$, Stephen M. Akers ${ }^{1,2}$, Debra Piktel ${ }^{2}$, Cheryl \\ Walton ${ }^{4}$, James E. Fortney ${ }^{2}$, Karen H. Martin ${ }^{2,5}$, Michael Craig ${ }^{2}$, \\ James Coad ${ }^{6}$, and Laura F. Gibson ${ }^{1,2,3}$
}

\footnotetext{
${ }^{1}$ Cancer Cell Biology Program, ${ }^{2}$ Mary Babb Randolph Cancer Center, ${ }^{3}$ Department of Microbiology, Immunology and Cell Biology, ${ }^{4}$ Department of Pediatrics, ${ }^{5}$ Department of Neurobiology and Anatomy, ${ }^{6}$ Department of Statistics, ${ }^{7}$ Marshall University Microarray Core Facility,

West Virginia University, School of Medicine, Morgantown, WV 26506
}

Springer/Kluwer Academic Publishers, Cancer Microenvironment 2010, In press. With kind permission of Springer Science and Business Media.

Heather O'Leary, Stephen M. Akers, Debra Piktel, Cheryl Walton, James E. Fortney, Karen H. Martin, Michael Craig, James Coad and Laura F. Gibson 


\begin{abstract}
:
The mechanisms by which the bone marrow microenvironment regulates tumor cell survival are diverse. This study describes the novel observation that in addition to Philadelphia chromosome positive $(\mathrm{Ph}+)$ acute lymphoblastic leukemia $(\mathrm{ALL})$ cell lines, primary patient cells also express Hypoxia Inducible Factor-2 $\alpha$ (HIF-2 $\alpha$ ) and Vascular Endothelial Cadherin (VE-cadherin), which are regulated by Abl kinase. Tumor expression of the classical endothelial protein, VE-cadherin, has been associated with aggressive phenotype and poor prognosis in other models, but has not been investigated in hematopoietic malignancies. Targeted knockdown of VE-cadherin rendered $\mathrm{Ph}+\mathrm{ALL}$ cells more susceptible to chemotherapy, even in the presence of bone marrow stromal cell (BMSC) derived survival cues. Pre-treatment of Ph+ ALL cells with ADH100191, a VE-cadherin antagonist, resulted in increased apoptosis during in vitro chemotherapy exposure. Consistent with a role for VE-cadherin in modulation of leukemia cell viability, lentiviral-mediated expression of VE-cadherin in Ph- ALL cells resulted in increased resistance to treatment-induced apoptosis. These observations suggest a novel role for VE-cadherin in modulation of chemoresistance in $\mathrm{Ph}+\mathrm{ALL}$.
\end{abstract}




\section{Introduction:}

Acute lymphoblastic leukemia (ALL) patients are classified as "high risk" based on the presence of tumor cells harboring the 9;22 translocation (Philadelphia chromosome; $\mathrm{Ph}+$ ). This translocation results in constitutively active Abl kinase, characteristic of cells resistant to standard chemotherapeutic regimens $\{1,2,3,4,5\}$. Although advances in treatment have increased the 5 year event free survival and cure rate, patients with $\mathrm{Ph}+\mathrm{ALL}$ continue to have a high incidence of bone marrow and central nervous system (CNS) relapse relative to $\operatorname{Ph}-\operatorname{ALL}\{6,7\}$. While first line treatment with Imatinib Mesylate (Gleevec, IM), in combination with conventional treatments, was initially thought to be successful in $\mathrm{Ph}+\mathrm{ALL}$, it has been demonstrated that specific mutations in the Abl kinase catalytic domain render this drug ineffective $\{8,9\}$. In addition to mutations inherent to the tumor cell, the role of the microenvironment in modulating drug resistance has proven to be an important factor in the efficacy of treatment in many tumors, including primary and relapsed ALL $\{10\}$. Previous reports indicate the importance of the microenvironment in protection of tumor cell viability during disease initiation and progression, and during treatment $\{11,12,13,14,15,16,17,18,19\}$.

We recently identified a unique population of $\mathrm{Ph}+\mathrm{ALL}$ cells that express Vascular Endothelial Cadherin (VE-cadherin) on their surface and respond to bone marrow stromal cells (BMSC) through stimulation of several anti-apoptotic pathways $\{20\}$. VE-cadherin expression is often discussed in the context of vasculogenic mimicry, a process by which tumor cells gain characteristics normally restricted to endothelial cells, allowing tumors to better utilize microenvironment cues contributing to increased survival $\{21\}$. VE-cadherin expression has also been shown to be an indicator of poor prognosis in melanoma and Ewings sarcoma $\{21,22\}$.

The Hypoxia Inducible Factor (HIF) family of proteins are transcriptional regulators of proangiogenic and survival proteins that have been shown to be important in tumor cell progression and aggressiveness $\{23\}$. HIF-2 $\alpha$ can be regulated by Erk and Akt-induced phosphorylation cascades that either directly phosphorylate HIF-2 $\alpha$ or are involved in its trans-activation $\{24,25,26\}$. Relevant to our 
model, HIF-2 $\alpha$ has been shown to regulate the transcription of VE-cadherin in other systems $\{27\}$. Because HIF-2 $\alpha$ can be active under normoxic conditions it is distinct from the more extensively studied, and more rigorously hypoxia-driven, HIF-1 $\alpha$. HIF-2 $\alpha$ regulates transcriptional targets through binding to distinct promoters, as well as promoters overlapping with HIF-1 $\alpha$, and the ability of HIF-2 $\alpha$ to respond to signals outside hypoxia driven regulation positions it to have both constitutive and hypoxiainduced functions in $\mathrm{Ph}+\mathrm{ALL}\{28\} . \mathrm{HIF}-2 \alpha$ is up-regulated in some primary tumors including bladder, renal and high grade neuroblastomas and is associated with poor prognosis $\{23,26,29,30,31\}$. Therefore, the regulation of HIF-2 $\alpha$ and VE-cadherin expression by bone marrow stromal cells (BMSC), and their role in hematopoietic tumor cell response to treatment, was investigated in the current study.

We demonstrate that, consistent with $\mathrm{Ph}+\mathrm{ALL}$ cell lines, primary $\mathrm{Ph}+$ patient derived leukapheresis samples also express surface VE-cadherin. Primary ALL (Ph+ and Ph-) bone marrow core sections were positive for VE-cadherin expression by IHC. Exposure of Ph+/VE-cadherin+ ALL to IM resulted in diminished HIF-2 $\alpha$ and VE-cadherin. Abl kinase activity, as well as expression of VEcadherin and $\beta$-catenin, are maintained by BMSC contact during in vitro exposure to chemotherapy with lentiviral-mediated surface expression of VE-cadherin increasing chemoresistance. Disruption of VEcadherin by siRNA or the antagonist ADH100191 (ADH) led to increased sensitivity of Ph+ ALL cells to chemotherapy, even in the presence of an adherent microenvironment, BMSC. Collectively, these observations suggest that BMSC may provide cues that converge on hematopoietic tumor cell VEcadherin as one of the factors that modulate response to therapy. 


\section{Materials and methods:}

\section{Cells and reagents}

Ph+ SUP-B15, and Ph- REH, leukemic cell lines were obtained from the ATCC (CRL-1929 and CRL-8286, Manassas, VA) and have been verified by both RT-PCR and fluorescent in situ hybridization (FISH) for analysis of Bcr/Abl, and other, translocations. Primary de-identified $\mathrm{Ph}+(\mathrm{IM}$ resistant) and

Ph- ALL leukophoresis and bone marrow core biopsies were evaluated by fluorescent in situ hybridization (FISH) for analysis of Bcr/Abl translocations. Maintenance and derivation of human BMSC has been previously described $\{11\}$. To establish long-term co-culture (LTCC) of BMSC and leukemic cells, SUP-B15 cells were seeded onto 70\% confluent BMSC, and SUP-B15 were subcultured onto new BMSC weekly for more than 12 months. Long term media cultures (LTMC) include SUP-B15 cells cultured in media alone and were used in short term (24-120 hour) co-culture experiments with adherent BMSC. The Bcr/Abl kinase inhibitor Imatinib Mesylate (IM) (LGM

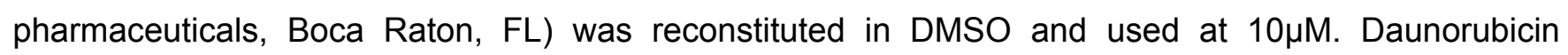
hydrochloride (DNR) (Sigma, St. Louis, MO) was diluted in Iscove's DMEM (CellGRO/Mediatech, Inc. Herndon,VA) immediately prior to use at $0.01-0.1 \mathrm{mg} / \mathrm{ml}$. The peptide antagonist of VE-cadherin, ADH100191, (ADH, Adherex Technologies Inc., Durham, NC) was used at a concentration of $1 \mathrm{mg} / \mathrm{ml}$.

Knockdown of VE-cadherin and HIF-2 $\alpha$ expression by RNAi

SmartPool siRNA for VE-cadherin (CDH5) or HIF-2 $\alpha$ (EPAS-1) was obtained from Dharmacon (Lafayette, CO) and Qiagen (Valencia, CA), respectively. Transient transfection of SUP-B15 cells, with sequence specific siRNA or scrambled control, was completed using oligofectamine (Invitrogen, Carlsbad, CA), 200nM siRNA and $1.5 \times 10^{6}$ cells per reaction as previously described $\{20\}$. Cells were then treated with DNR, and collected at 72 hours for evaluation of viability. Confirmation of knockdown was completed by flow cytometric analysis (FACS). 


\section{Confocal microscopy, flow cytometry and cell viability}

Anti-human antibodies specific for HIF-2 $\alpha$ (flow cytometry), VE-cadherin (flow cytometry) and phosphorylated $\beta$-catenin (confocal microscopy) were purchased from Novus (Littleton,CO clone ep190b), R\&D systems (Minneapolis, MN clone 123433) and Cell Signaling (Beverly, MA), respectively. In addition, a polyclonal antibody to VE-cadherin utilized for confocal microscopy was purchased from AXXORA LLC (San Diego, CA). Intracellular staining (for HIF-2 $\alpha$ and phosphorylated $\beta$-catenin) were completed by fixing the cells in $10 \%$ formaldehyde for 30 minutes, followed by a 30 minute ethanol permeabolization and a BSA block. For all staining, primary antibodies were used at $1 \mu \mathrm{g}$ per sample and all experiments included matched isotype controls. Following incubation in secondary antibody (Alexa fluor 488 or 555), cells were analyzed using a FACScalibur flow cytometer (BD, Franklin Lakes, NJ) with 10,000 events collected. Remaining cells were observed by confocal microscopy. Confocal images were acquired on a Zeiss LSM510 confocal system attached to an Axiolmager Z1 microscope using $40 x$ and $63 x / 1.3$ oil objective and the $405,488,543$ and $633 \mathrm{~nm}$ lasers. DAPI was used as a nuclear stain. The images were acquired and processed using the Zeiss LSM510 software version 3.21 (Carl Zeiss, Thornwood, NY) $\{20\}$. To assess viability, cells were enumerated via trypan blue exclusion, or stained with Annexin V FITC (R\&D systems, Minneapolis, MN) and analyzed by flow cytometry (FACS). Flow cytometric data were analyzed using Win Midi software.

\section{Immunohistochemistry}

Bone marrow core biopsy samples were formalin-fixed, lightly decalcified and paraffinembedded with samples representative of $\mathrm{Ph}+$ and $\mathrm{Ph}$ - patients at either primary or relapse stage of disease as indicated. Five micron sections were hand stained using ducal breast carcinoma as control tissue. In brief, the histologic sections were deparaffinized and antigen retrieval was performed by heating in a tris based buffer for 30 minutes. The primary antibody (mouse monoclonal anti-human VEcadherin, clone BV6; Millipore Billerica, MA) was applied at a dilution of 1:10 for 24 hours; negative controls used a 1:10 diluted mouse lgG2 matched isotype (BD Biosciences, San Jose CA). The slides 
were then incubated for 12 minutes with a conjugated secondary antibody and counterstained with hematoxylin. The slides were then analyzed using routine light microscopy and all images shown are 400x.

\section{Reverse Transcriptase (RT-PCR)}

Total RNA was isolated from leukemic cells using the Micro-to-Midi Total RNA Isolation kit (Invitrogen). Primers for HIF-2 $\alpha$ (EPAS1, PPH02551B), VE-cadherin (CDH5, PPH00668E) and actin, as a housekeeping gene control, were purchased from Superarray (Fredrick, MD). PCR conditions were in the linear range of amplification. Images were cropped to show only data relevant to this paper. However, all comparison data were run on the same gel.

\section{Constitutive expression of VE-cadherin}

Cloning of human VE-cadherin (CDH5) into pLenti6.2-DEST/V5 (Invitrogen), and generation of the pLenti6.2-DEST/V5 empty vector control and lentiviral particles has been described $\{20\}$. To generate lentiviral particles the pLenti6.2-Dest/V5 vectors were transfected into 293FT packaging cells and viral particles were collected, filtered, and concentrated as described by Burns et. al. \{32\}. Lentiviral stocks were titered with HT1080 (ATCC CCL-121) using the blasticidin-resistance colony assay. To generate REH cell lines stably expressing empty vector $\left(R E H^{\text {vect }}\right)$, or VE-cadherin $\left(R E H^{\mathrm{CDH} 5}\right)$, cells were infected with lentiviral supernatants with an $\mathrm{MOI}$ of 1 . Clones stably expressing the genes of interest were selected by blasticidin $(3 \mu \mathrm{g} / \mathrm{mL})$ and expression was confirmed by quantitative real time RT-PCR, flow cytometry and western blot.

\section{Western Blot analysis}

Anti-GAPDH $(1: 10,000)$ and anti-VE-cadherin (1:200) antibodies were purchased from Research Diagnostics Inc., (Flanders, NJ). Anti- $\beta$-catenin (1:200) and anti-phosphorylated CrkL (1:1000) antibodies were purchased from Santa Cruz (Santa Cruz, CA) and Cell Signaling Technology, Inc. (Danvers, MA), respectively. Leukemic cells were lysed in complete cell lysis buffer, protein concentrations were determined and westerns were performed as described by Wang et al $\{20\}$. Signal 
was visualized with enhanced chemiluminescence reagents (Amersham, Pharmacia Biotech, Piscataway, NJ). Images were cropped to show only data relevant to this paper. However, all comparison data were run on the same gel.

\section{Statistics}

Where appropriate, data were analyzed using the Students-t test or ANOVA with statistical significance of $p \leq .001$ denoted by “\#”, $p \leq .01$ by “*”, and $p \leq .05$ by “+”. Annexin experiments were not merged into one data set, but rather representative data from a single experiment are presented that are indicative of the consistent trend. As such, no error bars are shown. While absolute values between experiments may differ based on slightly different tumor cell viabilities at the start of the experiment, the magnitude and trend of the response is consistent. 


\section{Results}

VE-cadherin is expressed in primary, patient derived ALL cells.

Several studies have documented the unexpected presence of VE-cadherin in aggressive types of tumors $\{20,22,33,34,35\}$. Wang et al. showed that VE-cadherin was present in a panel of Philadelphia chromosome positive $(\mathrm{Ph}+)$ cell lines that express a stem cell like phenotype $\{20\}$. To further investigate our previous findings, primary patient derived $\mathrm{Ph}+$ and $\mathrm{Ph}-\mathrm{ALL}$ cells, obtained from leukapheresis, were assessed for the presence or absence of VE-cadherin and HIF-2 $\alpha$, a known regulator of VE-cadherin. Transcripts for VE-cadherin and HIF-2 $\alpha$ were detected in the Ph+ patient leukapheresis cells while patient cells lacking the $\mathrm{Ph}$ translocation had minimal levels of both VEcadherin and HIF-2 $\alpha$ mRNA (Figure 1A). Consistent with the gene expression profiles, Figure 1B shows that VE-cadherin and HIF-2 $\alpha$ proteins were expressed on the $\mathrm{Ph}+$ patient cells (black line) but were negligible on the $\mathrm{Ph}$ - patient cells (gray line). Additionally, 11/12 patient bone marrow core biopsies were positive for VE-cadherin, with four representative samples shown (Figure 1C and Table 1). Although IHC does not allow determination of the precise localization of VE-cadherin, the results are consistent with intracellular flow cytometry staining of $\mathrm{Ph}$ - and $\mathrm{Ph}+\mathrm{ALL}$ following paraformaldehyde fixation of cell lines in which expression of VE-cadherin was detected intracellularly (unpublished data) while only being consistently detected on the surface of $\mathrm{Ph}+$ tumor lines and primary cells. These data demonstrate that the expression patterns and localization of VE-cadherin and HIF-2 $\alpha$ in $\mathrm{Ph}+$ primary patient cells correlate with representative cell lines and suggest that SUP-B15 cells are a relevant model of $\mathrm{Ph}+\mathrm{ALL}$.

\section{BMSC maintain expression of Ph+ ALL VE-cadherin during treatment.}

It has been previously reported that VE-cadherin protein levels are decreased by treatment with Imatinib Mesylate (IM) without significantly altering cell viability in the absence of additional stress, such as chemotherapy $\{20,36\}$. However, the mechanism that underlies this decrease, and the contribution of bone marrow stromal cells (BMSC) to blunting this decrease, are unknown. To determine if the 
decrease in VE-cadherin occurs at the transcriptional level, and if BMSC can offset reduced expression, SUP-B15 cells were co-cultured with BMSC in the presence of IM, or DMSO control, for 24 hours. The relative abundance of VE-cadherin transcripts were decreased by treatment with IM, but co-culture with BMSC blunted the reduction (Figure 2A, left panel). In contrast, the HIF-2 $\alpha$ transcript was not affected by IM exposure (Figure 2A, right panel).

The mechanisms by which HIF-2 $\alpha$, an upstream regulator of VE-cadherin, is regulated in $\mathrm{Ph}+$ ALL, potentially through Abl kinase activity, has not yet been elucidated. Data from our laboratory shows that the activity of Abl kinase can be increased, and maintained during cellular stress, by bone marrow stromal cells (BMSC) and can physically interact with VE-cadherin and $\beta$-catenin $\{20\}$. Interestingly, Akt and Erk, both established regulators of HIF-2 $\alpha$, can be regulated by both Abl kinase and the stromal cell niche $\{12,37,38,39\}$. Therefore, we investigated if HIF-2 $\alpha$ and VE-cadherin were regulated by Abl kinase activity in Ph+ ALL cells. SUP-B15 cells were treated with Imatinib with HIF-2 $\alpha$ and VE-cadherin protein expression analyzed by FACS (Figure 2B). Inhibition of Abl kinase resulted in diminished levels of HIF-2 $\alpha$ and VE-cadherin protein without significantly altering cell viability when no additional stress was applied to the cells, suggesting a link between Abl kinase activity and regulation of the levels of VE-cadherin and HIF-2 $\alpha$. The specific mechanism between Abl activity and HIF-2 $\alpha$ remain to be determined in studies that are beyond the scope of this manuscript and may have relevance in the setting of physiological levels of Abl kinase as well in tumors that do not harbor the Bcr/Abl translocation.

We subsequently evaluated the ability of BMSC contact to modulate Imatinib-induced down regulation of VE-cadherin at the protein level, and found that consistent with the observation at the mRNA level, Imatinib induced a modest down regulation in VE-cadherin protein that was partially offset by the presence of BMSC during treatment as demonstrated by flow cytometric analysis and confocal microscopy (Figure 2C; top and bottom panels respectively). Due to the observations that Abl kinase activity can be increased by BMSC, and that VE-cadherin expression can be maintained by BMSC 
during IM treatment, we investigated the ability of BMSC to maintain VE-cadherin, phosphorylated CrkL (as an indicator of Abl kinase activity) and $\beta$-catenin (a pro-survival factor) during chemotherapy. Figure 2D shows that during treatment with Daunorubicin (DNR) the levels of all 3 proteins are reduced in leukemia cells in the absence of BMSC cues. However, BMSC co-culture increases the levels of all 3 proteins and maintains the increase in the presence of chemotherapy (Figure 2D). These data suggest that HIF-2 $\alpha$ and VE-cadherin protein expression is regulated by Abl kinase activity, with BMSC contact maintaining the expression of Abl kinase, VE-cadherin and $\beta$-catenin during treatment.

\section{The bone marrow microenvironment regulates HIF-2 $\alpha$}

We have shown that leukemic cell Bcr/Abl kinase activity, as well as $\beta$-catenin and VEcadherin, can be maintained by bone marrow stromal cells (BMSC), even in the presence of chemotherapy (Figure 2) and we have previously shown a physical interaction between Bcr/Abl, $\beta$ catenin, VE-cadherin $\{20\}$. The current study, and previous publication, demonstrates that in addition to a physical interaction, a signaling cascade may occur between Bcr/Abl and subsequent stabilization of HIF-2 $\alpha$, VE-cadherin and $\beta$-catenin (Figure 2D) $\{20,40\}$. However, the modulation of HIF-2 $\alpha$ by BMSC has not been investigated. Therefore, we determined the influence of BMSC on HIF-2 $\alpha$ expression. LTMC and LTCC SUP-B15 cells were cultured in media alone or with BMSC. HIF-2 $\alpha$ message and protein expression were analyzed by RT-PCR and FACS, respectively. Data presented in Figure 3A show that in both media alone and during co-culture with BMSC, the message levels of HIF-2 $\alpha$ remain constant. However, HIF-2 $\alpha$ protein is increased by co-culture with BMSC, regardless of whether ALL cells were originally from LTMC or LTCC conditions (Figure 3B). Consistent with this observation, VEcadherin levels increase with BMSC contact as well \{Figure 2C, 20\}. Additionally, when the baseline HIF-2 $\alpha$ expression in LTMC and LTCC cells was compared, by placing SUP-B15 cells from LTMC or LTCC in media for 24 (Figure 3C), or 120 hours (data not shown), the LTCC derived Ph+ ALL cells had higher levels of HIF-2 $\alpha$. This was intriguing as the LTCC cells also have increased resistance to treatment compared to the LTMC cells, and have higher levels of VE-cadherin at baseline $\{20\}$ (data 
not shown). To further substantiate the functional significance of BMSC increasing HIF-2 $\alpha$ protein levels, Oct-4, a stem cell marker and direct transcriptional target of HIF-2 $\alpha$, was evaluated and shown to increase in the presence of BMSC (Figure 3D).Taken together, these data suggest that BMSC increase HIF-2 $\alpha$ protein, as well as targets of HIF- $\alpha$, Oct-4 and VE-cadherin, in our model.

\section{Modulation of VE-cadherin reduces chemotherapy-induced apoptosis}

To further investigate the roles of HIF-2 $\alpha$ and VE-cadherin in regulation of apoptosis, SUP-B15 cells were treated with siRNA specific to HIF-2 $\alpha$, VE-cadherin, or scrambled control sequence. After 72 hours, efficiency of knockdown was determined by FACS (Figure 4A). The labels above the histogram represent the specific siRNA utilized for that experiment compared to the scrambled (Scr) control while the labels on the $\mathrm{X}$ axis correspond to the staining detected for either HIF-2 $\alpha$ or VE-cadherin in those cells. HIF-2 $\alpha$ has been shown to directly regulate the transcription of VE-cadherin and as expected, when HIF-2 $\alpha$ was down-regulated, VE-cadherin decreased as well (Figure 4A top panel).

Surprisingly, when VE-cadherin was down-regulated, slightly less HIF-2 $\alpha$ protein was detected (Figure 4A bottom panel). There are potentially intermediate regulators in this pathway, along with the possibility that HIF-2 $\alpha$ is acting directly as a transcription factor for VE-cadherin gene expression, as documented in studies from other laboratories $\{27\}$. Following down-regulation of HIF-2 $\alpha$ or VEcadherin, SUP-B15 cells were treated with Imatinib Mesylate (IM), Daunorubicin (DNR) or a combination of IM/DNR and viability was evaluated. Cells in which either VE-cadherin or HIF-2 $\alpha$ were down-regulated were more susceptible to chemotherapy-induced death than their controls, and VEcadherin down-regulation rendered the cells susceptible, even when co-cultured with BMSC (Figures 4B and 4C).

To confirm the potential role of surface VE-cadherin in modulation of therapeutic response, $\mathrm{Ph}$ /surface VE-cadherin- REH cells were transduced with a lentiviral vector containing full length VEcadherin $\left(\mathrm{REH}^{\mathrm{CDH5}}\right)$ or empty vector control $\left(\mathrm{REH}^{\text {Vect }}\right)$. Western blot and FACs analysis confirmed expression of VE-cadherin (Figure 5A, data not shown). $\mathrm{REH}^{\mathrm{CDH} 5}$ and $\mathrm{REH}^{\text {Vect }}$ expressing cells were 
challenged with DNR and viability was evaluated. Ph- REH cells expressing surface VE-cadherin show a modest, but statistically significant, increase in survival during chemotherapy compared to their VEcadherin negative vector control (Figure 5B).

\section{Disruption of VE-cadherin signaling as a therapeutic target}

To address the role of VE-cadherin as a potential therapeutic target in Ph+ ALL, ADH100191 $(\mathrm{ADH})$, a specific peptide inhibitor directed against the surface cell adhesion recognition sequence of the VE-cadherin extracellular domain, was utilized. SUP-B15 cells were pre-treated with $1 \mathrm{mg} / \mathrm{ml} \mathrm{ADH}$ for 6 hours prior to treatment with Daunorubicin (DNR). ADH pretreated Ph+/surface VE-cadherin+ leukemic cells were more susceptible to DNR as shown by trypan blue exclusion and Annexin-V-FITC staining (Figure 6A). This effect was consistent and was partially sustained in the presence of BMSC (Figure 6B). In experiments where all cells shown were treated with chemotherapy, ADH/IM, in combination with DNR, increased the sensitivity of the $\mathrm{Ph}+$ cells in media alone with the increased sensitivity sustained in the presence of BMSC (Figure 6C). In contrast, Ph-/surface VE-cadherin- REH cells pre-treated with ADH100191 (ADH) prior to Daunorubicin (DNR) had no increase in response to chemotherapy, demonstrating the specificity of the ADH for surface VE-cadherin positive cells poised to respond to a signaling antagonist (Figure 6D). Due to the specificity of the VE-cadherin antagonist ADH100191 (ADH) for surface VE-cadherin, and the ability of VE-cadherin to be endocytosed from the membrane, we evaluated the expression of surface VE-cadherin in the presence of ADH100191 (Figure 6E).

Our laboratory has previously shown physical interaction between Bcr/Abl, VE-cadherin and $\beta$ catenin in $\mathrm{Ph}+$ cells, a stabilization of $\beta$-catenin in cells expressing all 3 proteins, and the ability of BMSC to increase their expression and maintain expression during treatment (Figure 2C) $\{20\}$. We have additionally determined that $\mathrm{Ph}+$ cell lines have higher baseline levels of $\beta$-catenin compared to Ph- cell lines (unpublished data). Therefore, we sought to determine if the mechanism by which VEcadherin signaling influences response to cytotoxic agents was potentially $\beta$-catenin mediated. 
Treatment of SUP-B15 cells with ADH100191 (ADH) for 6 hours showed an increase in the amount of $\operatorname{Ser}(33,37) / \operatorname{Thr}(41)$ phosphorylated $\beta$-catenin, characteristic of that targeted for degradation, compared to untreated control cells (Figure 7A). Additionally, after treatment with the VE-cadherin antagonist ADH for 24 hours there was a decrease in total $\beta$-catenin protein detected (Figure 7B). 


\section{Discussion:}

In the current study we characterize the impact of VE-cadherin on the sensitivity of Philadelphia chromosome positive $(\mathrm{Ph}+)$ ALL cells to Daunorubicin (DNR) and Imatinib Mesylate (IM) in vitro. While VE-cadherin surface expression in this unique and difficult to treat, sub-type of ALL, and its expression in a panel of patient samples, was somewhat surprising initially, it is not the first description of its expression in non-endothelial cells. Previous studies have shown the expression of VE-cadherin in fetal liver cells with expression subsequently lost in adult stem cells and not present on the surface of Blineage cells $\{41,42\}$. Recent studies have also demonstrated that VE-cadherin is induced during epithelial-to-mesenchymal transition (EMT) in mammary tumor cells $\{35\}$, contributes to vascular mimicry in highly aggressive melanoma $\{43,44\}$ is required for successful endovascular invasion and normal placentation in cytotrophoblast stem cells $\{45\}$, is involved during trans-endothelial migration of metastatic cancer cells and is up-regulated in neighboring vasculature during tumor induced angiogenesis $\{46,47,48,49\}$, and is a critical regulator of TGF- $\beta$ signaling in endothelial cells $\{50\}$. Therefore, it is tempting to speculate that the surface expression of VE-cadherin in Ph+ ALL cells would position these tumors to better interact with signals from the microenvironment that promote tumor cell survival, including TGF- $\beta$. Interestingly, unpublished data from our laboratory observed that BMSC knock down of TGF- $\beta$ diminishes the ability of bone marrow stromal cells (BMSC) to protect B lineage leukemic cells from treatment.

Implications of VE-cadherin as a mediator of aggressive phenotype underscore our interest in understanding its regulation by the microenvironment in which ALL cells thrive. One upstream factor of interest, based on its stabilization by microenvironment-derived cues, and its influence on VE-cadherin expression, is HIF-2 $\alpha$ which can respond to low oxygen levels but also regulates VE-cadherin independent of hypoxia $\{27\}$. Therefore, HIF-2 $\alpha$ supported VE-cadherin expression would allow for homotypic tumor interactions as well as interactions with endothelial cells in bone marrow niches or other anatomical locations that include VE-cadherin positive cells. The expression of high levels of both 
HIF-2 $\alpha$ and VE-cadherin in primary ALL cells is consistent with the literature describing the role of these two proteins in other aggressive tumor models (Figure 1) $\{23,26,33,34,35,46,51\}$. Although one caveat of staining formalin fixed bone marrow core biopsy samples is the lack of specific cellular protein localization determination, it is intriguing to detect expression of VE-cadherin on the majority $(11 / 12)$ of samples and on the surface of $\mathrm{Ph}+$ leukapheresis samples (Figure1). While the interpretation of the IHC staining is limited, it supports the assertion that VE-cadherin protein expression is observed in primary $B$ lineage $A L L$, with the potential that it is stabilized and regulated uniquely in the context of high Abl kinase activity characteristic of Ph+ ALL. Accumulation of high levels of VE-cadherin may result in stabilization of $\beta$-catenin and transcription of downstream targets as we have previously published via binding to the TCF/LEF consensus sequence $\{20\}$ while also being presented on the cell surface where it may respond to inhibition via signaling antagonists such as ADH.

Data presented in the current study also show that forced surface expression of VE-cadherin in Ph- cells significantly increased their viability during treatment (Figure 5). In our model, bone marrow stromal cells (BMSC) modulated and maintained HIF-2 $\alpha$, Oct-4 and VE-cadherin in Ph+ ALL cells (Figure 2, 3) $\{20\}$. Our data suggests that the signaling pathway relies on active Abl kinase influencing HIF-2 $\alpha$, VE-cadherin and subsequently $\beta$-catenin (Figures 2 and 7 ) with potential intermediate effector proteins still to be determined. Importantly, the targeted inhibition of either HIF-2 $\alpha$ or VE-cadherin, during chemotherapy exposure in vitro, significantly diminished cell viability even in the presence of BMSCs (Figures 4 and 6) suggesting relevance in the context of the marrow microenvironment in which leukemic cells are often refractory to therapy, at relapse in particular. Somewhat speculative in nature, but worth consideration, is the possibility that BMSC cues influence tumor resistance to therapy, in part, by maintaining proteins associated with a tumor stem cell phenotype that is coincident with resistance.

HIF-2 $\alpha$ has been documented to increase expression of at least two factors relevant to the stem like phenotype of the Ph+ ALL cells in this study; Oct-4 (Oct-3/4, Pou5F1) $\{52\}$ and VE-cadherin $\{27\}$ under hypoxic and normoxic conditions, respectively. Of note, evaluations of anatomical regions within 
the marrow that support hematopoietic stem cells were localized predominantly to areas of low oxygen perfusion $\{53\}$. Recent literature suggests that over expression of HIF family members, and particularly HIF-2 $\alpha$, promoted differentiation of BMSC to the endothelial lineage $\{28\}$. The hypoxic nature of the stem cell niche in the marrow emphasizes the need to consider the influence of hypoxia on the expression and activity of factors, including the hypoxia inducible factors (HIF-1 $\alpha$ and HIF-2 $\alpha$ ), that can regulate genes that sustain tumor cell survival, proliferation, and self-renewal.

HIF target specificity has been shown to originate through its $\mathrm{N}$-terminal trans-activation domain and distinct target genes have been identified for these two factors, with little functional redundancy even though they have the potential to bind comparable DNA motifs $\{54\}$. The co-factors that contribute to their specificity of binding and gene regulation appear to be cell, tissue, and "circumstance" specific, and investigation of the details are underway to better understand these important factors in regulation of growth, survival, and differentiation. Relevant to our model is the unique role of HIF-2 $\alpha$ in support of VE-cadherin expression, and therefore its potential importance as a transcription factor that may regulate therapeutic response. Further investigation will determine if BMSC derived cues impact on binding partners of HIF-2 $\alpha$ that may influence its effect on ALL cells beyond its role as a transcription factor for VE-cadherin.

Exciting reports have recently emerged describing the use of diverse agents, including the microtubule destabilizing agent CA4P, to selectively disrupt VE-cadherin in endothelial cells $\{55,56\}$. CA4P was shown to increase tumor cell apoptosis without negatively affecting smooth muscle cells or the normal vasculature, highlighting its promise as a therapeutic agent. Our recent observations suggest that, in general, agents designed to disrupt vasculature and tumor angiogenesis, particularly those that target VE-cadherin, may have previously unappreciated benefit through their direct effects on hematopoietic tumor cells while not damaging normal cells or the stem cell pool $\{41,42\}$. Our utilization of the VE-cadherin antagonist, ADH100191 (ADH), demonstrates the importance of VEcadherin in $\mathrm{Ph}+\mathrm{ALL}$ cells, with the VE-cadherin antagonist having no effect on Ph- ALL cells (Figure 
6D) while decreasing the viability of $\mathrm{Ph}+$ cells during chemotherapy (Figures 6 and 7). The fact that hematopoietic tumor cells lacking surface VE-cadherin were spared any effect by ADH100191 underlies speculation that normal hematopoietic cells might also be unaffected by this agent making it a potentially useful chemo-sensitization therapy. It also suggests that while the majority of both $\mathrm{Ph}+$ and Ph- primary cells expressed VE-cadherin protein when a "total" protein IHC approach was utilized, the efficacy of VE-cadherin antagonists may be logically limited to those tumors in which the VE-cadherin is presented on the cell surface. The modulation of $\beta$-catenin in response to inhibition of VE-cadherin in our model of lymphoid leukemia (Figure 7 ) is consistent with a recent report documenting that $\beta$-catenin is essential for survival of $\mathrm{Ph}+$ myeloid leukemic stem cells $\{57,58\}$. Although the changes in viability when VE-cadherin signaling is inhibited are quantitatively modest, they remain relevant in the context of the significant proliferative potential of a small residual tumor load in the setting of aggressive leukemia which may subsequently contribute to relapse of disease.

Potentially, signals from the bone marrow microenvironment culminate on targets that are also impacted by the hypoxic nature of protective niches. Sustained expression of surface VE-cadherin in $\mathrm{Ph}+\mathrm{ALL}$ cells, supported by signals inherent to the tumor such as high Abl kinase activity and through microenvironment cues that influence transcriptional regulators including HIF-2 $\alpha$ and $\beta$-catenin, provide us a model in which we can begin to investigate the complexity of survival signals in the marrow milieu. From these models we can optimize novel therapeutic strategies designed to target residual tumor cells that are refractory to standard therapy by understanding the critical targets on which survival signals converge. Pathways that we have traditionally considered in the context of a solid tumor cell survival and support of vasculogenesis and angiogenesis warrant further consideration in the biology of hematological malignancies as well. 


\section{$\underline{\text { Reference List }}$}

1 Carroll,W.L., Bhojwani,D., Min,D.J., et al. Pediatric acute lymphoblastic leukemia, Hematology.Am.Soc.Hematol.Educ.Program., 102-131, 2003.

2 Pieters,R. and Carroll,W.L. Biology and treatment of acute lymphoblastic leukemia, Pediatr.Clin.North Am., 55: 1-20, ix, 2008.

3 Hoelzer,D. Acute lymphoblastic leukemia--progress in children, less in adults, N.Engl.J.Med., 329: 1343-1344, 1993.

4 Faderl,S., Kantarjian,H.M., Thomas,D.A., et al. Outcome of Philadelphia chromosome-positive adult acute lymphoblastic leukemia, Leuk.Lymphoma, 36: 263-273, 2000.

5 Radich,J.P. Philadelphia chromosome-positive acute lymphocytic leukemia, Hematol.Oncol.Clin.North Am., 15: 21-36, 2001.

6 Bailey,L.C., Lange,B.J., Rheingold,S.R. and Bunin,N.J. Bone-marrow relapse in paediatric acute lymphoblastic leukaemia, Lancet Oncol., 9: 873-883, 2008.

7 Pui,C.H. and Howard,S.C. Current management and challenges of malignant disease in the CNS in paediatric leukaemia, Lancet Oncol., 9: 257-268, 2008.

$8 \mathrm{Li}, \mathrm{S}$. and Li,D. Stem cell and kinase activity-independent pathway in resistance of leukaemia to BCR-ABL kinase inhibitors, J.Cell Mol.Med., 11: 1251-1262, 2007.

9 Jones,D., Thomas,D., Yin,C.C., et al. Kinase domain point mutations in Philadelphia chromosome-positive acute lymphoblastic leukemia emerge after therapy with BCR-ABL kinase inhibitors, Cancer, 113: 985-994, 2008.

10 Meads,M.B., Hazlehurst,L.A. and Dalton,W.S. The bone marrow microenvironment as a tumor sanctuary and contributor to drug resistance, Clin.Cancer Res., 14: 2519-2526, 2008.

11 Mudry,R.E., Fortney,J.E., York,T., Hall,B.M. and Gibson,L.F. Stromal cells regulate survival of Blineage leukemic cells during chemotherapy, Blood, 96: 1926-1932, 2000.

12 Wang,L., Fortney,J.E. and Gibson,L.F. Stromal cell protection of B-lineage acute lymphoblastic leukemic cells during chemotherapy requires active Akt, Leuk.Res., 28: 733-742, 2004.

13 Hall,B.M., Fortney,J.E., Taylor,L., et al. Stromal cells expressing elevated VCAM-1 enhance survival of B lineage tumor cells, Cancer Lett., 207: 229-239, 2004.

14 Sethi,T., Rintoul,R.C., Moore,S.M., et al. Extracellular matrix proteins protect small cell lung cancer cells against apoptosis: a mechanism for small cell lung cancer growth and drug resistance in vivo, Nat.Med., 5: 662-668, 1999.

15 Hazlehurst,L.A., Damiano,J.S., Buyuksal,I., Pledger,W.J. and Dalton,W.S. Adhesion to fibronectin via beta1 integrins regulates p27kip1 levels and contributes to cell adhesion mediated drug resistance (CAM-DR), Oncogene, 19: 4319-4327, 2000. 
16 Aoudjit,F. and Vuori,K. Integrin signaling inhibits paclitaxel-induced apoptosis in breast cancer cells, Oncogene, 20: 4995-5004, 2001.

17 Shain,K.H., Yarde,D.N., Meads,M.B., et al. Beta1 integrin adhesion enhances IL-6-mediated STAT3 signaling in myeloma cells: implications for microenvironment influence on tumor survival and proliferation, Cancer Res., 69: 1009-1015, 2009.

18 Iwamoto,S., Mihara,K., Downing,J.R., Pui,C.H. and Campana,D. Mesenchymal cells regulate the response of acute lymphoblastic leukemia cells to asparaginase, J.Clin.Invest, 117: 1049-1057, 2007.

19 Nishigaki,H., Ito,C., Manabe,A., et al. Prevalence and growth characteristics of malignant stem cells in B-lineage acute lymphoblastic leukemia, Blood, 89: 3735-3744, 1997.

20 Wang,L., O'Leary,H., Fortney,J. and Gibson,L.F. Ph+/VE-cadherin+ identifies a stem cell like population of acute lymphoblastic leukemia sustained by bone marrow niche cells, Blood, 110: 33343344, 2007.

21 Hendrix,M.J., Seftor,E.A., Hess,A.R. and Seftor,R.E. Molecular plasticity of human melanoma cells, Oncogene, 22: 3070-3075, 2003.

22 van der Schaft,D.W., Hillen,F., Pauwels,P., et al. Tumor cell plasticity in Ewing sarcoma, an alternative circulatory system stimulated by hypoxia, Cancer Res., 65: 11520-11528, 2005.

23 Maynard,M.A. and Ohh,M. The role of hypoxia-inducible factors in cancer, Cell Mol.Life Sci., 64: 2170-2180, 2007.

24 Akeno,N., Robins,J., Zhang,M., Czyzyk-Krzeska,M.F. and Clemens,T.L. Induction of vascular endothelial growth factor by IGF-I in osteoblast-like cells is mediated by the PI3K signaling pathway through the hypoxia-inducible factor-2alpha, Endocrinology, 143: 420-425, 2002.

25 Conrad,P.W., Freeman,T.L., Beitner-Johnson,D. and Millhorn,D.E. EPAS1 trans-activation during hypoxia requires p42/p44 MAPK, J.Biol.Chem., 274: 33709-33713, 1999.

26 Qing,G. and Simon,M.C. Hypoxia inducible factor-2alpha: a critical mediator of aggressive tumor phenotypes, Curr.Opin.Genet.Dev., 19: 60-66, 2009.

27 Le Bras,A., Lionneton,F., Mattot,V., et al. HIF-2alpha specifically activates the VE-cadherin promoter independently of hypoxia and in synergy with Ets-1 through two essential ETS-binding sites, Oncogene, 26: 7480-7489, 2007.

28 Ben-Shoshan,J., Schwartz,S., Luboshits, G et al. Constitutive expression of HIF-1alpha and HIF2alpha in bone marrow stromal cells differentially promotes their proangiogenic properties, Stem Cells, 26: 2634-2643, 2008.

29 Jones,A., Fujiyama,C., Blanche,C., et al. Relation of vascular endothelial growth factor production to expression and regulation of hypoxia-inducible factor-1 alpha and hypoxia-inducible factor-2 alpha in human bladder tumors and cell lines, Clin.Cancer Res., 7: 1263-1272, 2001.

30 Holmquist-Mengelbier,L., Fredlund,E., Lofstedt,T., et al. Recruitment of HIF-1alpha and HIF2alpha to common target genes is differentially regulated in neuroblastoma: HIF-2alpha promotes an aggressive phenotype, Cancer Cell, 10: 413-423, 2006. 
31 Raval,R.R., Lau,K.W., Tran,M.G., et al. Contrasting properties of hypoxia-inducible factor 1 (HIF1) and HIF-2 in von Hippel-Lindau-associated renal cell carcinoma, Mol.Cell Biol., 25: 5675-5686, 2005.

32 Burns,J.C., Friedmann,T., Driever,W., Burrascano,M. and Yee,J.K. Vesicular stomatitis virus G glycoprotein pseudotyped retroviral vectors: concentration to very high titer and efficient gene transfer into mammalian and nonmammalian cells, Proc.Natl.Acad.Sci.U.S.A, 90: 8033-8037, 1993.

33 Hendrix,M.J., Seftor,E.A., Meltzer,P.S., Gardner,L.M., Hess,A.R., Kirschmann,D.A., Schatteman,G.C. and Seftor,R.E. Expression and functional significance of VE-cadherin in aggressive human melanoma cells: role in vasculogenic mimicry, Proc.Natl.Acad.Sci.U.S.A, 98: 8018-8023, 2001.

34 Smith,M.E., Brown,J.I. and Fisher,C. Epithelioid sarcoma: presence of vascular-endothelial cadherin and lack of epithelial cadherin, Histopathology, 33: 425-431, 1998.

35 Labelle,M., Schnittler,H.J., Aust,D.E., et al. Vascular endothelial cadherin promotes breast cancer progression via transforming growth factor beta signaling, Cancer Res., 68: 1388-1397, 2008.

36 Vrekoussis,T., Stathopoulos,E.N., De,G.U., et al. Modulation of vascular endothelium by imatinib: a study on the EA.hy 926 endothelial cell line, J.Chemother., 18: 56-65, 2006.

37 Atfi,A., Abecassis,L. and Bourgeade,M.F. Bcr-Abl activates the AKT/Fox O3 signalling pathway to restrict transforming growth factor-beta-mediated cytostatic signals, EMBO Rep., 6: 985-991, 2005.

38 Cortez,D., Reuther,G. and Pendergast,A.M. The Bcr-Abl tyrosine kinase activates mitogenic signaling pathways and stimulates G1-to-S phase transition in hematopoietic cells, Oncogene, 15: 2333-2342, 1997.

39 Tabe,Y., Jin,L., Tsutsumi-Ishii,Y., et al. Activation of integrin-linked kinase is a critical prosurvival pathway induced in leukemic cells by bone marrow-derived stromal cells, Cancer Res., 67: 684-694, 2007.

40 Coluccia,A.M., Vacca,A., Dunach,M.,et al. Bcr-Abl stabilizes beta-catenin in chronic myeloid leukemia through its tyrosine phosphorylation, EMBO J., 26: 1456-1466, 2007.

$41 \mathrm{Kim}, \mathrm{I}$., Yilmaz,O.H. and Morrison,S.J. CD144 (VE-cadherin) is transiently expressed by fetal liver hematopoietic stem cells, Blood, 106: 903-905, 2005.

42 Koga,H., Sugiyama,S., Kugiyama,K., et al. Elevated levels of VE-cadherin-positive endothelial microparticles in patients with type 2 diabetes mellitus and coronary artery disease, J.Am.Coll.Cardiol., 45: 1622-1630, 2005.

43 Hendrix,M.J., Seftor,E.A., Hess,A.R. and Seftor,R.E. Vasculogenic mimicry and tumour-cell plasticity: lessons from melanoma, Nat.Rev.Cancer, 3: 411-421, 2003.

44 Seftor,E.A., Meltzer,P.S., Schatteman,G.C., et al. Expression of multiple molecular phenotypes by aggressive melanoma tumor cells: role in vasculogenic mimicry, Crit Rev.Oncol.Hematol., 44: 17-27, 2002. 
45 Zhou,Y., Fisher,S.J., Janatpour,M.,et al. Human cytotrophoblasts adopt a vascular phenotype as they differentiate. A strategy for successful endovascular invasion?, J.Clin.Invest, 99: 2139-2151, 1997.

46 Parker,B.S., Argani,P., Cook,B.P., et al. Alterations in vascular gene expression in invasive breast carcinoma, Cancer Res., 64: 7857-7866, 2004.

47 Shih,S.C., Robinson,G.S., Perruzzi,C.A., et al. Molecular profiling of angiogenesis markers, Am.J.Pathol., 161: 35-41, 2002.

48 Weis,S., Cui,J., Barnes,L. and Cheresh,D. Endothelial barrier disruption by VEGF-mediated Src activity potentiates tumor cell extravasation and metastasis, J.Cell Biol., 167: 223-229, 2004.

49 Voura,E.B., Sandig,M. and Siu,C.H. Cell-cell interactions during transendothelial migration of tumor cells, Microsc.Res.Tech., 43: 265-275, 1998.

50 Rudini,N., Felici,A., Giampietro,C.,et al. VE-cadherin is a critical endothelial regulator of TGF-beta signalling, EMBO J., 27: 993-1004, 2008.

51 Lofstedt,T., Fredlund,E., Holmquist-Mengelbier,L., et al. Hypoxia inducible factor-2alpha in cancer, Cell Cycle, 6: 919-926, 2007.

52 Covello,K.L., Kehler,J., Yu,H.,et al. HIF-2alpha regulates Oct-4: effects of hypoxia on stem cell function, embryonic development, and tumor growth, Genes Dev., 20: 557-570, 2006.

53 Parmar,K., Mauch,P., Vergilio,J.A., Sackstein,R. and Down,J.D. Distribution of hematopoietic stem cells in the bone marrow according to regional hypoxia, Proc.Natl.Acad.Sci.U.S.A, 104: 54315436, 2007.

54 Hu,C.J., Sataur,A., Wang,L., Chen,H. and Simon,M.C. The N-terminal transactivation domain confers target gene specificity of hypoxia-inducible factors HIF-1alpha and HIF-2alpha, Mol.Biol.Cell, 18: 4528-4542, 2007.

55 Vincent,L., Kermani,P., Young,L.M., et al. Combretastatin A4 phosphate induces rapid regression of tumor neovessels and growth through interference with vascular endothelial-cadherin signaling, J.Clin.Invest, 115: 2992-3006, 2005.

56 Petit,I., Karajannis,M.A., Vincent,L., et al. The microtubule-targeting agent CA4P regresses leukemic xenografts by disrupting interaction with vascular cells and mitochondrial-dependent cell death, Blood, 111: 1951-1961, 2008.

$57 \mathrm{Hu}, Y$., Chen,Y., Douglas,L. and Li,S. beta-Catenin is essential for survival of leukemic stem cells insensitive to kinase inhibition in mice with BCR-ABL-induced chronic myeloid leukemia, Leukemia, 23 : 109-116, 2009.

58 Abrahamsson,A.E., Geron,I., Gotlib,J.,et al. Glycogen synthase kinase 3beta missplicing contributes to leukemia stem cell generation, Proc.Natl.Acad.Sci.U.S.A, 106: 3925-3929, 2009. 


\section{Figure Legends:}

Figure 1: Patient derived ALL cells express VE-cadherin and HIF-2 $\alpha$. A) RNA was isolated from $5 \times 10^{6}$ patient derived cells and RT-PCR was performed for HIF-2 $\alpha$, VE-cadherin or actin. B) $1 \times 10^{6}$ patient derived $\mathrm{Ph}+$ (black line) and $\mathrm{Ph}$ - (gray line) cells were obtained from leukapheresis and stained to detect HIF-2 $\alpha$ (intracellular), VE-cadherin (surface), or matched isotype control and analyzed by FACS. C) $\mathrm{Ph}+$ and $\mathrm{Ph}$ - primary patient bone marrow core biopsies were stained for VE-cadherin or matched isotype control. 11/12 samples were positive for VE-cadherin and 4 representative samples are shown. All samples were positive for CD19, CD10, CD22, HLADR and TDT.

\section{Fiqure 2: Bone marrow stromal cells maintain Ph+ ALL expression of VE-cadherin during}

Imatinib treatment. A) SUP-B15 cells were cultured in media alone or co-cultured with BMSC and subsequently treated with $10 \mu \mathrm{M}$ Imatinib Mesylate (IM). RT-PCR was performed for VE-cadherin, HIF$2 \alpha$ and actin. B) SUP-B15 cells were exposed to DMSO as the control solvent, or to $10 \mathrm{uM}$ IM, for 24 hours. HIF-2 $\alpha$ and VE-cadherin proteins were evaluated by FACS. C) SUP-B15 cells were cultured in either media alone, in contact with BMSC, or in contact with BMSC and Imatinib for 24 hours. Tumor cells were subsequently fixed with $4 \%$ PFA, permeabilized with $0.5 \%$ Triton-X 100 and stained with anti-VE-cadherin antibody or a matched isotype control for evaluation by confocal microscopy (images shown are $63 \mathrm{X}$ with no zoom) or following the standard protocol described in materials and methods for flow cytometric analysis. D) SUP-B15 cells were cultured in media alone, or in the presence of BMSC for 24 hours, and subsequently treated with $0.1 \mathrm{mg} / \mathrm{ml}$ DNR overnight. Cells were collected, lysed and western blots were completed to analyze Bcr/abl activity as well as VE-cadherin and $\beta$-catenin expression. GAPDH was used as a loading control. Loading of gels is as follows: Lane 1 is media alone, Lane 2 is DNR treatment, Lane 3 is co-culture with BMSC and Lane 4 is co-culture with BMSC and DNR treatment.

Figure 3: Bone marrow stromal cells modulate HIF-2 $\alpha$. A \& B) LTMC and LTCC SUP-B15 cells were cultured in media alone or in the presence of BMSC. HIF-2 $\alpha$ mRNA and protein were evaluated 
by RT-PCR and FACS, respectively. C) LTMC and LTCC cells were placed in media for 24 hours and their baseline expression of HIF-2 $\alpha$ was evaluated by FACS. D) SUP-B15 cells were cultured in media alone or in the presence of BMSC and evaluated for expression of Oct-4.

Figure 4: Modulation of VE-cadherin results in altered chemosensitivity. A) SUP-B15 cells were transiently transfected with scrambled, HIF-2 $\alpha$, or VE-cadherin siRNA and conformation of downregulation was determined using FACS. B \& C) siRNA transfected cells were subsequently cultured in media alone or in the presence of BMSC and exposed to $10 \mathrm{uM} \mathrm{IM}$ or DMSO and $0.01 \mathrm{mg} / \mathrm{ml} \mathrm{DNR}$. Cell viability was determined by trypan blue exclusion and Annexin-V-FITC.

Figure 5: Expression of VE-cadherin decreases leukemic cell sensitivity to chemotherapy. A) Ph-/surface VE-cadherin- REH cells were transduced with virus containing empty vector control $\left(\mathrm{REH}^{\text {Vect }}\right)$ or wild type CDH5 (REH $\left.{ }^{\mathrm{CDH} 5}\right)$. Western blot was completed to demonstrate expression of VEcadherin. B) $\mathrm{REH}^{\text {Vect }}$ and $\mathrm{REH}^{\mathrm{CDH5}}$ cells were challenged with $0.6 \mathrm{mg} / \mathrm{ml} \mathrm{DNR}$ for 48 hours and viability was evaluated by trypan blue exclusion.

Figure 6: Disruption of VE-cadherin signaling using the VE-cadherin antagonist ADH increases Ph+ ALL sensitivity to apoptosis. A \& B) SUP-B15 were cultured in media alone or co-cultured with BMSC for 24 hours. The cells were then pre-treated with $1 \mathrm{mg} / \mathrm{ml} \mathrm{ADH}$, or media control, for 6 hours and subsequently challenged with chemotherapy $(0.1 \mathrm{mg} / \mathrm{ml}$ Daunorubicin (DNR)/24 hours). Viability was determined by trypan blue exclusion and Annexin-V-FITC. C) SUP-B15 cells we cultured in media alone or in the presence of BMSC for 24 hours, pre-treated with either media/DMSO, IM, ADH or a combination of IM \& ADH for 6 hours prior to treatment with DNR. Cell viability was then determined by trypan blue analysis. Statistical significance is shown comparing both the SUP-B15 on BMSC treated with DNR to the IM/DNR, ADH/DNR or IM/ADH/DNR groups as well as the comparison between the IM/DNR or ADH/DNR to IM/ADH/DNR. D) Ph- REH cells were pre-treated with $1 \mathrm{mg} / \mathrm{ml}$ or $2 \mathrm{mg} / \mathrm{ml} \mathrm{ADH}$ for 6 hours and subsequently treated with $0.6 \mathrm{mg} / \mathrm{ml}$ DNR. Viability was determined by Annexin-V-FITC. 
E. SUP-B15 cells were treated with media alone or with $1 \mathrm{mg} / \mathrm{ml}$ ADH for 24 hours and surface stained for VE-cadherin.

\section{Figure 7: Inhibition of VE-cadherin signaling leads to targeted degradation of $\beta$-catenin. A)}

SUP-B15 cells were treated with $1 \mathrm{mg} / \mathrm{ml}$ ADH or media control for 4 hours and subsequently stained for phospho- $\beta$-catenin (Ser33/37 and Thr41) or matched isotype control. Cells were analyzed by confocal microscopy (images shown are 40X with zoom). B) SUP-B15 cells were treated with $1 \mathrm{mg} / \mathrm{ml}$ $\mathrm{ADH}$ or media control for 24 hours and analyzed by western blot to observe changes in total $\beta$-catenin. Samples shown were run on the same gel, in outer lanes, and therefore the image was cut to show only bands relevant to the current study.

\section{Table 1:}

\begin{tabular}{|c|c|c|c|c|c|c|c|}
\hline Ph Status & $\%$ Marrow Involved & Age & Sex & Status & Normal Karyotype & Additional translocations/deletions & VE-cadherin \\
\hline Negative & 96 & 17 & M & Primary & Yes & & Positive \\
\hline Negative & 91 & 4 & $\mathrm{~F}$ & Primary & No & Trisomy 21 & Positive \\
\hline Negative & 81 & 2 & $\mathrm{~F}$ & Primary & Yes & TEL/AML fusion in $79 \%$ of cells $t(12 ; 21)$ & Positive \\
\hline Negative & 82 & 25 & M & Recurrent & No & $\begin{array}{l}\text { This is an abnormal karyotype with } \\
\text { translocation between chromosomes } 1 \\
\text { and } 9 \text {, involving the abl gene on } \\
\text { chromosome } 9 \text { in over half the cells. } \\
\text { About } 2 / 3 \text { of these cells also have an } \\
\text { additional translocation between } \\
\text { chromosomes } 12 \text { and } 22 \text {, which does not } \\
\text { involve the bcr locus. There was also a } \\
\text { single cells with unrelated multiple } \\
\text { structural abnormalities. } \\
\text { Previous bone marrow aspirates from } \\
3 / 1 / 07,3 / 27 / 07 \text { and } 11 / 1 / 07 \text { have had } \\
\text { normal male karyotypes. }\end{array}$ & Positive \\
\hline Negative & 97 & 7 & M & Primary & No & No information listed & Positive \\
\hline Negative & 87 & 11 & M & Primary & No & Hyperploidy of chromsomes 9 and 21 & Positive \\
\hline Negative & 91 & 4 & M & Primary & No & Tel/AML fusion & Positive \\
\hline Positive & 96 & 53 & $\mathrm{~F}$ & Primary & No & $84 \%$ of cells had $t(9 ; 22)$ & Positive \\
\hline Positive & 55 & 4 & M & Primary & Yes & $16 \%$ of cells had $t(9 ; 22)$ & Negative \\
\hline Positive & 90 & 48 & $\mathrm{~F}$ & Primary & No & $86 \%$ of cells had $t(9 ; 22)$ & Positive \\
\hline Positive & 80 & 68 & M & Primary & & & Positive \\
\hline Positive & 33 & 55 & M & Recurrent & No post BMT & $12 \%$ of cells had $t(9 ; 22)$ & Positive \\
\hline Positive & 80 & 54 & M & Primary & & $11 / 12$ cells $t(9 ; 22)$ & Positive \\
\hline
\end{tabular}

Table 1: Patient derived ALL cells express VE-cadherin. Table is representative of patient history of samples stained for VE-cadherin. All samples were positive for CD19, CD10, CD22, HLADR and TDT. 
A

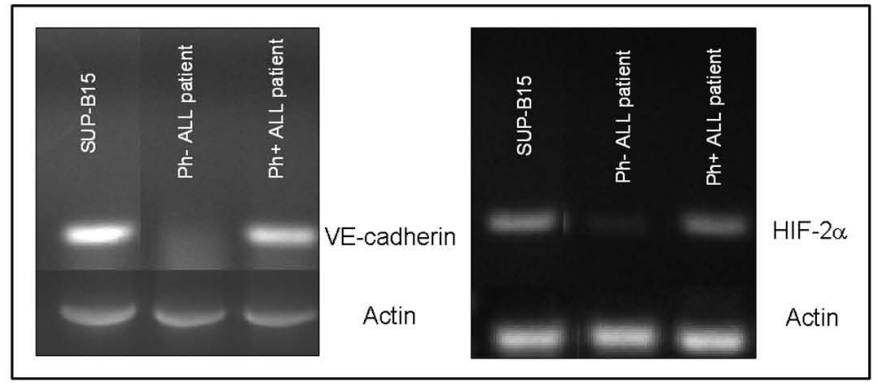

B
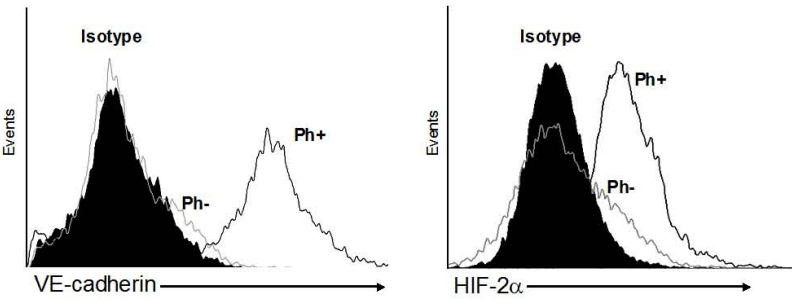

C
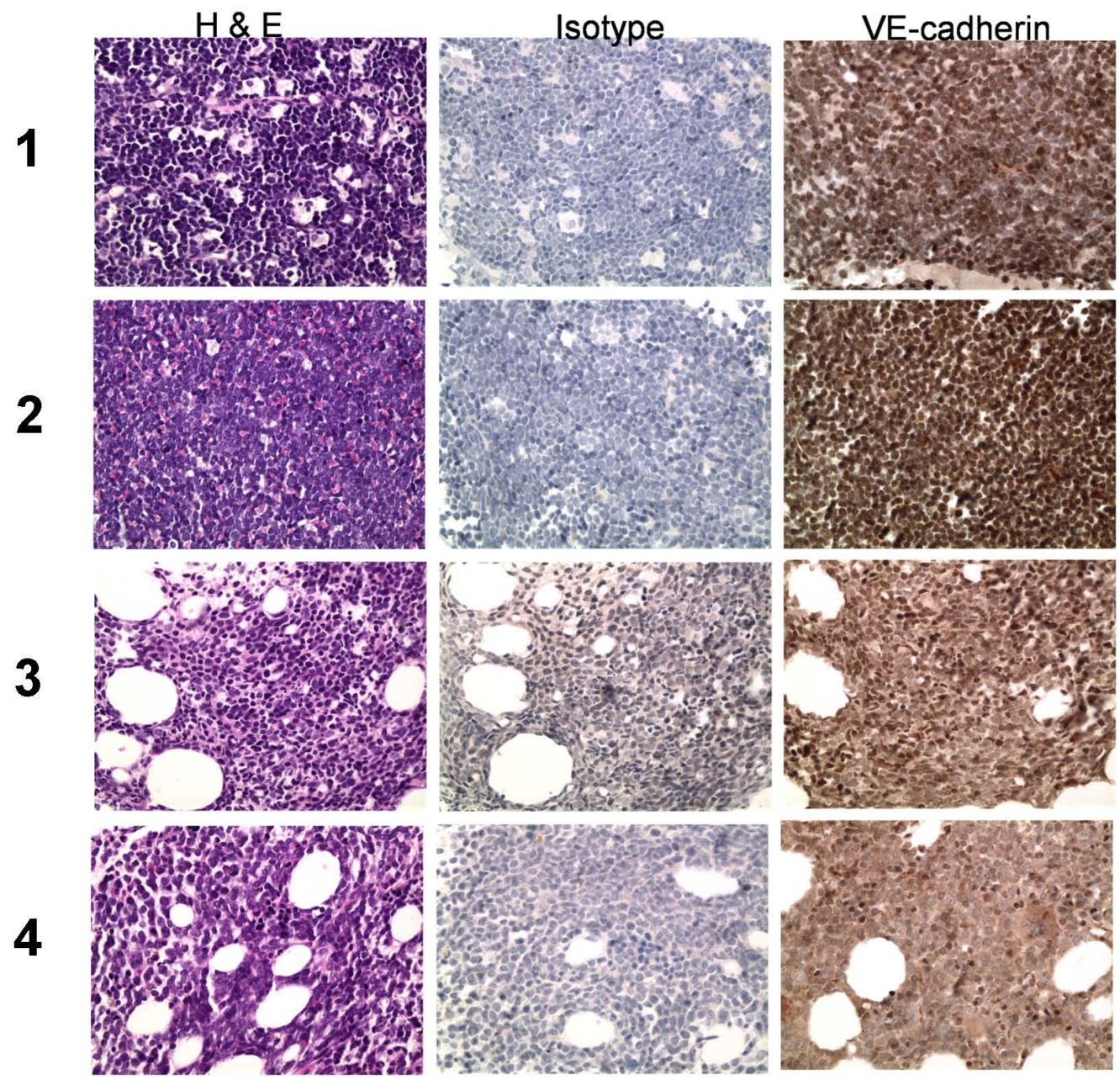

$\underline{\text { Bcr;Ab }}$

1: Ph-

2: $\mathrm{Ph}-$

3: $\mathrm{Ph}+$

53

F
Age

17

4

F

Primary collection

Primary

Normal

Trisomy 21

Karyotype

Status of disease at
Primary

184

Relapse
Minor Bcr $\mathrm{t}(9 ; 22)$ 
Figure 2

A

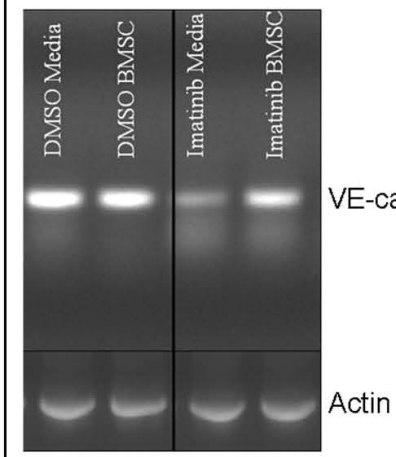

B

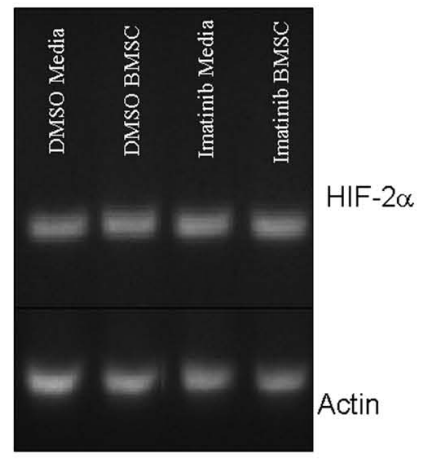

\section{Imatinib}

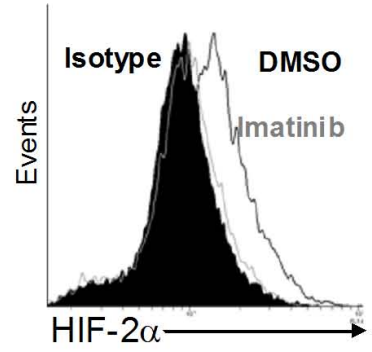

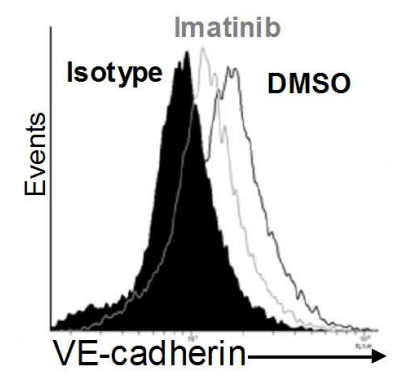
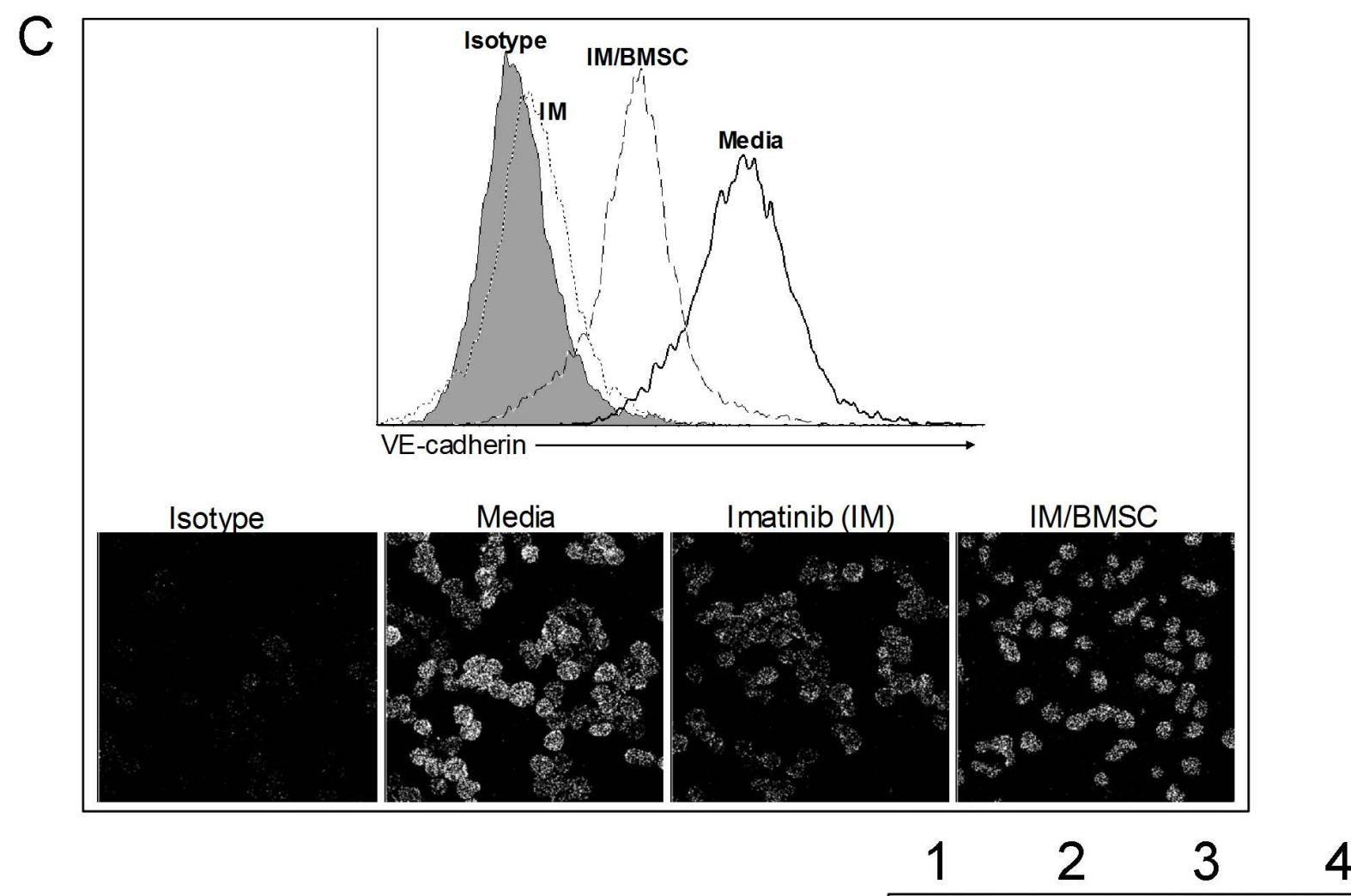

D

\section{VE-cadherin} (130 kD)

GAPDH

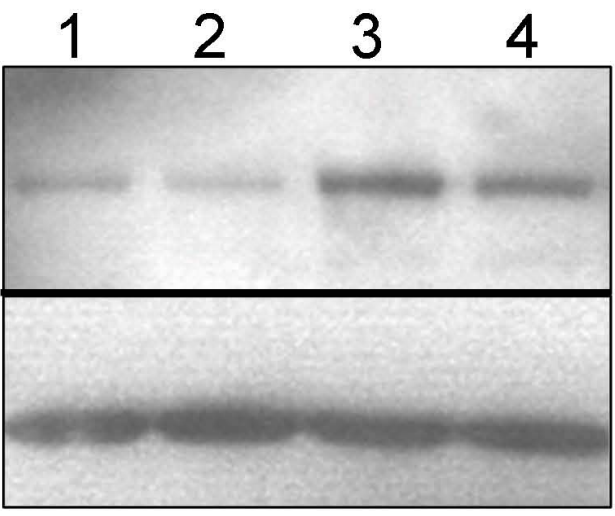

P-CrkL

(39kD)

$\beta$-catenin

(92kD)

(36kD)

185 GAPDH

(36kD) 
Figure 3

B

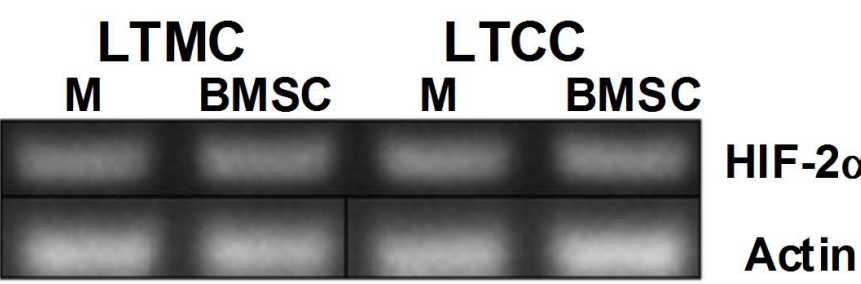

\section{LTMC}

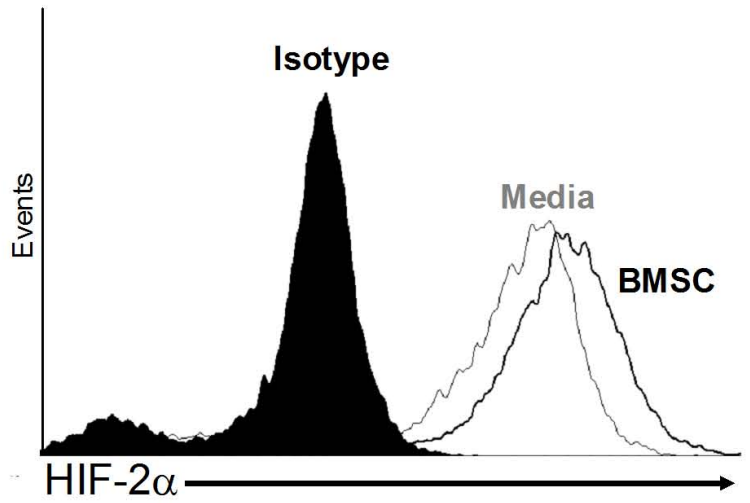

LTCC

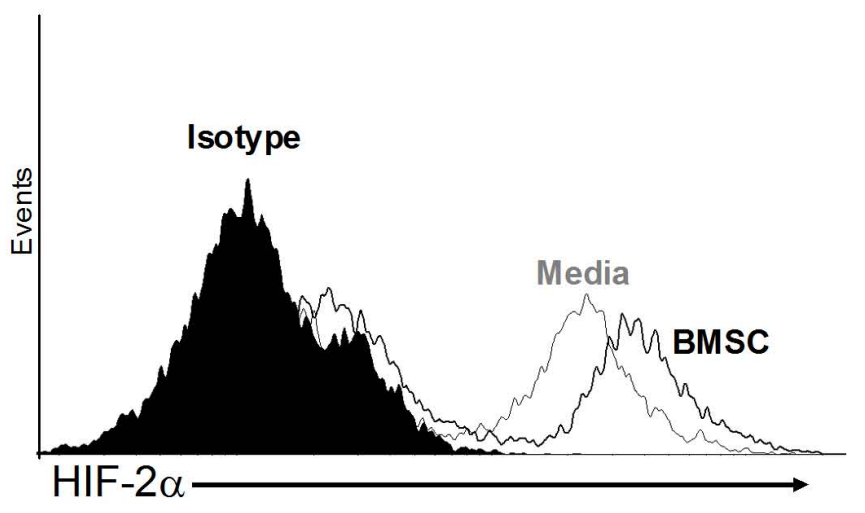

\section{C}

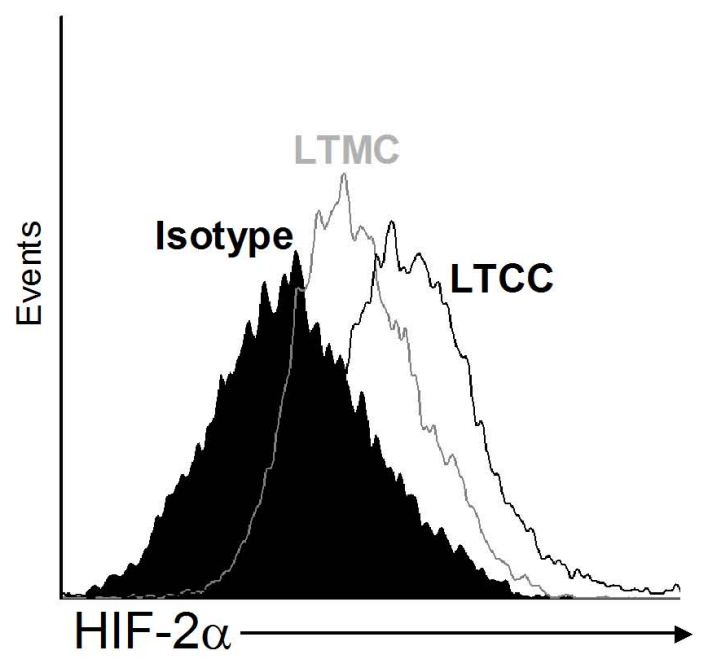

D

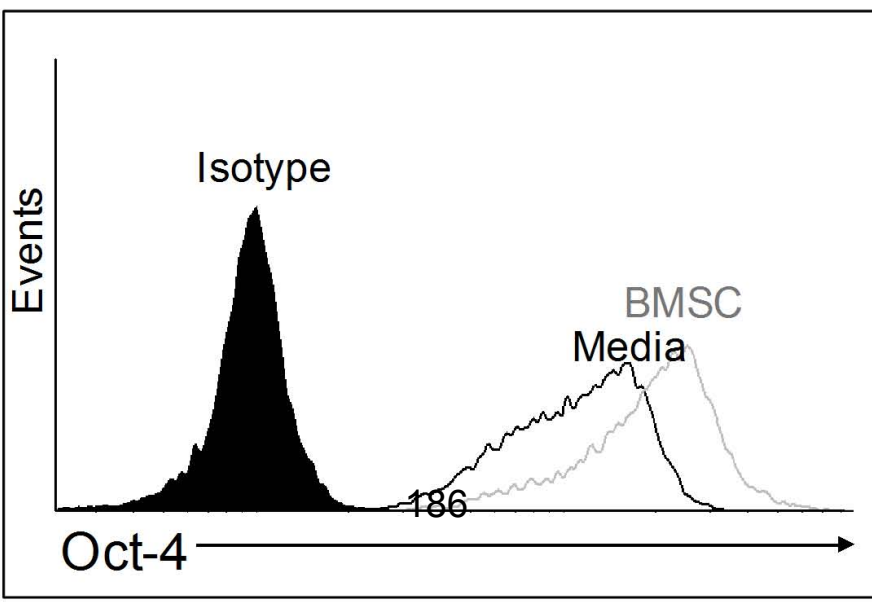


Figure 5

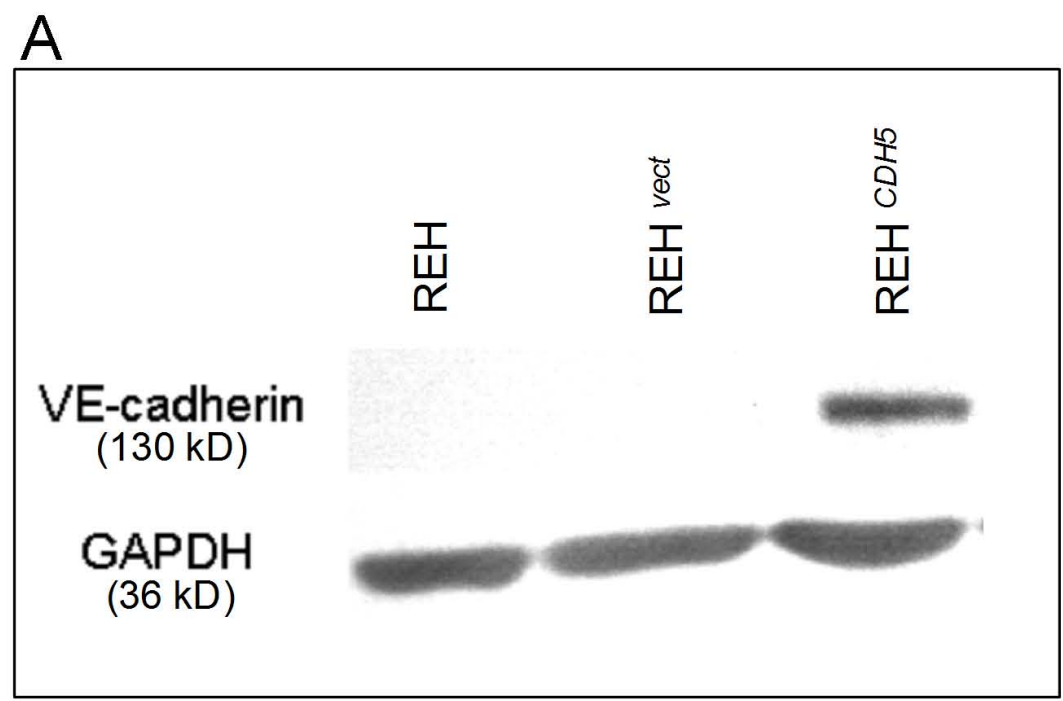

B

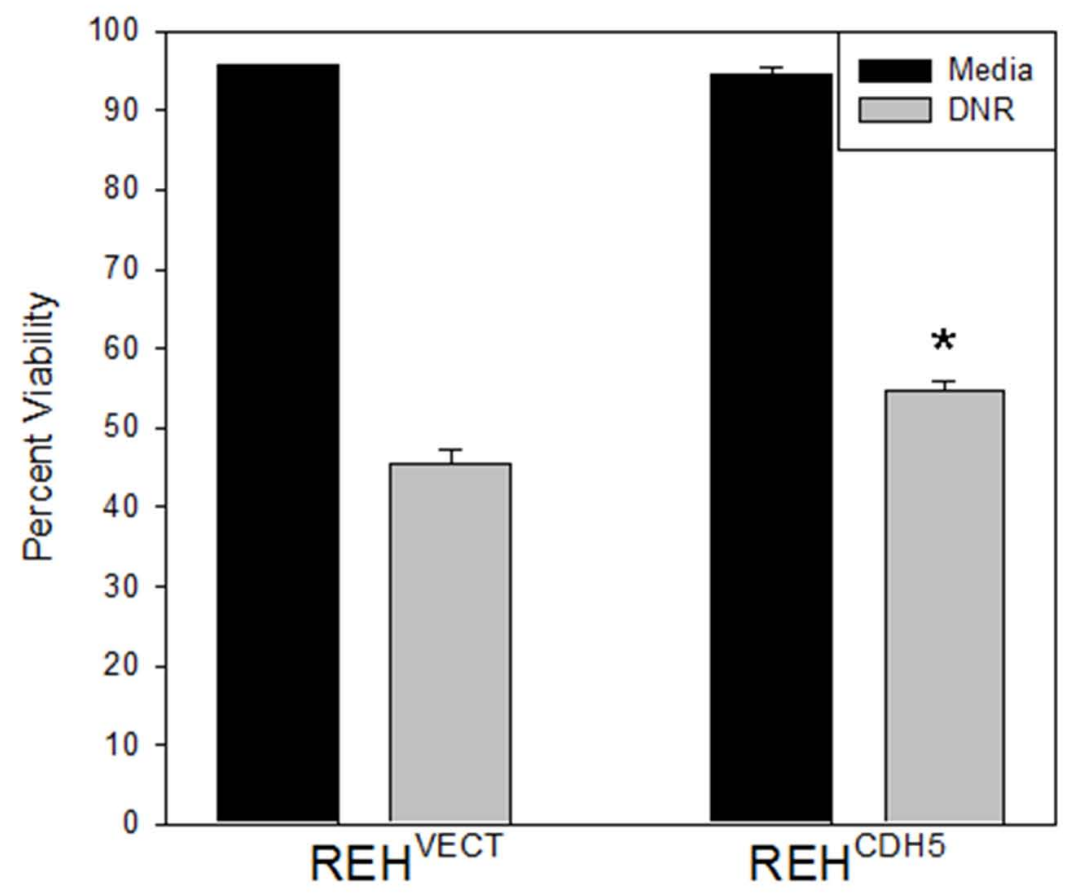


Figure 6

A

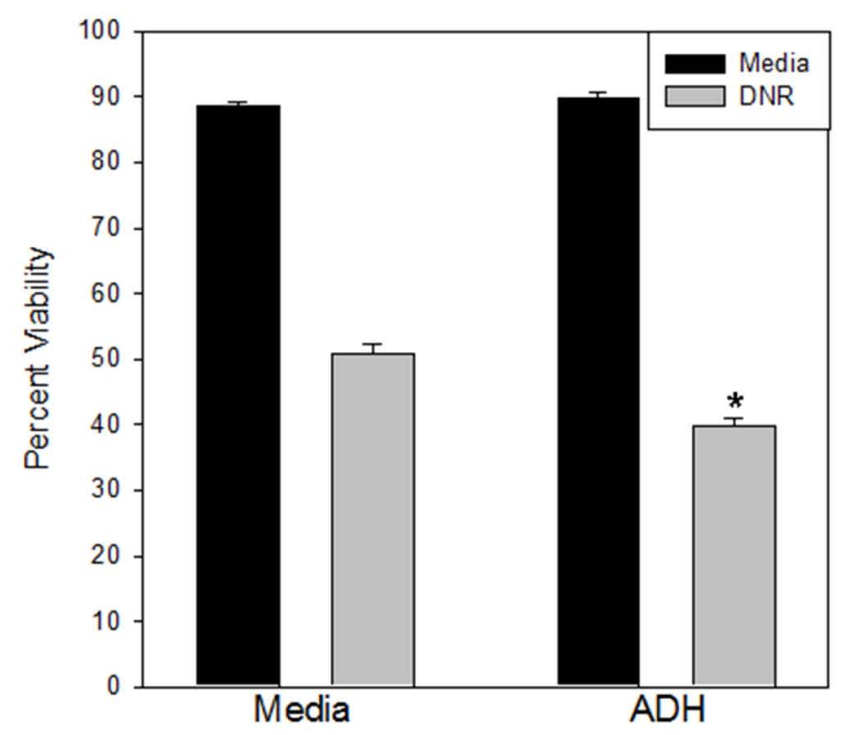

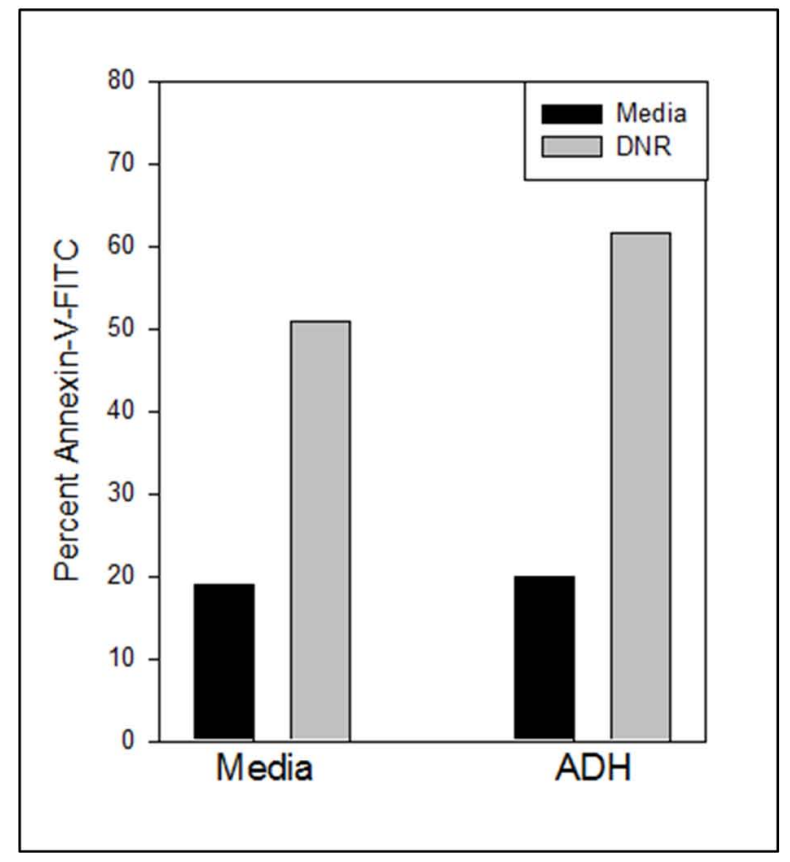

B

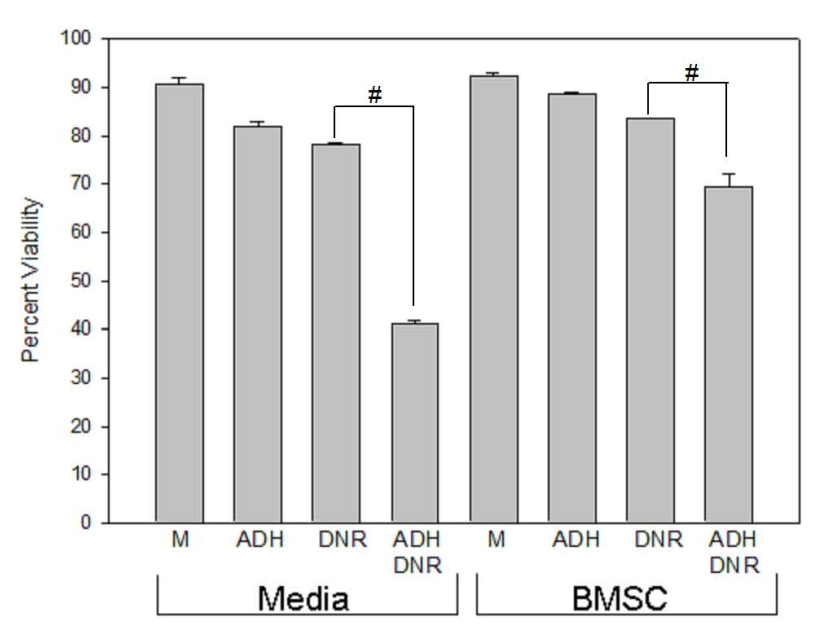

D

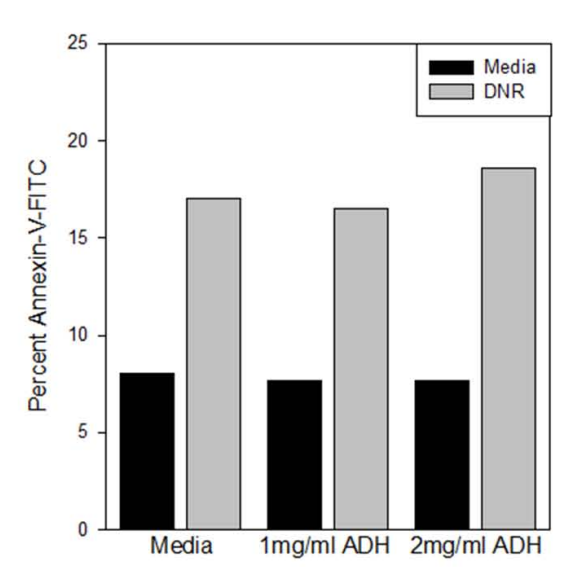

C

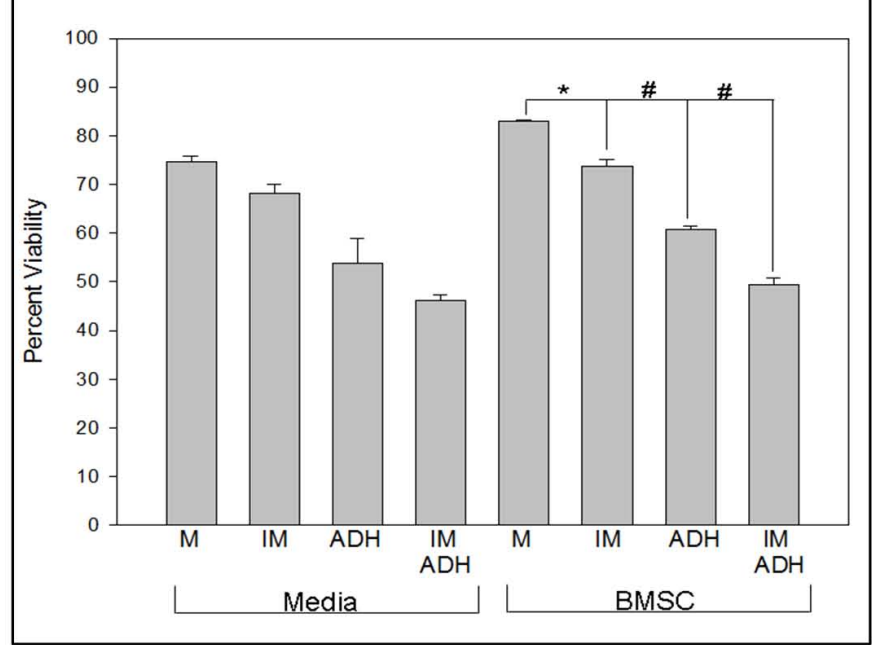

E

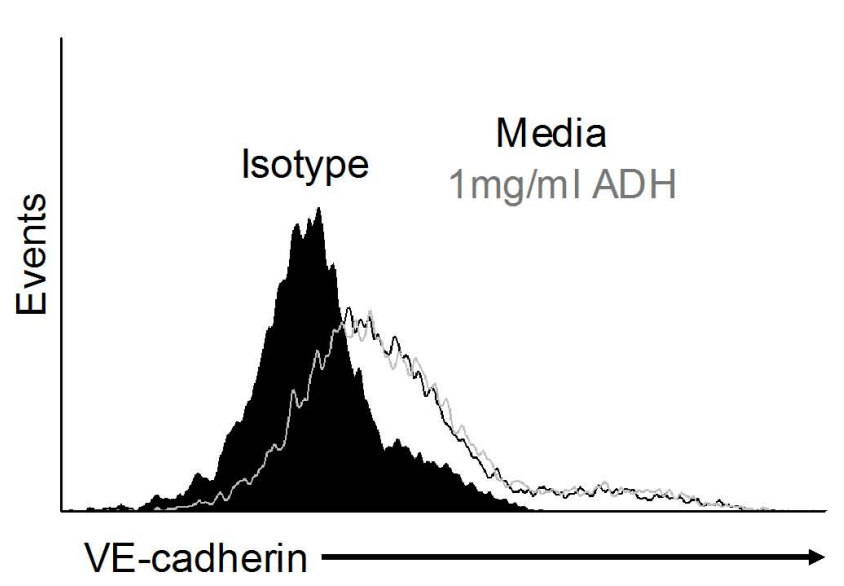


Figure 7

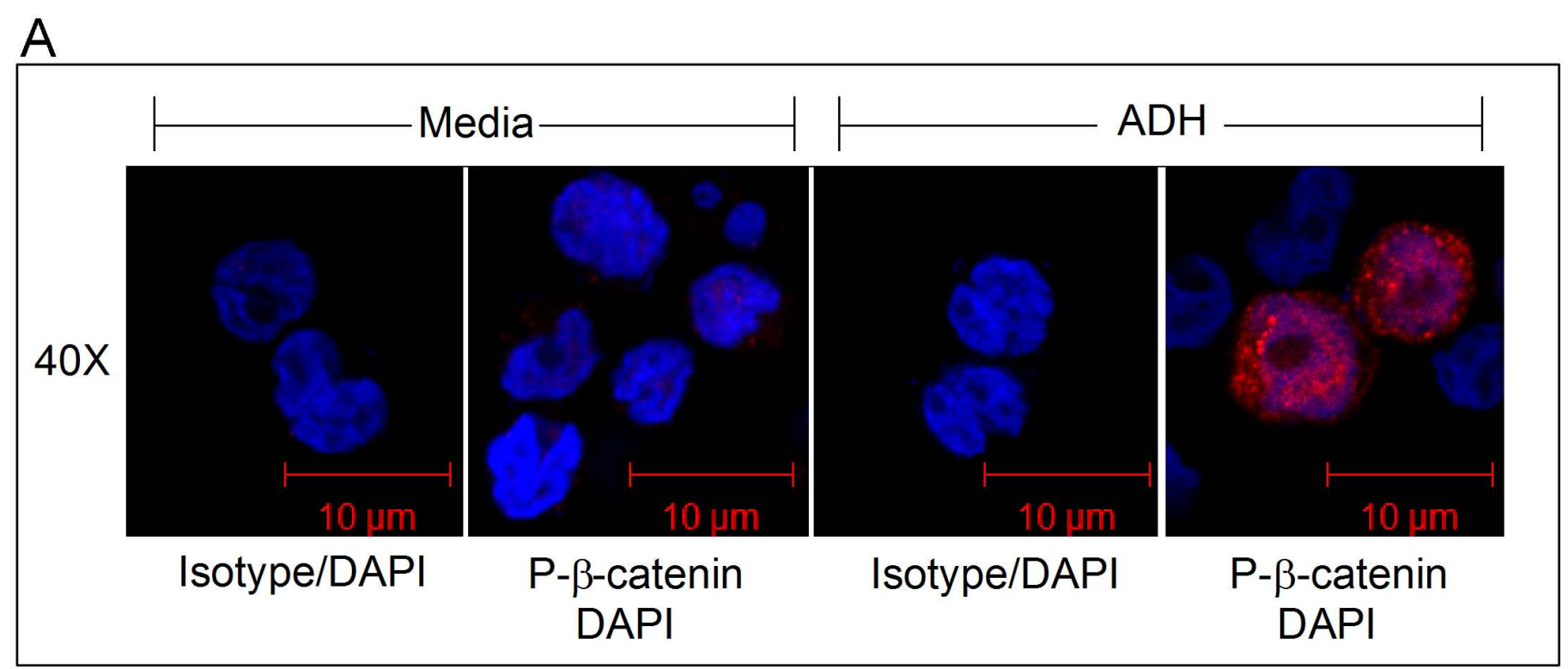

B

\begin{tabular}{|c|c|c|}
\hline & $\frac{\sqrt{0}}{\frac{D}{8}}$ & $\frac{T}{Q}$ \\
\hline $\begin{array}{c}\text { } \beta \text {-catenin } \\
(92 \mathrm{kD})\end{array}$ & 5 & $=9$ \\
\hline $\begin{array}{l}\text { GAPDH } \\
(36 \mathrm{kD})\end{array}$ & & \\
\hline
\end{tabular}


Chapter 6

\section{Discussion}




\section{Discussion:}

The broad goals of the studies presented in this work were two-fold. They are unified by an interest in understanding critical biological events that occur in the bone marrow microenvironment. First, we sought to better understand the direct and indirect damage of aggressive chemotherapy on supportive cells in the marrow, with focus on osteoblasts. As critical regulators of steady state hematopoeisis, as well as hematopoietic recovery following transplantation, we focused this investigation on the functional vulnerability of marrow osteoblasts and the mechanistic underpinnings of treatment-induced changes in osteoblasts that would negatively influence their capacity to support human stem, and progenitor, cell development. Based on the capacity of the marrow to nurture development of normal hematopoietic cells ${ }^{1 ; 2}$, and $B$ lineage cells in particular ${ }^{3-5}$, we next sought to evaluate interactions between B lineage hematopoietic tumors (ALL) and the marrow microenvironment. This investigation further drew on similarities that exist, and the fine line between, normal hematopoiesis and the development of hematopoietic malignancies - processes that share common signaling pathways and anatomical location ${ }^{6 ; 7}$. Investigations into ALL cell support by the marrow microenvironment, and mechanisms by which microenvironment derived cues modulate chemosensitivity as well as a "tumor stem cell" phenotype, brought into focus regulatory proteins that had not been previously appreciated in this context, including VE-cadherin.

To evaluate the effect of ablative chemotherapy on the endosteal niche, a key regulatory component of stem cell development in the bone marrow microenvironment, human primary derived osteoblasts $(\mathrm{HOB})$ were utilized and treated with a high dose of Melphalan and Etoposide (VP-16) which are clinically relevant chemotherapeutic agents for high-dose therapy prior to stem cell transplant ${ }^{8}$. The translational relevance of this study is drawn, in part, from the observation that patients who have received ablative 
therapy and stem cell transplantation report deficits in hematopoietic recovery up to 15 years post transplant compared to their normal counterparts ${ }^{9}$. This suggests that even after transplant there is residual damage to the microenvironment that alters the ability of the transplanted cells to normally incorporate and differentiate in the stem cell niche. While our mechanistic studies could not recapitulate this time frame, they did offer insight into possible reasons that underlie these reported deficits including alterations of cytokine and chemokine profiles subsequent to stress. Obtaining a better understanding of therapy induced damage has the potential to identify critical pathways that could be modulated during the aggressive pre-transplantation stage of treatment to increase the efficiency of hematopoietic recovery, and diminish the risks to patients, during this critical stage.

Initial studies included chemotherapy treated osteoblasts examined for both alterations in gene and protein expression as well as through functional assays. Studies from our laboratory and others had previously shown that ablative therapy increased the amount of active TGF- $\beta$ (transforming growth factor- $\beta$ ) secreted by bone marrow stromal cells ${ }^{10-12}$. Although results from patient tissues vary, some studies have shown that bone marrow stromal cells taken from patients who received ablative therapy had increases in active TGF- $\beta$ compared to their normal counterparts ${ }^{11}$. This led us to the hypothesis that osteoblasts in the endosteal niche may not only be damaged directly by ablative chemotherapy (ie: high dose Melphalan or VP-16) but also indirectly from the high levels of TGF- $\beta$ being secreted by the BMSC. Based on this question, we initiated experiments to determine if ablative chemotherapy would result in an increase in osteoblast secreted active TGF- $\beta$ and alter the ability of osteoblasts to support human embryonic stem cells and pro-B cells. 
These studies confirmed that dose escalated Melphalan or VP-16, at concentrations that mimic those reported in serum of patients prior to bone marrow transplantation, resulted in increases in the amount of active TGF- $\beta$ secreted by the osteoblasts, as measured by SMAD-3 phosphorylation. Additionally, HOB treated with high dose Melphalan, VP-16, or recombinant TGF- $\beta$ had diminished capacity to support pluripotent embryonic stem cell colonies, as measured by expression of the pluripotent stem cell protein Oct-4. Osteoblasts treated with chemotherapy or rTGF- $\beta$ had diminshed CXCL12 mRNA and protein as well as reduced pro-B cell chemotaxis and adherence to the HOB. Collectively, these results suggest that ablative therapy alters the osteoblasts' secretion of active TGF- $\beta$, suggesting that chemotherapy damage may result from both direct, and indirect effects, on the osteoblasts through paracrine and autocrine mechanisms. These data correlate with retrospective patient data and suggests a role for TGF- $\beta$ in the inability of engraftment and correct differentiation of stem cell transplants.

The overall conclusions of this study show for the first time that osteoblasts are damaged in response to both direct chemotherapy, as well as indirect TGF- $\beta$ secretion from damaged BMSC, and that both types of damage diminish the osteoblasts ability to support primitive and progenitor cells. This work gives insight into the broad damage done by ablative chemotherapy and a potential mechanism for the inhibition of engraftment and differentiation of transplanted HSC. Although this work answers some questions regarding damage during pre-transplant ablative therapy, it emphasizes the need for further studies to observe: 1) the impact of ablative therapy on MSC to determine if damage to the progenitor cells that osteoblasts and BMSC are derived from retain the damage caused by chemotherapy in a heritable manner, 2) studies in mouse models and subsequently patients to determine if the same damage seen in vitro is 
occurring in vivo consistent with hematopoietic deficits seen in patients post transplant as well as the incidence of minimal residual disease and relapse, 3) the determination of other factors that may be playing a role, and if the damage can be reversed, or diminished by the use of inhibitors such as the TGF- $\beta$ inhibitors (p144, LY2109761 and GC1008) currently in clinical trials, 4) in vitro and in vivo studies focusing on the mechanisms by which TGF- $\beta$ alters the engraftment and differentiation of HSC transplants and finally 5) an increase in the number of retrospective studies to better understand the potential genetic or epigenetic changes that may be present in patients who successfully have their marrow reconstituted after transplant, without delayed hematopoietic recovery, compared to those that do not. Interestingly, the infusion of MSC during hematopoietic stem cell transplants is beginning to be explored to treat other diseases such as stroke, auditory defects, type 1 diabetes and genetic diseases and clinical trials are underway to determine if it may be useful in the setting of ablative chemotherapy to help replace the damaged cells as well.

Our laboratory is not only interested in the marrow microenvironment as the home for normal hematopoieis, or hematopoietic recovery following transplantation, but also as a site of sanctuary for hematopoietic tumors. The similarity between normal proB cells and their malignant counterparts that comprise B lineage leukemia is intriguing, but also clinically challenging. Our investigation of tumor cell interactions with the bone marrow were focused on a sub-type of ALL that expresses the Bcr/Abl translocation. Patients that have this mutation are automatically placed in a high risk of relapse, poor prognosis group regardless of any other factor. They are typically resistant to therapy, and although it is a subpopulation of patients (3-5\% of pediatric ALL and $25-50 \%$ of adult $A L L)$, the survival rates for this disease with chemotherapy alone are $20 \%$ or less and chemotherapy treatment with allogeneic transplant only increases to survival rate to 30- 
$50 \%{ }^{13 ; 14}$. Therefore, it is relevant to study the phenotype of the cells, and our observations suggested this class of tumor may have stem cell like properties that could be contributing to therapeutic resistance.

Our first study was initiated, in part, based on the work of Mary Hendrix. Her group determined, in a melanoma model, that particularly aggressive tumor cells expressed VE-cadherin and were able to create neovasculature and form networks that imitated endothelial cells, a process termed "vasculogenic mimicry" 6;8;15. Therefore in our model of aggressive, $\mathrm{Ph}+\mathrm{ALL}$ we chose to look at the phenotype of these cells and the expression of stem cell markers. We determined that the $\mathrm{Ph}+$ cells had a unique phenotype of surface VE-cadherin expression that is more readily detected than in their Ph- counterparts, as well as PECAM-1. Ph+ cells also generated hemospheres when cultured with bone marrow stromal cells, that were reminiscent of mammospheres or neurospheres propagated from the stem cell pool of breast and neural cells ${ }^{16}$. Additionally, these VE-cadherin +, PECAM-1+, PH+ ALL cells had the ability to sprout branches like normal endothelial cells when grown in endocult giving endothelial signals.

The Ph+ cells and their hemospheres also had a stem-like phenotype and had the expression of Oct-4 as well as CD133 (promin-1). We further evaluated the effect of BMSC co-culture and soluble factors on this phenotype and determined, between our two tumor studies, that VE-cadherin, beta-catenin, HIF-2 alpha, Src, Oct-4 and Bcr/Abl kinase activity could all be increased by BMSC contact, and in the presence of chemotherapy most of these proteins are maintained by BMSC contact. We investigated the relationship between beta-catenin and VE-cadherin and noticed that $\mathrm{Ph}+$ cells had higher levels of beta-catenin at baseline than Ph- cells (unpublished data). We then determined that beta-catenin physically interacts with and is stabilized by VE-cadherin and that both of these proteins are regulated by Bcr/Abl kinase activity. Treatment of 
$\mathrm{Ph}+$ cells with the Abl kinase inihibitor Imatinib resulted in decreased VE-cadherin and beta-catenin protein.

This inhibition of survival proteins with modulation of Abl kinase or VE-cadherin led us to investigate the potential therapeutic importance of VE-cadherin. Although Imatinib was initially very successful in the treatment of $C M L$ and $P h+A L L$, patients who relapse tend to have mutations in the Abl kinase domain (E225K, T315I, as well as alternative splicing of $\mathrm{Bcr} / \mathrm{Abl})$. These mutations leave the patients resistant to Imatinib suggesting that proteins downstream of Abl kinase activity may be relevant therapeutic targets.

To confirm our previous results in cell lines, we obtained primary, patient leukapheresis and bone marrow core samples from $\mathrm{Ph}$ - and $\mathrm{Ph}+$ patient and examined them for the presence of VE-cadherin. The Ph+ leukapheresis samples had VE-cadherin on their surface while the Ph- samples did not. The staining of the bone marrow core samples was intracellular and all samples had VE-cadherin which correlated with our cell line data showing stabilized VE-cadherin on the surface of $\mathrm{Ph}+\mathrm{ALL}$ but found intracellularly on $\mathrm{Ph}+$ and $\mathrm{Ph}-\mathrm{ALL}$. We treated SUP-B15, a Ph+ ALL cell line, with Imatinib and determined that VE-cadherin and HIF-2 alpha protein were both decreased in the presence of Imatinib but that VE-cadherin could be maintained in the presence of BMSC. Baseline protein expression of VE-cadherin, HIF-2 alpha, Oct-4 and beta-catenin could all be increased by BMSC contact, and during chemotherapy VE-cadherin and beta-catenin protein were maintained (HIF and Oct were not tested.)

This led us to the hypothesis that Bcr/Abl was regulating HIF-2 alpha which subsequently could act as a transcription factor for VE-cadherin and Oct-4 and lead to VE-cadheirn mediated stability of beta-catenin and stem cell phenotype, respectively. When HIF-2 alpha or VE-cadherin were inhibited with siRNA, the Ph+ leukemic cells were more susceptible to daunorubicin treatment, even in the presence of BMSC. 
Inhibition of VE-cadherin signaling with ADH100191 (ADH), a VE-cadherin antagonist that binds to the extracellular domain, resulting in diminished viability during treatment as well as increased Ser/Thr phosphorylated beta-catenin targeted for degradation. Our data suggest that VE-cadherin is a novel and relevant therapeutic target that regulates beta-catenin expression which has been shown to be critical in leukemic $(C M L)$ stem cell survival during treatment ${ }^{17}$.

The collective observations of the studies discussed in chapters 2 and 3 demonstrates the importance of microenvironmental regulation of tumor cell signals during chemotherapy treatment. Not only is it clinically important and particularly challenging in the setting of hematopoietic malignancies to attempt to find markers on tumor cells that are not on normal cells, but it is also crucial to determine the functional relevance and regulation of these aberrantly expressed proteins. The expression of VEcadherin in leukemia, as well as breast, prostate and other tumors that commonly metastasize to the bone marrow, may not only play a role in tumor resistance to chemotherapy but may also underlie a new mechanism by which tumor cells incorporate into the vasculature.

A recent study by Alvero et al. showed that a stem-cell-like population of ovarian cancer cells expressed CD34+, VE-cadherin and were able to form xenograft tumors containing blood vessels, lined by human CD34+ cells ${ }^{18}$. Additionally, these cells mimicked the behavior of normal endothelial cells, could form vessel like structures in 24 hours and could form vessels with extended branching and maturation after 7 days of culture in matrigel ${ }^{18}$. Studies from multiple groups have shown an increase in microvessel density in patients with different types of leukemia (AML, CLL, ALL etc.) suggesting the potential broad therapeutic implications of specific VE-cadherin antagonists for cancer therapy ${ }^{19 ; 20}$. 
Clinical trials are ongoing for drugs that have effects on VE-cadherin such as Combrostatin-A-4-Phosphate (CA4P). CA4P results in the depolymerization of microtubules resulting in detachment and apoptosis of endothelial cells. Although CA4P seems to selectively target endothelial cells it is not specifically a VE-cadherin antagonist. The Rafii lab has shown that CA4P can induce regression of unstable nascent tumor neovessels and inhibit leukemic cell proliferation and survival in vitro and in vivo in part by VE-cadherin/ $\beta$-catenin/Akt signaling pathway and disruption of mitochondrial membrane potential resulting in caspase-dependent cell death, respectively ${ }^{21 ; 22}$. These studies, as well as the studies performed in our own laboratory, emphasize the ability of VE-cadherin inhibition, even in the presence of the protective tumor microenvironment, to be a potential novel therapeutic option for aggressive tumors that may express cadherin proteins as anti-apoptotic regulators and/or mediators of contribution to new vasculature as tumors reach significant size. These data suggest we should consider angiogenesis inhibitors in a novel context, that of hematological malignancies.

In addition to this work converging "in" the bone marrow, the studies focusing on normal leukemic cell survival also identified TGF- $\beta$ as an intriguing factor. We know from the studies shown here, as well as the studies previously published by our lab, that both bone marrow stromal cells and osteoblasts secrete high levels of active TGF- $\beta$ after treatment with chemotherapy ${ }^{12}$. In the normal hematopoieis model the secretion of active TGF- $\beta$ is tightly regulated, and high levels inhibit the ability of osteoblasts to interact with and support primitive stem cells as well as progenitor pro-B cells. However, in the leukemia model TGF- $\beta$ increased the amount of VE-cadherin expression in the $\mathrm{Ph}+$ cells coincident with protection of tumor cells from chemotherapy. The Dejana lab has shown that in normal endothelial cells VE-cadherin acts as a critical regulator of 
TGF- $\beta$ signaling, and a study by Labelle et al. demonstrated that VE-cadherin is induced during EMT in mammary tumor cells and is aberrantly expressed in invasive human breast carcinomas ${ }^{23 ; 24}$. VE-cadherin expression in these tumors influences the levels of Smad2 phosphorylation and expression of TGF- $\beta$. These data suggest a link between VE-cadherin and TGF- $\beta$ as well as a dual role for VE-cadherin, promotion of tumor progression via angiogenesis and enhancement of tumor cell proliferation through the TGF- $\beta$ signaling pathway.

These data remind us of the complexity of the marrow microenvironment in both its hematopoietic support role and its capacity to serve as a tumor sanctuary. Further, the studies emphasize the vulnerability of the "structural" components of the marrow, including osteoblasts, that regulate diverse processes through their expression of adhesion molecules, cytokines, chemokines, and ECM driven signals. Many questions emerge from a common niche that can house and support both healthy and transformed hematopoietic cells and is exposed to aggressive cytotoxic drugs in an attempt to eradicate tumor, or conversely, to prepare for transplantation of healthy stem cells. Future studies will be required for us to optimally modulate the bone marrow microenvironment to increase its utility as a tool in the treatment of patients with cancer. 


\section{Reference List}

1. Calvi LM, Adams GB, Weibrecht $\mathrm{KW}$ et al. Osteoblastic cells regulate the haematopoietic stem cell niche. Nature 2003;425:841-846.

2. Gong JK. Endosteal marrow: a rich source of hematopoietic stem cells. Science 1978;199:1443-1445.

3. LeBien TW, Tedder TF. B lymphocytes: how they develop and function. Blood 2008;112:1570-1580

4. McGinnes K, Quesniaux V, Hitzler J, Paige C. Human B-lymphopoiesis is supported by bone marrow-derived stromal cells. Exp.Hematol. 1991;19:294-303.

5. Wu JY, Purton LE, Rodda SJ et al. Osteoblastic regulation of B lymphopoiesis is mediated by Gs\{alpha\}-dependent signaling pathways. Proc.Natl.Acad.Sci.U.S.A 2008;105:16976-16981.

6. Campana D, Coustan-Smith E, Manabe A et al. Human B-cell progenitors and bone marrow microenvironment. Hum.Cell 1996;9:317-322.

7. Colmone A, Amorim M, Pontier AL et al. Leukemic cells create bone marrow niches that disrupt the behavior of normal hematopoietic progenitor cells. Science 2008;322:1861-1865

8. Ryu KH, Ahn HS, Koo HH et al. Autologous stem cell transplantation for the treatment of neuroblastoma in Korea. J.Korean Med.Sci. 2003;18:242-247.

9. Galotto M, Berisso G, Delfino L et al. Stromal damage as consequence of high-dose chemo/radiotherapy in bone marrow transplant recipients. Exp.Hematol. 1999;27:14601466. 
10. Barcellos-Hoff MH, Derynck R, Tsang ML, Weatherbee JA. Transforming growth factor-beta activation in irradiated murine mammary gland. J.Clin.Invest 1994;93:892899.

11. Corazza F, Hermans C, Ferster A et al. Bone marrow stroma damage induced by chemotherapy for acute lymphoblastic leukemia in children. Pediatr.Res. 2004;55:152158.

12. Wang L, Clutter S, Benincosa J, Fortney J, Gibson LF. Activation of transforming growth factor-beta1/p38/Smad3 signaling in stromal cells requires reactive oxygen species-mediated MMP-2 activity during bone marrow damage. Stem Cells 2005;23:1122-1134.

13. Radich JP. Philadelphia chromosome-positive acute lymphocytic leukemia. Hematol.Oncol.Clin.North Am. 2001;15:21-36.

14. Ravandi F, Kebriaei P. Philadelphia chromosome-positive acute lymphoblastic leukemia. Hematol.Oncol.Clin.North Am. 2009;23:1043-63, vi.

15. Hendrix MJ, Seftor EA, Hess AR, Seftor RE. Vasculogenic mimicry and tumour-cell plasticity: lessons from melanoma. Nat.Rev.Cancer 2003;3:411-421.

16. Bez A, Corsini E, Curti D et al. Neurosphere and neurosphere-forming cells: morphological and ultrastructural characterization. Brain Res. 2003;993:18-29.

17. Hu Y, Chen Y, Douglas L, Li S. Beta-Catenin is essential for survival of leukemic stem cells insensitive to kinase inhibition in mice with BCR-ABL-induced chronic myeloid leukemia. Leukemia 2009;23:109-116. 
18. Alvero $\mathrm{AB}, \mathrm{Fu} \mathrm{HH}$, Holmberg $\mathrm{J}$ et al. Stem-like ovarian cancer cells can serve as tumor vascular progenitors. Stem Cells 2009;27:2405-2413.

19. Padro T, Ruiz S, Bieker R et al. Increased angiogenesis in the bone marrow of patients with acute myeloid leukemia. Blood 2000;95:2637-2644.

20. Negaard HF, Iversen N, Bowitz-Lothe IM et al. Increased bone marrow microvascular density in haematological malignancies is associated with differential regulation of angiogenic factors. Leukemia 2009;23:162-169.

21. Petit I, Karajannis MA, Vincent $L$ et al. The microtubule-targeting agent CA4P regresses leukemic xenografts by disrupting interaction with vascular cells and mitochondrial-dependent cell death. Blood 2008;111:1951-1961.

22. Vincent L, Kermani $P$, Young LM et al. Combretastatin A4 phosphate induces rapid regression of tumor neovessels and growth through interference with vascular endothelial-cadherin signaling. J.Clin.Invest 2005;115:2992-3006.

23. Labelle M, Schnittler HJ, Aust DE et al. Vascular endothelial cadherin promotes breast cancer progression via transforming growth factor beta signaling. Cancer Res. 2008;68:1388-1397.

24. Rudini N, Felici A, Giampietro C et al. VE-cadherin is a critical endothelial regulator of TGF-beta signalling. EMBO J. 2008;27:993-1004. 